\author{
UNIVERSIDADE DE SÃO PAULO \\ ESCOLA DE ENGENHARIA DE SÃO CARLOS \\ DEPARTAMENTO DE ENGENHARIA MECÂNICA
}

\title{
UMA INTERFACE ELETRÔNICA E COMPUTACIONAL PARA Medições a TrÊs CoORdenadas.
}

\begin{abstract}
AlessANDRO MARQUES
Tese apresentada à Escola de Engenharia de São Carlos da Universidade de São Paulo, como parte dos requisitos para obtenção do título de Doutor em Engenharia Mecânica
\end{abstract}

OrIENTADOR: Prof. Dr. Benedito Di Giacomo

São Carlos

2003 
Ficha catalográfica preparada pela Seção de Tratamento da Informação do Serviço de Biblioteca - EESC/USP

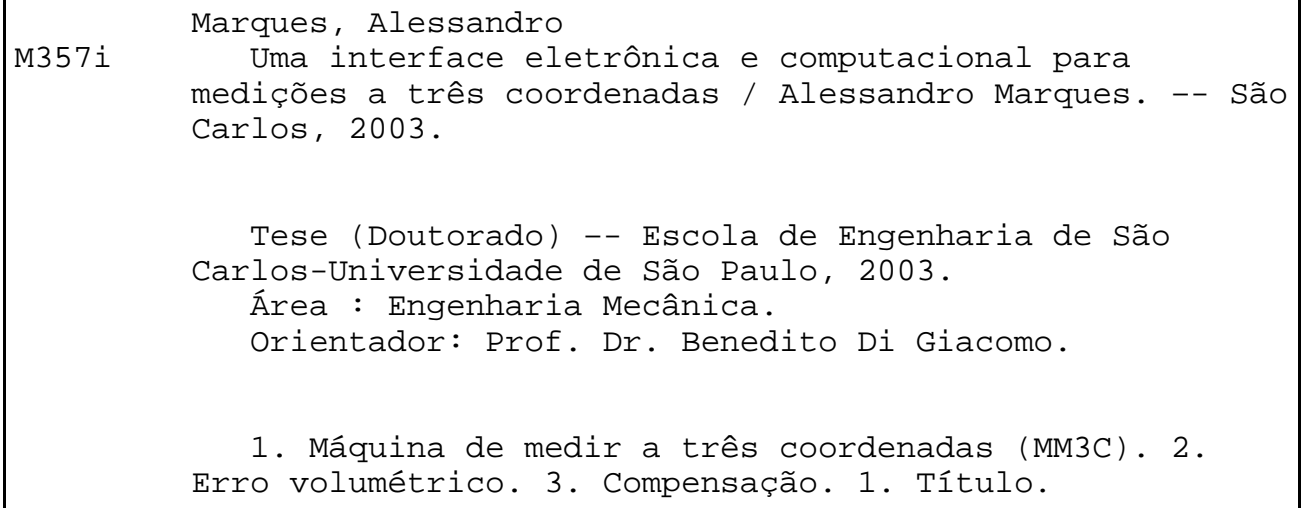


Aos meus pais Moacyr e Evanilde por minha educação e apoio constante. À minha avó Amábile. 


\section{AGRADECIMENTOS}

Ao final deste trabalho, gostaria de expressar meus mais sinceros agradecimentos ao Prof. Dr. Benedito Di Giacomo pela orientação, discussão, apoio, incentivo e amizade que transcenderam a realização deste trabalho.

Aos amigos de pós-graduação Fabrício Paziani, Rosenda, Andréa Cardoso, Alexandre Machado, Alessandra Teodoro, Alexandre Caporali, Márcia, Eraldo, Vagner Augusto de Souza, Bruno, Tércio, Juliana Keiko, Enzo pelo apoio manifestado durante o trabalho.

Ao Dr. Roberto Hideaki Tsunaki pelas sugestões e discussões que contribuíram preciosamente para a finalização deste trabalho.

Ao Luiz Carlos Neves, pela amizade e auxilio técnico. Pelos desenhos e ajuda nas montagens experimentais.

À Rita de Cássia pela ajuda na correção dos relatórios científicos, pela amizade e alegria contagiante.

Ao MSc. José Cláudio P. de Azevedo, pela ajuda no desenvolvimento das interfaces eletrônicas e companhia constate.

Aos funcionários da oficina Adão Santo Bolzan, José Carlos Risardi e José Carlos Botelho pelo apoio técnico.

Às secretárias Elizabeth Alexandre e Ana Paula, pela amizade.

À meus pais, minha avó Amábile, meus irmãos Jú e Rosana, sobrinhos Daniel, Aline e Gabriel, ao Creso e Edmara por existirem.

À Erika Regina Bregagnolo pelas lições de perseverança, pelo carinho e estimulo.

À FAPESP pela bolsa de estudo concedida durante a realização do trabalho. Projeto no 98/15437-3.

A todos aqueles que, direta ou indiretamente, contribuíram para o desenvolvimento deste trabalho.

À Deus, pela vida e por me dar saúde e força. 


\section{RESUMO}

MARQUES, A. (2003). Uma Interface Eletrônica e Computacional para Medições a Três Coordenadas. São Carlos, 2003. 150p. Tese (Doutorado) - Escola de Engenharia de São Carlos, Universidade De São Paulo, São Carlos.

As Máquinas de Medir a Três Coordenadas (MM3Cs) desde sua criação evoluíram sensivelmente, entretanto poucas foram as modificações estruturais observadas. Hoje, para fabricantes de máquinas destacarem-se no mercado, são necessários grandes investimentos na busca de novos materiais estruturais e no desenvolvimento de programas computacionais cada vez mais versáteis. O sistema eletrônico e os programas computacionais utilizados durante as medições são inacessíveis e rígidos. Estes aplicativos normalmente não podem ser analisados nem modificados pelo usuário. São exemplos clássicos desta rigidez as características préestabelecidas pelo programa, ou métodos de ajustes utilizados na definição das grandezas. Este trabalho tem por objetivo exibir a interface eletrônica e computacional que quebra essa rigidez e permite a aquisição dos sinais das escalas da MM3C, possibilitando o desenvolvimento de novos aplicativos computacionais. O sistema foi aplicado em uma MM3C do tipo Ponte Móvel. Foi desenvolvido um programa computacional, MaqMed 2000, que utiliza os valores dos pontos coordenadas capturados no volume de trabalho da MM3C, e faz a compensação das coordenadas dos pontos utilizados, através das equações do Modelo Reduzido de Sintetização de Erros (MRSE). A avaliação da compatibilidade do dispositivo construído foi feita através do MaqMed 2000 em situações práticas. Foram tomados pontos no perfil de artefatos-padrão e os pontos ajustados através de duas rotinas, uma com e outra sem compensação dos erros. Os artefatos foram medidos em várias posições no volume da MM3C e averiguada a proximidade entre os resultados compensados e os não compensados, ao valor calibrado do artefato. O sistema desenvolvido permitiu compensar os erros em até $98 \%$ para compensação bidimensional e $87 \%$ para tridimensional.

Palavras-chaves: Máquina de Medir a Três Coordenadas (MM3C), erro volumétrico e compensação. 


\section{ABSTRACT}

MARQUES, A. (2003). A Electronic and computational interface for coordinate measurement. São Carlos, 2003. 150p. Thesis (Ph.D.) Escola de Engenharia de São Carlos, Universidade de São Paulo, São Carlos.

Since the advent Coordinate Measuring Machines (CMMs) have improved substantially. However, only a small number of structural modifications were observed. Nowadays, considerable capital expenditure is needed to keep CMM builders competitive. Most important research fields concern structural material and production of more flexible and versatile software. The electronic system and the software used during measurement with CMM are rigid and inaccessible and no user modification is permitted. Typical examples are the predetermined software features and curve fitting methods used on the magnitudes definition process. This research aims to exhibit an interface that copes with the system stiffness and enables signal acquisition from the scales of the CMM, allowing the development of new types softwares. The proposed system was implemented on a moving bridge type CMM. A program that uses the values of the coordinate points obtained from the CMM work volume was created. The software MaqMed 2000 performs the compensation of the coordinates of the used points by means of synthesized errors equations. Evaluation of the performance of the built device was carried out using MaqMed 2000 in practical situations. Data sets were collected along the profile of artefacts and fitted by means of two routines, one with error compensation and the other not compensated. Artefacts were measured in several locations in the whole volume of the CMM. The proximity between the compensated and noncompensated results with respect to the calibrated artefact value was examined. The developed system allowed for error compensation of $98 \%$ for bi-dimensional compensation and $87 \%$ for tri-dimensional compensation.

Keywords: Three Coordinate Measuring Machines (CMM), volumetric error and compensation. 


\section{LISTA DE FIGURAS}

Figura 2.1 Tipos de MM3Cs.................................... 7

Figura 2.2 Micrômetro (concordância com o Princípio de Abbè) e paquímetro (transgressão do Princípio de Abbè)............ 9

Figura 2.3 Apalpador sem contato tipo laser (esquerda); apalpador por contato, touch-trigger (centro) e rígido (direita)...... 10

Figura 2.4 Esquema do apalpador................................. 11

Figura 2.5 Tipos de pontas..................................... 11

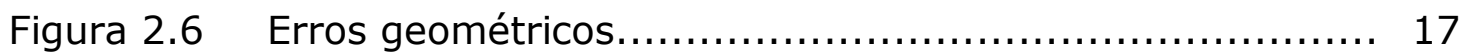

Figura 2.7 Formato das geratrizes utilizadas no método do volume dividido.................................................... 19

Figura 2.8 Barra de esfera (acima), esquema de montagem e barra de esfera telescópica..................................... 21

Figura 2.9 Padrão passo a passo................................. 22

Figura 2.10 Padrão de esfera............................................ 23

Figura 2.11 Padrão de círculos.................................... 24

Figura 2.12 Padrão tetraédrico................................... 24

Figura 3.1 Distribuições de probabilidade.......................... 54

Figura 3.2 Fator de abrangência e nível de confiança.................. 59

Figura 3.3 Fontes de incerteza nas medições a três coordenadas...... 60

Figura 3.4 Máquina Virtual de Medir a Três Coordenadas............... 62

Figura 5.1 MM3C do Laboratório de Metrologia-EESC-USP........... 72

Figura 5.2 Representação das geratrizes $G_{1}$ e $G_{i}$ no plano XY.......... 74

Figura 5.3 Representação de pontos pertencentes ao volume de trabalho da MM3C...................................... 76

Figura 5.4 Erro angular Yaw do eixo Y devido à existência de braço

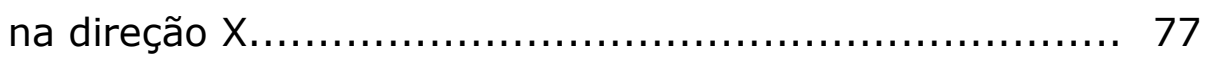

Figura 5.5 Erro angular Pitch do eixo Y amplificado pela existência

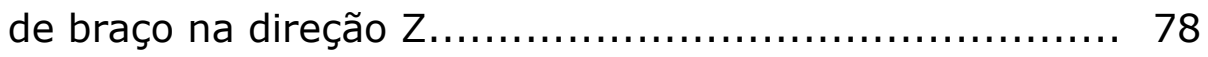

Figura 5.6 Tela do ProgCalibra..................................... 85

Figura $5.7 \quad$ Barra de furos............................................. 86 
Figura 5.8 Geratrizes medidas usando a barra de furos para determinar $E_{Y}$

Figura 5.9 Montagem da barra de furos para a medição do erro de posição do eixo $Y$.

Figura 5.10 Geratrizes medidas, usando a barra de furos, para calcular $E_{x}$

Figura 5.11 Posicionamento do esquadro para medição dos erros na direção $Y$......

Figura 5.12 Montagem para a medição dos erros $d X Y\left(X_{i}, Z_{0}\right)$...

Figura 5.13 Posicionamento do esquadro para medição dos erros na direção X

Figura 5.14 Posicionamento do esquadro para medição dos erros na

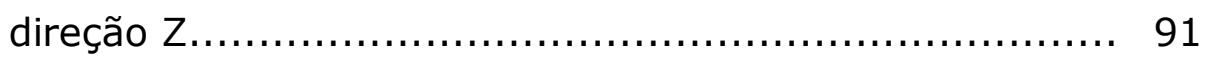

Figura 5.15 Descrição do sistema.................................. 92

Figura 5.16 Diagrama esquemático do gerador de largura de pulso..... 93

Figura 5.17 Medição da largura de pulso do trigger..................... 94

Figura 5.18 Diagrama esquemático do isolador ótico...................... 94

Figura 5.19 Foto da placa de aquisição.............................. 95

Figura 5.20 Arquitetura do hardware.............................. 96

Figura 5.21 Hardware do PreScale com a arquitetura do software de contagem................................................... 97

Figura 5.22 Fluxograma das primeiras rotinas.......................... 99

Figura 5.23 Tela inicial do MaqMed 2000............................ 100

Figura 5.24 Procedimentos para qualificação do apalpador.............. 100

Figura 5.25 Tela do Menu Principal.................................. 101

Figura 5.26 Diagrama de blocos da sequência de operações para o alinhamento................................................. 102

Figura 5.27 Telas para escolha da medição.......................... 103

Figura 5.28 Tela para medição de um furo e tela de resultados......... 103

Figura 5.29 Fluxograma de medições. .............................. 104

Figura 6.1 Erro Cíclico.......................................... 114

Figura 6.2 Superfícies $E_{X}$ nos diferentes planos de medição............ 116

Figura 6.3 Superfícies $E_{X}$ nos planos de medição XZ e YZ............. 117

Figura 6.4 Superfícies $E_{Y}$ nos diferentes planos de medição............ 118 
Figura 6.5 Superfícies $E_{Y}$ nos planos de medição XZ e $Y Z \ldots \ldots \ldots \ldots \ldots \ldots . .118$

Figura 6.6 Superfícies $E_{z}$ nos diferentes planos de medição............ 119

Figura 6.7 Superfícies $E_{Z}$ nos planos de medição XZ e $Y Z \ldots \ldots \ldots \ldots \ldots . .120$

Figura 6.8 Sistema de coordenadas da peça e da MM3C.............. 123

Figura 6.9 Posições ocupadas pelo bloco padrão durante o experimento............................................ 125

Figura 6.10 Resíduos na medição da distância na direção X $(\mu \mathrm{m}) \ldots \ldots \ldots 127$

Figura 6.11 Resíduos na medição da distância na direção $Y(\mu \mathrm{m}) \ldots \ldots . .129$

Figura 6.12 Posições ocupadas pelo anel padrão durante o experimento......................................... 129

Figura 6.13 Resíduos na medição do diâmetro $(\mu \mathrm{m}) \ldots \ldots \ldots \ldots \ldots \ldots \ldots \ldots \ldots \ldots \ldots$ 


\section{LISTA DE TABELAS}

Tabela 3.1 Número mínimo de pontos para o ajuste.................. 43

Tabela 5.1 Erros nas direções X, Y e Z............................. 73

Tabela 5.2 Parâmetros para determinar a incerteza da medição das distâncias entre os centros dos furos..................... 108

Tabela 5.3 Parâmetros para determinar a incerteza da medição de erros utilizando o esquadro e o apalpador LVDT............ 109

Tabela 6.1 Valores das distâncias dos furos das barras encontrados na SIP....

Tabela 6.2 Distâncias entre centros das barras de furos e desvio padrão em cada posição $(\mathrm{mm})$.

Tabela 6.3 Posições de colocação do esquadro na máquina.

Tabela 6.4 Valores do deslocamento experimentado pelo LVDT e desvio padrão $(\mu \mathrm{m})$.

Tabela 6.5 Parâmetros para o cálculo da incerteza padronizada combinada....

Tabela 6.6 Parâmetros para o cálculo da incerteza padronizada combinada.

Tabela 6.7 Incerteza na medição da barra de furos na posição $\mathrm{Y}=$ $164 \mathrm{~mm}$.

Tabela 6.8 Incerteza associada às componentes do erro volumétrico. 121

Tabela 6.9 Comparação dos valores obtidos com e sem compensação de erros na medição do bloco padrão.

Tabela 6.10 Comparação dos valores obtidos com e sem compensação de erros na medição do bloco padrão.

Tabela 6.11 Comparação dos valores obtidos com e sem compensação de erros na medição do anel padrão 130

Tabela A.1 Características técnicas da MM3C. 148 


\section{LISTA DE ACRÔNIMOS}

\begin{tabular}{|c|c|}
\hline ANOVA & ANalysis Of Variance; \\
\hline ANSI & American National Standards Institute; \\
\hline ASME & American Society of Mechanical Engineers; \\
\hline ASTM & American Society for Testing and Materials; \\
\hline BEMF & Barra de Esferas Magnética Fixa; \\
\hline BEMT & Barra de Esferas Magnética Telescópica; \\
\hline BIPM & Bureau International des Poids et Mesures; \\
\hline Bsi & British Standard institution; \\
\hline CIPM & Comitê Internacional de Pesos e Medidas; \\
\hline CLP & Controlador Lógico Programável; \\
\hline CMMA & Coordinate Measuring Machine Manufacturers Association; \\
\hline CNC & Controle Numérico Computadorizado; \\
\hline CPLD & Complex Programmable Lógic Devices; \\
\hline CPU & Central Processing Unit; \\
\hline DAM & Diâmetro do Apalpador de Medição; \\
\hline DLL & Dynamic Link Library; \\
\hline DPA & Diâmetro da Esfera da Ponta do Apalpador; \\
\hline DVS & Decomposição em Valores Singulares; \\
\hline EAL & European co-operation for Accreditation of Laboratories; \\
\hline FIFO & First Input First Output; \\
\hline GIDEP & Government-Industry Data Exchange Program; \\
\hline GUM & Guide to the expression or Uncertainty in Measurement; \\
\hline IEC & International Electrotechnical Commission; \\
\hline IFCC & International Federation of Clinical Chemistry; \\
\hline ISA & Industrial Standard Architecture; \\
\hline ISO & International Standard Organization; \\
\hline IUPAC & International Union of Pure and Applied Chemistry; \\
\hline IUPAP & International Union of Pure and Applied Physics; \\
\hline JIS & Japan Industrial Standard; \\
\hline LVDT & Linearly Variable Differential Transformers; \\
\hline MM3C & Máquina de Medir a Três Coordenadas; \\
\hline
\end{tabular}


MRSE Modelo Reduzido de Sintetização de Erros;

MVM3C Máquina Virtual de Medir a Três Coordenadas;

NBS National Bureau of Standard;

NIST National Institute of Standards and Technology;

OIML International Organization of Legal Metrology;

PSP Parallel Slave Port;

PTB Physikalisch-Technische Bundesanstalt;

SIP Société Genevoise d'Instruments de Physique;

SMC Sistemas de Medição por Coordenadas;

TH Transformações Homogêneas;

VCL Visual Component Library;

VDI / VDE Verein Deutscher Ingeniere / Verband Deutscher Elektrotechniker. 


\section{LISTA DE SÍMBOLOS}

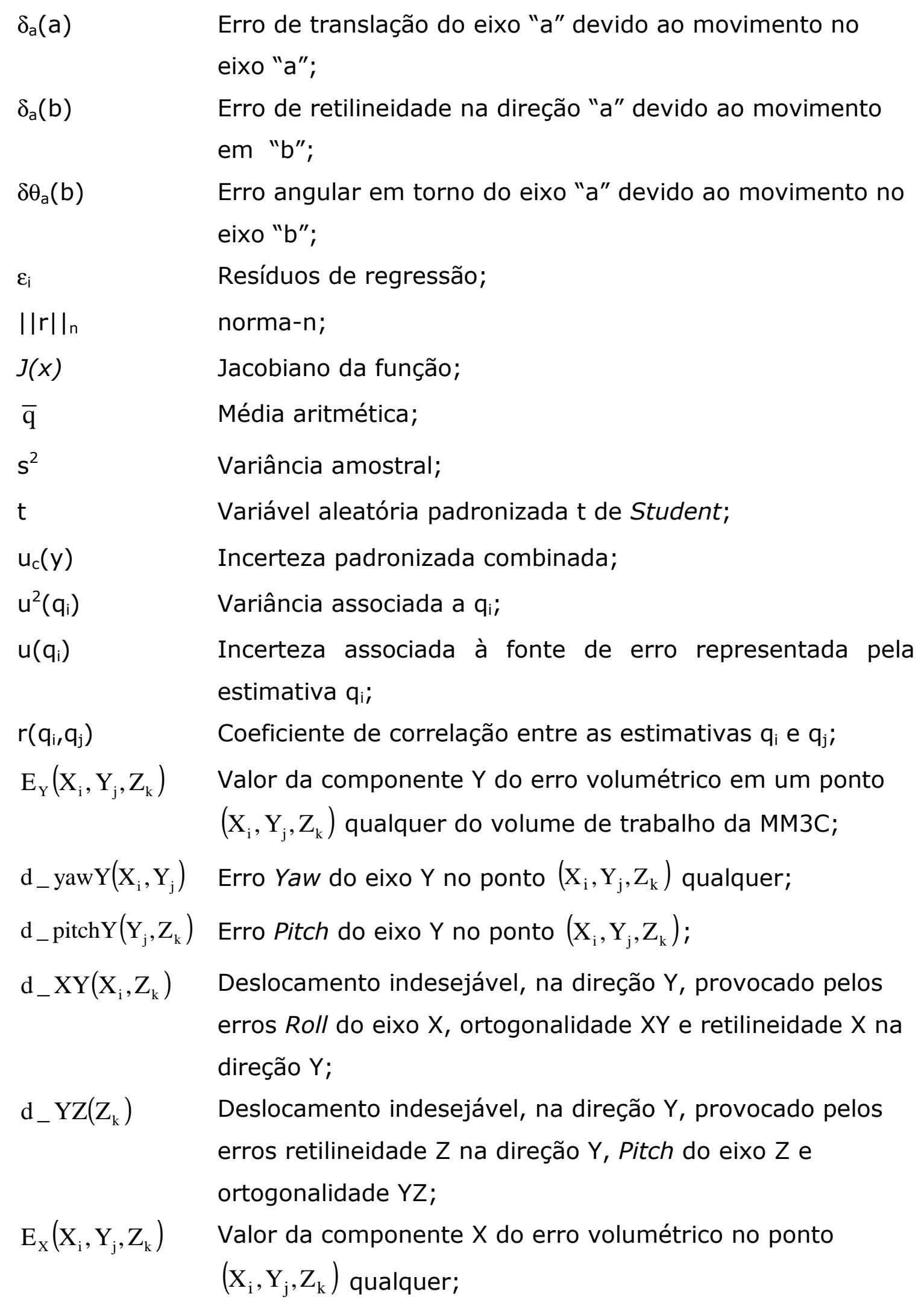


$\mathrm{d}_{\text {_p }}$ itchX $\left(\mathrm{X}_{\mathrm{i}}, \mathrm{Z}_{\mathrm{k}}\right)$ Erro Pitch do eixo $\mathrm{X}$ calculado no ponto i da geratriz paralela a $G_{7}$ localizada em $Z$ na posição $Z_{K}$;

$d_{-} \mathrm{YX}\left(\mathrm{Y}_{\mathrm{j}}, \mathrm{Z}_{\mathrm{k}}\right) \quad$ Deslocamento indesejável, na direção $\mathrm{X}$, provocado pelos erros Roll do eixo Y, Yaw do eixo $Y$, ortogonalidade $X Y$ e retilineidade $Y$ na direção $X$, nos pontos cujas coordenadas $Y$ e $Z$ são respectivamente $Y_{\mathrm{J}}$ e $Z_{K}$;

$\mathrm{d}_{\text {_ }} \mathrm{XZ}\left(\mathrm{Z}_{\mathrm{k}}\right) \quad$ Deslocamento indesejável, na direção $X$, provocado pelos erros retilineidade $Z$ na direção $X, Y a w$ do eixo $Z$ e ortogonalidade $X Z$;

$E_{Z}\left(X_{i}, Y_{j}, Z_{k}\right) \quad$ Valor da componente $Z$ do erro volumétrico no ponto $\left(X_{i}, Y_{j}, Z_{k}\right)$ qualquer;

$d_{-} Z \mathrm{Y}\left(\mathrm{X}_{\mathrm{i}}, \mathrm{Y}_{\mathrm{j}}\right) \quad$ Deslocamento indesejável, na direção $\mathrm{Z}$, provocado pelos erros retilineidade $Y$ na direção $Z$, Roll do eixo $Y$ e Pitch do eixo $Y$, nos pontos cujas coordenadas $X$ e $Y$ são respectivamente $X_{i}$ e $Y_{j}$;

$\mathrm{d}_{\text {_ }} \mathrm{ZX}\left(\mathrm{X}_{\mathrm{i}}\right) \quad$ Deslocamento indesejável, na direção $\mathrm{Z}$, provocado pelos erros de retilineidade $X$ na direção $Z$ e $R o l l$ do eixo $X$. 


\section{SUMÁRIO}

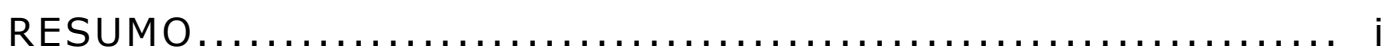

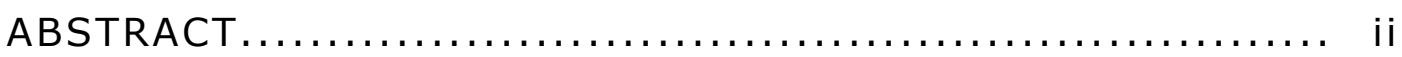

Lista de Figuras....................................... ii

Lista de Tabelas......................................... vi

Lista de Acrônimos........................................ vii

Lista de Símbolos............................................ ix

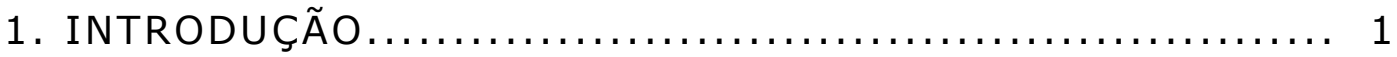

2. ERROS, FATORES CAUSADORES DE ERROS, CALIBRAÇÃO E MODELAGEM DE MM 3 CS $\ldots \ldots \ldots \ldots \ldots \ldots \ldots \ldots \ldots \ldots, 5$

2.1. Classificação geral das MM3Cs................... 6

2.2. Fontes e fatores causadores de erros nas MM3Cs. 8

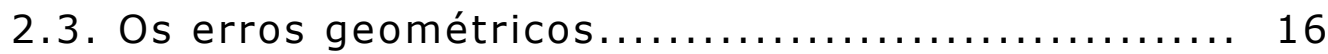

2.4. Calibração de MM3Cs............................. 18

2.4.1. Métodos de calibração direta.................. 18

2.4.2. Métodos de calibração indireta................ 20

2.5. Modelagem dos erros volumétricos............... 25

3. COMPENSAÇÃO DE ERROS E INCERTEZA DE MEDIÇÃO.... 30

3.1. Classificação dos erros quanto ao seu comportamento................................. 30

3.2. Compensação de erros............................ 31

3.3. Ajustes de curvas e superfícies................. 38

3.3.1. Método dos Mínimos Quadrados............... 38

3.3.2. Algoritmos de ajuste de elementos........... 42

3.4. Incerteza de medição a três coordenadas.......... 50 
3.4.1. Incerteza padronizada combinada............ 55

3.4.2. Incerteza expandida..................... 57

3.4.3. Métodos para a determinação de incerteza de medições a três coordenadas.................. 59

4. INTERFACE ELETRÔNICA E COMPUTACIONAL PARA MEDIÇÃO A TRÊS COORDENADAS ........................ 65

4.1. Modelagem dos erros volumétricos................ 66

4.2. Medição dos erros geométricos................... 67

4.3. Desenvolvimento das interfaces entre a máquina, o computador e o operador....................... 68

4.4. Compensação dos erros volumétricos e validação do sistema..................................... 69

4.5. Cálculo de incerteza da medição a três coordenadas...

5. DESENVOLVIMENTO DA METODOLOGIA PROPOSTA PARA MEDIÇÃO E COMPENSAÇÃO DE ERROS.................. 71

5.1. Modelagem matemática........................ 71

5.1.1. Modelo Reduzido de Sintetização de Erros

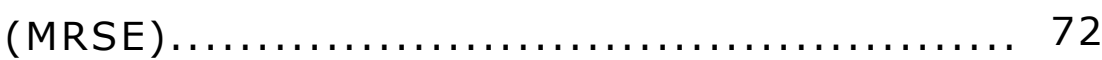

5.1.2. Levantamento do erro volumétrico............ 84

5.2. Calibração da MM3C............................ 84

5.2.1. Calibração utilizando a barra de furos........ 85

5.2.2. Calibração utilizando o esquadro mecânico e o apalpador............................... 88

5.3. Compensação dos erros.......................... 92

5.3.1. Placa de aquisição........................... 94

5.3.2. O programa computacional MaqMed 2000..... 98 
5.4. Estimativa das incertezas no cálculo das componentes do erro volumétrico...

5.4.1. Estimativa da incerteza na determinação das componentes $\mathrm{X}, \mathrm{Y}$ e $\mathrm{Z}$ do erro volumétrico... 106

5.4.2. Estimativa da incerteza na medição das distâncias entre os furos da barra na MM3C.. 107

5.4.3. Estimativa da incerteza de medição dos erros utilizando o Esquadro de Granito e o LVDT... 108

6. APRESENTAÇÃO E DISCUSSÃO DOS RESULTADOS......... 110

6.1. Resultados da calibração da MM3C................ 111

6.1.1. Componente $X$ do erro volumétrico........... 116

6.1.2. Componente $Y$ do erro volumétrico............ 117

6.1.3. Componente $Z$ do erro volumétrico........... 119

6.2. Cálculo da incerteza associada às componentes do erro volumétrico............................ 120

6.3. Programa computacional MaqMed 2000.......... 122

6.3.1. Validação do Sistema MaqMed 2000........... 124

7. CONCLUSÕES E PROPOSTAS PARA TRABALHOS FUTUROS 132 REFERÊNCIAS BIBLIOGRÁFICAS ......................... 136

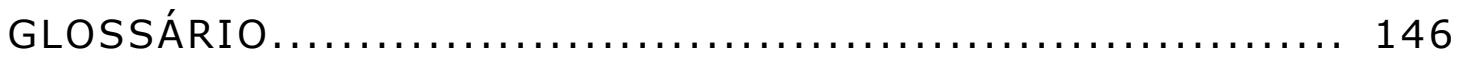

APÊNDICE A. Descrição da MM3C utilizada nos testes experimentais.............................. 147

APÊNDICE B. Rotinas básicas da placa de aquisição da régua ótica ................................. 149 


\section{CAPÍTULO 1}

\section{Introdução}

O controle de processos e a garantia de qualidade na fabricação moderna dependem cada vez mais das Máquinas de Medir a Três Coordenadas (MM3Cs), que nos últimos anos têm substituído alguns equipamentos convencionais de inspeção. Com grande flexibilidade as MM3Cs podem reduzir o custo no controle de qualidade ao mesmo tempo que aumentam a eficiência da inspeção.

$\mathrm{Na}$ metrologia convencional os elementos geométricos, são na maioria das vezes, medidos independentemente uns dos outros, utilizandose de diferentes instrumentos de medição. Para cada instrumento são utilizados diferentes sistemas de referência e montagens. Por outro lado, na metrologia a três coordenadas as medições são feitas através de ajustes de pontos coordenados, em um sistema de coordenadas que pode ser colocado na peça. Por esse motivo, geralmente não é necessária mais que uma montagem, e várias características podem ser medidas durante o mesmo processo de medição.

As MM3Cs são sistemas complexos de medição que possuem a capacidade de medir coordenadas cartesianas em um determinado volume de trabalho. A máquina simula mecanicamente um sistema de coordenadas cartesianas capaz de gerar as coordenadas de um ponto no espaço e são constituídas por vários subsistemas: os elementos estruturais, o sistema de 
apalpamento, o programa computacional e o computador dedicado. Os elementos estruturais de uma MM3C são: a base da máquina, o desempeno para suporte das peças a serem medidas, as colunas, as guias, as réguas óticas e os mancais aerostáticos.

O sistema de apalpamento é constituído de apalpador de medição e de uma interface eletrônica.

O último subsistema, do qual faz parte o programa computacional e o computador dedicado, é constituído de uma interface para leitura do sistema eletrônico do apalpador, uma interface para leitura das réguas óticas e de algoritmos para o cálculo das características da medição desejada. O programa computacional é, sem dúvida, uma das mais importantes partes no processo de medição a três coordenadas, pois é através dele que são processados os pontos coordenados, obtidos através do toque do apalpador e ajustado ao modelo matemático que define $o$ parâmetro específico desejado, seja ele uma dimensão, uma forma ou posição.

Por serem constituídas de partes de várias naturezas as MM3Cs são instrumentos complexos de medição, entretanto são, instrumentos fundamentalmente mecânicos que associadas a transdutores eletrônicos e microcomputador executando tarefas complexas e de grande precisão estão sujeitas a erros. Estes erros são inerentes à sua estrutura e natureza e afetam a qualidade da medição. Os erros que mais afetam o resultado das medições são os erros geométricos, que são decorrentes dos processos de fabricação e montagem de seus componentes e se materializam durante a movimentação e interação entre eles.

O levantamento dos erros ou avaliação do comportamento metrológico das máquinas é feito através dos testes de calibração. Conhecendo-se o comportamento metrológico das máquinas, sistemas de compensação de erros podem ser desenvolvidos.

No entanto, os programas computacionais utilizados pelas MM3Cs, são usualmente, desenvolvidos pelas empresas que fabricam as máquinas, estes aplicativos normalmente não podem ser analisados nem modificados pelo usuário, ou seja, seu código fonte não é acessível, pois são protegidos como segredos industriais, sob leis de patentes e licenças. 
Assim, diante do exposto, esse trabalho tem por objetivo principal desenvolver uma interface eletrônica e computacional para medição a três coordenadas. Uma interface eletrônica que possibilita a aquisição dos sinais da régua ótica e do apalpador de medição da MM3C, e uma interface computacional, com o código fonte aberto, que utilizam os sinais adquiridos para calcular características geométricas e possibilitam a compensação dos erros da MM3C.

Além disso, no programa computacional, chamado de MaqMed 2000, foi desenvolvida sub-rotinas que utilizam as equações do Modelo Reduzido de Sintetização de Erros, apresentado por ZIRONDI em 2002, para a correção das coordenadas dos pontos. A calibração da MM3C foi feita utilizando uma barra de furos e um esquadro mecânico.

Para a validação do Sistema proposto foi feita a medição de peçaspadrão e análises dos resultados obtidos, através da utilização do MaqMed 2000 em situações práticas.

O sistema proposto foi aplicado e testado em uma Máquina de Medir a Três Coordenadas, tipo "Ponte Móvel", do Laboratório de Metrologia, da Escola de Engenharia de São Carlos - USP.

Uma breve descrição do desenvolvimento do trabalho encontra-se a seguir.

No capítulo dois é apresentada a revisão bibliográfica sobre as fontes e fatores causadores de erros nas Máquinas de Medir a Três Coordenadas (MM3Cs). Além disso, o estudo dos erros geométricos e métodos para medição dos mesmos estão descritos, sendo dada atenção especial aos novos métodos de calibração.

No capítulo três estão apresentados alguns conceitos básicos para análise estatística dos dados. Estão descritos também, técnicas para o modelamento dos erros geométricos, estratégias para compensação dos erros volumétricos e métodos para avaliar a incerteza de medição.

O capítulo quatro apresenta a proposta do trabalho, isto é, o projeto e desenvolvimento da interface eletrônica e computacional para medição a três coordenadas. Uma descrição das etapas envolvidas para a efetivação da proposta também é apresentada. 
O desenvolvimento da metodologia proposta é apresentado no capítulo cinco. Neste estão descritos o modelo matemático dos erros volumétrico e o processo de calibração utilizado. Além disso, estão descritos: a estratégia e o programa computacional desenvolvidos para a compensação dos erros e também o cálculo para a determinação da incerteza de medição.

No capítulo seis os resultados experimentais são apresentados e discutidos. Também é validado o sistema de interfaceamento eletrônico e computacional proposto, através da medição de peças-padrão, em diversas posições do volume de trabalho da MM3C. Uma discussão sobre as rotinas computacionais é feita.

O capítulo sete apresenta as conclusões relativas ao trabalho desenvolvido e sugestões para futuros trabalhos. 


\section{CAPÍTULO 2}

\section{Erros, fatores causadores de erros, calibração e modelagem de MM3Cs}

São componentes que constituem as MM3Cs, os elementos estruturais, suportes de sustentação, as guias, os sistemas de deslocamentos, réguas óticas, apalpador de medição e os sistemas de controle. Os elementos estruturais de uma MM3C são: a base da máquina, o desempeno para suporte das peças a serem medidas, as colunas, os mancais aerostáticos e o suporte do apalpador de medição. Como pode ser observado as MM3Cs são constituídas de várias partes e isso as tornam instrumentos complexos de medição.

A repetibilidade e a acuracidade das medições são influenciadas por diversos fatores, que podem ser independentes da máquina ou inerentes à própria estrutura. Estes fatores causam movimentos indesejáveis dos componentes da máquina, que são denominados erros geométricos.

Apesar da evolução dos processos de usinagem, o uso de novos materiais e os avanços computacionais utilizados na fabricação das MM3Cs, os erros estão sempre presentes, provocando um desvio entre as trajetórias ideal e real do apalpador de medição, comumente chamado de erro volumétrico. É imprescindível, portanto, o conhecimento detalhado dos 
erros para interpretá-los corretamente e para atuar no sentido de minimizar os seus efeitos.

Nesse capítulo estão apresentados as fontes e fatores causadores de erros nas MM3Cs. Além disso, métodos de calibração e técnicas de modelagem matemática são discutidos.

\subsection{Classificação geral das MM3Cs}

De acordo com a British Standard institution (BSI) de 1989, a definição de MM3C é: um dispositivo com a capacidade de medir coordenadas cartesianas de pontos espaciais que inclui: apalpador de medição, estrutura, escala de medição e programas computacionais.

Baseado em trabalhos feitos pela American Society of Mechanical Engineers, a ANSI/ASME B89.4.1 de 1997, as máquinas foram classificadas de acordo com sua estrutura. Tal classificação foi feita para um melhor detalhamento das máquinas. Este detalhamento é extremamente útil no momento do desenvolvimento de uma formulação matemática para o equacionamento do erro volumétrico, pois as equações dos erros mudam de acordo com a estrutura analisada. No entanto, podem ser consideradas as mesmas equações para todas as máquinas de mesma estrutura.

Na Figura 2.1 pode-se observar alguns tipos de máquinas classificadas de acordo com a estrutura.

As MM3Cs que têm estrutura de Cantiléver possuem um carro que transporta uma viga engastada ortogonalmente a ele, o qual é responsável pelo movimento do carro que transporta a sonda. A peça a ser medida é colocada sobre a base fixa da máquina a qual não possui movimento, obtendo bom desempenho na medição de peças pesadas, pois elas poderiam afetar na acuracidade das medições. O deslocamento do carro ao longo da viga produz uma flexão que pode ser corrigida através de uma técnica de compensação de erros. As máquinas do tipo Cantilever oferecem pequena faixa de medição em dois eixos, porém, particularmente, são adequadas para a medição de partes longas.

Segundo a Brown \& Sharpe, a estrutura de Ponte Móvel é atualmente a mais utilizada, cerca de $95 \%$ de suas máquinas vendidas 
possuem esta tipo de estrutura. Tanto é, que NI e WÄLDELE (1995) a definiram como o "workhorse" das MM3Cs. A estrutura Ponte Móvel tem como características principais o desempeno fixo para suporte de peças e uma ponte que se movimenta. Devido ao projeto da máquina um fenômeno chamado Yawing ou Walking ocorre, pois as colunas se movimentam com passos diferentes, girando a ponte.

A estrutura de Ponte Fixa tem movimentos no desempeno e sua ponte é rigidamente ligada à estrutura da máquina. Sua principal vantagem é possuir estrutura rígida e como desvantagem pode-se citar sua limitação em relação ao peso da peça.

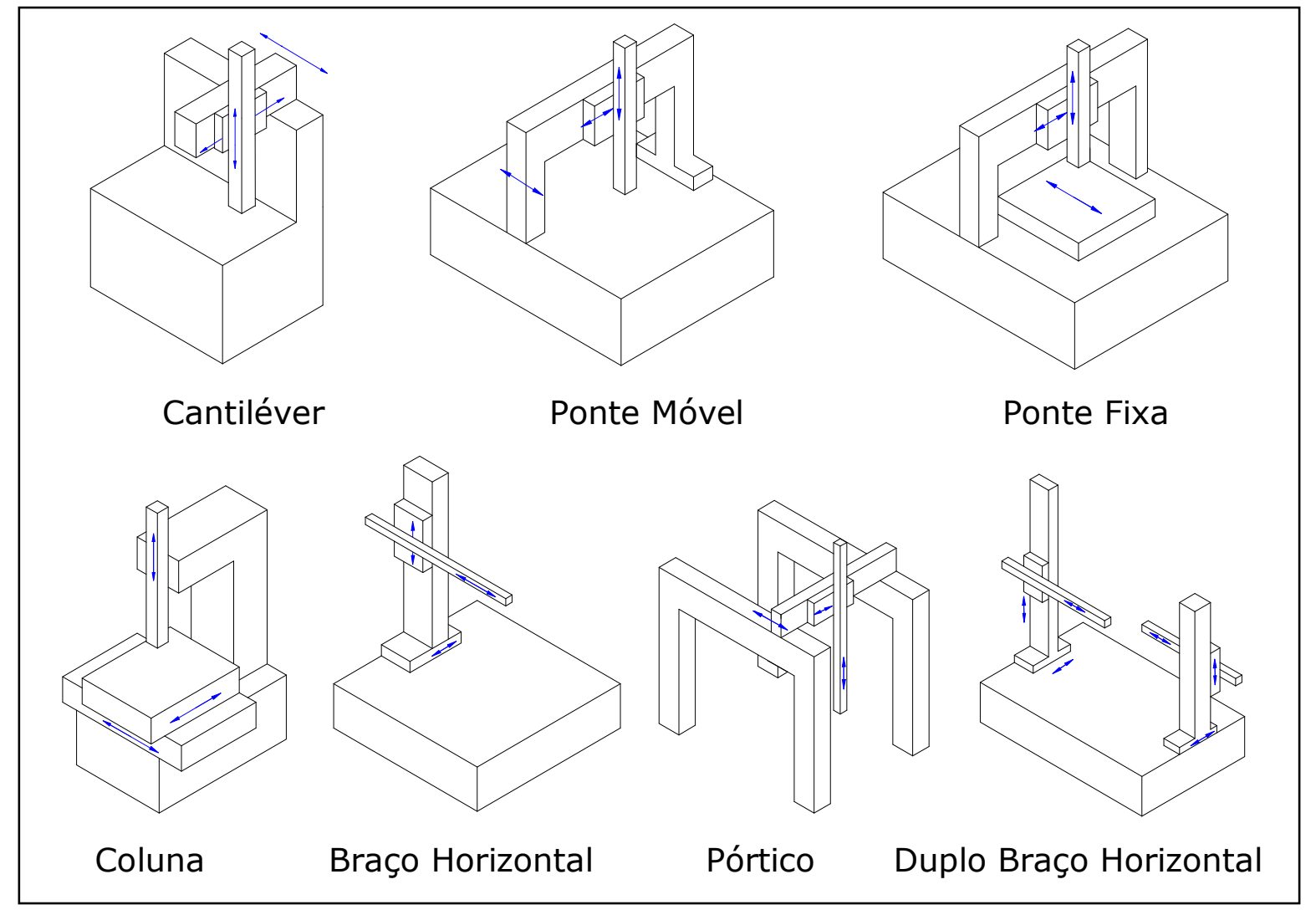

Figura 2.1: Tipos de MM3Cs

Devido à facilidade de acesso para colocação de peças, as máquinas maiores, geralmente, possuem estrutura de Braço Horizontal, Duplo Braço Horizontal ou Pórtico. Tais estruturas são muito utilizadas na indústria automotiva. No entanto, quanto maior a máquina, maior o 
comprometimento da acuracidade durante a medição devido às dimensões dos elementos da estrutura.

\subsection{Fontes e fatores causadores de erros nas MM3Cs}

Segundo SOSA CARDOZA (1995) existem dois tipos de fatores causadores de erros que influenciam a medição a três coordenadas: os dependentes e os independentes da máquina. Alguns dos fatores dependentes da máquina são: transgressão do Princípio de Abbè, erros devido ao apalpador de medição, erros devido à forma das guias, o desempeno de referência e erros devido ao peso próprio, além dos relativos a integridade dos programas computacionais. Quanto aos fatores independentes da máquina pode-se mencionar: o acabamento da peça, estratégia de medição e habilidade do operador. Além disso, existem fatores que podem ser dependentes ou independentes da máquina de acordo com as circunstâncias, estes são: os erros dinâmicos e os erros devido às variações de temperatura.

\section{Transgressão do Princípio de Abbè}

As MM3Cs podem ser encontradas em diferentes estruturas, como já mostrado no item 2.1. Estes diferentes tipos apresentam em comum a transgressão ao Princípio de Abbè (DI GIACOMO, 1986).

O Professor Abbè em 1890 publicou no "Journal for Instrumental Information", a primeira concepção a respeito do uso de escalas graduadas como sistema de medição de comprimentos e os benefícios obtidos caso estas escalas estivessem alinhadas com o comprimento a ser medido (BRYAN, 1979).

O primeiro e mais importante princípio de projeto de Máquinas Ferramentas e da metrologia dimensional consiste na concepção de máquinas com os sistemas de medição colineares com os deslocamentos a serem medidos. Neste caso, diz-se que há concordância com o Princípio de 
Abbè. No entanto, a concepção de máquinas de medir que não transgridem o princípio é praticamente impossível. Bryan reavaliou o Princípio de Abbè propondo o que se conhece como Princípio Generalizado de Abbè, que foi, assim enunciado:

"O sistema de medição de deslocamento deve estar colinear com o ponto funcional no qual o deslocamento é medido. Se isso não for possível, todas as guias que transferem o deslocamento devem estar livres de movimentos angulares ou os dados do movimento angular devem ser usados para calcular e compensar tais desvios."

A primeira sentença representa a recomendação original de Abbè, enquanto a segunda sentença sugere duas opções adicionais: uma quando não existe movimento angular e outra quando este está presente.

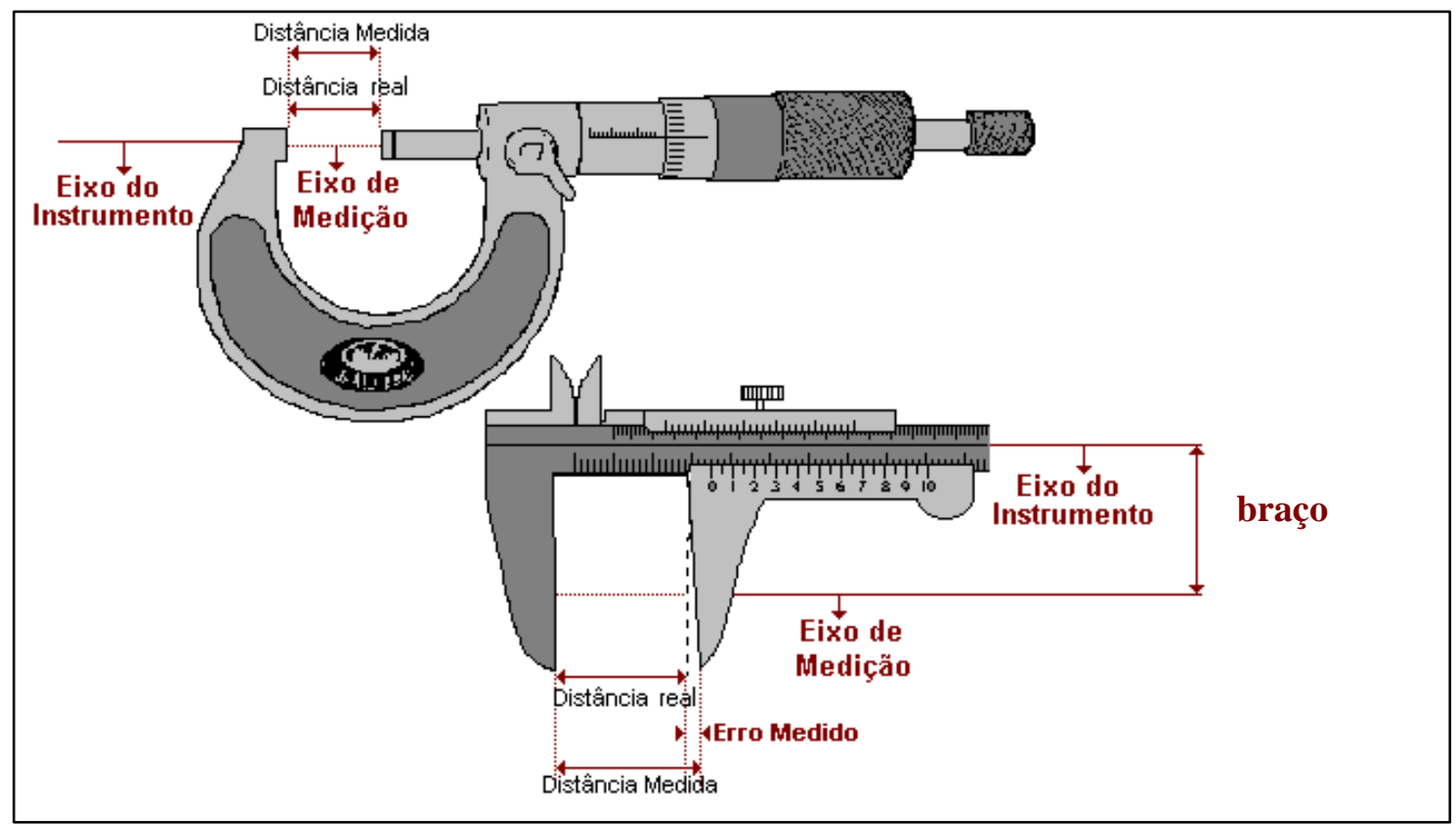

Figura 2.2: Micrômetro (concordância com o Princípio de Abbè) e paquímetro (transgressão do Princípio de Abbè)

É praticamente impossível obter guias isentas de movimentos angulares através dos processos de fabricação atuais. Dada esta impossibilidade, deve-se medir, calcular e corrigir os erros causados por esses movimentos. Os sistemas mais modernos, como o CNC (Controle Numérico Computadorizado), podem ser programados para aceitar dados 
do movimento angular, calcular e compensar os efeitos dos erros angulares (BRYAN, 1979).

O erro de Abbè é dependente da distância entre a posição do ponto que se está medindo e a escala do seu respectivo eixo. Esta distância é conhecida como braço de Abbè e está ilustrada na Figura 2.2, consequentemente quanto maior o braço de Abbè, maior será o erro devido à transgressão do Princípio de Abbè.

\section{ERROS DEVIDO AO APALPADOR}

O apalpador é responsável pela definição do ponto a ser medido. Ele funciona como uma interface entre a superfície em inspeção e o sistema de medição e pode ser classificado em função das suas características como apalpador por contato ou apalpador sem contato. Os apalpadores por contato podem ser do tipo rígido ou de gatilhamento e os sem contato do tipo ópticos à laser ou sistemas de visão (NI e WÄLDELE, 1995). A Figura 2.3 mostra alguns exemplos de apalpadores que podem ser utilizadas para medição.
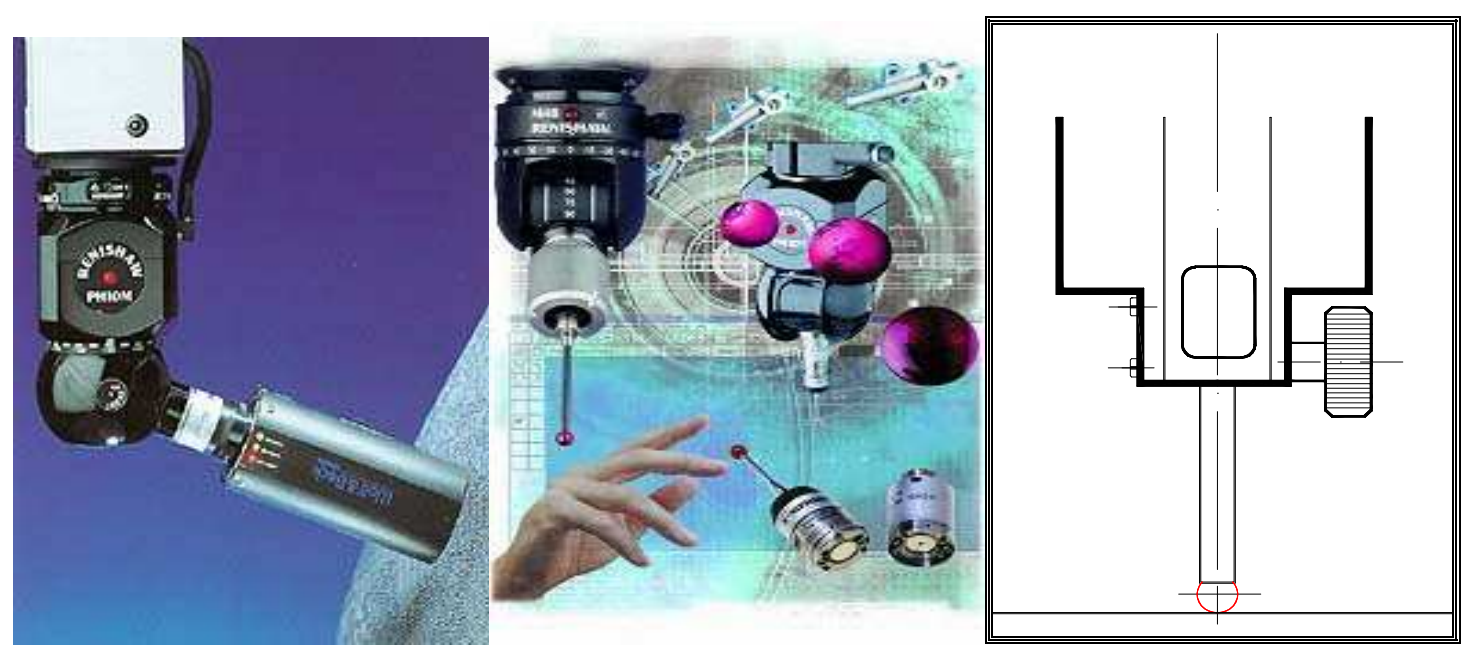

Figura 2.3: Apalpador sem contato tipo laser (esquerda); apalpador por contato, touch-trigger (centro) e rígido (direita)

Os apalpadores mais usados nas MM3C são os conhecidos como touch-trigger. Este tipo de apalpador funciona com um interruptor elétrico que envia um impulso lógico ao sistema de controle. Quando a ponta do 
apalpador faz contato com a superfície da peça, sinais de leitura são enviados das três escalas da máquina e imediatamente "congelados" e, então a leitura da posição é feita.

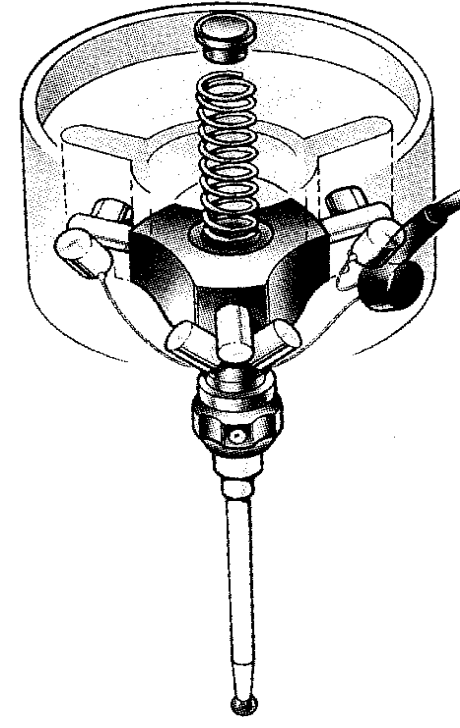

Figura 2.4: Esquema do apalpador

Os apalpadores touch-trigger funcionam com 9 cilindros dispostos 3 a 3 a 120 graus uns dos outros, Figura 2.4, sobre os cilindros tem-se 3 hastes que estão interligadas a uma quarta, a ponta do apalpador. Quando 1, 2 ou as 3 hastes perdem o contato com os cilindros, o apalpador emite um sinal sonoro e há o "congelamento" das coordenadas naquela posição.

Tais apalpadores têm haste de aço inox ou metal duro. A fixação no cabeçote é feita através de roscas ou de imãs. As pontas de medição são normalmente esféricas e feitas com rubi sintético. Podem também ser pontas secas, semi-esféricas ou de disco em material cerâmico, Figura 2.5 (NI, 1995).
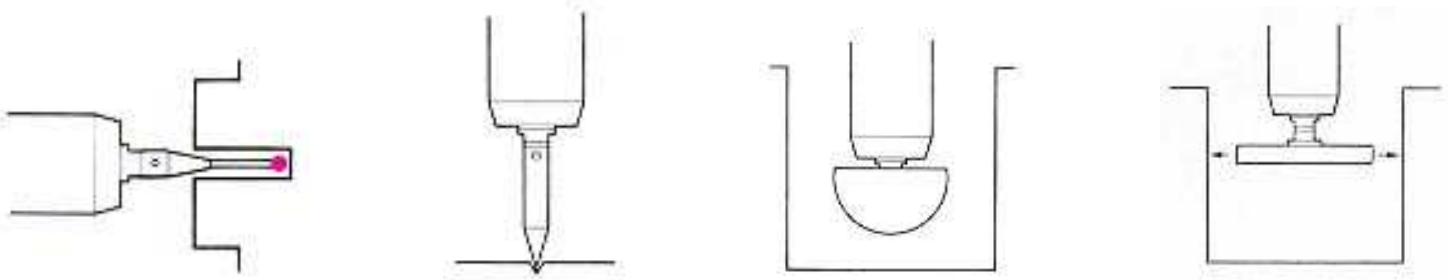

Figura 2.5: Tipos de pontas

As fontes que influenciam a acuracidade do sistema apalpador são: problemas eletrônicos, desgastes dos apoios cinemáticos, variações de forças devido a direção de contato, erro de esfericidade da ponta do apalpador entre outras. Deve-se então, sempre que possível, conhecer o desempenho do apalpador e seus erros para compensá-los durante as medições (HARVIE, 1986). 


\section{ERROS DEVIDO À FORMA DAS GUIAS E DO DESEMPENO DE REFERÊNCIA}

As MM3Cs dependem fundamentalmente da precisão das guias. Os erros de forma, como por exemplo os erros de retilineidade e planicidade, estão presentes nas guias devido a imperfeições dos processos de usinagem. Estes erros produzem movimentos indesejáveis nos carros e consequentemente na ponta do apalpador. Então quanto menores forem os erros de forma das guias, menores serão os erros da máquina.

O desempeno de referência equipa todas as MM3Cs e serve para o posicionamento das peças. Ele é feito de granito natural, sintético ou ainda em ferro fundido. $O$ erro de planicidade do desempeno deve estar dentro de limites de tolerâncias, pois este serve como superfície de referência (PAHK e BURDEKIN, 1991).

\section{ERROS DEVIDO AO PESO PRÓPRIO}

O movimento dos carros encarregados de posicionar o ponto de prova dentro do volume de trabalho de uma MM3C desloca o centro de gravidade de sua estrutura, provocando variações dos estados de deformação da mesma (MARTINEZ ORREGO, 1999).

Os efeitos dos erros induzidos pelo peso próprio dos componentes das MM3Cs podem ser minimizados utilizando materiais capazes de fornecer maior rigidez à estrutura das máquinas. É comum o uso de técnicas de protensão e de apoio de Airy para minimizar as flexões sofridas pelas vigas ou guias muito longas (MARTINEZ ORREGO, 1999;KUNZMANN et al., 1995).

\section{INTEGRIDADE DOS PROGRAMAS COMPUTACIONAIS}

Os programas computacionais das MM3Cs têm a função de facilitar o processo de medição: ajustando os pontos medidos através de modelos matemáticos e mostrando os resultados para o usuário (KREJCI, 1995).

Nas máquinas controladas numericamente, os movimentos podem ser programados para efetuar sequências de medição. A qualidade da 
avaliação dos dados pode ser questionada e um teste de verificação realizado.

Os pesquisadores do Physikalisch-Technische Bundesanstalt - PTB, PORTA e WÄLDELE, em 1986, relataram os resultados da primeira fase de um projeto da Commission of the European Communities sobre testes realizados com algoritmos matemáticos para calcular reta, plano, circulo, cilindro e cone, usados por 12 programas diferentes de MM3Cs. Nesses testes, foi usado um conjunto de pontos coordenados simulados para cada uma das geometrias e os resultados foram comparados com os resultados de um programa de referência desenvolvido pelo PTB. As diferenças encontradas nesta comparação foram atribuídas aos algoritmos usados, verificando que os programas computacionais não estão livres de erros (MARTINEZ ORREGO, 1999).

Dois caminhos de verificação podem ser tomados: um é avaliar o algoritmo conhecendo todos os detalhes deste, o que na prática é difícil por se tratar de um segredo dos fabricantes e outro é avaliar pontos que simulem uma superfície conhecida; neste caso, WECKENMANN e HEINRICHOWSKI (1985) sugerem o uso de padrões volumétricos virtuais.

Em 22 de agosto de 1988, o Government-Industry Data Exchange Program, publicou a nota GIDEP No. X1-A-88-01. Essa nota alertou que certos algoritmos usados nas MM3Cs não calculavam as características desejadas corretamente conforme a Dimensioning and Tolerancing Standard, ANSI/ASME Y14.5 de 1994. Como resultado desta nota, métodos para testes foram desenvolvidos. O primeiro método de teste foi o seguinte: criar um conjunto de dados, carrega-los diretamente no algoritmo, sem os erros de medição, e calcular a característica. Os resultados desse teste destacam várias preocupações, tais como, o impacto dos erros na aceitação do programa computacional, a possibilidade de outros erros na máquina e como o programa computacional da MM3C pode ser certificado.

A ANSI Y14.5 não foi uma solução, pois é apenas um esboço de norma e não define matematicamente nenhum modelo de algoritmo. 


\section{INFLUÊNCIA DO ACABAMENTO E DO PESO DA PEÇA}

O acabamento da peça pode levar a erros na interpretação dos resultados. Por este motivo, deve-se antes da medição fazer uma análise rápida da qualidade da peça quanto às tolerâncias de dimensão, de forma e de acabamento superficial. O diâmetro da ponta do apalpador pode ser definido para minimizar essas influências.

O peso da peça combinado com seu posicionamento e montagem no desempeno, também influenciam o resultado das medições, pois causam deformações na estrutura da máquina. A grandeza destas deformações depende do tipo e do tamanho da MM3C. Para eliminar a influência do peso da peça nos resultados da medição, podem ser usadas diferentes "técnicas de reversão" (ESTLER, 1985; EVANS et al., 1996).

\section{ERROS DEVIDO A VARIAÇõES DE TEMPERATURA}

A temperatura padrão para operação nas MM3Cs é definida em $20 \pm 1^{\circ} \mathrm{C}$, de acordo com a ANSI/ASME STANDART B89.6.2 de 1973. Caso contrário, podem ocorrer mudanças nos comprimentos das escalas de medição, nos elementos da máquina e nas peças a serem medidas. Para reduzir as influências térmicas são utilizados ambientes controlados para instalação das MM3Cs. No entanto, há grandes esforços dos fabricantes para que as máquinas trabalhem em chão de fábrica, ou seja, lugares onde não há controle de temperatura. Sendo assim, as pesquisas realizadas nos últimos anos tendem a estudar métodos de compensação que levem em consideração os erros termicamente induzidos.

Sistemas de compensação para os efeitos térmicos podem ser aplicados com a escolha de materiais adequados e técnicas de projeto que consigam minimizar as reações às interferências térmicas (BALSAMO et al., 1990; LINGARD et al., 1991; BRYAN, 1995).

KRUTH et al. (2001) realçaram a necessidade de um sistema de compensação de temperatura nas MM3Cs devido ao crescente número destas máquinas em ambientes sem controle de temperatura. Apresentaram uma parametrização para descrever a relação entre 
transiente de temperatura e deformações nas MM3Cs. Calcularam o coeficiente de correção da ponta do apalpador, baseando-se em um número limite de entradas de temperatura.

As principais fontes de erros térmicos para MM3Cs são as seguintes: influência do ambiente, o operador, o efeito conhecido como memória térmica, o calor gerado pela própria MM3C, motores e sistemas eletrônicos, e outras máquinas e equipamentos nas proximidades.

\section{ERROS DINÂMICOS}

Os erros dinâmicos podem ocorrer devido a fontes internas ou externas à máquina. As fontes internas são as acelerações e desacelerações das partes móveis durante o trabalho de medição. As vibrações no ambiente em que se encontra a MM3C são consideradas fontes externas (WEEKERS e SCHELLEKENS, 1997).

Os erros dinâmicos serão entendidos como todos aqueles que acontecem ou que são amplificados devido a variações de velocidade e aceleração durante um processo de medição.

Para levar o apalpador de medição até o ponto de contato na peça, os elementos móveis que pertencem à $M M 3 C$ sofrem acelerações e desacelerações nas direções preferenciais de movimentação. É conveniente que a aproximação seja feita de forma bastante lenta para evitar choques e eventuais danos ao apalpador ou à peça. Depois de tocada a superfície, deve-se recuar o apalpador e inicia-se um novo ciclo de medição. Neste processo a máquina experimenta excitações devido às acelerações dos elementos móveis da máquina modificando o posicionamento do ponto de prova. Estes deslocamentos indesejáveis são erros aqui entendidos como de origem dinâmica.

Ainda durante o processo de medição as MM3Cs experimentam ciclos diferentes de velocidades. Os ciclos devem ser planejados para otimizar o desempenho da máquina durante a medição diminuindo o tempo gasto no processo, mas mantendo acuracidade e repetibilidade convenientes.

As MM3Cs com capacidade de medição por varredura podem 
alcançar velocidades bastante altas e por isso são sempre candidatas a ocupar posições onde há demanda por alto desempenho. É de conhecimento geral, entretanto, que as velocidades de medição degradam substancialmente características como acuracidade e repetibilidade e, portanto são fatores limitantes no processo, pois impõem sobre a medição erros chamados de erros de varredura e que são caracterizados pela presença simultânea de acelerações em diversas direções.

Dentre todas as influências dinâmicas sobre as MM3Cs os modos de vibrar são aquelas de menor influência nas componentes do erro volumétrico, entretanto do ponto de vista do projeto de máquinas e, portanto do interesse dos fabricantes, estas informações são de extrema importância.

Alcançar um bom desempenho das MM3Cs em termos dinâmicos constitui uma árdua tarefa, uma vez que o estudo, entendimento e compensação dos erros dinâmicos são alguns dos problemas mais complexos nas medições a três coordenadas.

\section{OUTROS ERROS}

Outros fatores que influenciam na medição nas MM3Cs, são: falta de continuidade e uniformidade da energia elétrica, suprimento descontínuo do ar comprimido, umidade e pressão atmosférica.

\subsection{Os erros geométricos}

Os erros geométricos podem ser classificados em 2 grandes grupos: os paramétricos e os não paramétricos. Os paramétricos abrangem aqueles que podem ser parametrizados em função da posição, enquanto os não paramétricos são aqueles que acontecem devido à relação entre elementos, tais como, os erros de ortogonalidade e os erros de paralelismo.

Nas MM3Cs há 21 erros geométricos, sendo 6 erros paramétricos em cada eixo de movimentação somando 18 , e ainda 3 erros nãoparamétricos, que são os erros de ortogonalidade entre os eixos (KUNZMANN et al., 1995). 
Para melhor entendimento sobre os erros geométricos, considere um carro de uma máquina como um corpo rígido, com a possibilidade de movimento de translação em apenas uma direção, como ilustra a Figura 2.6. Observe que o movimento de deslocamento é realizado na direção $X$. No entanto, é possível que a leitura da escala de posição do eixo $X$ não indique o valor exato do deslocamento experimentado pelo carro. Este erro é denominado erro de posição ou de escala e denota-se por $\delta_{\mathrm{x}}(\mathrm{x})$.

As translações nas outras direções e rotações indesejáveis que o carro experimenta são denominados erros de retilineidade e angulares, respectivamente. Os erros de rotação são comumente conhecidos como Yaw, Pitch e Roll conforme a direção do deslocamento do carro, e particularmente, para a ilustração da Figura 2.6, são respectivamente denotados por $\delta \theta_{z}(x), \delta \theta_{y}(x)$ e $\delta \theta_{x}(x)$. Neste caso $\delta \theta_{z}(x), \delta \theta_{y}(x) \delta \theta_{x}(x)$ são as rotações indesejadas em torno dos eixos $Z, Y$ e $X$, respectivamente.

Na Figura 2.6 pode-se observar ainda o erro de retilineidade na direção $Y$ devido ao movimento no eixo $X$, denotado por $\delta_{y}(x)$, e o erro de retilineidade na direção $Z$ devido ao movimento no eixo $X$, denotado por $\delta_{z}(x)$. Os eixos $X$ e $Z$ definem um plano horizontal, então $\delta_{z}(x)$ é chamado de "retilineidade horizontal" e $\delta_{\mathrm{y}}(\mathrm{x})$ é chamado de "retilineidade vertical".

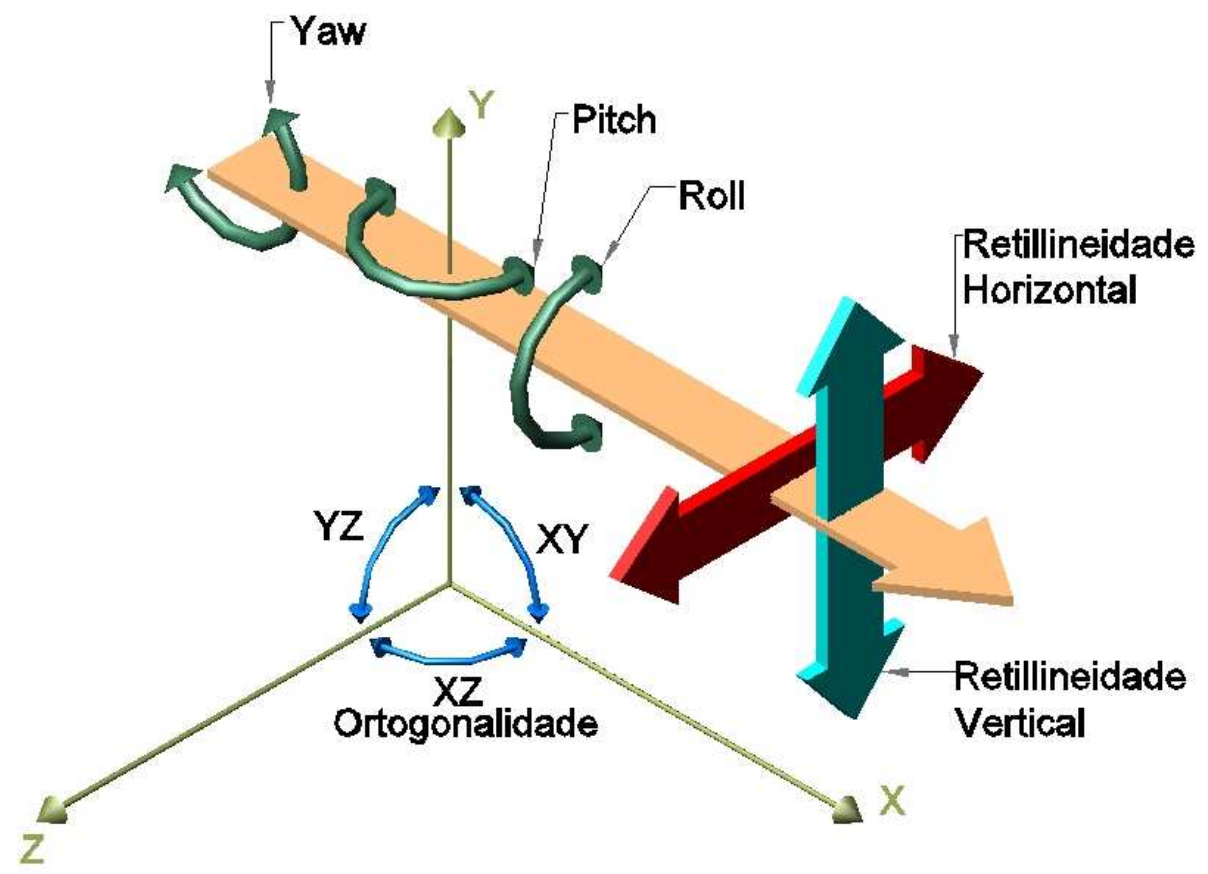

Figura 2.6: Erros geométricos. 


\subsection{Calibração das MM3Cs}

Para a minimização dos erros que ocorrem durante a operação de medição de dimensões nas MM3Cs, é necessário que se tenha o conhecimento prévio do comportamento e do valor destes erros. Estas informações podem ser obtidas através de uma calibração da máquina.

A norma ANSI/ASME B89.4.1, 1997, define a calibração como sendo a determinação da diferença entre o valor indicado por um instrumento de medição e o valor nominal ou "verdadeiro". A calibração deve ser válida para todas as condições de operação sob as quais pode ser utilizado o instrumento calibrado.

A utilização dos métodos de calibração das MM3Cs é de vital importância, pois é através deles que o comportamento metrológico das máquinas pode ser levantado. A calibração pode ser classificada em calibração direta e calibração indireta.

\subsubsection{MÉTOdos de calibração direta}

A calibração direta tem como característica avaliar cada tipo de erro individualmente para cada eixo preferencial de movimento, e normalmente é executada pelo fabricante (PIRATELLI, 1997). Através deste procedimento é possível qualificar a máquina, classificá-la e ordená-la conforme a significância dos erros (BURDEKIN et al., 1984).

A aplicação do método de calibração direta é demorada, porém permite a obtenção de uma grande quantidade de informações sobre a MM3C (KNAPP et al., 1991; DI GIACOMO, 1986). Estas informações são confiáveis e completas, permitindo identificar fontes de erros significativos e anomalias da geometria da máquina (SATO, 1998).

A calibração direta pode ser realizada utilizando-se de duas técnicas: a do volume dividido e a de sintetização. A primeira baseia-se na medição dos erros de posição de cada um dos eixos coordenados da máquina, em todo seu volume de trabalho. Esta medição é feita em geratrizes paralelas a cada um dos eixos da máquina e em várias posições de cada um dos eixos, formando assim uma grade (Figura 2.7). A distância 
real entre pontos sucessivos sobre as geratrizes é medida usando um instrumento padrão como, por exemplo, o Interferômetro Laser. As coordenadas reais de cada nó da rede são comparadas com as coordenadas nominais, obtendo-se então os erros.

A técnica do volume dividido tem como ponto positivo ser um dos mais rigorosos e não necessita de hipóteses simplificadoras, servindo para o diagnóstico de fontes de erros e também para a construção de matrizes de erros e sistemas de compensação. Como ponto negativo pode-se ressaltar a necessidade de muito tempo para testes, o que o torna caro e mais sensível a incertezas devido as mudanças de temperatura durante os ensaios (DI GIACOMO, 1986; BURDEKIN et al., 1984).

$\mathrm{Na}$ calibração direta, utilizando a técnica de sintetização, cada componente do erro volumétrico é medida individualmente com um padrão adequado. Tais erros podem ser medidos utilizando-se de instrumentos convencionais, para exemplificar, réguas, esquadros, níveis e relógios comparadores, ou ainda instrumentos sofisticados como o Interferômetro Laser (WECK, 1984; ESTLER, 1985; NI e WU, 1993). Esta técnica apresenta-se como a mais completa para avaliação de MM3C, possibilitando o diagnóstico das fontes de erros e permitindo a minimização das mesmas.

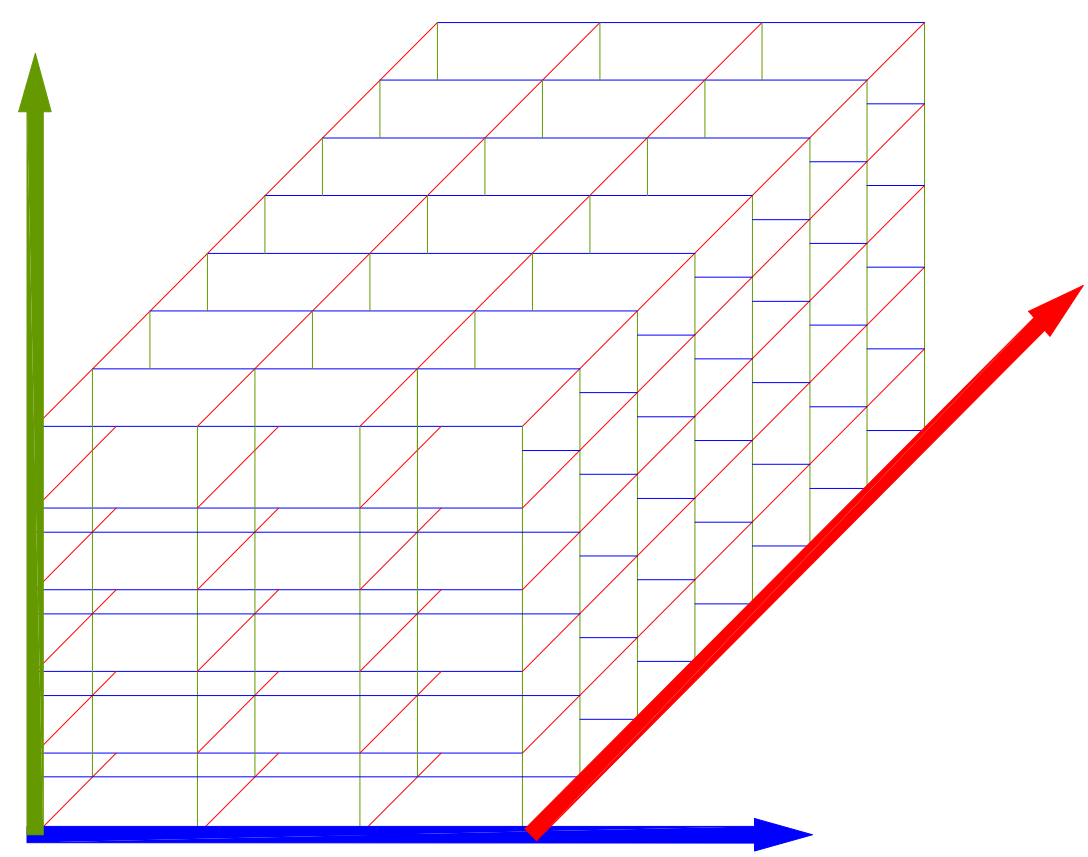

Figura 2.7: Formato das geratrizes utilizadas no método do volume dividido 
A modelagem matemática da estrutura da máquina oferece as expressões para o cálculo das componentes do erro volumétrico. Este modelo é desenvolvido de acordo com a estrutura da máquina, utilizando o princípio da cinemática de corpo rígido (SATO, 1998).

\subsubsection{MÉtodos de CALIBRAÇÃo INDIRETA}

Durante os últimos anos muitas organizações internacionais de normalização, institutos de pesquisa, universidades e empresas particulares têm desenvolvido diferentes métodos de calibração para serem utilizados como testes de aceitação e verificação periódica das MM3Cs (KNAPP et al., 1991).

O procedimento de calibração indireta tem como característica a avaliação dos erros das máquinas por intermédio de peças padrões préqualificadas e normalizadas, cujas dimensões e erros são conhecidos (KNAPP et al., 1991; DI GIACOMO, 1986). É o procedimento mais indicado para inspeção periódica, pois pode ser feito pelo usuário e apresenta tempo e custo menores que os envolvidos na calibração direta. Em muitos casos, nesses ensaios, não se consegue separar os erros por suas características e nem diagnosticar suas fontes.

Os artefatos padrões são fundamentais para o método de calibração indireta. Estes artefatos se apresentam em diversas formas geométricas e dimensões, devendo ser avaliados e escolhidos de acordo com o número de coordenadas do sistema de medição. São construídos com materiais especiais, tais como: ligas cromo-níquel, fibra de carbono, Invar e Zerodur que são muito estáveis térmica e dimensionalmente (SATO, 1998).

A seguir são apresentados os padrões mais utilizados:

\section{BARRA DE ESFERAS}

A barra de esferas consiste de uma barra de comprimento fixo, com duas esferas colocadas uma em cada um dos extremos da barra e um suporte para sua fixação em diferentes orientações. O método de calibração com barras de esferas é o mais utilizado para a avaliação do desempenho 
volumétrico da MM3C, sendo este recomendado pela norma ANSI/ASME B 89.4.1.

A calibração de uma MM3C com a barra de esferas consiste em medir a distância entre centros das esferas em posições e orientações estratégicas, dentro do volume de trabalho. Os desvios na medição, com relação ao padrão, indicam o erro.

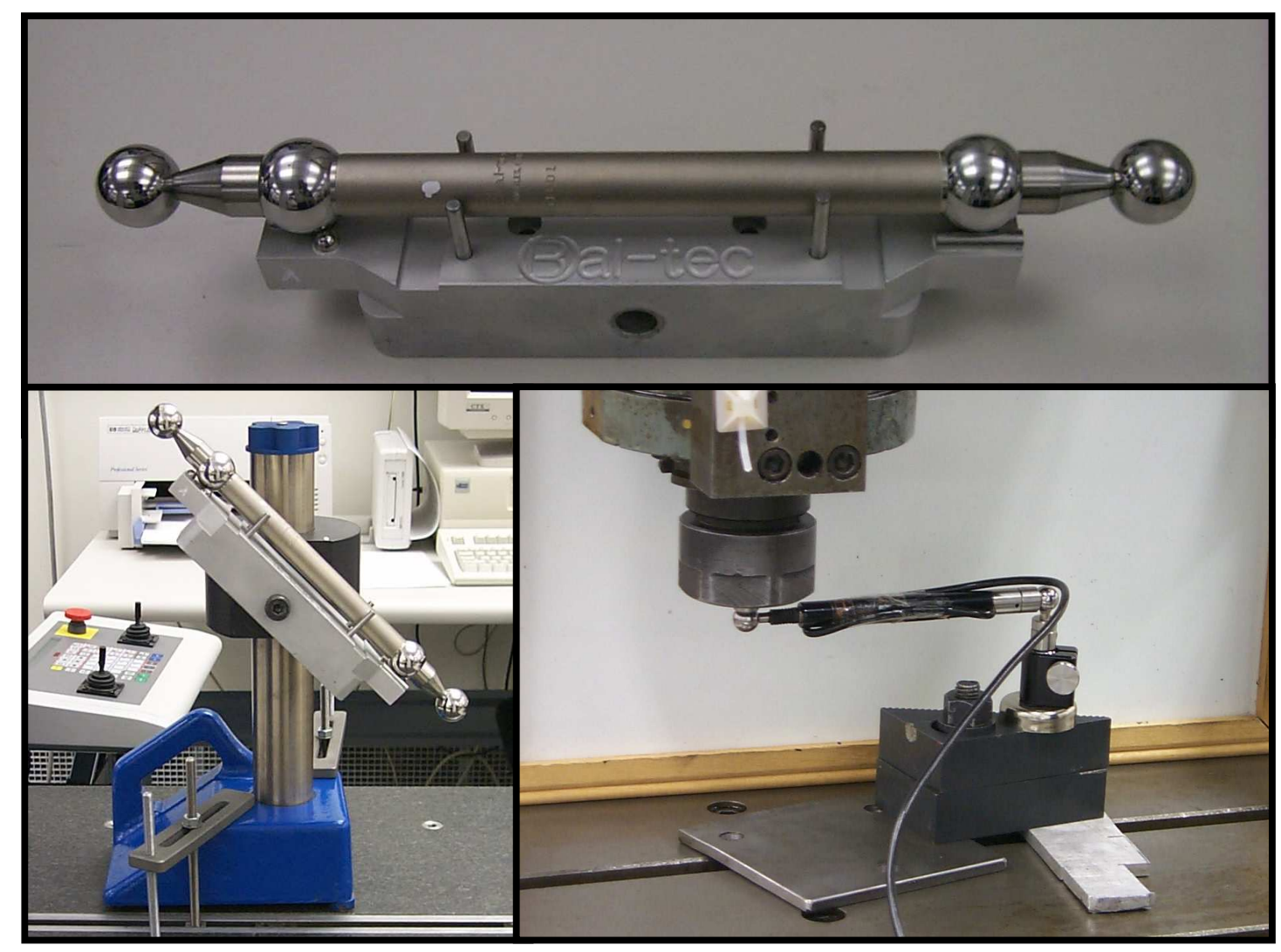

Figura 2.8: Barra de esfera (acima), esquema de montagem e barra de esfera telescópica

Segundo BRYAN (1982) o uso da barra de esferas se mostra rápido e preciso para indicação de acuracidade bi ou tri-dimensional das MM3Cs. Dois tipos mais sofisticados de barras foram projetadas com apoios chamados cinemáticos (Figura 2.8), a Barra de Esferas Magnética Fixa (BEMF) e a Barra de Esferas Magnética Telescópica (BEMT). 


\section{PADRÃO PASSO A PASSO}

O padrão passo a passo (Figura 2.9) consiste em um conjunto de blocos-padrão com igual comprimento nominal, dispostos linearmente sobre uma guia. A posição relativa de cada um deles determina a distância padrão.

O tempo para a avaliação das MM3Cs utilizando este tipo de artefato é bastante reduzido. Tal artefato possibilita estimar os erros de posicionamento e os erros angulares de cada eixo quando alinhado com os mesmos, possibilitando também, estimar os erros de retilineidade $\mathrm{e}$ ortogonalidade quando alinhado às diagonais dos planos formados pelos eixos XY, XZ e YZ (KNAPP et al., 1991).

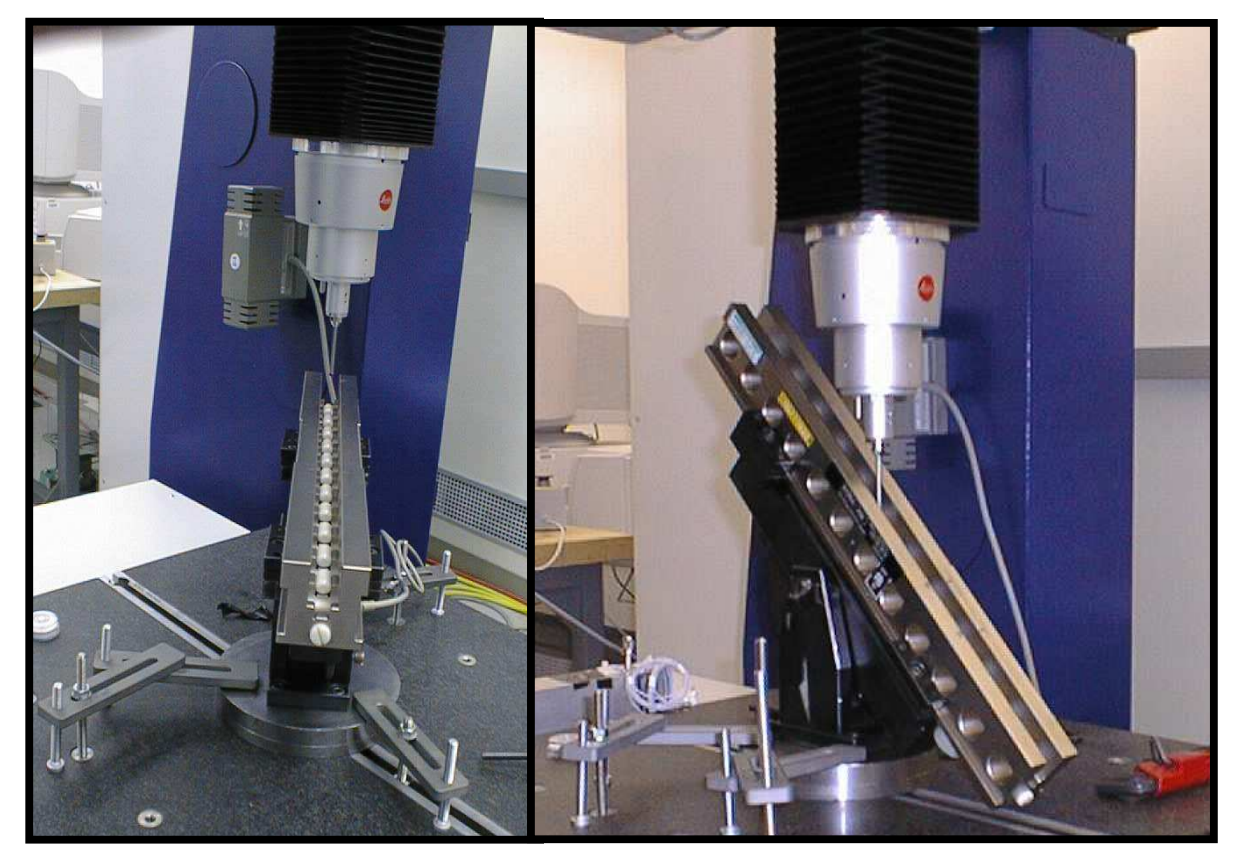

Figura 2.9: Padrão passo a passo

\section{Placa de esferas}

A placa de esferas consiste de uma superfície de aço onde são fixadas diversas esferas no mesmo plano arranjadas em uma grade regular, como mostra a Figura 2.10. Os diâmetros e as distâncias entre esferas são padronizados. Este método baseia-se no posicionamento do padrão no volume de trabalho da MM3C em posições estratégicas e execução de 
medições das distâncias entre as esferas. A calibração com este artefato pode ser aplicada para a determinação dos 21 erros geométricos de uma MM3C, gerando o mapa de erros.

TAKATSUJI et al. (2002) desenvolveram um modelo matemático para procedimentos de calibração de acordo com o Guia de Incerteza de Medição (GUM). Foi feita a calibração de uma placa de esferas na MM3C. Um bloco padrão foi utilizado simultaneamente para a compensação dos erros de escala, mantendo assim, a rastreabilidade do padrão de comprimento. Os resultados não se mostraram apropriados para um bloco padrão e o erro de escala só pôde ser compensado com uma montagem de múltiplos blocos-padrão.

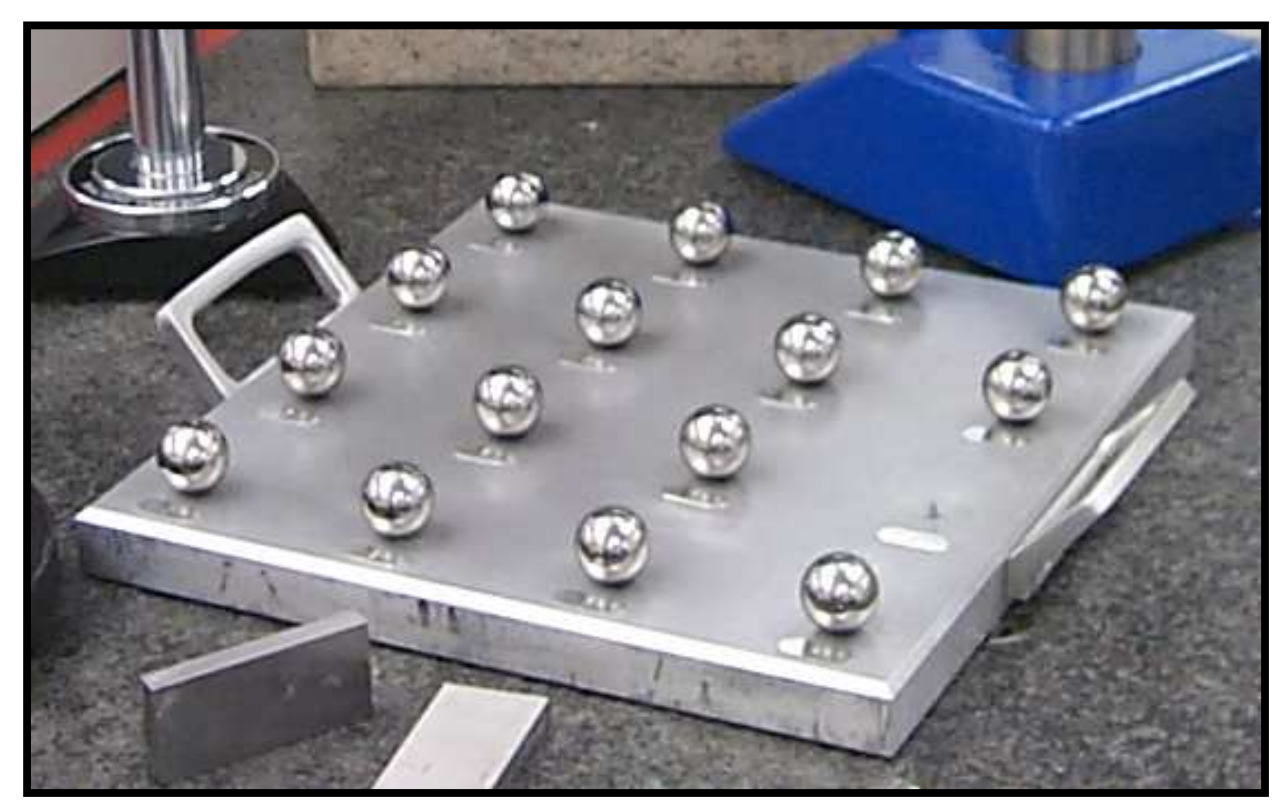

Figura 2.10: Padrão de esfera

\section{Placa de furos}

A placa de furos consiste em um conjunto de furos, com diâmetro e desvio de circularidade conhecidos, arranjados simetricamente sobre uma placa plana, Figura 2.11. A calibração com a placa de furos é análoga à calibração com a placa de esferas, a diferença básica é que com esta medese distância entre furos. 
A calibração utilizando placa de furos também gera o mapa de erros das MM3Cs.

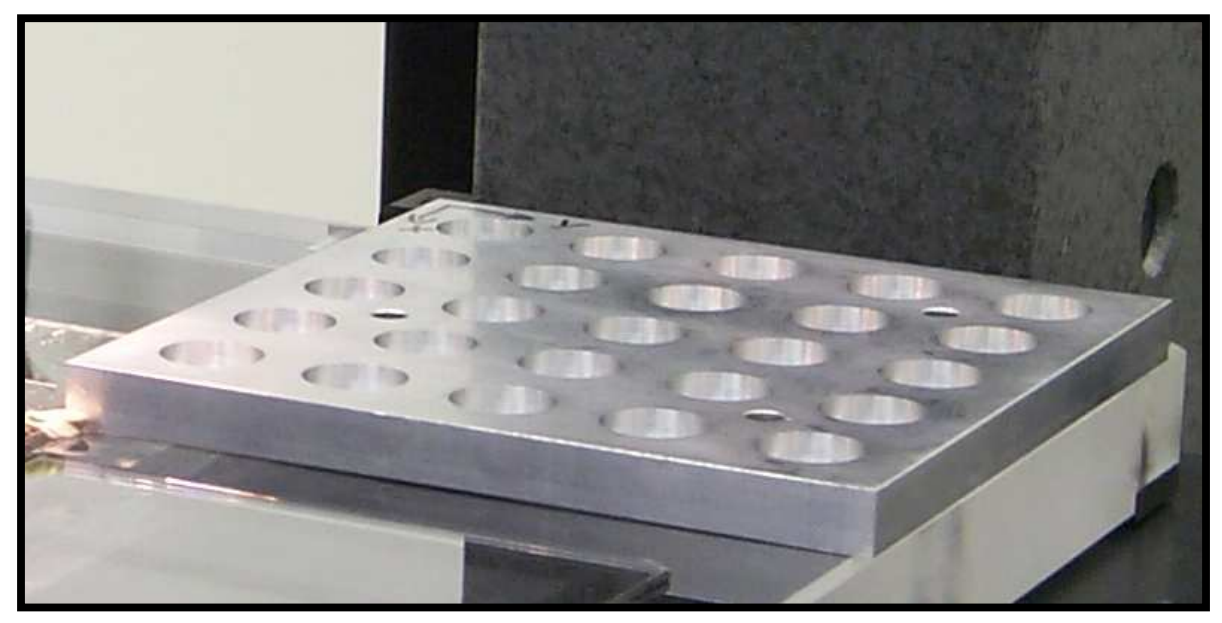

Figura 2.11: Padrão de círculos

\section{PAdRÃo TETRAÉdRICo}

Padrões tridimensionais têm grande aceitação para calibração das MM3Cs (BURY, 1976; BELFORTE et al., 1987). Os padrões tetraédricos (Figura 2.12) foram propostos e construídos primeiramente por BURY.

$\mathrm{O}$ artefato consiste em uma montagem tridimensional de barras de esferas de grande estabilidade dimensional e que permitem ser calibradas com instrumentos de medição linear. As esferas podem ser de carbeto de tungstênio ou de aço, acopladas umas às outras através de barras reforçadas com fibra de carbono (HARVIE, 1986).

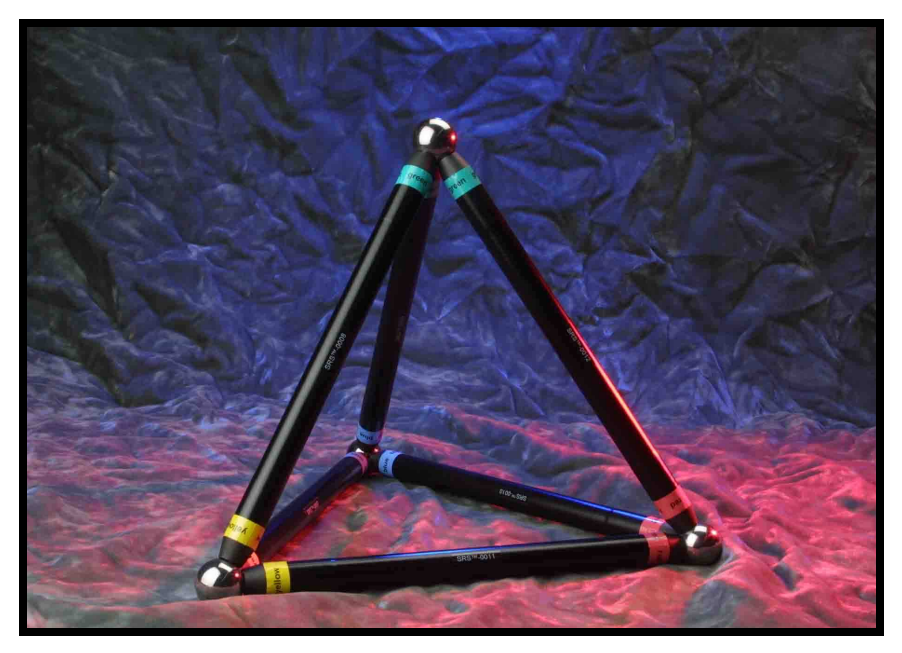

Figura 2.12: Padrão tetraédrico 
O interesse na utilização deste artefato deve-se à facilidade de avaliação de vários erros geométricos conjuntamente. No entanto, o alto custo envolvido na construção e calibração, restringe o uso aos casos onde o interesse é avaliar as condições de medição de peças de geometria complexas (PEGGS, 1990).

AQUINO SILVA e BURDEKIN (2002) pesquisaram uma nova forma de estrutura espacial para rápida avaliação de erros em MM3Cs. Essa estrutura possui forma tetraédrica e modular, compreendendo conexões de esferas magnéticas e uma placa de esferas. Os resultados experimentais encontrados mostraram que o sistema tem uma repetibilidade aceitável, fornecendo um artefato mecânico prático e de baixo custo para a determinação da acuracidade volumétrica de máquinas de pequeno e médio porte.

\subsection{Modelagem dos erros volumétricos}

A modelagem das MM3Cs tem crescido na sua importância, pois através de modelos matemáticos é possível determinar a grandeza e o comportamento dos erros. Desta forma, pode-se compensar os erros. Muitos pesquisadores têm estudado e desenvolvido modelos para representar erros em MM3Cs e técnicas variadas tem sido utilizadas para este fim.

Os modelos matemáticos utilizados na metrologia da medição a três coordenadas têm como função combinar, de forma adequada e ponderada, os erros individuais de cada uma das direções preferenciais da máquina formando o chamado erro volumétrico. Tais modelos determinam a diferença entre o caminho real e o caminho ideal descrito pela ponta do apalpador.

O modelo matemático dos erros pode ser construído através das técnicas: Análise Geométrica Estrutural, Análise Vetorial dos Caminhos de Medição, Análise Matricial através de Transformações Homogêneas e a Análise Estatística. A seguir é apresentado uma breve descrição de algumas destas técnicas. 


\section{ANÁLISE Vetorial:}

Através de vetores é feita uma representação dos caminhos de medição. Desta forma, o erro volumétrico é definido como a diferença vetorial entre os vetores que descrevem os caminhos de medição com e sem erros.

Através da análise vetorial, ZHANG et al. (1985), baseado na cinemática de corpo rígido, um modelo para descrever os erros em uma MM3C do tipo "Ponte Móvel" foi desenvolvido. Tal modelo foi projetado para compensar os erros geométricos e o efeito da dilatação térmica das escalas de medição. Foram feitas medições da temperatura utilizando termopares e corrigidas as expansões térmicas das escalas.

ZHANG e FU (2000) utilizaram análise vetorial para obter um modelo de erros para MM3Cs e, uma placa de esferas foi utilizada na calibração da máquina. O modelo proposto pelos autores é simples, entretanto assume que um dos três eixos da máquina tenha sido calibrado com um interferômetro laser.

\section{TRANSFORMADAS HOMOGÊNEAS:}

A aplicação das técnicas de transformação homogêneas (TH) nos problemas de cinemática foi iniciada em 1875 , com a publicação do trabalho de F. REULEAUX, e que serviu como base para o método introduzido por DENAVIT-HARTENBERG em 1955. Através desta técnica, e mediante o uso de matrizes de transformação $4 \times 4$, é possível representar movimentos de translação, de rotação ou a combinação desses dois, possibilitando estabelecer as relações entre partes móveis de um mecanismo e um sistema de coordenadas de referência (PAUL, 1981).

Cada componente da máquina sofre rotações e translações com relação a um sistema de coordenadas de referência, e cada um destes componentes pode ser representado por um sistema de coordenadas intermediário. Desta forma, através de vetores e matrizes é desenvolvida uma sistemática que generaliza a representação da posição e da orientação do apalpador da máquina em relação ao sistema de coordenadas de 
referência. A definição do comportamento cinemático da máquina consiste na determinação das matrizes de transformação homogênea dos diferentes sistemas de coordenadas, com relação a um sistema de coordenadas de referência.

A matriz 4x4 utilizada para determinar a posição de um corpo rígido com relação a um sistema de coordenadas fixo é exemplificada a seguir.

$$
\delta \mathrm{A}=\left[\begin{array}{cccc}
1 & -\gamma & \beta & \Delta \mathrm{x} \\
\gamma & 1 & -\alpha & \Delta \mathrm{y} \\
-\beta & \alpha & 1 & \Delta \mathrm{z} \\
0 & 0 & 0 & 1
\end{array}\right] \text { onde: } \begin{aligned}
& \alpha \text { - rotação infinitesimal sobre o eixo } \mathrm{x} . \\
& \beta \text { - rotação infinitesimal sobre o eixo } \mathrm{y} . \\
& \\
& \Delta \mathrm{x} \text { - translação sobre o eixo } \mathrm{x} . \\
& \Delta \mathrm{y} \text {-translação sobre o eixo y. } \\
& \Delta z \text { - translação sobre o eixo } \mathrm{z} .
\end{aligned}
$$

Os valores de $\alpha, \beta, \gamma, \Delta x, \Delta y$ e $\Delta z$ são funções da posição ao longo do eixo.

HOCKEN et al., (1977), modelaram através das matrizes de transformações homogêneas, nesta ocasião, os erros angulares em MM3Cs controladas por computador.

DI GIACOMO et al. 1997, utilizando técnica de transformações homogêneas, modelaram MM3Cs com o objetivo de determinar a influência dos termos de segunda ordem no erro volumétrico. Dois modelos foram desenvolvidos, um deles incluindo os termos de segunda ordem e um outro desprezando-os. Como resultado obteve-se que a inclusão dos termos de segunda ordem nos modelos acarreta uma diferença menor que $1 \mathrm{~nm}$, mostrando que eles podem ser desprezados, desde que o valor esperado dos erros volumétricos esteja na ordem do $\mu \mathrm{m}$. Devido ao estreitamento nas tolerâncias nos projetos e os estudos envolvendo a nanotecnologia futuramente os termos de segunda ordem não poderão mais serem desprezados.

A técnica de Transformações Homogêneas constitui uma poderosa ferramenta matemática, com relativa facilidade de uso e elevado poder de diagnóstico. 


\section{ANÁLISE GEOMÉTRICA:}

Através da análise geométrica da estrutura, verifica-se a parcela de cada erro nas componentes do erro volumétrico. A soma algébrica de tais parcelas para cada um dos eixos forma as denominadas equações de sintetização.

DI GIACOMO (1986), apresentou a determinação dos erros geométricos individuais utilizando análise geométrica para, posteriormente, determinar as componentes do erro volumétrico em cada direção preferencial " $X$ ", "Y" e "Z" de uma MM3C da marca "Ferranti Conquest MKII".

\section{ANÁLISE eStatística:}

As técnicas estatísticas têm sido utilizadas para avaliar o comportamento dos erros de MM3Cs e portanto de seu desempenho. Através do uso desta técnica é possível se determinar o erro de medição em tais máquinas.

Em 1978 GUYE propôs um método para avaliar os erros de medição de uma MM3C. Tal método consiste na construção de histogramas a partir dos valores dos erros de posição levantados utilizando um interferômetro laser. Neste caso, o desvio padrão do conjunto de resultados é considerado como indicador do desempenho da máquina avaliada.

POOLE (1983) sugeriu um método para verificar o desempenho das MM3Cs usando técnicas de análise de variância. Este método permite investigar o efeito da localização no volume de trabalho na acuracidade da máquina. Para isto, o volume da máquina avaliada foi dividido em oito partes iguais, e os erros em cada parte foram determinados utilizando-se uma peça padrão. Esta peça consiste de uma barra com dois furos circulares cuja distância entre centros é conhecida.

$\mathrm{Na}$ atualidade, as técnicas de planejamento de experimentos vem ganhando destaque na experimentação. Um planejamento adequado dos experimentos permite minimizar o número de ensaios, o tempo de execução e o custo das pesquisas. 
PIRATELLI (1997) apresentou um método para avaliação indireta do desempenho de MM3Cs através da utilização de técnicas de planejamento de experimentos e do uso de uma barra de esferas. O método proposto consiste no planejamento e execução de dois experimentos, um empregando o arranjo L9 proposto por TAGUCHI e outro empregando o arranjo fatorial $3^{2}$. Os erros de medição obtidos foram analisados através da técnica de análise de variância. Como resultados foram obtidas informações valiosas sobre o desempenho metrológico de uma MM3C, que envolve a determinação das variáveis que mais influenciam o desempenho da máquina e a identificação das condições críticas de operação. Embora o teste de avaliação do desempenho, indicado na norma ANSI/ASME B89.4.1 (1997), seja menos complexo que o método proposto, este último apresenta vantagens significativas, que o fazem superior. $\mathrm{O}$ autor afirma ainda que o método proposto pode ser usado em qualquer tipo de MM3C, sendo muito adequado para aplicação em MM3C com maior grau de automação, uma vez que o tempo de experimentação pode ser drasticamente reduzido. 


\section{CAPÍTULO 3}

\section{Compensação de erros e incerteza}

\section{de medição}

Neste capítulo serão abordadas as técnicas estatísticas utilizadas para classificação dos erros, através da análise dos dados levantados durante a calibração da MM3C. Será também apresentada uma extensa revisão bibliográfica sobre compensação de erros e incerteza de medição a três coordenadas. Além da teoria sobre ajustes de curvas e superfícies.

\subsection{Classificação dos erros quanto ao seu comportamento}

Erros de medição podem ser definidos como as diferenças entre os valores verdadeiros e os valores observados nas medições. Eles contêm duas componentes fundamentais: uma componente aleatória e outra sistemática (SHEN e DUFFIE, 1991).

São denominados erros aleatórios aqueles erros que resultam de influências internas ou externas não controladas (SLOCUM, 1992). Estes erros podem ser observados através de medições repetidas, pois em geral diferem a cada leitura. Geralmente, métodos estatísticos podem ser usados para quantificar estes tipos de erros. 
Os erros sistemáticos, por sua vez, são aqueles que permanecem constantes em sinal e grandeza durante as medições e são causados na maior parte das vezes por problema durante o riscamento das escalas, ausência de rigidez e interação entre componentes geometricamente imperfeitos. Uma vez determinados, podem ser minimizados após análise dos dados obtidos a partir do processo da calibração. Portanto, os erros sistemáticos ocorrem de maneira previsível e devem ser compensados.

Pode-se também definir o erro de histerese como sendo um erro sistemático, determinado pela diferença entre as médias dos erros observados quando avaliam-se os dois sentidos de aproximação, ida e volta, em cada ponto de medição (WECK, 1984).

A parcela de erro aleatório pode ser fixada de acordo com níveis de confiança iguais a $\pm 1,2$ ou 3 vezes o desvio padrão, obtido a partir dos erros medidos para cada posição. Este valor é determinado separadamente para cada sentido do deslocamento. Estando a máquina ajustada mecanicamente pode-se assumir que esta parcela é aproximadamente a mesma para o sentido de "ida" e "volta" (SATO,1998).

A parcela sistemática, segundo WECK (1984), pode ser obtida utilizando as médias do trajeto de "ida" e "volta". Entretanto, contrapondose a esse entendimento pode-se afirmar que se os valores possuírem a mesma grandeza e sinais contrários o erro sistemático será igual a zero apesar deste estar presente.

\subsection{Compensação de erros}

As MM3Cs foram criadas a partir da necessidade de sistemas de medição flexíveis, rápidos e confiáveis, para a execução do controle dimensional. Além da necessidade de obtenção de altas acuracidades durante as medições.

Para aumentar a acuracidade é necessária a correção dos erros sistemáticos que afetam a medição.

A princípio, a estratégia para obter melhor desempenho da máquina está na anulação dos erros por meio do aumento de precisão na fabricação e por melhorias no projeto das máquinas. No entanto, após a fabricação, e 
mesmo com possíveis melhorias no projeto, ainda há erros presentes e para minimizá-los utiliza-se da compensação de erros. Tal compensação pode ser feita de duas formas: uma é compensar os erros existentes através de programas computacionais, isto é, mudar ou corrigir as coordenadas dos pontos utilizados no cálculo da geometria; outra forma está relacionada com as modificações do posicionamento físico dos elementos da máquina (KUNZMANN et al., 1995).

A compensação relacionada com as modificações do posicionamento físico dos elementos da máquina é usualmente aplicada nas máquinasferramenta, pois, durante a usinagem de uma peça pode-se mudar o posicionamento dos componentes da máquina, de acordo com um mapa de erros, e fazer com que a peça fique mais próxima do valor nominal especificado no desenho.

A compensação através de programas computacionais pode ser subdividida em três outros tipos, essa subdivisão depende exclusivamente de como os erros utilizados na compensação são obtidos. Quando obtidos através de instrumentação apropriada, ao mesmo tempo em que a medição está sendo processada é chamado de compensação por hardware. Se os erros são obtidos através de instrumentação apropriada em uma précalibração, isto é, o levantamento dos erros feito em uma etapa anterior ao processo de medição é chamado de compensação por software. Um misto destes dois processos é chamado de compensação híbrida (DI GIACOMO, 1986).

A compensação de erros por software é um método muito econômico para se conseguir altas acuracidades das máquinas (LIU e VENUVINOD, 1999).

Para esclarecer melhor a diferença entre o sistema de compensação por software e por hardware pode-se dizer o seguinte: o sistema de compensação por software utiliza-se de dados de erros de uma calibração previamente feita na máquina, enquanto o sistema de compensação por hardware usa dados dos erros medidos durante o procedimento de medição. 
O método de compensação por software tem crescido, ganhando aceitação, pois na maioria dos casos, há uma maior eficácia e um menor custo.

A preocupação com a acuracidade de medição deve começar na fabricação e nos ajustes de cada um dos componentes da MM3C. Mas mesmo com a presente preocupação e ajustes técnicos, a acuracidade que se pode alcançar é limitada.

Mesmo se todos os componentes estão dentro de tolerâncias exigidas, erros adicionais podem ser introduzidos durante a montagem, em particular, os erros de ortogonalidade entre os eixos coordenados. Além disso, a estabilidade de longo termo pode ser influenciada por tensões nas áreas de contato dos elementos.

Devido à complexidade estrutural de uma MM3C, numerosos fatores contribuem para o seu desempenho. São estes: o tipo da máquina (Ponte Móvel, Braço Horizontal, etc...), os elementos da estrutura, as influências dos apoios, as guias, o sistema de deslocamento de medição e a ponta do apalpador.

Um projetista tem que considerar todos estes fatores (provavelmente com diferentes pesos) se a repetibilidade e a acuracidade forem os maiores anseios do projeto. A solução mais efetiva para evitar ou diminuir os erros é a otimização dos erros ainda na fase de projeto das máquinas (SPUR, 1988).

A correção de erros através de software deve ser o passo final na cadeia de estratégias (KUNZMANN et al., 1995). Deve-se levar em consideração as questões econômicas e de acuracidade, dependendo do nível de desempenho que se está procurando na máquina.

O desenvolvimento de sistemas de compensação de erros sempre foi um desafio para fabricantes e pesquisadores e as tecnologias descritas para este fim têm sido alvo de muitas pesquisas (TRAPET e WÄLDELE, 1989; CHEN et al., 1993; HOCKEN et al., 1977; ZHANG et al., 1985; BOSH, 1995; BARAKAT et al., 2000).

A primeira tentativa real de criação de um sistema de compensação que considerasse os braços de Abbè foi feita por BURDEKIN em 1982. Porém, o sistema apresentado por ele não estava totalmente completo. Este 
sistema basicamente aplicava um procedimento de compensação híbrida para as componentes dos erros sistemáticos ao longo do eixo $\mathrm{X}$ em uma Máquina de Medir Ferranti Conquest. Foram usados valores dos erros obtidos através de uma calibração em um modelo cinemático da estrutura e os princípios de sintetização das componentes dos erros.

Como a parte de hardware do modelo híbrido, a máquina foi ajustada com um fio esticado e um par de sensores opto-eletrônicos que foi tencionado para obter informações instantâneas dos movimentos angulares, deste modo pode-se deduzir a posição da ponta do apalpador. Neste sentido, o sistema não conta somente com componentes unidirecionais do erro, mas também com os erros de histerese entre direções opostas ao movimento.

Uma outra proposta feita por CLEMENT e BOURDENT, 1981 utilizando compensação por software, usava equações da trajetória verdadeira da ponta do apalpador de medição em uma MM3C. Com a hipótese da predominância de erros sistemáticos, os movimentos da máquina puderam ser modelados. Foram geradas três equações, dependentes das posições de cada um dos eixos $\mathrm{X}, \mathrm{Y}$ e $\mathrm{Z}$, e usadas para corrigir a posição da ponta do apalpador.

Em 1985, ZHANG et al. utilizou uma máquina do tipo Ponte Móvel da National Bureau of Standards (NBS), hoje National Institute of Standard Technology (NIST). Um modelo da máquina foi planejado para compensar os erros geométricos sistemáticos e a expansão térmica das escalas. O erro geométrico foi medido e armazenado, enquanto a temperatura das escalas da máquina era coletada. Foram encontradas três equações de erros e o erro volumétrico foi calculado baseado na suposição dos corpos serem rígidos. As técnicas de sintetização foram usadas e um pequeno grupo de dados de medição para cada eixo foram utilizados para o cálculo dos erros por todo volume de trabalho. $O$ erro de ortogonalidade foi determinado usando medições de deslocamento linear ao longo dos eixos e da diagonal.

DUFFIE e YANG (1985) criaram um sistema que usa equações de erros cinemáticos paramétricos aplicadas para a correção do erro volumétrico. Tal sistema é baseado no fato de que a medição do erro volumétrico é frequentemente mais fácil do que a medição de todas as 
componentes do erro separadamente. Assim, baseado na medição do erro volumétrico e com a ajuda das equações, o erro volumétrico em cada direção foi calculado. Esta função foi usada para diagnosticar as fontes de erro para o cálculo das componentes individuais.

Ainda em 1985, KUNZMANN e WÄLDELE, do Physikalish-Technische Bundesanstalat (PTB) na Alemanha, propuseram outro sistema de correção de erros para MM3Cs baseado em software. A explicação para tal desenvolvimento é o baixo custo da correção quando utilizado programas computacionais, contra o alto custo na correção de partes mecânicas para melhorar a acuracidade.

O sistema usa um modelo teórico que é independente do tipo de MM3C, todos os componentes mecânicos são assumidos como um corpo rígido. Baseado em tais hipóteses, todos os componentes da máquina puderam ser descritos por três erros de translação e três angulares (seis graus de liberdade). Todos os erros são considerados dependentes da posição no volume de trabalho, mas independentes uns dos outros. Assim, todos os erros da máquina podem ser medidos separadamente. Somandose os três erros de ortogonalidade entre os eixos coordenados, um total de doze procedimentos de medição devem ser levados em consideração e agrupados em uma matriz de compensação de erros.

De acordo com esses autores, o efeito da correção por software em uma MM3C "Ponte Móvel", por comparação com medição com blocos-padrão e padrão passo a passo, mostra muitas melhorias. Além disso, eles enfatizam que a acuracidade pode somente ser obtida por inspeção permanente da temperatura das escalas e testes em peças.

Tentativas de compensação de erros através de software foram também apresentadas por ZHANG et al. (1985) e BALSAMO et al. (1990). BELFORTE et al. em 1987 usaram um programa computacional para estimar erros em uma MM3C e compensaram principalmente os erros geométricos e cinemáticos. A compensação para correção de erros tem vantagens na redução do custo, na correção propriamente dita e para diminuir ou mesmo eliminar os erros, aumentando assim a acuracidade da máquina para aproximá-la de um nível maior de resolução. Uma outra vantagem da correção numérica de erros está baseada na existência de um modelo 
desenvolvido para descrever os erros da máquina, assim pode simbolizar indiretamente os valores destes modelos.

Através da calibração de erros "on-the-fly" e de um sistema híbrido de compensação, DI GIACOMO (1986) formulou o erro volumétrico de uma MM3C. O sistema de compensação através de software e hardware foi testado usando um interferômetro laser e também um artefato padrão para uma, duas e três dimensões. A aplicação do sistema híbrido mostrou-se eficiente na melhoria da acuracidade quando o erro era relativamente maior do que a resolução da máquina, mas não tão eficiente quando o erro é aproximadamente da mesma ordem.

ELSHENNAWY e HAM (1988), descreveram o desenvolvimento e aplicação de uma técnica de compensação de erros para a melhoria do desempenho de uma Máquina de Medir. Este procedimento exigiu a calibração completa e o desenvolvimento de um modelo cinemático, o método considera somente os erros de posicionamento e ignora os efeitos térmicos. O aumento da acuracidade pode ser conseguido de duas formas diferentes: eliminação do erro e compensação do erro. Segundo os autores a eliminação do erro significa a eliminação da fonte ou do efeito do erro, em geral, procura-se desenvolver um projeto que seja precavido e cuidadoso para evitar o erro. Na compensação, o efeito de um erro é compensado sem corrigir diretamente a fonte do erro.

Segundo os autores, três passos básicos foram considerados para iniciar a compensação de erros de uma Máquina de Medir:

- Desenvolvimento de um modelo matemático da máquina para descrever a interação dos parâmetros do erro;

- Execução da medição dos erros paramétricos da máquina;

- Cálculo das componentes do erro.

Um estudo para compensar os erros induzidos por gradientes quaseestáticos em tempo real, numa Máquina de Medir SIP 560M, usando o Método dos Elementos Finitos, foi feito por SARTORI, 1990. Este estudo é o mais ambicioso e talvez o mais importante dos desenvolvidos na época.

Os resultados comprovaram que 80 a $85 \%$ das deformações puderam ser expressas através do modelo. As correções feitas automaticamente eram capazes de compensar de 65 a $75 \%$ dos erros. 
MOU e LIU (1993) apresentaram uma estratégia de compensação baseada em um método capaz de se adaptar durante o processo de usinagem. Foram integrados um processo de calibração intermitente e técnicas de observação de estado para monitorar os erros termicamente induzidos e então modificar os coeficientes do modelo de erros durante o processo de usinagem. Técnicas de análise de variância (ANOVA) foram usadas para identificar as variáveis significantes para modelar o efeito térmico. Foi obtido um modelo de regressão linear múltiplo para identificar a dinâmica dos erros termicamente induzidos que variam no tempo. Resultados experimentais mostraram que os erros da máquina devido a variação de tempo podem ser estimados com a acuracidade desejada.

VELDHUIS e ELBESTAWI (1994) implementaram uma rede neural como estratégia de compensação de erros em máquinas para usinagem de cinco eixos. A escolha da estratégia de compensação depende, em grande parte, do tipo de controle usado na máquina e sua flexibilidade.

Em 1996, SHEN e MOON desenvolveram um sistema de compensação de erros em MM3Cs com controle numérico usando redes neurais. Foi desenvolvida e treinada uma rede neural usando o algoritmo back-propagation. O número de entradas e saídas foi definido pelo sistema que se estava trabalhando. Já o número de camadas intermediárias (ou ocultas), o número de neurônios em cada uma delas e suas características internas foram definidos pelo projetista da rede. A rede neural projetada e treinada para responder como se desejava, foi usada para a compensação on-line dos erros do apalpador. Dados experimentais foram usados para treinar as redes e predizer o pré-travel do apalpador. Foram feitos testes que analisaram o caminho real do apalpador, o caminho previsto e a predição do erro. O desvio padrão da predição do erro ficou em torno de 0,6 $\mu \mathrm{m}$.

BARAKAT et al. (2000) compensaram os erros geométricos e cinemáticos de uma MM3C. Foi desenvolvido um modelo investigativo ponderando adequadamente os erros geométricos relevantes, utilizando para isso as técnicas de Transformações Homogêneas e a hipótese de cinemática de corpo rígido. Diferentes enfoques foram empregados para avaliar a eficiência do modelo. Num primeiro enfoque foi feita a medição de 
um anel padrão no volume de trabalho da máquina. Erros resultantes desta medição foram usados em conjunto com alguns métodos estatísticos para ajustar os valores dos coeficientes do modelo. O segundo enfoque é baseado na medição dos 21 erros individuais utilizando um sistema interferométrico laser. Esta medição foi usada para avaliar o conjunto de coeficientes do modelo.

Ainda segundo BARAKAT et al. (2000), para que os programas computacionais sejam eficientes dois pontos principais devem ser considerados:

- É impossível criar um modelo perfeito ou um modelo que seja geral e,

- As correções devem ser realizadas para erros pequenos. A correção dos erros grandes deve ser feita no projeto da máquina.

\subsection{Ajustes de curvas e superficies}

Os ajustes são realizados com base na teoria de otimização, a partir dos dados obtidos pelos sistemas de medição da MM3C. As curvas e superfícies assim obtidas constituem as curvas ou superfícies de referência, também denominadas ajuste ótimo de referência (DRAPER e SMITH, 1966; THOMAS, 1974).

\subsubsection{MÉTOdo dOS MÍNIMOS QUADRADOS}

Nas investigações científicas, frequentemente deseja-se ajustar uma reta, uma curva, um plano, uma superfície, etc., a um dado conjunto de pontos. Pode-se denominar este processo de ajuste paramétrico. Em geral tem-se um grande número de pontos, obtidos a partir de ensaios experimentais ou a partir de dados simulados, quando for o caso. A escolha da função matemática para realizar o ajuste paramétrico está baseada sempre em expectativas teóricas ou práticas, como no caso de Metrologia, na aparência do objeto. 
A discussão do Método dos Mínimos Quadrados pode se iniciar através da escolha da função linear de uma variável, dada por $f(x)=a_{1}+a_{2} x$, utilizada para ajustar um conjunto de $n$ pontos dados $\left(x_{i}, y_{i}\right)$. Nos problemas reais é quase sempre impossível encontrar uma função linear que passe por todos estes pontos. Em vez disso pode-se procurar uma função (obtenção de $a_{1}$ e $a_{2}$ ) que torne as diferenças $\varepsilon=\left|y_{i}-f\left(x_{i}\right)\right|$ as menores possíveis. Novamente é quase sempre impossível encontrar uma função linear que torne mínimos simultaneamente esses resíduos. Então torna-se necessário estabelecer uma relação de compromisso, um critério, que seja possível ser minimizado de forma objetiva.

Seja definido o vetor dos resíduos $\mathrm{r}=\left[\mathrm{r}_{1}, \mathrm{r}_{2}, \cdots, \mathrm{r}_{\mathrm{n}}\right]^{\mathrm{T}}$ onde

$$
r_{i}=y_{i}-f\left(x_{i}\right), \mathrm{i}=1,2, \ldots, \mathrm{n}
$$

O problema de mínimo pode ser estabelecido de forma clara escolhendo-se alguma norma para o vetor dos resíduos. A solução é obtida através da busca de um mínimo para esta norma. A solução depende, portanto, da norma escolhida. Por exemplo, escolhendo-se a norma-2, norma Euclidiana, procura-se o mínimo para:

$$
\|\mathbf{r}\|_{2}=\sqrt{\sum_{i=1}^{n}\left|y_{i}-f\left(x_{i}\right)\right|^{2}}
$$

Outras normas, usadas em outras áreas da engenharia, também podem ser aplicadas, como, a norma-1, dada por:

$$
\|\mathbf{r}\|_{1}=\sum_{i=1}^{n}\left|y_{i}-f\left(x_{i}\right)\right|
$$

Ou a norma- $\infty$, dada por 


$$
\|\mathbf{r}\|_{\infty}=\max _{1 \leq i \leq n}\left|y_{i}-f\left(x_{i}\right)\right|
$$

Estes problemas matemáticos têm sido estudados de muitas formas e aplicados em muitas áreas da ciência. Na área da Metrologia, a norma Euclidiana é bastante usada, ou mais precisamente, o seu quadrado $E=\|\boldsymbol{r}\|_{2}^{2}=\sum_{i=1}^{n}\left|y_{i}-f\left(x_{i}\right)\right|^{2}$.

O problema de minimizar a norma Euclidiana equivale ao de minimizar o seu quadrado e é chamado de problema de Mínimos Quadrados.

Embora tenha sido usada a função linear de uma única variável como exemplo, todo o raciocínio se estende igualmente para funções não lineares (polinômios, círculos, etc.), funções lineares de duas variáveis (planos) ou funções não lineares de duas variáveis (superfícies de esferas, cilindros, etc.).

Seja, por exemplo, um polinômio de grau $m-1$ dado pela equação (3.5),

$$
f(x)=a_{1}+a_{2} x+a_{3} x^{2}+\cdots+a_{m} x^{m-1},
$$

e um conjunto de pontos $\left(x_{i}, y_{i}\right)$ sendo $i=1,2, \cdots, n$. Usualmente o número de pontos $n$ é bem maior que o grau do polinômio $m-1$. Para este caso, o conjunto de polinômios de grau menor que $\mathrm{m}$, dados por $\phi_{j}=x^{j-1}$, forma uma base do espaço vetorial de dimensão $m$. Então, pode-se escrever $f(x)=\sum_{j=1}^{m} a_{j} \phi_{j}(x)$ observando-se que $\phi_{1}(x)=x^{0}$, ou seja, $\phi_{1}(x)=1$. Há outras bases para os polinômios, algumas melhores do ponto de vista computacional, como os polinômios de Lagrange, por exemplo. Ainda mais, pode-se escrever outras funções não lineares $f(x)$ nesta mesma forma, adotando outras bases como, por exemplo, funções trigonométricas, exponenciais, etc. 
Para todos os $n$ pontos dados pode-se escrever de forma geral, tanto para o problema polinomial utilizado como exemplo, como para outros tipos de funções

$$
\sum_{j=1}^{m} a_{j} \phi_{j}\left(x_{i}\right)=b_{i} i=1,2, \cdots, n
$$

ou, na forma matricial

$$
\left[\begin{array}{cccc}
\phi_{1}\left(x_{1}\right) & \phi_{2}\left(x_{1}\right) & \cdots & \phi_{m}\left(x_{1}\right) \\
\phi_{1}\left(x_{2}\right) & \phi_{2}\left(x_{2}\right) & \cdots & \phi_{m}\left(x_{2}\right) \\
\vdots & \vdots & & \vdots \\
\phi_{1}\left(x_{n}\right) & \phi_{2}\left(x_{n}\right) & \cdots & \phi_{m}\left(x_{n}\right)
\end{array}\right]\left[\begin{array}{c}
a_{1} \\
a_{2} \\
\vdots \\
a_{m}
\end{array}\right]=\left[\begin{array}{c}
b_{1} \\
b_{2} \\
\vdots \\
b_{n}
\end{array}\right] \Leftrightarrow \quad \mathbf{A a}=\mathbf{b}
$$

Como usualmente $m>n$ o sistema é sobre-determinado, isto é, há mais equações que incógnitas. Assim geralmente não há solução exata para os coeficientes $a_{j}$. Por outro lado, pode haver solução no sentido de minimizar a soma dos quadrados dos resíduos, ou seja, minimizar a função $E\left(a_{1}, a_{2}, \cdots, a_{m}\right)=\|\mathbf{r}\|_{2}^{2} \operatorname{com} \mathbf{r}=\mathbf{b}-\mathbf{A a}$.

A solução procurada deve satisfazer as $m$ equações

$$
\frac{\partial E\left(a_{1}, a_{2}, \cdots, a_{m}\right)}{\partial a_{j}}=0 j=1,2, \cdots, m \text {, }
$$

que resultam nas equações normais. Estas mesmas equações podem ser obtidas facilmente fazendo $\mathbf{A}^{T} \mathbf{A a}=\mathbf{A}^{T} \mathbf{b}$ ou $\mathbf{B a}=\mathbf{c}$ com $\mathbf{B}=\mathbf{A}^{T} \mathbf{A}$ e $\mathbf{c}=\mathbf{A}^{T} \mathbf{b}$. Logo, a solução deste sistema de equações, agora $m \times m$ pode ser obtida diretamente através da inversa de $B$, ou seja, $\mathbf{a}=\mathbf{B}^{-1} \mathbf{c}=\mathbf{B}^{-1} \mathbf{A}^{T} \mathbf{b}$.

Pode-se também utilizar a Decomposição em Valores Singulares (DVS) da matriz B. Não há vantagens neste caso, mas este procedimento também é usado. Decompõe-se a matriz quadrada $B$ em três fatores 
$\mathbf{B}=\mathbf{U S V}^{T}$, onde $\mathrm{U}$ e $\mathrm{V}$ são matrizes unitárias e $\mathrm{S}$ é uma matriz diagonal. Logo a solução a partir destes fatores é dada por:

$$
\mathbf{a}=\mathbf{B}^{-1} \mathbf{c}=\mathbf{V S}^{-1} \mathbf{U} \mathbf{A}^{T} \mathbf{b}
$$

Observa-se que sendo $S$ diagonal, sua inversão é simples. Entretanto a obtenção da DVS tem um custo computacional que pode não ser vantajoso em relação a métodos de obtenção da inversa de B.

Pode-se usar também a denominada inversa Moore-Penrose, diretamente no problema $\mathbf{A a}=\mathbf{b}$, da seguinte forma, $\mathbf{a}=\mathbf{A}^{+} \mathbf{b}$, onde $\mathbf{A}^{+} \mathbf{A}=\mathbf{I}$ é a matriz identidade $m \mathrm{Xm}$. A matriz $\mathbf{A}^{+}$também é denominada matriz pseudo inversa. Pode ser usada a DVS diretamente na matriz A para a obtenção da solução. Sendo retangular, a sua decomposição é dada por $\mathbf{A}=\mathbf{U S V}^{T}$ onde $\mathrm{U}$ e $\mathrm{V}$ são matrizes unitárias, $n \times n$ e $m \mathrm{X} m$, respectivamente, e S é matriz diagonal $n \mathrm{Xm}$. A correspondente pseudo-inversa é calculada facilmente através de $\mathbf{A}^{+}=\mathbf{V S}^{+} \mathbf{U}^{T}$ onde $\mathbf{S}^{+} \mathbf{S}=\mathbf{I}$ é a matriz identidade $m \mathrm{Xm}$ obtida rapidamente. Logo a solução do problema é

$$
\mathbf{a}=\mathbf{A}^{+} \mathbf{b}=\mathbf{V S}^{+} \mathbf{U}^{T} \mathbf{b}
$$

\subsubsection{Algoritmos de AJUSte de elementos}

Os algoritmos serão desenvolvidos separadamente por tipo de elemento geométrico, para cada elemento é necessário um número mínimo de pontos dados $\left(x_{i}, y_{i}, z_{i}\right)$, para o ajuste. A Tabela 3.1 lista o número mínimo de pontos necessários para cada elemento.

Para manter a precisão numérica, a posição média $(\bar{x}, \bar{y}, \bar{z})$ dos pontos, dada por: $\bar{x}=\frac{1}{n} \sum_{i=1}^{n} x_{i}, \bar{y}=\frac{1}{n} \sum_{i=1}^{n} y_{i}$ e $\bar{z}=\frac{1}{n} \sum_{i=1}^{n} z_{i}$ pode ser transladada para a origem $(0,0,0)$ no desenvolvimento dos algoritmos, quando for conveniente. 
Tabela 3.1: Número mínimo de pontos para o ajuste

\begin{tabular}{|c|c|}
\hline Elemento geométrico & Número mínimo de pontos \\
\hline Reta & 2 \\
\hline Plano & 3 \\
\hline Círculo & 3 \\
\hline Esfera & 4 \\
\hline Cilindro & 5 \\
\hline Cone & 6 \\
\hline
\end{tabular}

A seguir descrevem-se resumidamente os algoritmos para cada elemento geométrico.

\section{RETAS EM UM PLANO ESPECÍfico}

Dado um plano $x-y$ e $n$ pontos $\left(x_{i}, y_{i}\right)$, deseja-se obter os coeficientes da reta

$$
f(x)=a_{1}+a_{2} x
$$

Assim tem-se $\phi_{1}(x)=1, \phi_{2}(x)=x$ e, portanto,

$$
\mathbf{A}=\left[\begin{array}{cc}
1 & x_{1} \\
1 & x_{2} \\
\vdots & \vdots \\
1 & x_{n}
\end{array}\right], \quad \mathbf{a}=\left[\begin{array}{l}
a_{1} \\
a_{2}
\end{array}\right], \quad \mathbf{b}=\left[\begin{array}{c}
y_{1} \\
y_{2} \\
\vdots \\
y_{n}
\end{array}\right]
$$

De acordo com a teoria do critério de ajuste pelo Método dos Mínimos Quadrados, mostrada no item anterior, obtém-se: 


$$
\left[\begin{array}{cc}
n & \sum x_{i} \\
\sum x_{i} & \sum x_{i}^{2}
\end{array}\right]\left[\begin{array}{l}
a_{1} \\
a_{2}
\end{array}\right]=\left[\begin{array}{c}
\sum y_{i} \\
\sum x_{i} y_{i}
\end{array}\right]
$$

este sistema tem solução fácil, dada por:

$$
a_{1}=\frac{\sum y_{i} \sum x_{i}^{2}-\sum x_{i} \sum x_{i} y_{i}}{n \sum x_{i}^{2}-\sum x_{i} \sum x_{i}} \mathrm{e}^{a_{2}}=\frac{n \sum x_{i} y_{i}-\sum x_{i} \sum y_{i}}{n \sum x_{i}^{2}-\sum x_{i} \sum x_{i}} .
$$

Este problema também pode ser resolvido com o conceito de resíduo de uma outra forma, mais adequado aos conceitos de melhor ajuste de referência, utilizados em Engenharia, particularmente na área de Metrologia.

Toma-se o resíduo como a menor distância entre o ponto $\left(x_{i}, y_{i}\right)$ e a reta. Para este procedimento uma reta no plano $x-y$ é especificada por um ponto $\left(x_{0}, y_{0}\right)$ sobre ela e os seus co-senos diretores $(\mathrm{a}, \mathrm{b})$, obtendo-se assim a forma parametrizada. Nesta forma, qualquer ponto $(x, y)$ sobre a reta satisfaz as equações paramétricas:

$$
\frac{y-y_{0}}{x-x_{0}}=\frac{b}{a} \Leftrightarrow \frac{y-y_{0}}{b}=\frac{x-x_{0}}{a}=t \text { ou }\left\{\begin{array}{l}
x=x_{0}+a t \\
y=y_{0}+b t
\end{array}\right.
$$

Desta forma, a distância $r_{i}$ de um ponto $\left(x_{i}, y_{i}\right)$ a esta reta é dada por $r_{i}=b\left(x_{i}-x_{0}\right)-a\left(y_{i}-y_{0}\right)$ enquanto que a distância entre um ponto $\left(x_{i}, y_{i}\right)$ e o ponto $\left(x_{0}, y_{0}\right)$ é $d_{i}=\sqrt{\left(x_{i}-x_{0}\right)^{2}+\left(y_{i}-y_{0}\right)^{2}}$.

O problema de Mínimos Quadrados pode ser determinado estabelecendo a função $E(a, b)=\sum_{i=1}^{n} r_{i}^{2}$ e fazendo a sua otimização através de $\frac{\partial E(a, b)}{\partial a}=0$ e $\frac{\partial E(a, b)}{\partial b}=0$.

Obtém-se, com este procedimento, um problema matricial de autovalores e autovetores, dado por: 
$\mathbf{B}\left[\begin{array}{l}a \\ b\end{array}\right]=\lambda\left[\begin{array}{l}a \\ b\end{array}\right]$

$\operatorname{com} \mathbf{B}=\left[\begin{array}{cc}\sum\left(x_{i}-x_{0}\right)^{2} & \sum\left(x_{i}-x_{0}\right)\left(y_{i}-y_{0}\right) \\ \sum\left(x_{i}-x_{0}\right)\left(y_{i}-y_{0}\right) & \sum\left(y_{i}-y_{0}\right)^{2}\end{array}\right]$ e $\lambda=\sum_{1=1}^{n} d_{i}^{2}$, que pode ser resolvido através do cálculo do centróide $(\bar{x}, \bar{y})$, da formação da matriz $\mathrm{B}$ (ou $A$ ) e da obtenção de $(a, b)$.

\section{Planos}

Um plano é especificado por um ponto $\left(x_{0}, y_{0}, z_{0}\right)$ sobre o plano e os co-senos diretores $(a, b, c)$ da normal ao plano. Desta forma, qualquer ponto $(x, y, z)$ sobre o plano satisfaz:

$$
a\left(x-x_{0}\right)+b\left(y-y_{0}\right)+c\left(z-z_{0}\right)=0
$$

A distância de um ponto $\left(x_{i}, y_{i}, z_{i}\right)$ ao plano é dada por $d_{i}=a\left(x_{i}-x_{0}\right)+b\left(y_{i}-y_{0}\right)+c\left(z_{i}-z_{0}\right)$.

O problema de Mínimos Quadrados pode ser determinado estabelecendo a função $E(a, b, c)=\sum_{i=1}^{n} e_{i}^{2} \quad \operatorname{com} \quad e_{i}=d_{i} \quad$ e fazendo sua otimização através de $\frac{\partial E(a, b, c)}{\partial a}=0, \frac{\partial E(a, b, c)}{\partial b}=0$ e $\frac{\partial E(a, b, c)}{\partial c}=0$. Obtémse a partir destas equações o seguinte problema matricial de autovalores e autovetores:

$$
\mathbf{B}\left[\begin{array}{l}
a \\
b \\
c
\end{array}\right]=\lambda\left[\begin{array}{l}
a \\
b \\
c
\end{array}\right],
$$

e B é dado por: 


$$
\mathbf{B}=\left[\begin{array}{ccc}
\Sigma\left[\left(y_{i}-y_{0}\right)^{2}+\left(z_{i}-z_{0}\right)^{2}\right] & -\Sigma\left(x_{i}-x_{0}\right)\left(y_{i}-y_{0}\right) & -\Sigma\left(x_{i}-x_{0}\right)\left(z_{i}-z_{0}\right) \\
-\Sigma\left(x_{i}-x_{0}\right)\left(y_{i}-y_{0}\right) & \Sigma\left[\left(x_{i}-x_{0}\right)^{2}+\left(z_{i}-z_{0}\right)^{2}\right] & -\Sigma\left(y_{i}-y_{0}\right)\left(z_{i}-z_{0}\right) \\
-\Sigma\left(x_{i}-x_{0}\right)\left(z_{i}-z_{0}\right) & -\Sigma\left(y_{i}-y_{0}\right)\left(z_{i}-z_{0}\right) & \Sigma\left[\left(x_{i}-x_{0}\right)^{2}+\left(y_{i}-y_{0}\right)^{2}\right]
\end{array}\right]
$$

Pode-se construir também uma matriz $C$ a partir de $A$, sendo

$$
\mathbf{A}=\left[\begin{array}{ccc}
x_{1}-x_{0} & y_{1}-y_{0} & z_{1}-z_{0} \\
x_{2}-x_{0} & y_{2}-y_{0} & z_{2}-z_{0} \\
\vdots & \vdots & \vdots \\
x_{n}-x_{0} & y_{n}-y_{0} & z_{n}-z_{0}
\end{array}\right] \Rightarrow \mathbf{C}=\mathbf{A}^{T} \mathbf{A}
$$

Resolvendo a equação (3.19) da mesma forma que a anterior, o plano ajustado é dado por:

$$
z_{a}=z_{0}-\frac{a}{c}\left(x-x_{0}\right)-\frac{b}{a}\left(y-y_{0}\right)
$$

\section{CírCulos em um PLANO eSPeCÍfico}

Um círculo no plano $\mathrm{x}-\mathrm{y}$ é especificado pelo seu centro $\left(x_{0}, y_{0}\right)$ e pelo seu raio $r$. Desta forma, qualquer ponto $(x, y)$ sobre o círculo satisfaz:

$$
\left(x-x_{0}\right)^{2}+\left(y-y_{0}\right)^{2}=r^{2},
$$

e a distância de um ponto $\left(\mathrm{x}_{\mathrm{i}}, \mathrm{y}_{\mathrm{i}}\right)$ ao círculo e dada por $\mathrm{d}_{\mathrm{i}}=\mathrm{r}_{\mathrm{i}}-\mathrm{r}$ onde $r_{i}=\sqrt{\left(x_{i}-x_{0}\right)^{2}+\left(y_{i}-y_{0}\right)^{2}}$.

O problema de otimização através dos Mínimos Quadrados pode ser estabelecido a partir da função $E$

$$
E\left(x_{0}, y_{0}, r\right)=\sum_{i=1}^{n} e_{i}^{2}
$$


Fazendo $\quad e_{i}=d_{i}$, obtém-se $\quad e_{i}^{2}=d_{i}^{2}=r_{i}^{2}-2 r_{i} r+r^{2} \quad$ ou $e_{i}^{2}=\left(x_{i}^{2}-x_{0}^{2}\right)+\left(y_{i}^{2}-y_{0}^{2}\right)-2 r \sqrt{\left(x_{i}^{2}-x_{0}^{2}\right)+\left(y_{i}^{2}-y_{0}^{2}\right)}+r^{2}$.

As equações são então estabelecidas através de $\frac{\partial E\left(x_{0}, y_{0}, r\right)}{\partial x_{0}}=0$, $\frac{\partial E\left(x_{0}, y_{0}, r\right)}{\partial y_{0}}=0$ e $\frac{\partial E\left(x_{0}, y_{0}, r\right)}{\partial r}=0$.

Entretanto, estas equações geram um problema não linear que só pode ser resolvido de forma aproximada. A matriz A tem seus coeficientes dependentes dos parâmetros do círculo.

Então, o procedimento que será usado para o melhor ajuste é o algoritmo de Gauss-Newton. Este procedimento é um método iterativo e requer estimativas iniciais para os parâmetros. Resolve-se em cada passo j o sistema sobre-determinado $\mathbf{J} \Delta=-\mathbf{d}$ onde os elementos da matriz Jacobiana J, de dimensão $n \times 3$, são as derivadas parciais de $d_{i}$, ou seja:

$$
\mathbf{J}=\left[\begin{array}{ccc}
\frac{\partial d_{1}}{\partial x_{0}} & \frac{\partial d_{1}}{\partial y_{0}} & \frac{\partial d_{1}}{\partial r} \\
\frac{\partial d_{2}}{\partial x_{0}} & \frac{\partial d_{2}}{\partial y_{0}} & \frac{\partial d_{2}}{\partial r} \\
\vdots & \vdots & \vdots \\
\frac{\partial \dot{d}_{n}}{\partial x_{0}} & \frac{\partial \dot{d}_{n}}{\partial y_{0}} & \frac{\partial \dot{d}_{n}}{\partial r}
\end{array}\right]
$$

$$
\frac{\partial d_{i}}{\partial x_{0}}=-\frac{\left(x_{i}-x_{0}\right)}{r_{i}}
$$

onde: $\begin{aligned} \frac{\partial d_{i}}{\partial y_{0}} & =-\frac{\left(y_{i}-y_{0}\right)}{r_{i}} \\ \frac{\partial d_{i}}{\partial z_{0}} & =-1\end{aligned}$ e $\quad \Delta=\left[\begin{array}{c}\Delta x_{0} \\ \Delta y_{0} \\ \Delta r\end{array}\right]$ e $\quad \mathbf{d}=\left[\begin{array}{c}d_{1} \\ d_{2} \\ \vdots \\ d_{n}\end{array}\right]$

sendo $\Delta x_{0}, \Delta y_{0}$ e $\Delta r$ as correções no parâmetros do círculo.

O ajuste ótimo para o círculo pode ser obtido através dos seguintes passos: formar o vetor $d$, cujos elementos são as distâncias $d_{i}$ e a matriz 
Jacobiana J a partir de estimativas iniciais para os parâmetros do círculo $\left(x_{0}, y_{0}\right)$ e r;

$$
\text { Resolver o sistema de Mínimos Quadrados linear } \mathbf{J}\left[\begin{array}{c}
\Delta x_{0} \\
\Delta y_{0} \\
\Delta r
\end{array}\right]=-\mathbf{d} \text {; }
$$

Atualizar a estimativa dos parâmetros para o passo seguinte $j+1$ fazendo:

$$
\begin{aligned}
& x_{0}^{(j+1)}=x_{0}^{(j)}+\Delta^{(j)} x_{0} \\
& y_{0}^{(j+1)}=y_{0}^{(j)}+\Delta^{(j)} y_{0} ; \\
& r^{(j+1)}=r^{(j)}+\Delta^{(j)} r
\end{aligned}
$$

Repetir os passos anteriores até que ocorra convergência nos valores dos parâmetros correspondentes às coordenadas do centro $\left(x_{0}, y_{0}\right)$ e ao raio $r$ do círculo. O critério de convergência pode ser estabelecido para qualquer um desses parâmetros, ou mesmo para uma norma do vetor $\Delta$ correspondente aos incrementos calculados em cada passo.

$$
\begin{aligned}
& \varepsilon_{x} \leq\left|x_{0}^{(j+1)}-x_{0}^{(j)}\right| \\
& \varepsilon_{y} \leq\left|y_{0}^{(j+1)}-y_{0}^{(j)}\right| \\
& \varepsilon_{r} \leq\left|r^{(j+1)}-r^{(j)}\right|
\end{aligned}
$$

O ajuste ótimo de referência é especificado por $\left(x_{0}, y_{0}\right)$ e r.

\section{ESFERAS}

Uma esfera é especificada pelo seu centro $\left(x_{0}, y_{0}, z_{0}\right)$ e pelo seu raio r. Desta forma, qualquer ponto $(x, y, z)$ sobre a esfera satisfaz:

$$
\left(x-x_{0}\right)^{2}+\left(y-y_{0}\right)^{2}+\left(z-z_{0}\right)^{2}=r^{2},
$$


e a distância de um ponto $\left(x_{i}, y_{i}, z_{i}\right)$ à esfera é dada por $d_{i}=r_{i}-r$ onde $r_{i}=\sqrt{\left(x_{i}-x_{0}\right)^{2}+\left(y_{i}-y_{0}\right)^{2}+\left(z_{i}-z_{0}\right)^{2}}$.

O problema de determinação dos parâmetros da esfera através do Método dos Mínimos Quadrados é, da mesma forma que no caso do círculo, não linear. Por esta razão, o algoritmo de Gauss-Newton será utilizado também.

Os elementos da matriz Jacobiana J são as derivadas parciais de $d_{i}$, dados por:

$\frac{\partial d_{i}}{\partial x_{0}}=-\frac{\left(x_{i}-x_{0}\right)}{r_{i}} ; \quad \frac{\partial d_{i}}{\partial y_{0}}=-\frac{\left(y_{i}-y_{0}\right)}{r_{i}} ; \quad \frac{\partial d_{i}}{\partial z_{0}}=-\frac{\left(z_{i}-z_{0}\right)}{r_{i}} \quad$ e $\quad \frac{\partial d_{i}}{\partial r}=-1$

De forma semelhante ao círculo, o ajuste ótimo para a esfera pode ser obtido através do algoritmo de Gauss-Newton, resumido nos seguintes passos: formar o vetor d e a matriz Jacobiana $\mathrm{J}$, a partir de estimativas iniciais para a coordenadas do centro $\left(x_{0}, y_{0}, z_{0}\right)$ e para o raio $r$, sendo:

$\mathbf{J}=\left[\begin{array}{cccc}\frac{\partial d_{1}}{\partial x_{0}} & \frac{\partial d_{1}}{\partial y_{0}} & \frac{\partial d_{1}}{\partial z_{0}} & \frac{\partial d_{1}}{\partial r} \\ \frac{\partial d_{2}}{\partial x_{0}} & \frac{\partial d_{2}}{\partial y_{0}} & \frac{\partial d_{2}}{\partial z_{0}} & \frac{\partial d_{2}}{\partial r} \\ \vdots & \vdots & \vdots & \vdots \\ \frac{\partial d_{n}}{\partial x_{0}} & \frac{\partial d_{n}}{\partial y_{0}} & \frac{\partial d_{n}}{\partial y_{0}} & \frac{\partial d_{n}}{\partial r}\end{array}\right] \quad$ e $\quad \mathbf{d}=\left[\begin{array}{c}d_{1} \\ d_{2} \\ \vdots \\ d_{n}\end{array}\right]$

Resolvendo o sistema linear $\mathbf{J} \Delta=-\mathbf{d}$ onde $\Delta=\left[\begin{array}{c}\Delta x_{0} \\ \Delta y_{0} \\ \Delta z_{0} \\ \Delta r\end{array}\right]$;

Corrigindo a estimativa do parâmetro de acordo com: 


$$
\begin{aligned}
& x_{0}^{(j+1)}=x_{0}^{(j)}+\Delta^{(j)} x_{0} \\
& y_{0}^{(j+1)}=y_{0}^{(j)}+\Delta^{(j)} y_{0} ; \\
& z_{0}^{(j+1)}=z_{0}^{(j)}+\Delta^{(j)} z_{0} \\
& r^{(j+1)}=r^{(j)}+\Delta^{(j)} r
\end{aligned}
$$

Repetir os passos anteriores até que ocorra convergência nos valores dos parâmetros do centro $\left(x_{0}, y_{0}, z_{0}\right)$ e do raio $\mathrm{r}$ da esfera. $\mathrm{A}$ convergência pode ser verificada através de algum critério, como, por exemplo, estabelecimento de um mínimo para as diferenças:

$$
\begin{aligned}
& \varepsilon_{x} \leq\left|x_{0}^{(j+1)}-x_{0}^{(j)}\right| \\
& \varepsilon_{y} \leq\left|y_{0}^{(j+1)}-y_{0}^{(j)}\right| \\
& \varepsilon_{z} \leq\left|z_{0}^{(j+1)}-z_{0}^{(j)}\right| . \\
& \varepsilon_{r} \leq\left|r^{(j+1)}-r^{(j)}\right|
\end{aligned}
$$

O ajuste ótimo de referência é especificado pelo centro da esfera $\left(x_{0}, y_{0}, z_{0}\right)$ e pelo seu raio $r$.

O algoritmo de Gauss-Newton requer estimativas iniciais para os parâmetros da esfera. Neste caso, pode-se buscar algum algoritmo de ajuste que não exija estimativas iniciais. Isto pode ser alcançado a partir de uma modificação do Método dos Mínimos Quadrados. Esta modificação permite estabelecer um problema linear de mínimos quadrados.

\subsection{Incerteza de medição a três coordenadas}

O resultado de uma medição é apenas uma estimativa do valor verdadeiro do mensurando devido à influência de vários fatores que interferem no processo de medição. A estimativa da incerteza total é, de qualquer forma, dificultada pelo fato dos Sistemas de Medição por Coordenadas (SMC) serem instrumentos de múltiplas finalidades de 
medição e terem associadas a eles, variações do instrumento, do operador, das condições ambientes, entre outros. Por este motivo, após avaliar todos as componentes de erros conhecidos e efetuar as correções dos efeitos sistemáticos no resultado de uma medição, ainda permanece uma dúvida sobre o quão correto é o valor declarado. Essa dúvida, proveniente dos efeitos aleatórios e da correção imperfeita do resultado, no que diz respeito aos efeitos sistemáticos, é denominada incerteza de medição.

WILHELM et al. em 2001 dividiram as incertezas dos SMC em cinco categorias:

$\checkmark \quad$ hardware: incertezas inerentes a estrutura das máquinas, suas escalas e sistemas de apalpamento, incluindo os 21 erros paramétricos: aleatórios e sistemáticos, e ainda a troca de apalpadores e a incerteza das articulações;

$\checkmark$ peça: são causados por desvios de forma, restrições de acessibilidade, distribuição na amostra, efeitos causados na fixação, mecanismo de contato, acabamento superficial e deformação elástica devido à força de contato com a ponta do apalpador;

$\checkmark$ estratégia de medição: erros devido à medição inadequada, a interação da estratégia de medição com erros de forma e estratégias para medição de estruturas complexas;

$\checkmark \quad$ ajuste e avaliação do algoritmo: incertezas devido à precisão computacional e às formas com que os dados são analisados; e

$\checkmark$ fatores externos: incertezas associadas à habilidade do operador, limpeza da máquina e peça.

Segundo o documento ISO: GUM e cuja versão brasileira - "Guia para Expressão da Incerteza de Medição", publicada em 1997, a incerteza de medição pode ser definida como sendo o parâmetro, associado ao resultado de uma medição, que caracteriza a dispersão dos valores que poderiam ser atribuídos à grandeza medida. A incerteza de medição é expressa, geralmente, como uma faixa de valores distribuídos simetricamente em torno do valor obtido como resultado de uma medição. $\mathrm{Na}$ incerteza de medição estão contidos os efeitos de todos os fatores que influenciam o resultado da medição. 
Institutos de Normalização Industrial de vários países têm se preocupado em estabelecer critérios para a determinação do valor que representa a incerteza, pois ele pode ser considerado como um indicador do desempenho dos instrumentos de medição (BARRY e CHRIS, 1994).

O GUM foi ratificado por sete das maiores Organizações Internacionais Metrológicas, incluindo Bureau International des Poids et Measures (BIPM), ISO, International Electrotechnical Commission (IEC), International Federation of Clinical Chemistry (IFCC), International Union of Pure and Applied Physics (IUPAP), International Union of Pure and Applied Chemistry (IUPAC) e International Organization of Legal Metrology (OIML).

O guia sugere que de acordo com o tipo de avaliação, as incertezas podem ser classificadas em: incertezas do Tipo A e incertezas do Tipo B.

Quando as componentes da incerteza podem ser calculadas por meios estatísticos e seu valor descreve a dispersão da série de medições esta avaliação de incertezas é do Tipo A (GUM, 1997; LINK, 1997).

O desvio padrão caracterizando uma componente de uma avaliação tipo A é chamado de incerteza padronizada tipo A e é obtido de uma função densidade de probabilidade derivada da observação de uma distribuição de frequência (LIRA, 2001).

Em quase todos os casos a melhor estimativa disponível do valor esperado $\mathrm{u}_{\mathrm{q}}$ de uma grandeza aleatória $\mathrm{q}$ é a média aritmética $\bar{q}$ de $\mathrm{n}$ observações independentes, como mostra a equação 3.31 :

$$
\bar{q}=\frac{1}{n} \sum_{k=1}^{n} q_{k}
$$

Sabendo que as observações individuais $q_{k}$ diferem em valor devido a variações aleatórias a variância experimental $\sigma^{2}$ da distribuição de probabilidade de q, é dada pela equação 3.32 :

$$
s^{2}\left(q_{k}\right)=\frac{1}{n-1} \sum_{k=1}^{n}\left(q_{k}-\bar{q}\right)^{2}
$$


Esta estimativa de variância e a raiz quadrada da variância, denominada desvio padrão experimental, caracterizam a variabilidade dos valores $q_{k}$ observados ou mais especificamente a dispersão em torno de sua média $\bar{q}$. Além disso, pode ser denominado incerteza padronizada tipo A.

Dois parâmetros que quantificam o quanto $\bar{q}$ estima bem o valor esperado $\mu_{\mathrm{q}}$ é assim a variância da média e o desvio padrão experimental da média.

Um ponto importante é que o número de observações deve ser suficientemente grande para garantir que $\bar{q}$ forneça uma estimativa confiável de $\mu_{\mathrm{q}}$ da variável aleatória q e que $\mathrm{s}^{2}(\bar{q})$ forneça uma estimativa confiável da variância.

É denominada incerteza do tipo B, quando a incerteza é estimativa de uma grandeza que não tenha sido obtida por observações repetidas, a variância estimada ou a incerteza padronizada é avaliada por julgamento científico, baseando-se em informações disponíveis sobre a possível variabilidade de $\mathrm{q}_{i}$. O conjunto de informações pode ser obtido de dados provenientes de medidas prévias, resultados de medições similares anteriores, experiência ou do conhecimento do comportamento do instrumento, dados do fabricante, dados fornecidos por certificados de calibração, referências de manuais de instrução, etc. (GUM, 1997).

Segundo LINK (1997), em uma avaliação do tipo B é necessário considerar e incluir pelo menos os originários das seguintes fontes: incerteza associada ao padrão de referência e qualquer instabilidade em seu valor ou indicação; incerteza associada ao equipamento de medida ou calibração; incerteza associada ao equipamento a ser medido ou calibrado; incerteza associada ao procedimento de calibração; incerteza associada ao efeito das condições ambiente em um ou mais dos itens acima.

É importante ressaltar que muitas vezes as informações sobre as incertezas do tipo B estabelecem intervalos de confiança, sendo necessário extrair o valor da incerteza a partir do conhecimento da distribuição de probabilidade.

A distribuição mais usada para calcular a incerteza é a normal, pois, ela é geralmente utilizada para descrever erros experimentais. Entretanto, 
existem outros tipos de distribuições de probabilidade: a trapezoidal, a retangular, a triangular, etc.

A título de ilustração, algumas destas distribuições estão mostradas na Figura 3.1, onde $\mu_{\mathrm{t}}$ é a média da distribuição.

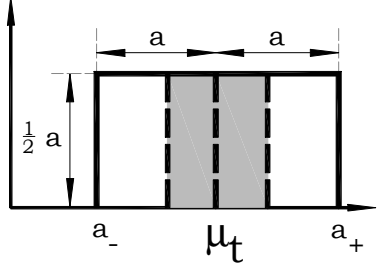

Distribuição Retangular

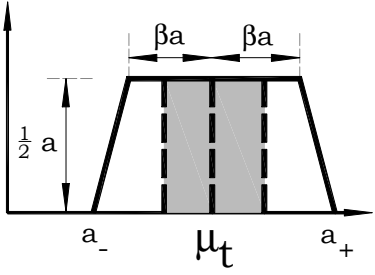

Distribuição Trapezoidal

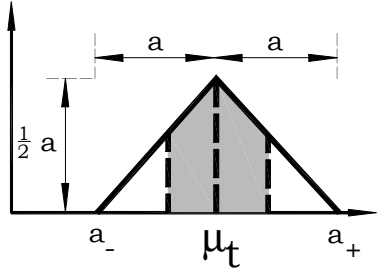

Distribuição Triangular

Figura 3.1: Distribuições de probabilidade

A distribuição retangular é utilizada na ausência de qualquer informação.

Segundo LINK (1997), se não for possível conhecer os possíveis valores de $\mathrm{q}_{i}$ dentro do intervalo, pode-se assumir que é igualmente provável estar em qualquer ponto do intervalo, e consequentemente o seu grau de liberdade é infinito. Então a variância para uma distribuição quadrada é dada pela equação (3.33).

$u^{2}\left(q_{i}\right)=\frac{\left(a_{+}-a_{-}\right)^{2}}{12}$

Se a diferença entre os limites, $a_{+}$- a. é designada por $2 a_{\text {, então a }}$ equação (3.33) torna-se:

$u^{2}\left(q_{i}\right)=\frac{a^{2}}{3}$

A distribuição com geometria trapezoidal pode ser aplicada nos casos, onde é razoável considerar, que os valores junto aos limites do intervalo são menos prováveis de ocorrerem que os valores próximos ao 
centro. Há nestes casos, a aplicação de uma distribuição trapezoidal simétrica, com a base maior do trapézio igual a $2 \mathrm{a}$ e a base menor $2 \beta a$ com $0 \leq \beta \leq 1$. Se $\beta \rightarrow 1$ a distribuição trapezoidal deve se aproximar da retangular, enquanto quando $\beta=0$ a distribuição é triangular (GUM, 1997).

Assumindo que qi tenha uma distribuição trapezoidal a variância associada é dada por:

$$
s^{2}\left(q_{i}\right)=\frac{a^{2}\left(1+\beta^{2}\right)}{6}
$$

Agora assumindo que $\mathrm{q}_{i}$ tenha distribuição triangular a variância associada é dada pela equação (3.36):

$$
s^{2}\left(q_{i}\right)=\frac{a^{2}}{6}
$$

\subsubsection{INCERTEZA PADRONIZADA COMBINADA}

Muitas vezes deseja-se medir uma grandeza $Y$ e esta não pode ser medida diretamente, mas é determinada a partir de $\mathrm{N}$ outras grandezas através de uma relação funcional $f$.

$Y=f\left(q_{1}, q_{2}, \ldots, q_{N}\right)$

Considere a expressão matemática que modela a relação (3.37) conhecida, y a estimativa da grandeza $Y, q_{i}$ a estimativa da variável $Q_{i} e$ $u^{2}\left(q_{i}\right)$ a variância associada a $q_{i}$, para todo i variando de 1 até $\mathrm{N}$, onde $\mathrm{N}$ é o número de variáveis que afetam a variável resposta $Y$.

A incerteza padronizada combinada, $u_{c}(y)$, considerando a equação (3.37), é dada pela raiz quadrada positiva da expressão (3.38):

$$
u_{c}^{2}(y)=\sum_{i=1}^{N}\left(\frac{\partial f}{\partial q_{i}}\right)^{2} u^{2}\left(q_{i}\right)+2 \sum_{i=1}^{N-1} \sum_{j=i+1}^{N} \frac{\partial f}{\partial q_{i}} \frac{\partial f}{\partial q_{j}} \mathrm{u}\left(\mathrm{q}_{\mathrm{i}}\right) \cdot u\left(q_{j}\right) \cdot r\left(q_{i}, q_{j}\right)
$$


onde:

- $u\left(q_{i}\right)$ é a incerteza associada à fonte de erro representada pela estimativa $\mathrm{q}_{\mathrm{i}}$;

- $r\left(q_{i}, q_{j}\right)$ é o coeficiente de correlação entre as estimativas $q_{i}$ e $q_{j}$.

A equação (3.38), referenciada como a Lei de Propagação de Incerteza, é baseada numa aproximação da série de Taylor de primeira ordem da equação (3.37) (DOEBELIN, 1990; LIRA, 2001).

As derivadas parciais, frequentemente denominadas de coeficientes de sensibilidade, descrevem como a estimativa de saída $\mathrm{Y}$ varia com alterações nos valores de entrada.

Segundo o Guia para Expressão das Incertezas de Medição (1999) as grandezas $Q_{i}$ podem ser divididas nas seguintes categorias:

- Grandezas cujos valores e incertezas podem ser diretamente determinados na presente medição, onde os seus valores podem ser obtidos através de avaliações tipo A ou tipo B e, podem envolver correções nas leituras de instrumentos por conta de grandezas de influência tais como temperatura ambiente, pressão barométrica e umidade;

- Grandezas cujos valores e incertezas são incorporados a partir de fontes externas, tais como grandezas associadas com padrões de medição calibrados, materiais de referência certificados e dados de referência obtidos de manuais técnicos.

Muitas vezes os coeficientes de sensibilidade, em vez de serem calculados pela função $f$, são determinados experimentalmente medindo-se a variação em $Y$ causada por uma variação em um dado $Q_{i}$, enquanto se mantém constantes as grandezas de entrada restantes. Neste caso, o conhecimento da função $f$ (ou de parte desta função quando somente vários coeficientes de sensibilidade são assim determinados) é reduzida a uma expressão da série de Taylor de primeira ordem, empírica, baseada nos coeficientes de sensibilidade medidos.

A equação (3.38) pode ser simplificada através do conhecimento da correlação entre as grandezas. 
Grandezas de entrada não correlacionadas: pode-se dizer que as grandezas não são correlacionadas, ou melhor, independentes umas das outras. A equação (3.38) torna-se:

$$
u_{c}^{2}(Y)=\sum_{i=1}^{n}\left[\frac{\delta f}{\delta Q_{i}}\right]^{2} u^{2}\left(Q_{i}\right)
$$

Grandezas de entrada correlacionadas: são aquelas grandezas dependentes umas das outras, a expressão apropriada para a variância combinada é a apresentada através da equação (3.38).

Onde, $u\left(q_{i}, q_{j}\right)=u\left(q_{j}, q_{i}\right)$ é a covariância estimada associada com $q_{i}$ e $q_{j}$. O grau de correlação entre $q_{i}$ e $q_{j}$ é caracterizado pelo coeficiente de correlação estimado, mostrado na equação (3.40),

$$
r\left(q_{i}, q_{j}\right)=\frac{u\left(q_{i}, q_{j}\right)}{u\left(q_{i}\right) u\left(q_{j}\right)},
$$

onde, $-1 \leq r\left(q_{i}, q_{j}\right) \leq 1$. Se as estimativas $q_{i}$ e $q_{j}$ são independentes $r\left(q_{i}, q_{j}\right)=$ 0 e a variação numa delas não implica em uma variação esperada na outra.

Os cálculos requeridos para obtenção da incerteza padrão combinada pode ser um processo longo, particularmente quando existem muitas contribuições individuais.

\subsubsection{INCERTEZA EXPANDIDA}

PHILLIPS (1995) escreveu que uma estimativa da incerteza de medição está incompleta se não for dado o nível de confiança para seu valor. Por este motivo, existe a incerteza expandida que define um intervalo em torno de uma medição no qual se espera abranger uma grande fração da distribuição (nível de confiança) dos valores que podem ser razoavelmente atribuídos à grandeza.

Para associar um nível de confiança específico ao intervalo definido pela incerteza expandida, são necessárias suposições explícitas ou implícitas 
com respeito à distribuição de probabilidade caracterizada pelo resultado da medição e sua incerteza padronizada combinada. O nível de confiança que pode ser atribuído a este intervalo só pode ser conhecido na medida em que tais suposições sejam justificadas.

A Recomendação INC-1 (1980) do Grupo de Trabalho sobre a Declaração de Incertezas, no qual o GUM é baseado, e as Recomendações 1 (CI-1981) e 1 (CI-1986) do Comitê Internacional de Pesos e Medidas (CIPM) exigem que a incerteza padronizada combinada seja usada "por todos os participantes no fornecimento de resultados de todas as comparações internacionais ou outros trabalhos feitos sob os auspícios do CIPM e dos seus Comitês Consultivos".

Entretanto, para algumas aplicações comerciais, industriais e regulamentadoras é muitas vezes necessário definir um intervalo em torno do resultado da medição com o qual se espera abranger uma grande parcela da distribuição de valores, que poderiam ser razoavelmente atribuídos à grandeza. A existência desta necessidade foi reconhecida pelo Grupo de Trabalho e levou ao parágrafo 5 da Recomendação INC-1 (1980). Ela também está refletida na Recomendação 1 (CI-1986) do CIPM.

A incerteza expandida é convenientemente expressa por $Y=y \pm U_{p}$, que é esse intervalo com o qual uma grande parcela da distribuição de valores que podem ser razoavelmente atribuídos a $\mathrm{Y}$.

O valor da incerteza expandida, $U_{p}$, é obtido pela equação (3.41), onde $\mathrm{u}_{\mathrm{c}}$ é a incerteza padrão combinada e $\mathrm{k}>0$ é o fator de abrangência:

$$
\mathrm{U}_{\mathrm{p}}=\mathrm{k} \cdot \mathrm{u}_{\mathrm{c}}
$$

Entretanto deve ser reconhecido que, na maioria dos casos, o nível de confiança é um tanto incerto, não somente pelo conhecimento limitado da distribuição de probabilidade caracterizada, mas também pela incerteza da própria incerteza combinada (ZIRONDI, 2002).

O fator de abrangência é escolhido com base no nível de confiança requerido para o intervalo. Em geral, para os metrologistas, estará entre 2 e 3. Para aplicações especiais pode estar fora desta faixa. A determinação do fator de abrangência requer um conhecimento extenso da distribuição de 
probabilidade caracterizada pelos resultados de medição e sua incerteza padronizada combinada.

Na Figura 3.2, pode-se observar a aproximação mais simples e adequada para situações onde a distribuição é aproximadamente normal e o grau de liberdade efetivo da incerteza combinada é de tamanho significativo, $\mathrm{k}=2$ para um nível de confiança de 95,5\% e k = 3 para um nível de confiança de $99,7 \%$.

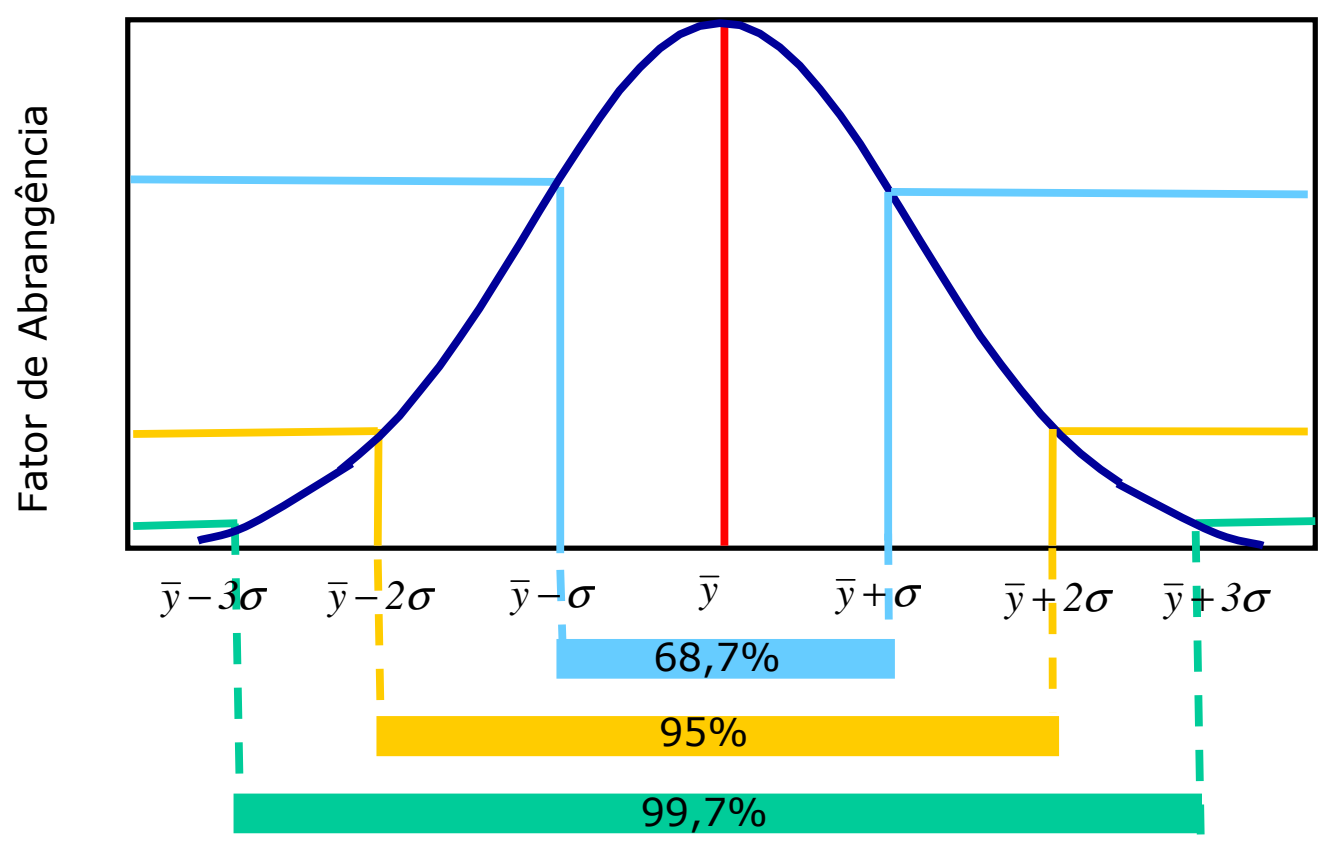

Nível de confiança

Figura 3.2: Fator de abrangência e nível de confiança

\subsubsection{MÉtodos para a determinaçÃo de INCERTEZA de MEdições A TRÊS COORDENADAS}

Aparentemente existem três métodos para a solução do problema de determinação de incerteza de medição a três coordenadas. No entanto, não há consenso internacional para a determinação das incertezas das medições realizadas com tais instrumentos. A falta deste consenso é a maior limitação para a expansão do uso das Máquinas de Medir a Três Coordenadas (ZIRONDI, 2002).

WECKENMANN et al. (2001) sintetizam em um gráfico as fontes de incerteza das medições a três coordenadas. Observe a Figura 3.3. 
Existem três abordagens para o problema da determinação das incertezas: o método do comparador, o método do teste de desempenho e o método do modelo matemático (PHILLIPS, 1995).

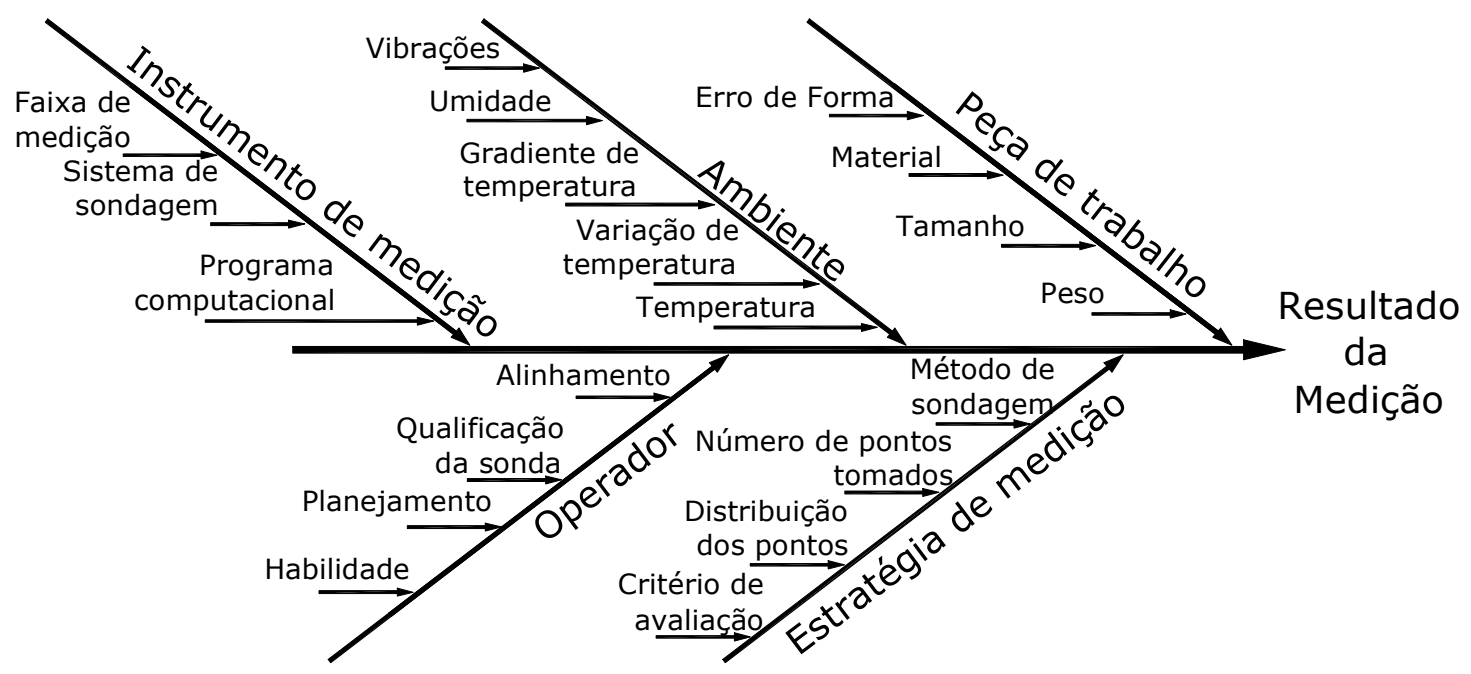

Figura 3.3: Fontes de incerteza nas medições a três coordenadas

\section{MÉTODO DO COMPARADOR}

O Método do Comparador tem como princípio o uso de artefatospadrão corporificados calibrados para a medição de uma característica particular, as medições realizadas são então comparadas às do padrão.

Este método é rígido, pois as medições somente são rastreáveis quando o objeto medido coincide exatamente em tamanho, forma geométrica, mesma posição, temperatura e estratégia de medida além do mesmo coeficiente de dilatação que o elemento de referência. Neste enfoque a MM3C é reduzida a um aparelho de medição com um só fim, comparador de peças por substituição, o que impede explorar a principal vantagem das MM3Cs, sua flexibilidade (KUNZMANN et al., 1995).

Uma vantagem da técnica é a facilidade com que obtém-se a correta combinação das diversas fontes de erros. Tal técnica é a única forma efetiva de testar outros métodos de levantamento de incertezas garantindo a presença na cadeia de rastreabilidade (DI GIACOMO, 1999). 


\section{MÉTOdO dO TESTE DE DESEMPENHO}

O método do teste de desempenho tem como principal característica a utilização de artefatos-padrão pré-calibrados e equipamentos especiais tais como calibradores passo a passo, anéis padrões, interferômetro laser, entre outros, para o levantamento das incertezas de medição na MM3C. As medições devem ser repetidas várias vezes em posições e orientações dentro do volume de trabalho da máquina. O desempenho da máquina é avaliado tomando-se a diferença entre o valor determinado pela MM3C e o valor calibrado do artefato (valor verdadeiro).

Várias normas, tais como, ASME B89, VDI/VDE 2617, CMMA, BS 6808, JIS B7440 e a ISO 10360, já normalizaram testes de desempenho das MM3Cs.

A norma EAL-G17 Technical Guideline de 1995 estabelece que testes de desempenho não garantem a rastreabilidade das medições em todas as características. Isto se deve ao fato que os testes de desempenho, baseiam-se na idéia de que a distorção do volume de trabalho de uma MM3C pode ser descrita através dos erros das distâncias entre os pontos coordenados que o formam.

A técnica tem como vantagem a possibilidade de usar testes padronizados e métodos de avaliação de desempenho desenvolvidos pelas organizações nacionais e internacionais de padronização. A principal desvantagem é que esse teste não é direcionado para uma tarefa específica. Na maioria das vezes superestima a incerteza de medição e, em outras a subestima, significativamente. Devido a isto a avaliação de desempenho não é boa estimadora de incerteza (DI GIACOMO, 1999).

\section{MÉTOdO do MODELO MATEMÁTICO}

O método do modelo matemático tem como principal característica a utilização de equações matemáticas que representam a MM3C no que diz respeito a medição e a combinação dos erros. Esta abordagem baseia-se na utilização de simulação para prever os erros e as incertezas a eles 
associadas. São as chamadas Máquinas Virtuais de Medir a Três Coordenadas (MVM3Cs).

Uma MVM3C é um sistema numérico que simula através de um modelo matemático as operações de medição de uma MM3C. Através desse modelo as diferentes fontes de incerteza são combinadas e seus efeitos propagados. A partir do conhecimento do erro volumétrico, é possível simular uma geometria ideal (sem erro) da característica medida da peça. A geometria simulada funciona como um artefato padrão e o erro de medição seria dado pela diferença entre a geometria calculada pela MM3C e a geometria simulada pela MM3C Virtual. A incerteza de medição seria específica para cada processo de medição (SOSA CARDOZA, 1995). A Figura 3.4 ilustra o conceito de Máquina Virtual.

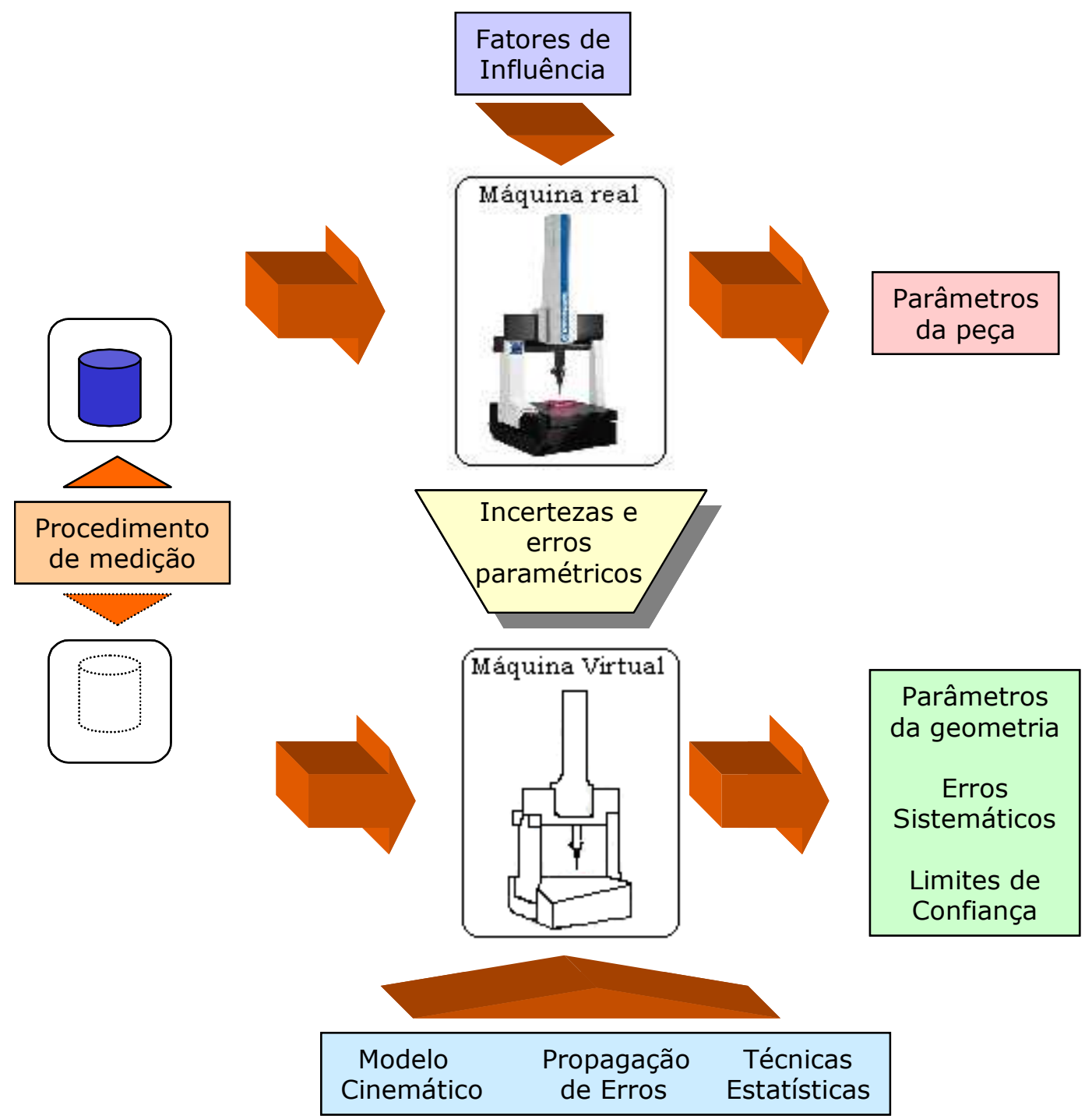

Figura 3.4: Máquina Virtual de Medir a Três Coordenadas 
Uma das desvantagens das MVM3Cs é a necessidade da reavaliação dos erros periodicamente, pois estes mudam com as condições de trabalho e idade da máquina.

Para se chegar à declaração da incerteza de uma medição, utilizando a modelagem matemática, é necessário conhecer detalhes relativos a inspeção (GUM), ou seja:

- Identificar todas as fontes de incerteza, isto é, todas as variáveis envolvidas na medição que afetam o valor do mensurando;

- Descrever a relação matemática entre a variável resposta e todas as variáveis que contribuem com alguma componente de incerteza;

- Determinar as incertezas-padrão (e também seus tipos: Tipo A ou Tipo B) das variáveis que afetam o comportamento do instrumento;

- Calcular a incerteza de medição a partir das incertezas padrões individuais, através do uso da lei de propagação de incertezas. Se necessário declarar a incerteza expandida.

Para medições unidimensionais, executar os passos descritos acima é relativamente simples. A determinação da incerteza de medições a três coordenadas, no entanto, é mais complexa e trabalhosa. Em muitas características medidas em uma MM3C, tais como distância entre um ponto e uma reta, distância entre ponto e plano, diâmetro de círculos, diâmetro de esferas, etc, a propagação de incerteza não envolve somente as incertezas associadas aos pontos medidos, pois, tais características são determinadas por programas computacionais (Método dos Mínimos Quadrados, Método da Mínima Zona, etc., que fica encarregado de ajustar a geometria a um conjunto de pontos medidos sobre a superfície da peça). Portanto, a incerteza de medição deve considerar também, as incertezas associadas aos parâmetros obtidos pelo método que ajusta a geometria e que determina a característica (SATO, 2002). Assim sendo, os passos necessários para determinação das estimativas de incertezas de medições a três coordenadas, com base nos procedimentos descritos no GUM são:

- Identificar as fontes de incerteza; 
- Construir um modelo matemático que gera o mapa de erros da máquina, ou seja, determinar a relação entrada-saída do sistema da máquina, onde todas as fontes de incertezas relevantes para a inspeção são consideradas as entradas e as componentes do erro volumétrico, as saídas do sistema;

- Determinar a incerteza de cada ponto coordenado medido sobre a superfície analisada. A incerteza de cada um desses pontos é o resultado da combinação das incertezas dos pontos observados na calibração e das incertezas associadas a outras variáveis de entrada, propagadas através das equações que descrevem o erro volumétrico. Desta forma, tem-se a nuvem de incerteza de cada ponto medido pela máquina sobre a superfície da peça inspecionada;

- Utilizar um método matemático (Mínimos Quadrados, Mínima Zona, ou outro) para ajustar a geometria ao conjunto de pontos medidos sobre a superfície da peça;

- Determinar as incertezas associadas aos estimadores do método de ajuste. Tal incerteza é a combinação das incertezas dos pontos utilizados pelo método de ajuste, propagadas através das expressões dos estimadores;

- Determinar a incerteza padrão combinada da característica requerida.

Como pode ser observado, a equação de propagação de incerteza deve ser utilizada em várias etapas e isso implica calcular múltiplas derivadas parciais para descrever a incerteza de medição, de uma dada geometria. Apesar de possível, é um trabalho árduo analisar todas as incertezas associadas ao cálculo da característica dimensional desejada e combiná-las de forma que ofereçam a incerteza de medição requerida. 


\section{CAPÍTULO 4}

\section{Interface eletrônica e}

\section{computacional para medição a três}

\section{coordenadas}

Neste trabalho é apresentada uma interface eletrônica e computacional que visa a modelagem, a medição e a compensação dos erros de uma MM3C. Tendo por objetivo o aumento da acuracidade nas medições e a diminuição dos erros em qualquer ponto do volume de trabalho. Neste novo método de compensação as coordenadas do ponto medido são modificadas de acordo com o valor do erro pré-determinado por calibração.

Utilizando um modelo de sintetização de erros conhecido como Modelo Reduzido de Sintetização de Erros (MRSE), desenvolvido por ZIRONDI (2002), foi possível calcular o erro de posicionamento da ponta do apalpador, em qualquer direção $X, Y$ ou $Z$, de qualquer ponto coordenado. Depois de corrigidas as coordenadas, os pontos foram utilizados para os cálculos das características desejadas.

Para que um sistema de compensação seja construído, é necessário o conhecimento prévio do comportamento dos erros de cada elemento da máquina. Esses erros podem ser obtidos através de procedimentos de 
calibração e os valores dos erros, combinados adequadamente através de expressões matemáticas, geram as componentes do erro volumétrico da máquina.

A validação da interface eletrônica e computacional proposta para medição e compensação dos erros, aplicado em uma MM3C do tipo "Ponte Móvel", foi feita através da medição de peças padrões medidas em várias posições no volume de trabalho da máquina e então foram analisadas as diferenças entre os valores obtidos para diversas características, quando os cálculos foram feitos com rotinas de compensação e com rotinas sem a compensação dos pontos coordenados.

As etapas envolvidas para realização da proposta foram divididas em sub-itens para um melhor entendimento e são: a modelagem dos erros volumétricos, a medição dos erros geométricos da MM3C, 0 desenvolvimento das Interfaces Máquina/Computador/Operador, a compensação dos erros através do programa computacional MaqMed 2000, e finalmente o cálculo de incerteza da medição a três coordenadas.

\subsection{Modelagem dos erros volumétricos}

Os modelos matemáticos têm sido estudados como ferramenta para melhorar a acuracidade das MM3Cs. Utilizados na metrologia da medição a três coordenadas têm como principal função, sintetizar as componentes dos erros volumétricos, isto é, combinar, de forma adequada e ponderada, os erros geométricos individuais em cada uma das direções preferenciais de movimentação da máquina formando o chamado erro volumétrico.

A ferramenta matemática escolhida neste trabalho para modelagem da MM3C, foi o Modelo Reduzido de Sintetização de Erros (MRSE). A escolha foi feita devido à possibilidade de observar a influência dos erros individuais sobre o posicionamento da ponta do apalpador para diferentes posições no volume de trabalho da máquina, ainda há possibilidade de considerar o sistema de apalpamento do equipamento, no processo de calibração. Além disso, o MRSE possui equações de sintetização, para $E_{x}, E_{Y}$ e $E_{Z}$, reduzidas, em comparação a outros modelos conhecidos. Necessita de pouco tempo de 
calibração o que reduz o custo desta atividade, possibilita o diagnóstico das fontes de erros e garante a rastreabilidade dos erros calculados.

O MRSE permite calcular o erro de posicionamento da ponta do apalpador, nas direções $X, Y$ e $Z$, de qualquer ponto coordenado a partir dos erros, eventualmente chamados deslocamentos indesejáveis. Tais deslocamentos indesejáveis, foram divididos em dois grupos: aqueles que possuem a mesma direção do movimento e, aqueles que ocorrem nas direções perpendiculares à direção do movimento.

Para a modelagem da MM3C os seguintes procedimentos foram seguidos:

- Estudo da estrutura da máquina: observação das disposições relativas de componentes móveis e fixos;

- Posicionamento do sistema de coordenadas: colocação do sistema de referência sobre um elemento fixo da MM3C, tal posição foi definida sobre o desempeno de granito, o mais próximo possível da guia do eixo $Y$.

Definida a posição do sistema de referência, foi verificada a contribuição de cada erro geométrico nas direções preferências, através de uma análise geométrica detalhada da máquina. Formularam-se, então, as equações reduzidas de sintetização para $E_{X}, E_{Y}$ e $E_{Z}$. Os erros geométricos foram descritos em função da posição.

\subsection{Medição dos erros geométricos}

Após a modelagem da máquina pôde-se traçar a estratégia de calibração de acordo com o modelo proposto, ou seja, todos os erros geométricos presentes nas equações de sintetização de erros devem ser medidos. A medição dos erros geométricos foi realizada em uma MM3C da marca Brown \& Sharpe, classificada como do tipo "Ponte Móvel", que se encontra no Laboratório de Metrologia da Escola de Engenharia de São Carlos - USP.

A calibração da máquina foi feita utilizando como artefatos padrões uma barra de furos e um esquadro mecânico. Os erros, que ocorrem na mesma direção do movimento foram medidos utilizando a barra de furos e, 
os que ocorrem nas direções perpendiculares à direção do movimento, um esquadro mecânico.

A barra de furos foi pré-calibrada utilizando uma Máquina de Medir Universal, SIP. Foi feita a medição da distância entre os centros dos furos e o resultado desta medição foi considerado como o "valor verdadeiro". A barra foi medida a temperatura de $20^{\circ} \mathrm{C}$ e necessitou-se de 8 horas para estabilização do sistema.

\subsection{Desenvolvimento das interfaces entre a máquina, o computador e o operador}

Os programas computacionais utilizados pelas MM3Cs, são usualmente, desenvolvidos pelas empresas que fabricam as máquinas, estes aplicativos normalmente não podem ser analisados nem modificados pelo usuário, isso acontece com o programa computacional dedicado da máquina utilizada. Para resolução deste problema, foi confeccionada uma placa para aquisição dos sinais da régua ótica e do apalpador de medição, que lê os sinais em quadratura das escalas dos três eixos da MM3C, além de "congelar" estas leituras quando um sinal eletrônico do apalpador de medição é enviado. Tal placa de aquisição faz o interfaceamento entre máquina e computador.

Na CPU do computador dedicado à MM3C foi construída uma saída com três sinais do tipo $A$ quad $B$, um para cada eixo de movimentação. Os sinais das réguas óticas e do apalpador, são enviados para a placa de aquisição, que está conectada ao barramento ISA de um microcomputador, responsável pelo controle do sistema e visualização da leitura.

No computador que recebe os sinais foi desenvolvido um programa computacional, denominado MaqMed 2000, tal programa faz a interface computador/operador. O MaqMed 2000 foi desenvolvido em ambiente $D E L P H I^{T M}$, e é constituído de várias janelas, botões e gráficos o que torna o programa visualmente agradável e de fácil utilização.

O MaqMed 2000 tem rotinas de cálculo para características geométricas simples, tais como círculos, retas, distâncias e ângulos e 
possibilita a compensação dos erros da MM3C além dos cálculos das incertezas de medição.

\subsection{Compensação dos erros volumétricos e validação do sistema}

Após a modelagem matemática e a medição dos erros da MM3C pode-se executar a compensação dos erros.

A compensação dos erros foi efetuada através de programas computacionais, isto é, foi desenvolvido um procedimento que corrige as coordenadas dos pontos utilizados no cálculo das geometrias. Os erros foram obtidos através de instrumentação apropriada em uma précalibração, como visto no item 4.2, ou seja, o levantamento dos erros foi feito em uma etapa anterior a qualquer processo de medição. Devido a estas características, por definição, pode-se dizer que a compensação efetuada é a compensação de erros por software.

O MaqMed 2000 faz a compensação das coordenadas dos pontos através das equações do MRSE e dos valores encontrados nas medições dos erros medidos com a barra e o esquadro mecânico.

A validação da interface eletrônica e computacional proposta para a compensação dos erros, foi verificada através do programa computacional MaqMed 2000. Um anel e um bloco padrão foram medidos, os pontos tomados são corrigidos pelo MaqMed 2000 e os resultados são apresentados. O anel e o bloco são medidos em várias posições no volume da MM3C, e então é verificada a proximidade entre os valores obtidos com e sem a compensação dos erros.

\subsection{Cálculo de incerteza da medição a três coordenadas}

Após a validação do sistema fez-se a determinação das incertezas associadas às componentes do erro volumétrico para cada ponto coordenado. 
$\mathrm{Na}$ grande maioria das medições dimensionais realizadas os valores das grandezas são influenciados por fatores do ambiente, tais como temperatura e umidade, e do próprio instrumento, como por exemplo, a sua resolução. A influência desses fatores, muitas vezes, não necessita de correção, devido à ordem de grandeza requerida. Entretanto, contribuem para a incerteza das medições.

Foram escritas as equações das grandezas medidas considerando todos os fatores que influenciam a medição. Foi verificado o tipo de incerteza, se do tipo A: o tamanho da amostra, o grau de liberdade efetivo, distribuição de probabilidade e a propagação das incertezas bem como os coeficientes de sensibilidade; se do tipo B: uma avaliação por julgamento científico baseando-se em todas as informações disponíveis sobre possíveis variabilidades. 


\title{
CAPÍTULO 5
}

\section{Desenvolvimento da metodologia}

\author{
proposta para medição e
}

compensação de erros

A metodologia proposta para o desenvolvimento da interface eletrônica e computacional para compensação de erros em MM3C está detalhada neste capítulo que, para uma melhor compreensão, foi dividido em quatro partes. Na primeira parte é apresentado o MRSE, Modelo Reduzido de Sintetização de Erros. Na segunda parte, a técnica de calibração utilizada, a barra de furos bem como as características operacionais e construtivas da MM3C onde foram realizados todos os testes experimentais estão apresentadas. Posteriormente, na terceira parte estão descritos toda a eletrônica do sistema e o programa computacional de medição desenvolvidos para a compensação do erro volumétrico. E finalmente foi feita uma análise das incertezas envolvidas no processo de medição com a máquina.

\subsection{Modelagem Matemática}

Um modelo matemático, denominado Modelo Reduzido de Sintetização de Erros (MRSE), que combina as influências dos erros 
geométricos em cada direção preferencial da máquina será utilizado para determinar o erro de posicionamento da ponta do apalpador, em qualquer direção $X, Y$ ou $Z$, de qualquer ponto coordenado. O MRSE é desenvolvido a partir de uma análise geométrica da máquina, e as expressões das componentes do erro volumétrico são determinadas através da soma do erro de posição e parcelas de correções (MARTINEZ ORREGO, 1999; ZIRONDI, 2002). Tais expressões são extremamente simples e requerem um número menor de calibrações, o que reduz o tempo dos ensaios. Uma das características interessantes desse modelo é a simplicidade da análise de propagação das incertezas dos pontos coordenados. O modelo, combinado com um método de calibração adequado, permite estabelecer uma cadeia de rastreabilidade para as medições efetuadas na MM3C analisada.

\subsubsection{Modelo Reduzido de Sintetização de ErRos (MRSE)}

O MRSE permite determinar o erro de posicionamento em qualquer direção: $X, Y$ ou $Z$, de qualquer ponto coordenado, a partir de medições das barras de furos e do esquadro mecânico em 15 geratrizes.

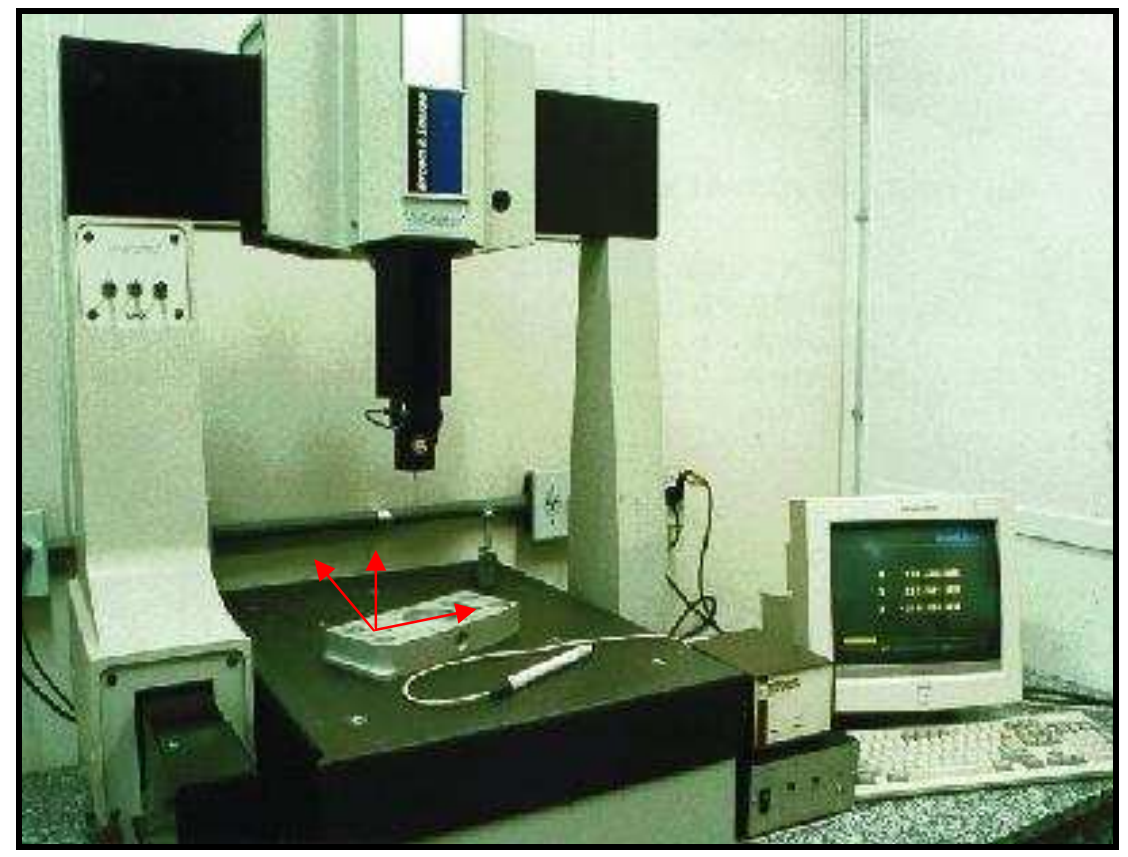

Figura 5.1: MM3C do Laboratório de Metrologia-EESC-USP 
A primeira providência a ser tomada para modelar a MM3C é definir a posição onde deve ser colocado o sistema de coordenadas de referência. Este sistema foi posicionado sobre o desempeno de granito, o mais próximo possível da guia do eixo $Y$, conforme indicado na Figura 5.1, que mostra a MM3C utilizada. As características técnicas da MM3C estão descritas no Apêndice A.

Tabela 5.1: Erros nas direções X, Y e Z

\begin{tabular}{|c|c|c|c|}
\hline $\begin{array}{c}\text { Componentes do Erro } \\
\text { Volumétrico }\end{array}$ & Erro geométrico & Movimento em & Braço em \\
\hline \multirow{9}{*}{$\mathrm{x}$} & Posição & $\bar{x}$ & \\
\hline & Retilineidade Y na direção $\mathrm{X}$ & $\mathrm{Y}$ & \\
\hline & Retilineidade $Z$ na direção $X$ & $\bar{Z}$ & \\
\hline & Erro angular Pitch do eixo $\mathrm{X}$ & $x$ & Z \\
\hline & Erro angular Yaw do eixo $Y$ & $\mathrm{Y}$ & $Y(f i x o)$ \\
\hline & Erro angular Yaw do eixo $\mathrm{Z}$ & Z & Z \\
\hline & Erro angular Roll do eixo $\mathrm{Y}$ & $\mathrm{Y}$ & Z \\
\hline & Ortogonalidade $\mathrm{XY}$ & & $Y(f i x o)$ \\
\hline & Ortogonalidade $\mathrm{XZ}$ & & Z \\
\hline \multirow{9}{*}{$\mathrm{Y}$} & Posição & $\bar{Y}$ & \\
\hline & Retilineidade $X$ direção $Y$ & $x$ & \\
\hline & Retilineidade $Z$ direção $Y$ & Z & \\
\hline & Erro angular Yaw do eixo $Y$ & $\bar{Y}$ & $\mathrm{X}$ \\
\hline & Erro angular Pitch do eixo $\mathrm{Y}$ & $\mathrm{Y}$ & Z \\
\hline & Erro angular Pitch do eixo $\mathrm{Z}$ & Z & Z \\
\hline & Erro angular Roll do eixo $\mathrm{X}$ & $\mathrm{X}$ & $\bar{Z}$ \\
\hline & Ortogonalidade $\mathrm{XY}$ & & $\mathrm{X}$ \\
\hline & Ortogonalidade $Y Z$ & & Z \\
\hline \multirow{6}{*}{ Z } & Posição & $\bar{Z}$ & \\
\hline & Retilineidade $\mathrm{X}$ direção $\mathrm{Z}$ & $\mathrm{X}$ & \\
\hline & Retilineidade Y direção $Z$ & $\mathrm{Y}$ & \\
\hline & Erro angular Pitch do eixo $\mathrm{Y}$ & $\mathrm{Y}$ & $Y(f i x o)$ \\
\hline & Erro angular Roll do eixo $\mathrm{X}$ & $\mathrm{X}$ & $Y(f i x o)$ \\
\hline & Erro angular Roll do eixo $\mathrm{Y}$ & $\mathrm{Y}$ & $\mathrm{x}$ \\
\hline
\end{tabular}

Definida a posição do sistema de referência, uma análise geométrica da estrutura da máquina foi efetuada com o propósito de definir a contribuição de cada erro geométrico nas suas direções preferenciais. 
A Tabela 5.1 apresenta os resultados obtidos com a análise geométrica da MM3C. As contribuições de segunda ordem foram desprezadas por serem consideradas insignificantes.

De posse das informações obtidas com a análise geométrica da máquina, formularam-se as equações reduzidas de sintetização para $E_{X}$, $E_{Y}$ e $E_{Z}$.

\section{EXPRESSÃO DA COMPONENTE Y DO ERRO VOLUMÉTRICO}

Considere duas geratrizes, denotadas por $G_{1}$ e $G_{i}$, no plano $X Y$, paralelas ao eixo $Y$, com coordenadas $X$ diferentes. $A$ geratriz $G_{1}$ foi localizada o mais próximo possível da escala $Y$ para que os efeitos dos braços de Abbé, fossem minimizados. Desta forma, obtém-se o erro de posição do eixo $\mathrm{Y}$, propriamente dito. A Figura 5.2 apresenta, esquematicamente, as geratrizes $\mathrm{G}_{1}$ e $\mathrm{G}_{\mathrm{i}}$.

Na Figura 5.2, dois pontos $\mathrm{P}_{1}$ e $\mathrm{P}_{\mathrm{i}}$ pertencentes respectivamente, às geratrizes $G_{1}$ e $G_{i}$, tem coordenadas que diferem apenas na coordenada $X$.

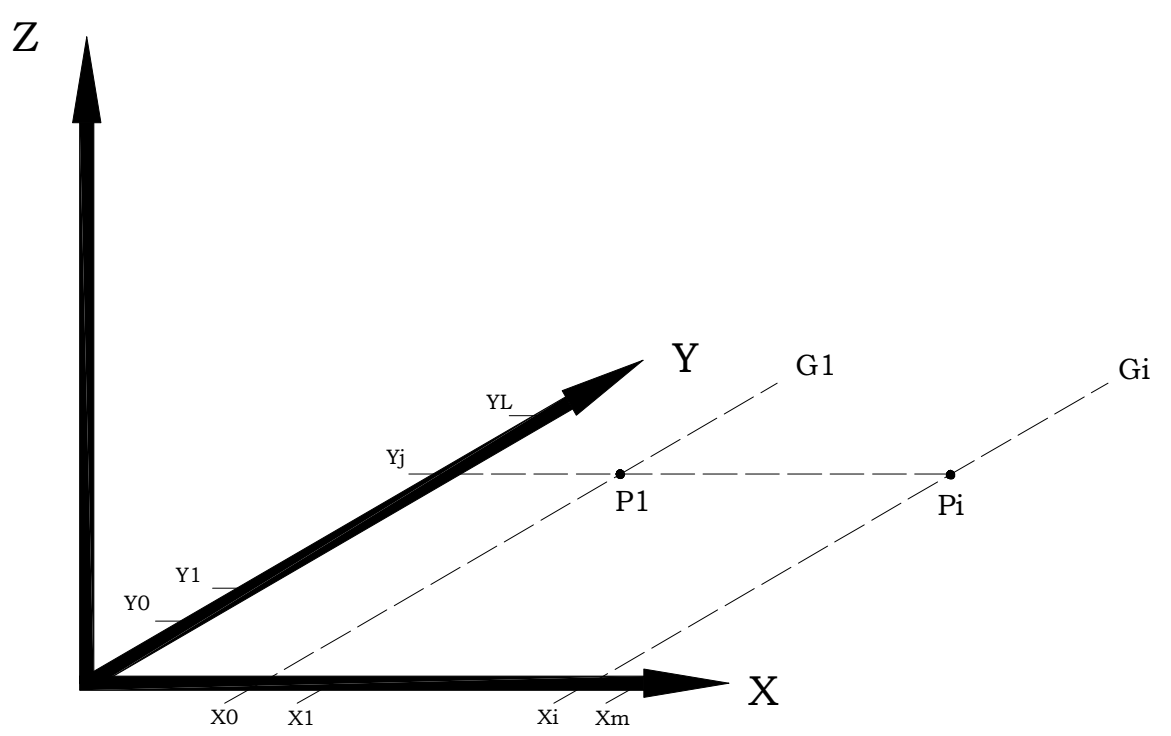

Figura 5.2: Representação das geratrizes $G_{1}$ e $G_{i}$ no plano $X Y$

Os valores medidos dos erros em $\mathrm{P}_{1}$ e $\mathrm{P}_{\mathrm{i}}$ são diferentes. Essas diferenças devem-se aos movimentos angulares cujas contribuições 
dependem da posição $X$ (braços em $X$ ) e influências dos erros com a mudança da posição $X_{0}$ para $a X_{i}$. De acordo com a análise geométrica, Tabela 5.1, os erros que provocam diferenças no erro de posicionamento da ponta do apalpador na direção $Y$, no plano $X Y$, são: Yaw do eixo $Y$, ortogonalidade $X Y$, Roll do eixo $X$ e retilineidade $X$ na direção $Y$. Assim sendo, supondo que seja conhecido o erro de posição, na direção $Y$, do ponto $P_{1}$ pode-se determinar o erro em $P_{i}$ através da equação (5.1).

$$
\begin{aligned}
\mathrm{E}_{\mathrm{Y}}\left(\mathrm{X}_{\mathrm{i}}, \mathrm{Y}_{\mathrm{j}}, \mathrm{Z}_{0}\right) & =\mathrm{E}_{\mathrm{Y}}\left(\mathrm{X}_{0}, \mathrm{Y}_{\mathrm{j}}, \mathrm{Z}_{0}\right)+\operatorname{Retilineidade} \mathrm{Y}(\mathrm{X})+\mathrm{Yaw}(\mathrm{Y}) \cdot[\operatorname{braço} \mathrm{X}]+ \\
& \operatorname{Roll}(\mathrm{X}) \cdot[\operatorname{braço} \mathrm{Z}]+\operatorname{OrtogonalidadeX} \mathrm{X} \cdot[\operatorname{braço} \mathrm{X}]
\end{aligned}
$$

onde:

- $\mathrm{E}_{\mathrm{Y}}\left(\mathrm{X}_{0}, \mathrm{Y}_{\mathrm{j}}, \mathrm{Z}_{0}\right)$ é o erro de posição do eixo $\mathrm{Y}$ em um ponto $\mathrm{P}_{1}$ arbitrário pertencente à geratriz $\mathrm{G}_{1}$;

- $\mathrm{E}_{\mathrm{Y}}\left(\mathrm{X}_{\mathrm{i}}, \mathrm{Y}_{\mathrm{j}}, \mathrm{Z}_{0}\right)$ é o erro de posição do eixo $\mathrm{Y}$ em um ponto $\mathrm{P}_{2}$, localizado em uma geratriz $G_{i}$ qualquer, paralela a $G_{1}$ no plano $X Y$;

- braço $X$ e braço $Z$ são distâncias nas respectivas direções $X$ e $Z$, entre o apalpador e o eixo $\mathrm{Y}$.

Procedendo a análise de forma semelhante, pode-se avaliar $\mathrm{E}_{\mathrm{Y}}$ em qualquer posição do volume de trabalho da MM3C. Para tanto, considere um ponto $\mathrm{P}_{\mathrm{k}}$ pertencente a uma geratriz contida no plano $\mathrm{YZ}$ e paralelo a $\mathrm{Y}$.

Observando-se a Figura 5.3, pode-se dizer que a diferença no posicionamento de $P_{i}$ e $P_{k}$, na direção $Y$, se deve aos movimentos angulares que dependem de braços em $Z$ e dos erros com movimentação na direção Z. De acordo com a Tabela 5.1, os erros que provocam diferenças no posicionamento relativo de $\mathrm{P}_{2}$ e $\mathrm{P}_{3}$ são: retilineidade $Z$ direção $Y$, Pitch do eixo $Y$, Pitch do eixo $Z$, Roll do eixo $X$ e ortogonalidade $Y Z$. Como o erro angular Roll do eixo $X$ já foi considerado na equação (5.1) tem-se que o valor de $E_{Y}$ no ponto $P_{3}$ pode ser escrito em função do valor de $E_{Y}$ no ponto $\mathrm{P}_{2}$ pela expressão (5.2). Nessa expressão, $\mathrm{E}_{\mathrm{Y}}\left(\mathrm{X}_{\mathrm{i}}, \mathrm{Y}_{\mathrm{j}}, \mathrm{Z}_{\mathrm{k}}\right)$ é o valor da 
componente $\mathrm{Y}$ do erro volumétrico em um ponto $\left(\mathrm{X}_{\mathrm{i}}, \mathrm{Y}_{\mathrm{j}}, \mathrm{Z}_{\mathrm{k}}\right)$ qualquer do volume de trabalho da MM3C.

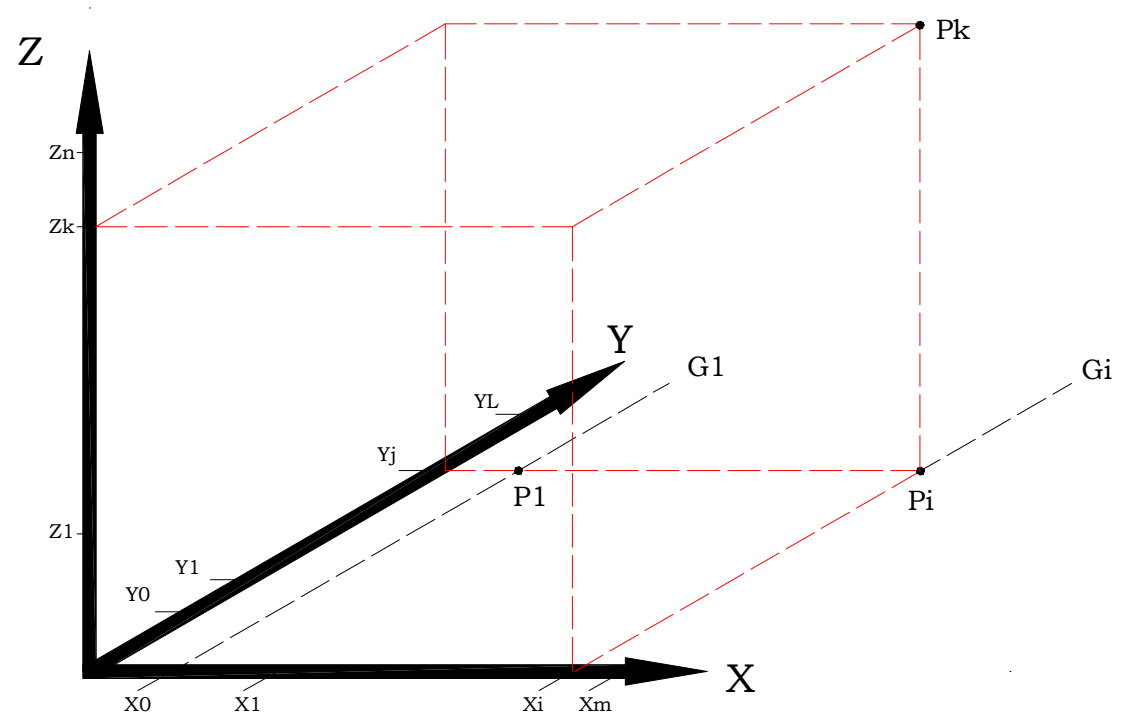

Figura 5.3: Representação de pontos pertencentes ao volume de trabalho da MM3C

$$
\begin{aligned}
E_{Y}\left(X_{i}, Y_{j}, Z_{k}\right) & =E_{Y}\left(X_{i}, Y_{j}, Z_{0}\right)+\operatorname{Re} \operatorname{tilineidadeY}(Z)+\operatorname{Pitch}(Y) \cdot[\text { braço } Z]+ \\
& \text { Pitch }(Z) \cdot[\text { braço } Z]+\text { OrtogonalidadeYZ } \cdot[\operatorname{braço~Z~}]
\end{aligned}
$$

Substituindo a equação (5.1) na equação (5.2) tem-se a equação de sintetização de $\mathrm{E}_{\mathrm{Y}}$, válida para qualquer ponto do volume de trabalho da MM3C, equação (5.3). Nessa equação, o termo Ortogonalidade foi simplificado por Ort.

$$
\begin{aligned}
\mathrm{E}_{\mathrm{Y}}\left(\mathrm{X}_{\mathrm{i}}, \mathrm{Y}_{\mathrm{j}}, \mathrm{Z}_{\mathrm{k}}\right)= & \mathrm{E}_{\mathrm{Y}}\left(\mathrm{X}_{0}, \mathrm{Y}_{\mathrm{j}}, \mathrm{Z}_{0}\right)+\operatorname{Re} \text { tilineidade } \mathrm{Y}(\mathrm{X})+\operatorname{Re} \operatorname{tilineidade} \mathrm{Y}(\mathrm{Z})+ \\
& \mathrm{Yaw}(\mathrm{Y}) \cdot[\operatorname{braço} \mathrm{X}]+\operatorname{Pitch}(\mathrm{Y}) \cdot[\operatorname{braço} \mathrm{Z}]+\operatorname{Pitch}(\mathrm{Z}) \cdot[\operatorname{braço} \mathrm{Z}]+ \\
& \operatorname{Roll}(\mathrm{X}) \cdot[\operatorname{braço} \mathrm{Z}]+\operatorname{Ort} \mathrm{XY} \cdot[\operatorname{braço} \mathrm{X}]+\operatorname{Ort} \mathrm{YZ} \cdot[\operatorname{braço} \mathrm{Z}]
\end{aligned}
$$

Para se determinar o valor de $\mathrm{E}_{\mathrm{Y}}$ em qualquer posição do volume de trabalho da MM3C, é necessário quantificar a contribuição de todos os erros geométricos que aparecem na expressão (5.3). 
De acordo com a equação (5.3), a parcela que corresponde à contribuição do erro Yaw do eixo $Y$, na direção $Y$ do erro volumétrico, é diferente e proporcional à coordenada $X$ desses pontos. A Figura 5.4 ilustra esse fato.

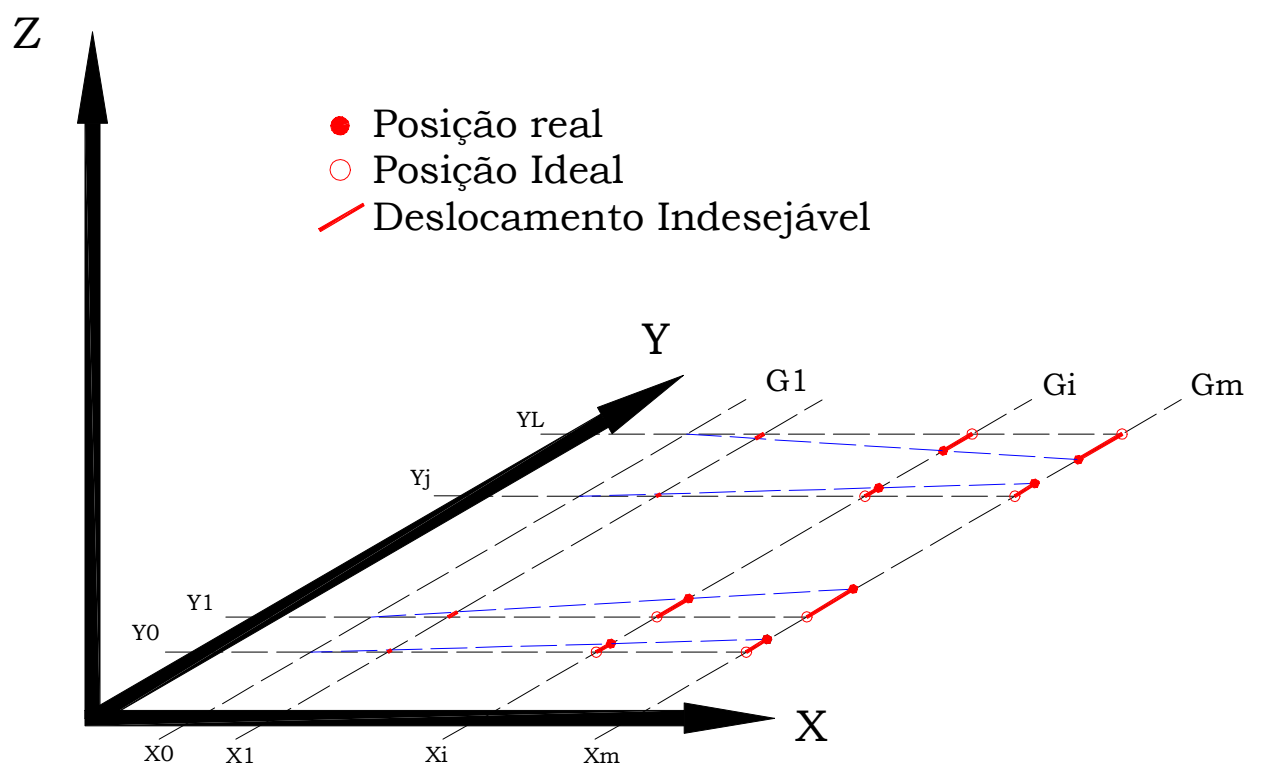

Figura 5.4: Erro angular Yaw do eixo $Y$ devido à existência de braço na direção $X$

A parcela de $E_{Y}$ correspondente ao erro $Y a w$ do eixo $Y$, em qualquer ponto $\left(X_{i}, Y_{j}, Z_{k}\right)$ do volume de trabalho da MM3C pode ser obtida a partir de medições efetuadas em duas geratrizes distintas diferentes em um dado plano $X Y$. Como os braços na direção $Z$ não interferem nos resultados, o plano $X Y$ que contém as geratrizes pode estar em qualquer posição $Z$. Assim sendo, o erro Yaw do eixo $Y$ em qualquer posição espacial pode ser calculado pela expressão (5.4), onde:

- $\delta\left(\mathrm{X}_{1}, \mathrm{Y}_{\mathrm{j}}\right)$ é o posicionamento do ponto $\mathrm{j}$ medido na geratriz $\mathrm{G}_{1}$. Neste caso temos braço em $X$ mínimo.

- $\delta\left(\mathrm{X}_{\mathrm{M}}, \mathrm{Y}_{\mathrm{j}}\right)$ é o posicionamento do ponto $\mathrm{j}$ medido na geratriz $\mathrm{G}_{2}$ (geratriz paralela $a G_{1}$, no plano $X Y$ ), localizado na posição $X_{M}$ do eixo $X$ (braço em X é máximo) 
78

- d_yaw $Y\left(X_{i}, Y_{j}\right)$ é o erro Yaw do eixo $Y$ no ponto $\left(X_{i}, Y_{j}, Z_{k}\right)$ qualquer

$$
d_{-} \operatorname{yaw} Y\left(X_{i}, Y_{j}\right)=\frac{\delta\left(X_{M}, Y_{j}\right)-\delta\left(X_{1}, Y_{j}\right)}{X_{M}-X_{1}} \cdot\left(X_{i}-X_{1}\right)
$$

Observação semelhante pode ser feita para Pitch do eixo Y, cuja contribuição na direção $Y$ cresce proporcional ao braço $Z$.

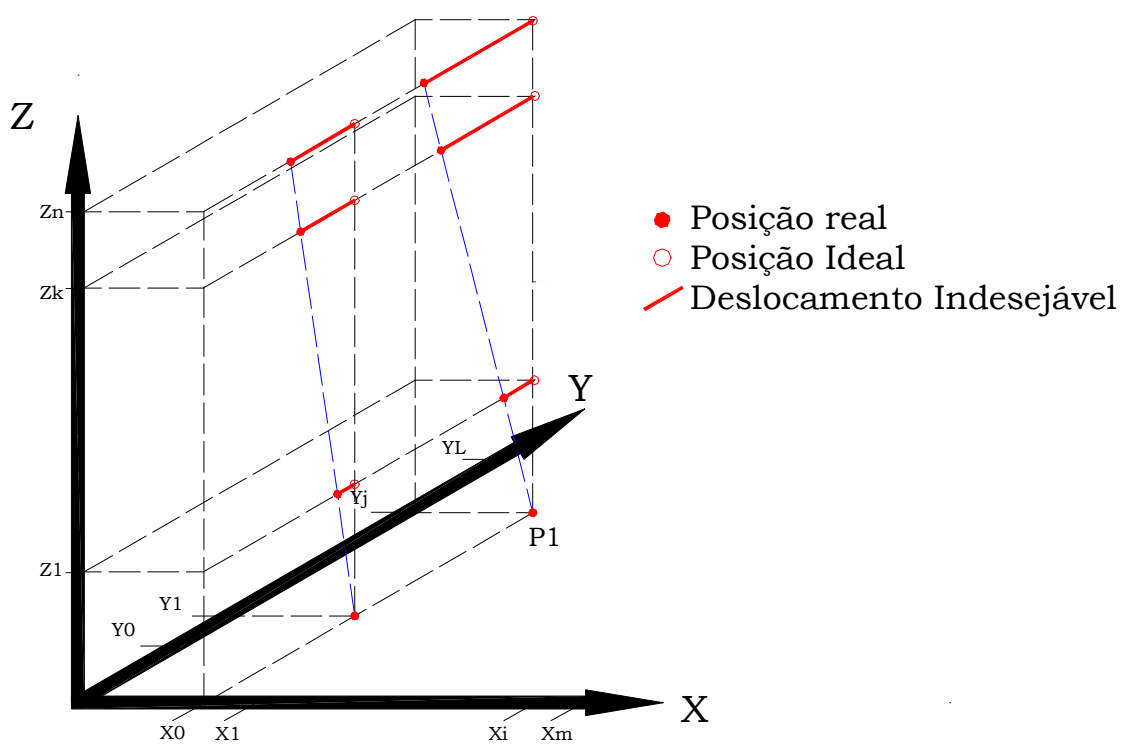

Figura 5.5: Erro angular Pitch do eixo Y amplificado pela existência de braço na direção $Z$

Na Figura 5.5 pode-se visualizar o erro angular Pitch do eixo $Y$ devido à existência de braço na direção Z. A expressão (5.5) apresenta o cálculo para o erro Pitch do eixo Y em qualquer posição espacial, onde:

- $\delta\left(\mathrm{Y}_{\mathrm{j}}, \mathrm{Z}_{0}\right)$ é o posicionamento do ponto $\mathrm{j}$ medido na geratriz $\mathrm{G}_{1}$ (braço Z mínimo);

- $\delta\left(\mathrm{Y}_{\mathrm{j}}, \mathrm{Z}_{\mathrm{N}}\right)$ é o posicionamento do ponto $\mathrm{j}$ medido em uma geratriz $\mathrm{G}_{3}$, geratriz paralela a $\mathrm{G}_{1}$ distante desta na direção $\mathrm{Z}$ (braço $\mathrm{Z}$ máximo); - d_pitchY $\left(\mathrm{Y}_{\mathrm{j}}, \mathrm{Z}_{\mathrm{k}}\right)$ é o erro Pitch do eixo $\mathrm{Y}$ no ponto $\left(\mathrm{X}_{\mathrm{i}}, \mathrm{Y}_{\mathrm{j}}, \mathrm{Z}_{\mathrm{k}}\right)$. 
$d_{-} \operatorname{pitchY}\left(Y_{j}, Z_{k}\right)=\frac{\delta\left(Y_{j}, Z_{N}\right)-\delta\left(Y_{j}, Z_{0}\right)}{Z_{N}-Z_{0}} \cdot\left(Z_{k}-Z_{0}\right)$

Analisando a equação (5.3), pode-se notar também, erros que alteram o posicionamento na direção $Y$ que dependem da coordenada $X$, ou de braços nesta direção: retilineidade $X$ na direção $Y$, Roll do eixo $X$ e ortogonalidade $\mathrm{XY}$. Seja $\mathrm{d}_{-} \mathrm{XY}\left(\mathrm{X}_{\mathrm{i}}\right)$ a parcela de $\mathrm{E}_{\mathrm{y}}$ que agrupa as influências desses erros na posição $X_{i}$. Deve-se observar, entretanto, que o valor de $\mathrm{d}_{-} \mathrm{XY}\left(\mathrm{X}_{\mathrm{i}}\right)$ não permanece inalterado com a variação da coordenada $Z$ devido à influência do erro Roll do eixo $X$. Ou seja, se a medição de $d_{-} X Y\left(X_{i}\right)$ for realizada para um braço $Z$ mínimo $e$, posteriormente, para um braço $Z$ máximo, as diferenças entre os deslocamentos encontrados, para um mesmo $X_{i}$, ocorrem somente devido ao erro Roll do eixo X. Assim sendo, o deslocamento provocado pelo Roll do eixo $X$, ortogonalidade $X Y$ e retilineidade $X$ na direção $Y$ pode ser determinado pela soma de duas parcelas: o valor obtido com a medição realizada para um braço $Z$ mínimo (onde a influência de Roll do eixo $X$ é mínima) e o valor da diferença encontrada entre as duas medições. Como essa diferença é linear, para uma dada coordenada $X$, e é proporcional ao braço na direção $Z$, o erro resultante pode ser determinado pela expressão (5.6), onde:

- d $d_{-} X Y\left(X_{i}, Z_{k}\right)$ é o deslocamento indesejável, na direção $Y$, provocado pelo erro Roll do eixo $X$, ortogonalidade $X Y$ e retilineidade $X$ na direção $Y$

- $\operatorname{dXY}\left(X_{i}, Z_{N}\right)$ é o deslocamento indesejável, na direção $Y$, medido no ponto i da geratriz $\mathrm{G}_{4}$ (geratriz no plano $X Y$, localizada perto da escala $X)$. Neste caso tem-se braço em $Z$ mínimo

- $\mathrm{dXY}\left(\mathrm{X}_{\mathrm{i}}, \mathrm{Z}_{0}\right)$ é o deslocamento indesejável, na direção $\mathrm{Y}$, medido no ponto i da geratriz $\mathrm{G}_{5}$ (geratriz paralela a geratriz $\mathrm{G}_{4}$ afastada desta na direção $Z$ ). A geratriz $G_{5}$ está distante da escala do eixo X (braço $Z$ máximo) 


$$
d_{-} X Y\left(X_{i}, Z_{k}\right)=d X Y\left(X_{i}, Z_{N}\right)+\frac{d X Y\left(X_{i}, Z_{0}\right)-d X Y\left(X_{i}, Z_{N}\right)}{\left(Z_{0}-Z_{N}\right)} \cdot\left(Z_{k}-Z_{N}\right)
$$

Além dos erros citados, existem ainda, na expressão (5.3), outros erros dependentes da coordenada $Z$ ou de braços em $Z$ que alteram 0 posicionamento na direção $Y$. São eles: retilineidade $Z$ na direção $Y$, Pitch do eixo $\mathrm{Z}$ e ortogonalidade $\mathrm{YZ}$. Considere $\mathrm{d}_{-} \mathrm{YZ}\left(\mathrm{Z}_{\mathrm{k}}\right)$ a parcela de $\mathrm{E}_{\mathrm{y}}$ que agrupa as influências destes erros, para uma coordenada $Z_{k}$ qualquer. $O$ erro $d_{-} Y Z\left(Z_{k}\right)$ é medido em uma geratriz $G_{6}$, de um plano $Y Z$.

Substituindo os erros na equação (5.3) tem-se a equação do MRSE para sintetizar $\mathrm{E}_{\mathrm{Y}}$, expressão (5.7).

$$
\begin{gathered}
E_{Y}\left(X_{i}, Y_{j}, Z_{k}\right)=E_{Y}\left(X_{0}, Y_{j}, Z_{0}\right)+d_{-} \operatorname{yaw} Y\left(X_{i}, Y_{j}\right)+d_{-} \operatorname{pitchY}\left(Y_{j}, Z_{k}\right)+ \\
d_{-} Y Z\left(Z_{k}\right)+d_{-} X Y\left(X_{i}, Z_{k}\right)
\end{gathered}
$$

\section{EXPRESSÃO DA COMPONENTE X DO ERRO VOLUMÉTRICO}

Análise semelhante à realizada para a componente $Y$ do erro volumétrico pode ser feita para a componente $X$.

Suponha conhecido o erro de posição do eixo $X$, ou melhor, o erro de posicionamento na direção $X$, de pontos localizados em uma geratriz $G_{7}$, do plano $X Z$, paralela à direção preferencial $X$ e o mais próxima possível da escala X. Utilizando o mesmo procedimento descrito anteriormente, pode-se determinar o valor de $\mathrm{E}_{\mathrm{X}}$ para qualquer ponto do volume de trabalho da MM3C, equação (5.8).

$$
\begin{aligned}
\mathrm{E}_{\mathrm{X}}\left(\mathrm{X}_{\mathrm{i}}, \mathrm{Y}_{\mathrm{j}}, \mathrm{Z}_{\mathrm{k}}\right)= & \mathrm{E}_{\mathrm{X}}\left(\mathrm{X}_{\mathrm{i}}, \mathrm{Y}_{0}, \mathrm{Z}_{\mathrm{N}}\right)+\operatorname{Re} \operatorname{tilineidadeX}(\mathrm{Y})+\operatorname{Re} \operatorname{tilineidadeX}(\mathrm{Z})+ \\
& \operatorname{Pitch}(\mathrm{X}) \cdot[\operatorname{braço} \mathrm{Z}]+\mathrm{Yaw}(\mathrm{Y}) \cdot[\mathrm{Y} \text { fixo }]+\mathrm{Yaw}(\mathrm{Z}) \cdot[\operatorname{braço} \mathrm{Z}]+, \\
& \operatorname{Roll}(\mathrm{Y}) \cdot[\operatorname{braço} \mathrm{Z}]+\operatorname{Ort} \mathrm{XY} \cdot[\mathrm{Y} \text { fixo }]+\operatorname{Ort} \mathrm{XZ} \cdot[\operatorname{braço} \mathrm{Z}]
\end{aligned}
$$

onde: 
- $\mathrm{E}_{\mathrm{X}}\left(\mathrm{X}_{\mathrm{i}}, \mathrm{Y}_{\mathrm{j}}, \mathrm{Z}_{\mathrm{k}}\right)$ é o valor da componente $\mathrm{X}$ do erro volumétrico no ponto $\left(X_{i}, Y_{j}, Z_{k}\right)$ qualquer

- $\mathrm{E}_{\mathrm{X}}\left(\mathrm{X}_{\mathrm{i}}, \mathrm{Y}_{0}, \mathrm{Z}_{\mathrm{N}}\right)$ é o erro de escala do eixo $\mathrm{X}$ na posição $\mathrm{i}$

- Y fixo é a distância entre as escalas $X$ e $Z$

Observando a equação (5.8) pode-se notar que o erro Pitch do eixo $X$ é o único erro que provoca erros na direção $X$, que cresce proporcionalmente ao braço $Z$ apresentando um comportamento linear para uma mesma coordenada X. Portanto, o cálculo desse erro pode ser feito de forma análoga ao descrito para o Yaw do eixo $\mathrm{Y}$.

A expressão para o cálculo é dada pela equação (5.9), onde:

- $\delta\left(\mathrm{X}_{\mathrm{i}}, \mathrm{Z}_{\mathrm{N}}\right)$ é o posicionamento do ponto $\mathrm{i}$ medido na geratriz $\mathrm{G}_{7}$ (braço Z mínimo)

- $\delta\left(\mathrm{X}_{\mathrm{i}}, \mathrm{Z}_{0}\right)$ é o posicionamento do ponto $\mathrm{i}$ medido na geratriz $\mathrm{G}_{8}$ geratriz do paralela $a G_{7}$, que dista desta na direção $Z$ (braço $Z$ máximo)

- d_pitchX $\left(X_{\mathrm{i}}, \mathrm{Z}_{\mathrm{k}}\right)$ é o erro Pitch do eixo $X$ calculado no ponto i da geratriz paralela a $G_{7}$ localizada em $Z$ na posição $Z_{k}$

$$
d_{-} \operatorname{pitchX}\left(X_{i}, Z_{k}\right)=\frac{\delta\left(X_{i}, Z_{0}\right)-\delta\left(X_{i}, Z_{N}\right)}{Z_{0}-Z_{N}} \cdot\left(Z_{k}-Z_{N}\right)
$$

$\mathrm{Na}$ equação (5.8) pode-se notar também, erros que modificam o posicionamento na direção $X$, dependendo da coordenada $Y$, ou de braços nesta direção: retilineidade $Y$ na direção $X$, Roll do eixo $Y$, Yaw do eixo $Y$ e ortogonalidade $X Y$. Desses erros, a influência do erro Roll do eixo $Y$ aumenta proporcionalmente ao braço Z. Assim sendo, o deslocamento indesejável na direção $X$, provocado pelo erro de retilineidade $Y$ na direção $X$, Roll do eixo $Y$, Yaw do eixo $Y$ e ortogonalidade $X Y$ pode ser determinado por: 


$$
d_{-} Y X\left(Y_{j}, Z_{k}\right)=d Y X\left(Y_{j}, Z_{0}\right)+\frac{d Y X\left(Y_{j}, Z_{N}\right)-d Y X\left(Y_{j}, Z_{0}\right)}{\left(Z_{N}-Z_{0}\right)} \cdot\left(Z_{k}-Z_{0}\right)
$$

onde:

- d_YX $\left(\mathrm{Y}_{\mathrm{j}}, \mathrm{Z}_{\mathrm{k}}\right)$ é o deslocamento indesejável, na direção $\mathrm{X}$, provocado pelos erros Roll do eixo $Y$, Yaw do eixo $Y$, ortogonalidade $X Y$ e retilineidade $Y$ na direção $X$, nos pontos cujas coordenadas $Y$ e $Z$ são respectivamente $\mathrm{Y}_{\mathrm{j}}$ e $\mathrm{Z}_{\mathrm{k}}$

- $\operatorname{dYX}\left(\mathrm{Y}_{\mathrm{j}}, \mathrm{Z}_{0}\right)$ é o deslocamento indesejável, na direção $\mathrm{X}$, medido, no ponto j, da geratriz $G_{9}$, geratriz do plano XY com braço $Z$ mínimo

- $\operatorname{dYX}\left(\mathrm{Y}_{\mathrm{j}}, \mathrm{Z}_{\mathrm{N}}\right)$ é o deslocamento indesejável, na direção $\mathrm{X}$, medido, no ponto $j$, da geratriz $G_{10}$, geratriz paralela a $G_{9}$ com um braço $Z$ máximo

Para finalizar a análise dos termos que aparecem na equação (5.8), basta determinar os erros que modificam o posicionamento na direção $X$, dependendo da coordenada $Z$, ou de braços nesta direção. Considere $\mathrm{d}_{\text {_ }} \mathrm{XZ}\left(\mathrm{Z}_{\mathrm{k}}\right)$ o deslocamento medido na posição $\mathrm{k}$ de uma geratriz $\mathrm{G}_{11}$ do plano $X Z$, que agrupa as influências dos erros: retilineidade $Z$ na direção $X$, Yaw do eixo $Z$ e ortogonalidade $X Z$.

$A$ equação do MRSE para sintetizar $E_{X}$ em qualquer posição do volume de trabalho da MM3C é dada por:

$$
E_{X}\left(X_{i}, Y_{j}, Z_{k}\right)=E_{X}\left(X_{i}, Y_{0}, Z_{N}\right)+d_{-} \operatorname{pitchX}\left(X_{i}, Z_{k}\right)+d_{-} Y X\left(Y_{j}, Z_{k}\right)+d_{-} X Z\left(Z_{k}\right)(
$$

\section{EXPRESSÃO DA COMPONENTE $Z$ DO ERRO VOLUMÉTRICO}

A expressão do MRSE para sintetizar a componente $Z$ do erro volumétrico foi obtida através de procedimentos análogos aos empregados para as componentes $\mathrm{X}$ e $\mathrm{Y}$.

Supondo conhecido o erro de posição do eixo Z (o erro de posicionamento na direção $Z$, de pontos localizados em uma geratriz do plano $X Z$, paralela à direção preferencial $Z$ ), pode-se expressar $E_{Z}$ em 
qualquer posição do volume de trabalho da MM3C da forma descrita na equação (5.12):

$$
\begin{aligned}
E_{Z}\left(X_{i}, Y_{j}, Z_{k}\right) & =E_{Z}\left(X_{0}, Y_{0}, Z_{k}\right)+\operatorname{Re} \text { tilineidadeZ }(X)+\operatorname{RetilineidadeZ}(Y)+ \\
& \operatorname{Pitch}(Y) \cdot[Y \text { fixo }]+\operatorname{Roll}(X) \cdot[Y \text { fixo }]+\operatorname{Roll}(Y) \cdot[\operatorname{braço~X}]
\end{aligned}
$$

onde:

- $\mathrm{E}_{\mathrm{Z}}\left(\mathrm{X}_{\mathrm{i}}, \mathrm{Y}_{\mathrm{j}}, \mathrm{Z}_{\mathrm{k}}\right)$ é o valor da componente $\mathrm{Z}$ do erro volumétrico no ponto $\left(\mathrm{X}_{\mathrm{i}}, \mathrm{Y}_{\mathrm{j}}, \mathrm{Z}_{\mathrm{k}}\right)$ qualquer;

- $\mathrm{E}_{\mathrm{Z}}\left(\mathrm{X}_{0}, \mathrm{Y}_{0}, \mathrm{Z}_{\mathrm{k}}\right)$ é o erro de escala do eixo $\mathrm{Z}$ na posição $\mathrm{k}$. Erro medido na geratriz G12.

Analisando a equação (5.12), observa-se que as parcelas de contribuições, na direção $Z$, dos erros de retilineidade $X$ na direção $Z$ e Roll do eixo $X$, variam com a movimentação na direção $X$. Seja d_ZX $\left(X_{i}\right)$ o deslocamento medido na posição i da geratriz $\mathrm{G}_{13}$ (geratriz do plano $\mathrm{XZ}$ ), que agrupa as influências desses erros.

Os demais erros que aparecem na equação (5.15) influenciam $E_{Z}$ devido ao movimento em $Y$ : retilineidade $Y$ na direção $Z$, Roll do eixo $Y$ e Pitch do eixo $Y$. O efeito do Roll do eixo $Y$ na direção $Y$ cresce proporcionalmente à coordenada $X$ e apresenta, para uma dada coordenada Y, um comportamento linear. Portanto, o deslocamento indesejável provocado pelos erros: retilineidade $Y$ na direção $Z$, Roll do eixo $Y$ e Pitch do eixo $Y$, pode ser determinado pela expressão $(5,13)$, onde:

- d_ $\mathrm{ZY}\left(\mathrm{X}_{\mathrm{i}}, \mathrm{Y}_{\mathrm{j}}\right)$ é o deslocamento indesejável, na direção $\mathrm{Z}$, provocado pelos erros retilineidade $Y$ na direção $Z$, Roll do eixo $Y$ e Pitch do eixo $Y$, nos pontos cujas coordenadas $X$ e $Y$ são respectivamente $X_{i}$ e $Y_{j}$;

- $\mathrm{dZY}\left(\mathrm{X}_{0}, \mathrm{Y}_{\mathrm{j}}\right)$ é o deslocamento indesejável, na direção $\mathrm{Z}$, medido, no ponto $j$, da geratriz $G_{14}$ (geratriz do plano $Y Z$ na posição $X$ perto do zero da escala $X)$. Braço em $X$ é mínimo;

- $\mathrm{dZY}\left(\mathrm{X}_{\mathrm{M}}, \mathrm{Y}_{\mathrm{j}}\right)$ é o deslocamento indesejável, na direção $\mathrm{Z}$, medido, no ponto $j$, da geratriz $G_{15}$ (geratriz localizada no mesmo plano $X Y$ da 
geratriz $\mathrm{G}_{14}$ e paralela a esta, na posição $\mathrm{X}_{\mathrm{M}}$ do eixo $\mathrm{X}$ ). Braço em $\mathrm{X}$ é máximo.

$$
d_{-} Z Y\left(X_{i}, Y_{j}\right)=d Z Y\left(X_{0}, Y_{j}\right)+\frac{d Z Y\left(X_{M}, Y_{j}\right)-d Z Y\left(X_{0}, Y_{j}\right)}{\left(X_{M}-X_{0}\right)} \cdot\left(X_{i}-X_{0}\right)
$$

$A$ equação do MRSE para sintetizar $E_{Z}$ em qualquer posição do volume de trabalho da MM3C é dada por:

$$
E_{Z}\left(X_{i}, Y_{j}, Z_{k}\right)=E_{Z}\left(X_{0}, Y_{0}, Z_{k}\right)+d_{-} Z Y\left(X_{i}, Y_{j}\right)+d_{-} Z X\left(X_{i}\right)
$$

\subsection{Calibração da MM3C}

O MRSE determina o erro de posicionamento em qualquer direção: $X, Y$ ou $Z$, de um ponto do volume de trabalho da MM3C, a partir de erros medidos em 15 geratrizes. Estes erros ocorrem na direção do movimento ou perpendicular ao movimento.

Os erros que ocorrem na direção do movimento foram determinados a partir de medições efetuadas com uma barra de furos. São eles: os erros de posição dos eixos $X, Y$ e $Z$ e os erros d_yaw $Y\left(X_{i}, Y_{j}\right), d_{-}$pitchY $\left(Y_{j}, Z_{k}\right)$ e $\mathrm{d}_{-} \operatorname{pitchX}\left(\mathrm{X}_{\mathrm{j}}, \mathrm{Z}_{\mathrm{k}}\right)$.

Os erros que ocorrem perpendicularmente à direção do movimento $\left(d_{-} Y Z\left(Z_{k}\right), d_{-} X Y\left(X_{i}, Z_{k}\right), d_{-} Y X\left(Y_{j}, Z_{k}\right), d_{-} X Z\left(Z_{k}\right), d_{-} Z Y\left(X_{i}, Y_{j}\right)\right.$ e $\left.\mathrm{d}_{-} \mathrm{ZX}\left(\mathrm{X}_{\mathrm{i}}\right)\right)$ foram medidos com um esquadro de granito, também conhecido como esquadro mecânico, e um apalpador eletrônico do tipo LVDT.

Das quinze geratrizes onde são medidos os erros, em nove são utilizados o esquadro mecânico e o apalpador eletrônico LVDT e em seis a barra de furos.

Tanto a Barra de Furos quanto o esquadro mecânico são, convenientemente, posicionados no volume de trabalho da MM3C. Estas 
posições são determinadas analisando-se a influência dos braços de Abbè sobre os erros individuais, como apresentado no item 5.1.

\subsubsection{CALIBRAÇÃo UTILIZANDO A BARRA de FUROS}

Para calibração da MM3C foi desenvolvido um programa computacional, denominado ProgCalibra, que faz parte do MaqMed 2000.

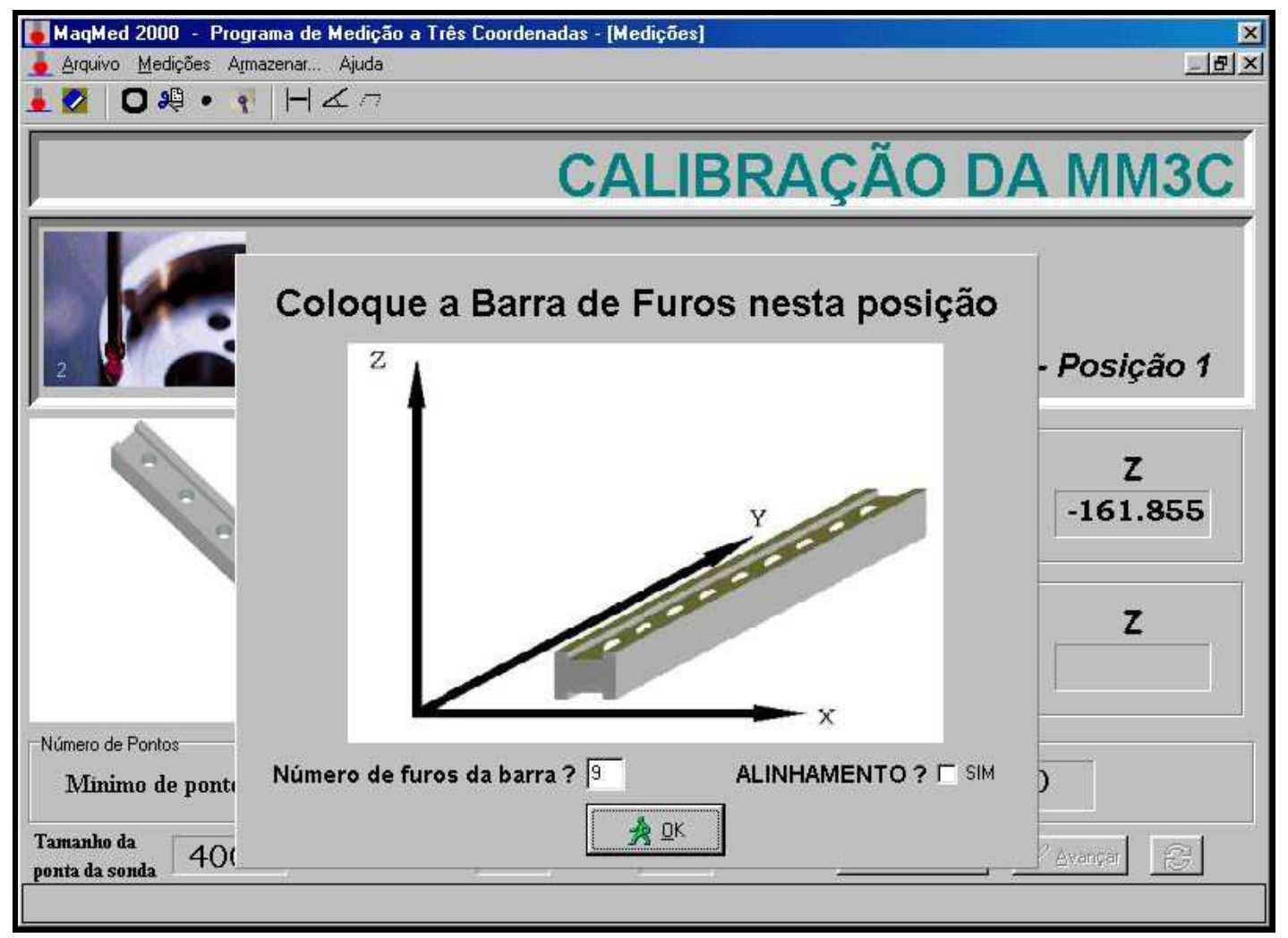

Figura 5.6: Tela do ProgCalibra

O programa desenvolvido permite a coleta automática dos dados e especifica as posições a serem colocadas a barra, observar Figura 5.6. Foi utilizada a placa de aquisição que faz a interface entre a MM3C e um microcomputador.

A barra foi fabricada em aço ferramenta ASTM O1 que possui uma boa estabilidade dimensional e resistência à deformação, Figura 5.7, no Laboratório de Máquinas Ferramentas da EESC-USP. 
As distâncias nominais entre os centros dos furos da barra são iguais e os furos possuem o mesmo diâmetro nominal. A secção transversal é em $\mathrm{H}$ no intuito de minimizar as deformações quando esta estiver biapoiada.

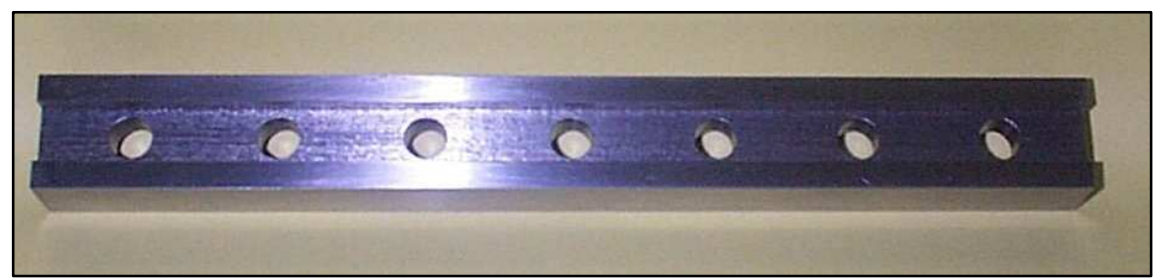

Figura 5.7: Barra de furos

Em cada geratriz, o zero de referência foi colocado no ponto mais próximo do sistema de coordenadas de referência, (o sistema de coordenadas de referência pode ser visualizado na Figura 5.1). A distância entre os pontos de uma dada geratriz, foi medida pela MM3C e pela barra de furos e o erro determinado pela diferença expressa em (5.15).

$\mathrm{E}_{\mathrm{i}}=$ Valor encontrado com o ProgCalibra - Leitura da SIP,

onde:

$E_{i}$ : Erro de posição no ponto i.

Os erros de escala devem ser medidos com a barra de furos, posicionada paralelamente ao eixo, o mais próximo possível do eixo a ser avaliado. A referência é colocada no centro do primeiro furo da barra (furo 1) e as distâncias entre os centros dos furos $j$ para $j=2, \ldots, n$ até o centro do furo 1 são medidas.

\section{MEDIÇÃo dOS ERROS NA DIREÇÃo Y}

Os erros na direção $Y$ foram determinados a partir de medições efetuadas nas geratrizes esquematizadas na Figura 5.8. Os erros $\mathrm{E}_{\mathrm{Y}}\left(\mathrm{X}_{0}, \mathrm{Y}_{\mathrm{j}}, \mathrm{Z}_{0}\right)$ foram medidos na geratriz $\mathrm{G} 1$. Além dessas medições, foram 
realizadas medições nas geratrizes G2 e G3 para obter os erros $d_{-} \operatorname{yaw} Y\left(X_{i}, Y_{j}\right)$ e d_pitchY $\left(Y_{j}, Z_{k}\right)$, respectivamente.

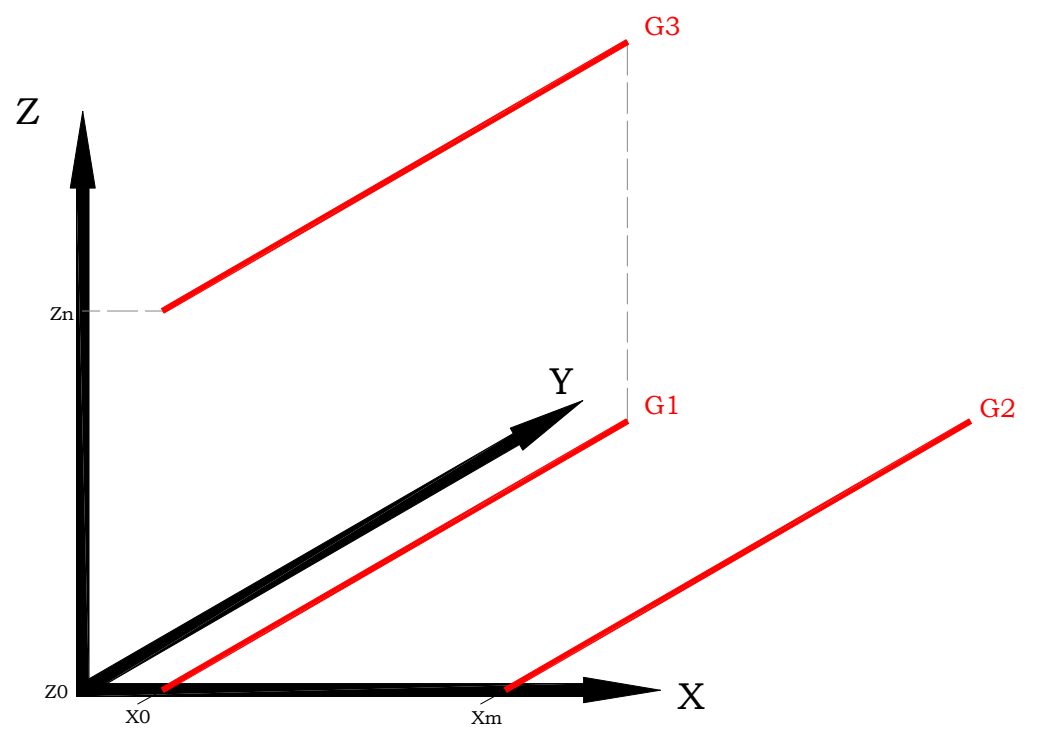

Figura 5.8: Geratrizes medidas usando a barra de furos para determinar $\mathrm{E}_{\mathrm{Y}}$

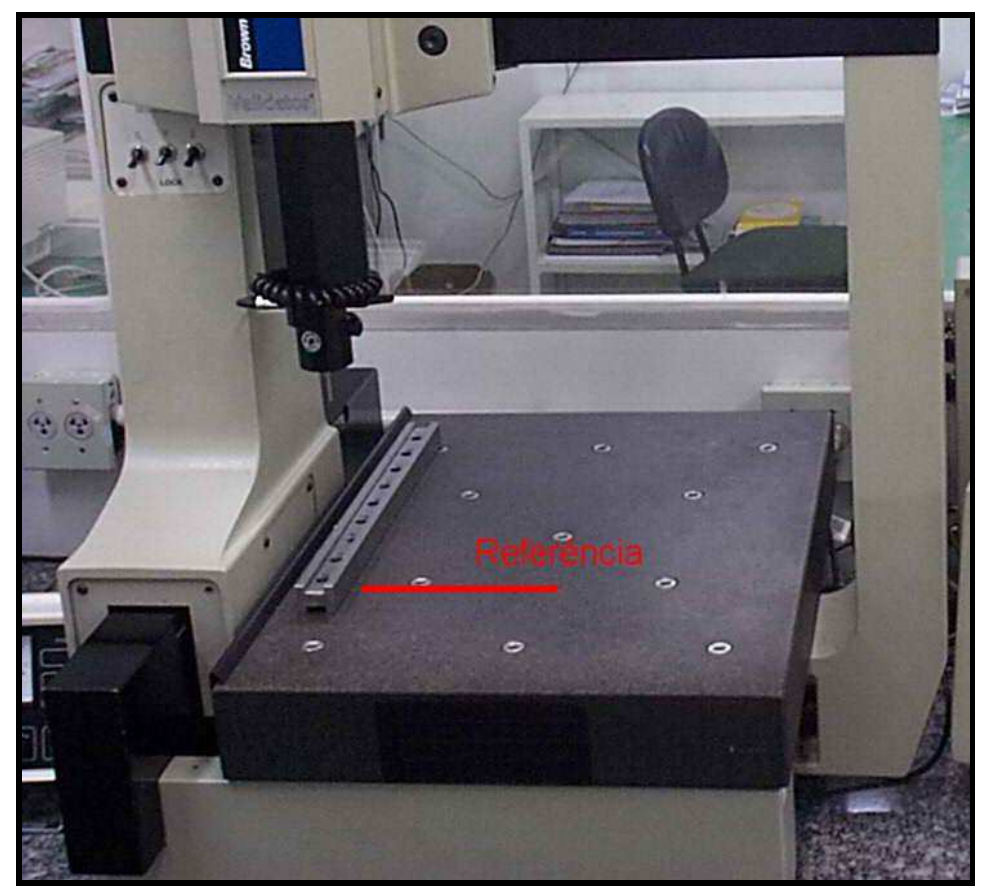

Figura 5.9: Montagem da barra de furos para a medição do erro de posição Y

\section{MEDIÇÃo dOS ERROS NA DIREÇÃo X}

As geratrizes medidas para se determinar os erros que ocorrem na direção $X$ estão representadas na Figura 5.10. Os erros $E_{X}\left(X_{i}, Y_{0}, Z_{N}\right)$ foram 
obtidos com a medição do ponto i na geratriz G7. Para determinar os erros $\mathrm{d}_{\text {_ }}$ pitchX $\left(\mathrm{X}_{\mathrm{i}}, \mathrm{Z}_{\mathrm{k}}\right)$, além das medições na geratriz $\mathrm{G7}$ devem-se efetuar medições na geratriz G8.

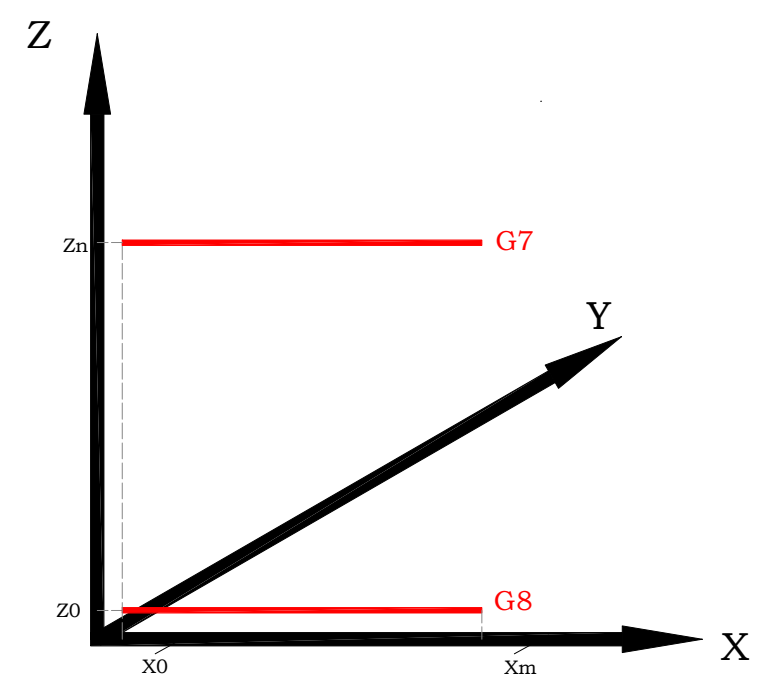

Figura 5.10: Geratrizes medidas, usando a barra de furos, para calcular $\mathrm{E}_{\mathrm{X}}$

\section{MEDIÇÃo dOS ERROS NA DIREÇÃo Z}

O erro de escala do eixo $Z$ pode ser avaliado em qualquer geratriz perpendicular ao plano $\mathrm{XY}$.

\subsubsection{CALIBRAÇÃo UTILIZANDO O ESQUADRO MECÂNICO E O APALPADOR}

A medição com o esquadro foi efetuada colocando-o em um plano $(X Y, Y Z$ ou $X Z)$, com uma de suas arestas paralela à direção da componente do erro volumétrico que está sendo avaliada. As leituras foram efetuadas para diferentes pontos na aresta perpendicular ao eixo analisado. Cada medição também foi repetida 5 vezes, tomando-se o valor médio em cada ponto de medição para representar o erro, foi então calculado o desvio padrão das medições. 


\section{MEDIÇÃo dOS ERROS NA DIREÇÃo Y}

Os erros $d_{-} \mathrm{YZ}\left(\mathrm{Z}_{\mathrm{k}}\right)$ foram medidos na geratriz de um plano $\mathrm{YZ}$, posicionada em $\mathrm{Y}=\mathrm{Y}_{0}$. $\mathrm{O}$ plano $\mathrm{YZ}$ pode estar em qualquer posição $\mathrm{X}$. $\mathrm{A}$ Figura 5.11(a) apresenta, esquematicamente, o posicionamento do esquadro no plano YZ. A face menor do esquadro foi alinhada com o eixo $Y$, direção de interesse, e leituras foram efetuadas para diferentes pontos na direção Z.

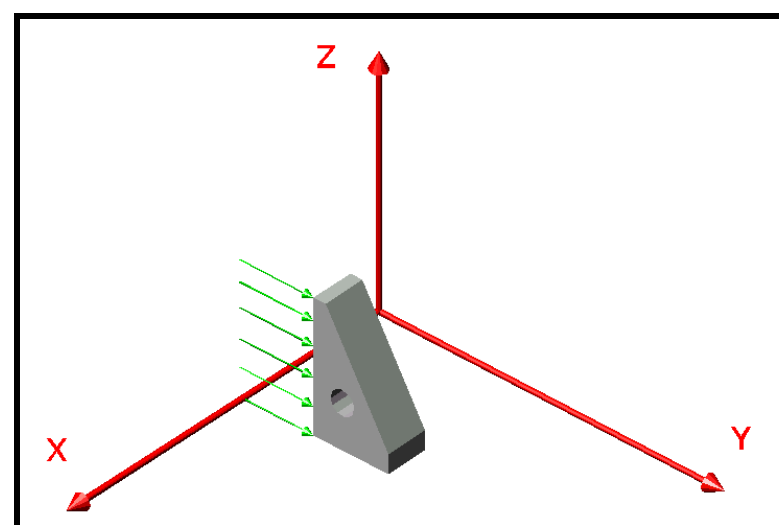

(a) Medição d_ $\mathrm{YZ}\left(\mathrm{Z}_{\mathrm{k}}\right)$

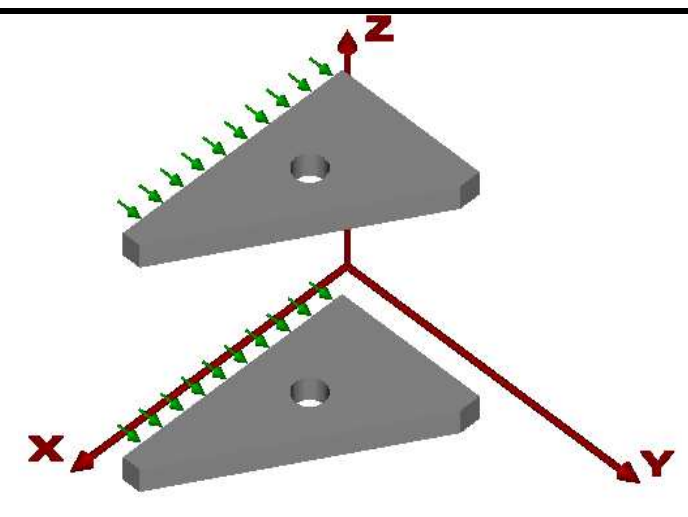

(b) Medição $\mathrm{dXY}\left(\mathrm{X}_{\mathrm{i}}, \mathrm{Z}_{\mathrm{N}}\right)$ e $\mathrm{dXY}\left(\mathrm{X}_{\mathrm{i}}, \mathrm{Z}_{0}\right)$

Figura 5.11: Posicionamento do esquadro para medição dos erros na direção $Y$

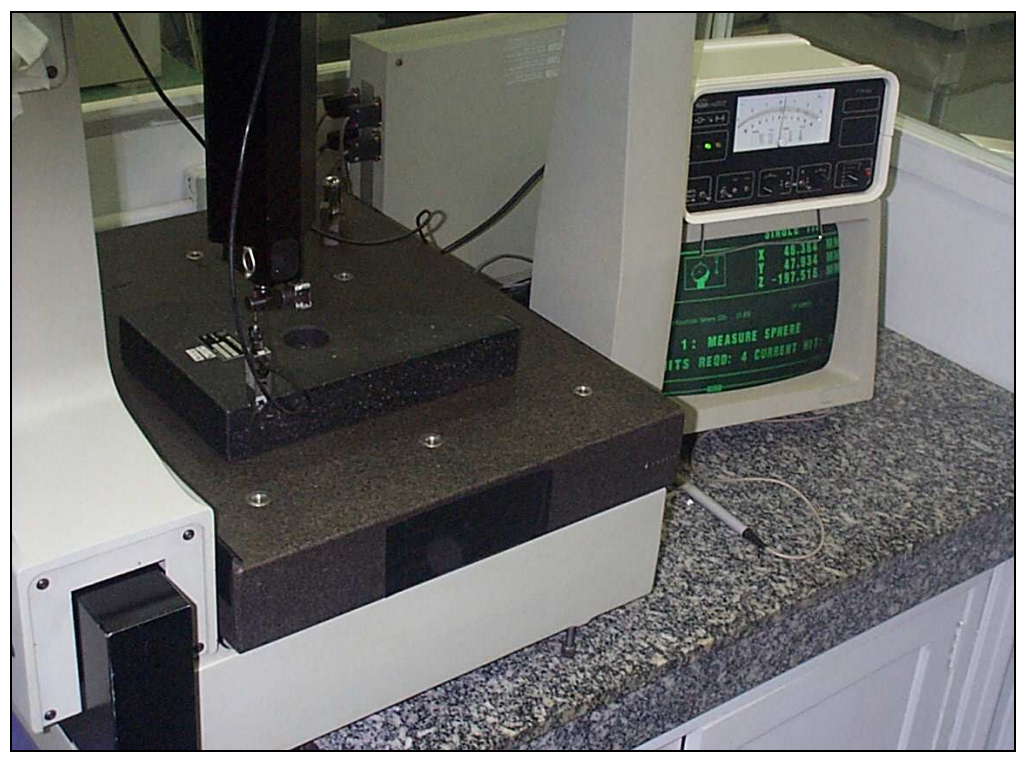

Figura 5.12: Montagem para a medição dos erros $\mathrm{dXY}\left(\mathrm{X}_{\mathrm{i}}, \mathrm{Z}_{0}\right)$ 
Os erros que dependem da coordenada $X$ ou de braços nesta direção, que alteram o posicionamento na direção $Y$ foram determinados a partir de medições em duas geratrizes: uma para um braço $Z$ máximo (próxima do desempeno da máquina) e outra para um braço em $Z$ mínimo (próxima da escala $X$ ). A Figura 5.11(b) ilustra o procedimento de medição dos erros $\mathrm{dXY}\left(\mathrm{X}_{\mathrm{i}}, \mathrm{Z}_{0}\right)$ e $\mathrm{dXY}\left(\mathrm{X}_{\mathrm{i}}, \mathrm{Z}_{\mathrm{N}}\right)$, necessários para o cálculo do erro $\mathrm{d}_{-} \mathrm{XY}\left(\mathrm{X}_{\mathrm{i}}, \mathrm{Z}_{\mathrm{k}}\right)$, que agrupa as influências na direção $\mathrm{Y}$, dos erros Roll do eixo $X$, ortogonalidade $X Y$ e retilineidade $X$ na direção $Y$.

Na Figura 5.12 pode-se visualizar a montagem para a medição dos erros $\mathrm{dXY}\left(\mathrm{X}_{\mathrm{i}}, \mathrm{Z}_{0}\right)$.

\section{MEDIÇÃo dOS ERROS NA DIREÇÃo X}

Os erros na direção $X$, que ocorrem devido a movimentos na direção $Y$, ou de braços nesta direção, foram calculados a partir de medições em duas geratrizes paralelas pertencentes a planos $X Y$ diferentes. Um dos planos localizado perto do desempeno e outro longe deste. Para essas medições a face menor do esquadro foi alinhada com o eixo $X$ e medições foram feitas na direção $\mathrm{Y}$. O esquema do posicionamento do esquadro para essas medições pode ser visto na Figura 5.13(a).

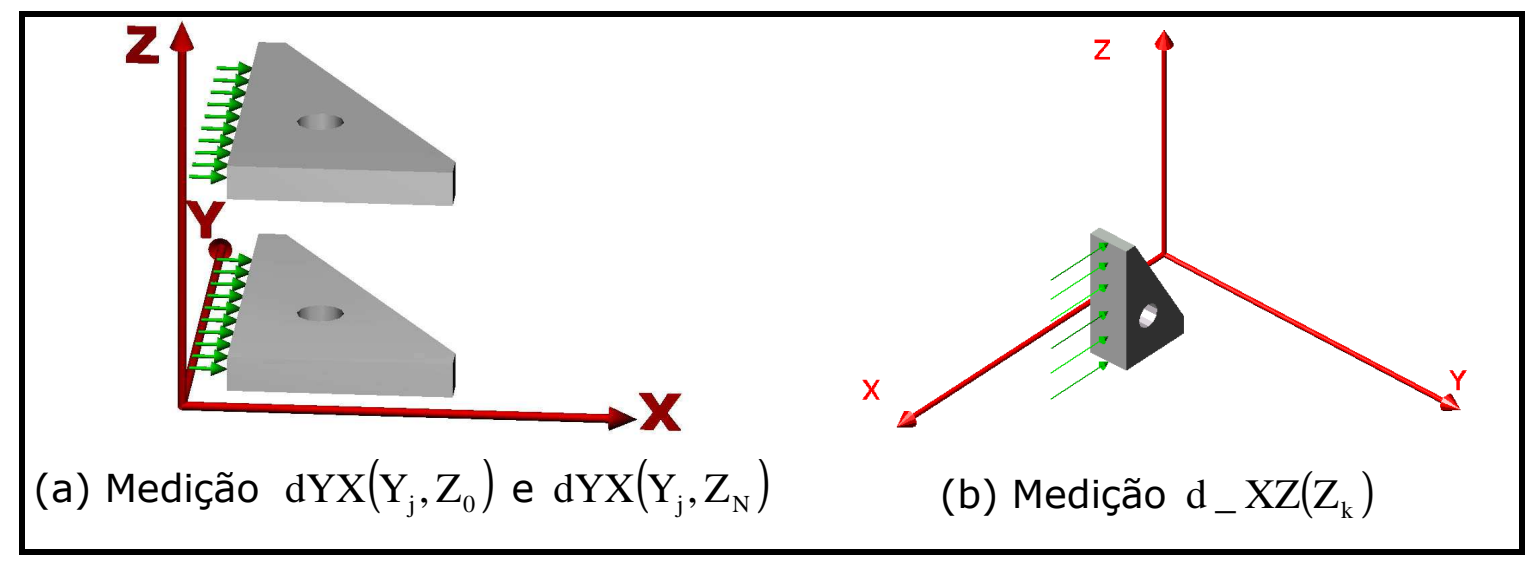

Figura 5.13: Posicionamento do esquadro para medição dos erros na direção X 
Para a medição dos erros $d_{-} X Z\left(Z_{k}\right)$, o esquadro foi colocado em um plano $X Z$ com a face menor alinhada com o eixo $X$, e medições foram efetuadas para diferentes valores de Z, Figura 5.13(b).

\section{MEDIÇÃo DOS ERROS NA DIREÇÃo Z}

O agrupamento de erros, na direção $Z$, que ocorrem devido a movimentos nas direções $Y$ e $X$, não contém nenhum erro de ortogonalidade. Portanto, para medição desses erros, não foi necessário o alinhamento de uma das faces do esquadro com o eixo $Z$.

Os erros d_ZX $\left(\mathrm{X}_{\mathrm{i}}\right)$ foram medidos utilizando-se a face maior do esquadro paralela ao eixo X e movimentação em X, Figura 5.14(a).

Para a medição dos erros $\mathrm{dZY}\left(\mathrm{X}_{0} \mathrm{Y}_{\mathrm{j}}\right)$ e $\mathrm{dZY}\left(\mathrm{X}_{\mathrm{M}} \mathrm{Y}_{\mathrm{j}}\right)$ a face maior do esquadro estava paralela ao eixo $Y$ e a movimentação foi nesta direção, Figura 5.14(b). Os deslocamentos, na direção $Z$, que ocorrem devido ao movimento na direção $\mathrm{Y}, \mathrm{d}_{-} \mathrm{ZY}\left(\mathrm{X}_{\mathrm{i}}, \mathrm{Y}_{\mathrm{j}}\right)$, foram determinados a partir das medições dos $\mathrm{dZY}\left(\mathrm{X}_{0} \mathrm{Y}_{\mathrm{j}}\right)$ e $\mathrm{dZY}\left(\mathrm{X}_{\mathrm{M}} \mathrm{Y}_{\mathrm{j}}\right)$, que são respectivamente, os erros medidos com o esquadro posicionado na direção $X$ em $X_{0}$ (braço em $X$ mínimo) e $\mathrm{X}_{\mathrm{M}}$ (braço em $\mathrm{X}$ máximo).

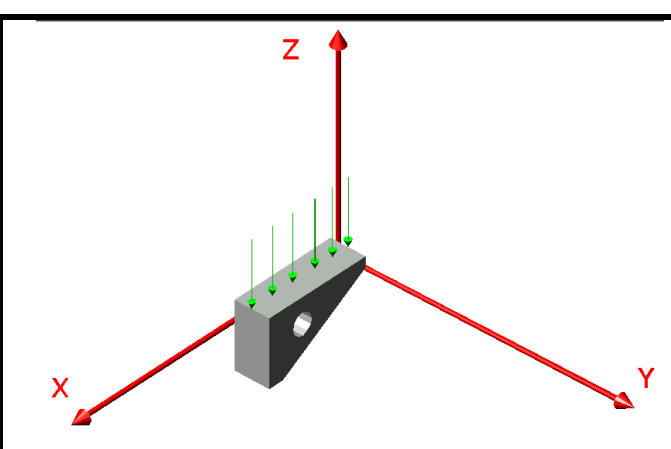

(a) Medição d_ZX $\left(X_{i}\right)$

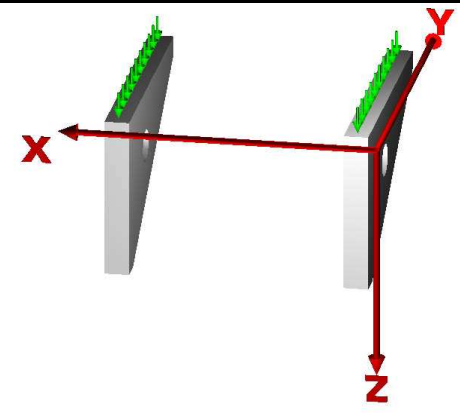

(b) Medição $d Z Y\left(X_{0}, Y_{j}\right)$ e $d Z Y\left(X_{M}, Y_{j}\right)$

Figura 5.14: Posicionamento do esquadro para medição dos erros na direção $Z$ 


\subsection{Compensação dos erros}

Os programas computacionais que são utilizados pelas MM3Cs não podem ser modificados pelo usuário, e para implementação da compensação é necessário que os pontos coordenados sejam adquiridos antes do processamento no microprocessador dedicado. Por isso, foi preparado um sistema com uma interface eletrônica e computacional cujo esquema pode ser visto na Figura 5.15. Nessa figura pode-se observar a MM3C, sua Unidade Central de Processamento (CPU) e as ligações que foram necessárias para a aquisição dos valores das réguas e do apalpador de medição.

O abandono completo do sistema dedicado não foi possível, uma vez que toda a eletrônica e potência utilizada nas réguas óticas ficam nele alojado.

O sistema implementado tem como função capturar, através de uma saída A quad B, e enviar para um microcomputador, o sinal das três escalas da MM3C, antes que este sofra qualquer influência da CPU da MM3C. O microcomputador que recebe o sinal tem uma placa de aquisição, que será detalhada no item 5.3.1, confeccionada exclusivamente para este fim.

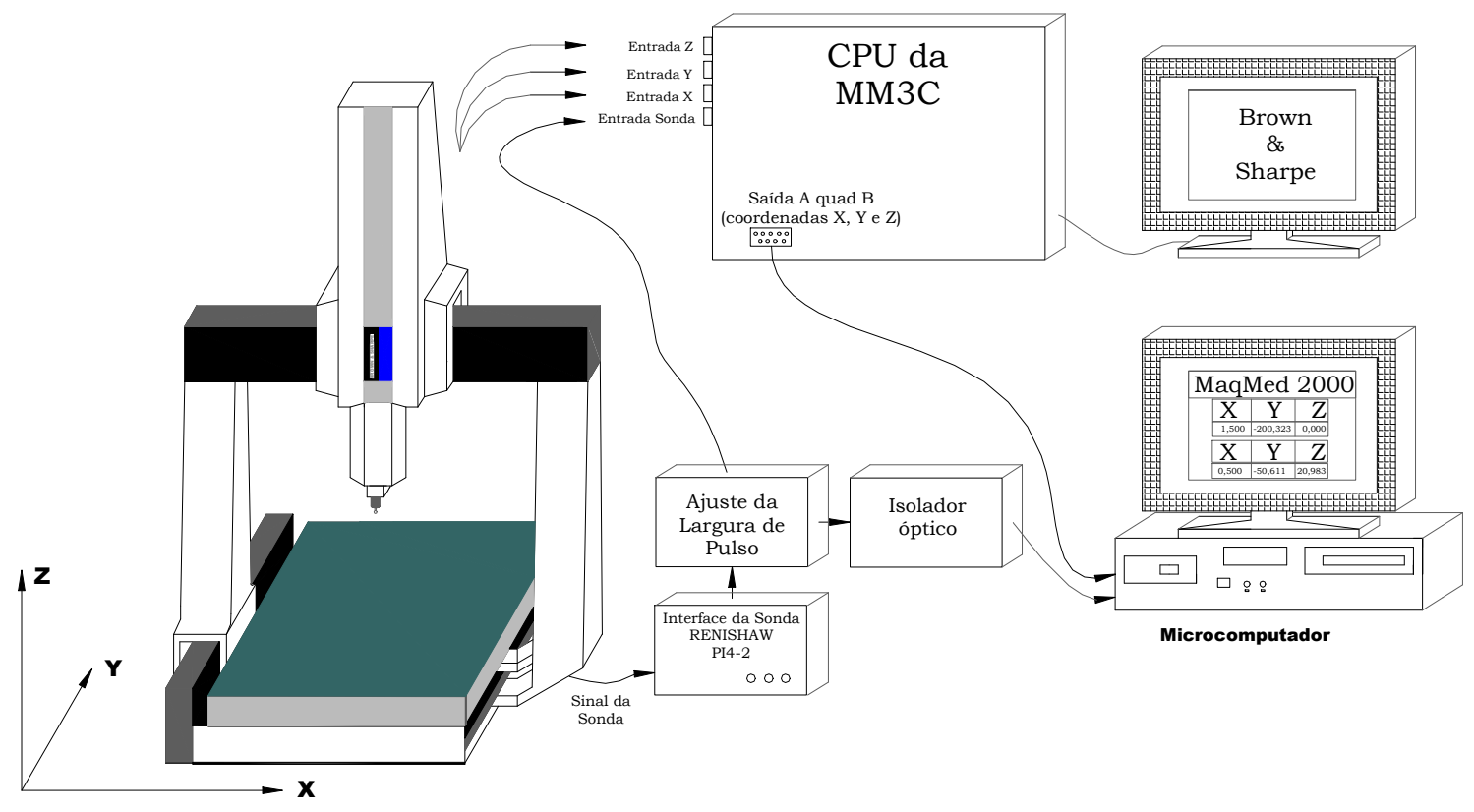

Figura 5.15: Descrição do sistema 
Ainda na Figura 5.15, podem-se ver dois cabos entrando no microcomputador, um possui os sinais A quad B das réguas óticas e o outro, o sinal de trigger do apalpador de medição.

Os sinais, tipo $A$ quad $B$, das réguas óticas são enviados para a CPU da MM3C, e são $A_{x}$ e $B_{x}, A_{y}$ e $B_{y}$ e $A_{z}$ e $B_{z}$ referentes as coordenadas $X, Y$ e $Z$ respectivamente. Cada eixo envia dois sinais em quadratura ( $A$ quad $B$ ) para a placa, a qual deve realizar a contagem e repassar estes dados para 0 computador que hospeda esta placa.

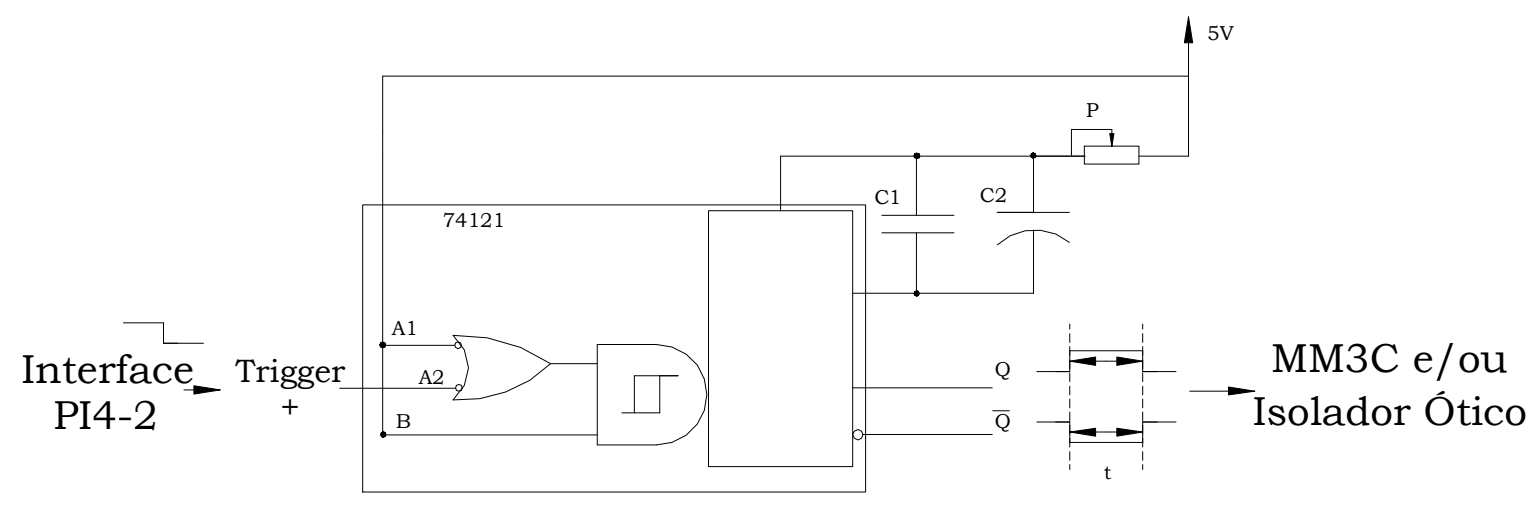

Figura 5.16: Diagrama esquemático do gerador de largura de pulso

O microcomputador equipado com a placa de aquisição, e o programa computacional MaqMed 2000 recebe os sinais A quad B. O sinal do apalpador de medição (sinal de trigger) passa por uma interface comercial da Renishaw, Probe Interface PI4-2, e é enviado para um controlador de largura de pulso (ver diagrama esquemático na Figura 5.16) que ajusta a largura de pulso t. Após testes experimentais feitos com auxílio de instrumentação adequada constatou-se que o valor $\mathbf{t}$ deveria ser igual a 70ms, para que houvesse o gatilhamento, na placa de aquisição. A foto do osciloscópio mostra os sinais e o atraso entre eles, Figura 5.17.

O sinal de trigger, depois de ajustado pelo controlador de largura de pulso, percorre dois caminhos: um que vai até a CPU da MM3C e outro vai para um isolador ótico e para o microcomputador. O isolador ótico é utilizado para que haja uma proteção elétrica entre a MM3C e a placa, pode visualizar o diagrama esquemático do isolador ótico na Figura 5.18. 
Com os sinais $\mathrm{X}, \mathrm{Y}$ e $\mathrm{Z}$ das réguas óticas e o sinal de trigger do apalpador de medição disponíveis no microcomputador, pode-se fazer qualquer tipo de manipulação numérica ou computacional.

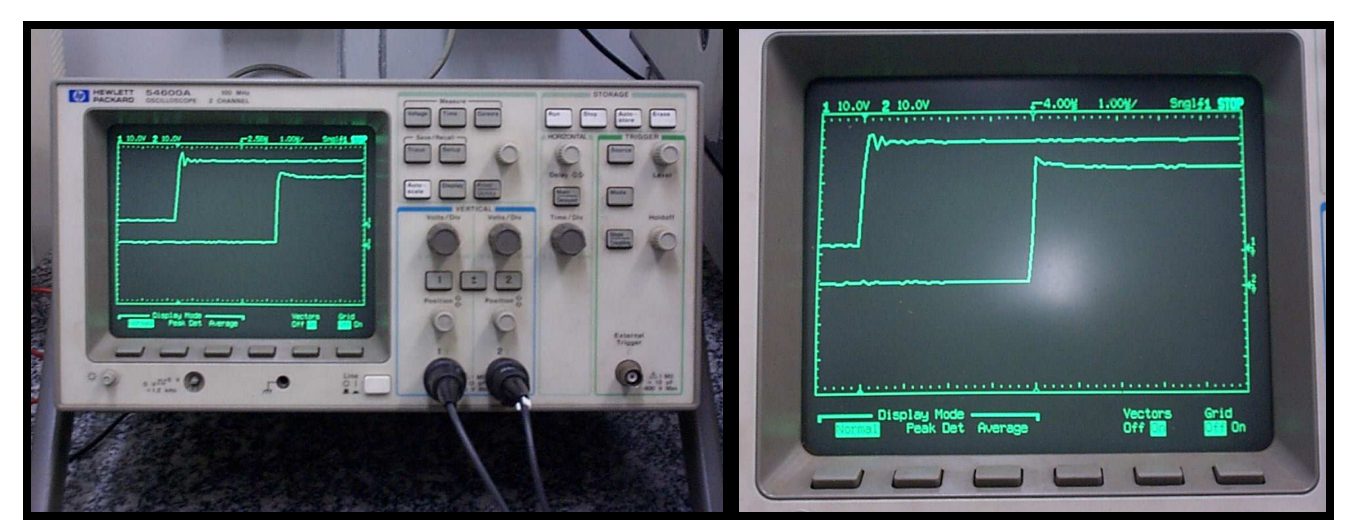

Figura 5.17: Medição da largura de pulso do trigger

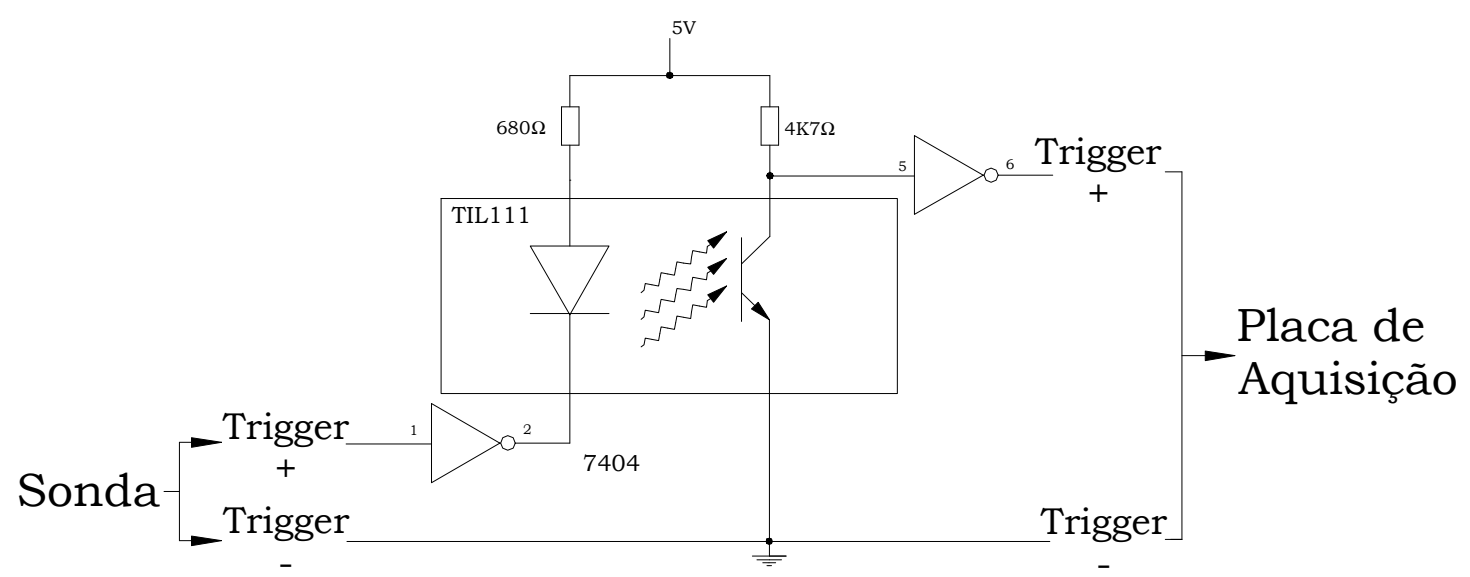

Figura 5.18: Diagrama esquemático do isolador ótico

\subsubsection{Placa de AQUisição}

A placa de aquisição que recebe os sinais da régua ótica é composta por dois dispositivos principais, um CPLD (Dispositivo Programável para Lógica Complexa) da marca Altera tipo EPF7128, e um microcontrolador PIC 16C64 (ENCINAS e MOREIRA, 1999). Tal placa foi confeccionada pela T\&S Equipamentos Eletrônicos, projetada para a leitura dos sinais em quadratura das escalas dos três eixos da MM3C. Esta placa é conectada ao barramento ISA de um microcomputador, responsável pelo controle do sistema e visualização da leitura, através de um programa desenvolvido em 
Borland Delphi ${ }^{T M}$ versão 6.0. Uma foto da placa utilizada pode ser vista na Figura 5.19.

A placa foi projetada para a medição em eixos de comprimento máximo de $1 \mathrm{~m}$ nesta resolução (19 bits). O comprimento do maior eixo da MM3C, que é o $Y$, é de $406 \mathrm{~mm}$, com uma resolução de $2 \mu \mathrm{m}$, portanto é suficiente realizar a medição de cada um dos 3 eixos desta máquina. Como já foi dito, cada eixo envia dois sinais em quadratura ( $A$ quad B) para a placa, a qual deve realizar a contagem e repassar estes dados para o computador que hospeda esta placa.

Para uma velocidade máxima de deslocamento em um eixo desta máquina o período do sinal de quadratura não deve ser inferior a $40 \mu \mathrm{s}$, o que significa uma frequência máxima de contagem de $25 \mathrm{KHz}$, capacidade suportada pela placa. Além disto, a placa é dotada de um buffer FIFO (First Input First Output) de 20 posições para não haver nenhuma perda de contagem na velocidade máxima.

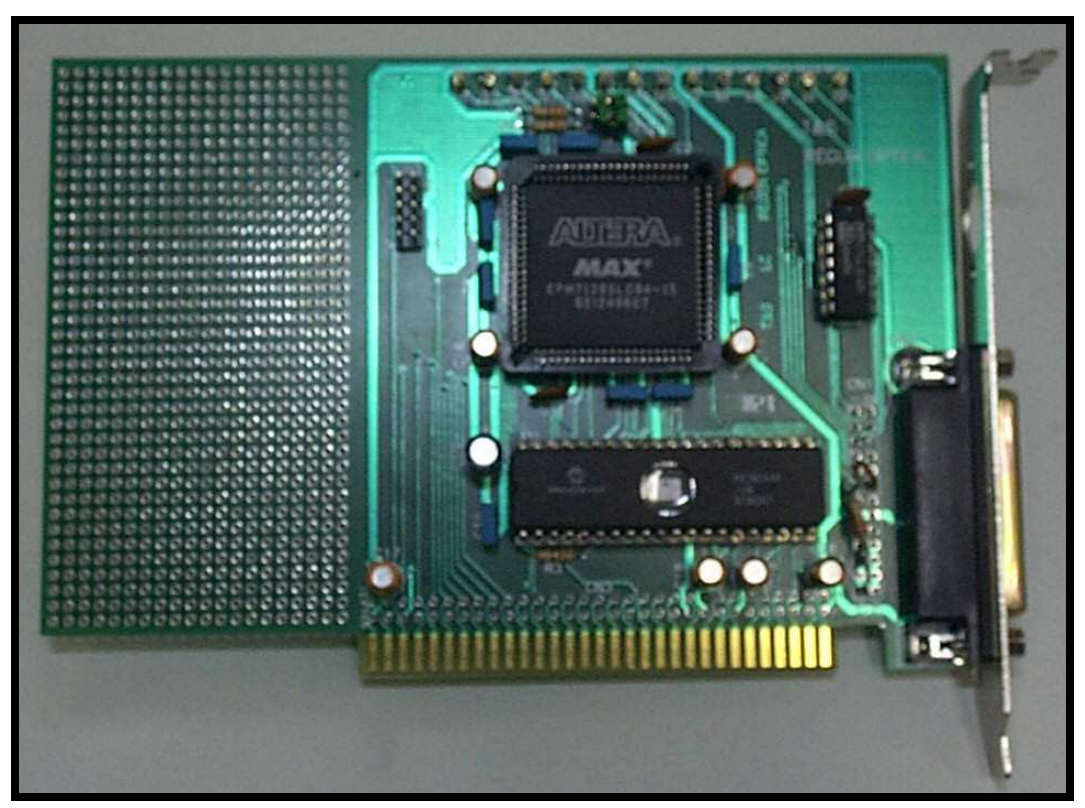

Figura 5.19: Foto da placa de aquisição

O microcomputador que hospeda a placa deverá ler a posição dos três eixos, simultaneamente e em qualquer instante. Tal leitura deverá ser realizada com mínimo atraso, a partir do sinal de trigger externo que é gerado pelo apalpador de medição. 
A principal vantagem desta placa é o seu projeto otimizado especificamente para esta máquina e para o desenvolvimento dos programas computacionais, objetivos deste trabalho. Para tanto, o projeto da placa também envolve a especificação de bibliotecas de vínculo dinâmico (DLLs) com todas as funções necessárias para a implementação e programação dos algoritmos aqui desenvolvidos, testados e validados experimentalmente.

\section{ARQUiteTURA DA PLACA}

A Placa Contadora foi confeccionada de acordo com as funções previamente estabelecidas por nosso grupo de trabalho, e estas são as seguintes: uma função Quad Decoder para mostrar a direção e a velocidade do deslocamento; um Contador Up-Down para localizar a posição medida; um Supervisor de Trigger Externo para congelar e armazenar a posição quando acontecer o gatilhamento do apalpador de medição; um armazenador de posição e um dispositivo para calcular a velocidade de deslocamento. Assim sendo, foi utilizada a arquitetura da Figura 5.20 para execução destas tarefas. Três destes circuitos foram utilizados, um para cada eixo.

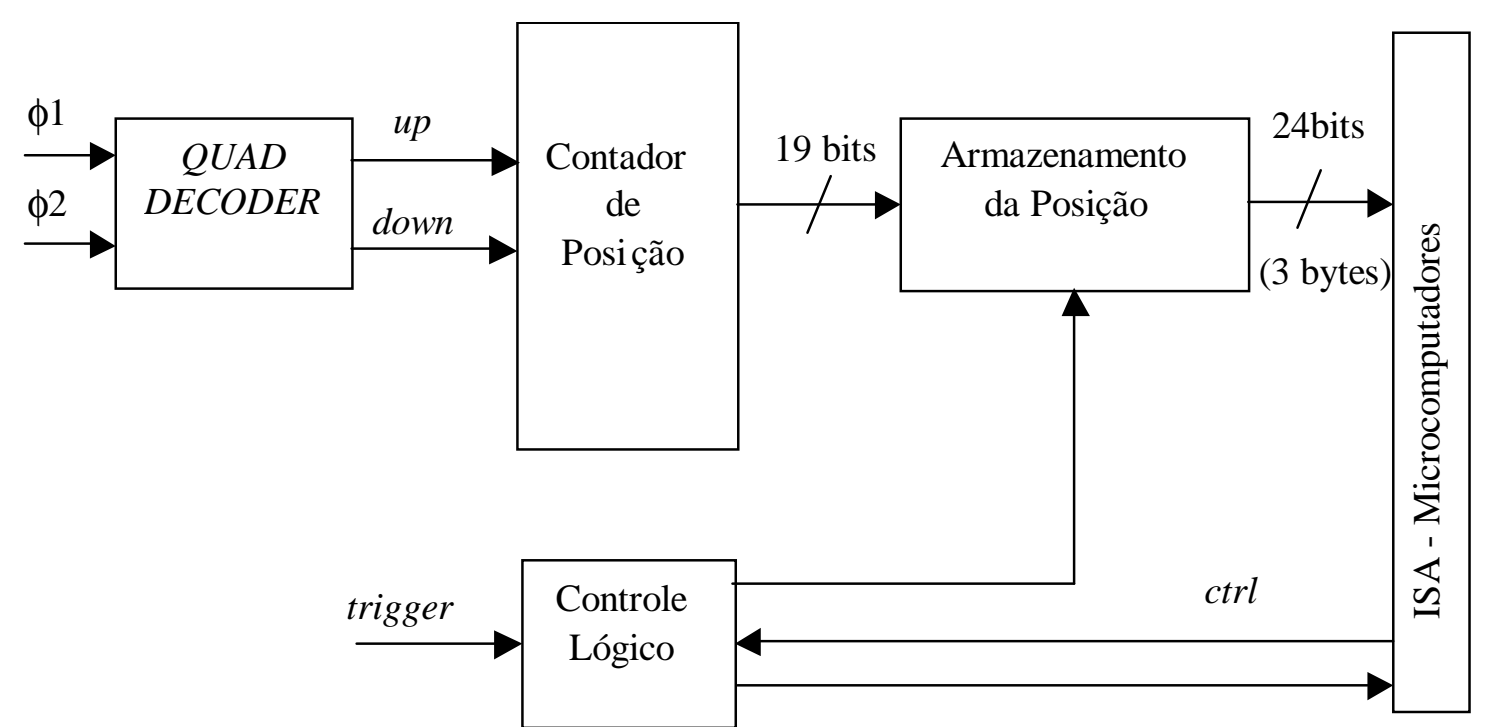

Figura 5.20: Arquitetura do hardware 
Um contador em um típico CPLD usa um ou dois blocos lógicos por bit. Como existem três contadores com 19 bit, são utilizados pelo menos 57 blocos lógicos para construir estes contadores, além disso, são necessários outros blocos lógicos para realizar outras tarefas. Para simplificar o projeto os blocos lógicos de um CPLD foram programados para implementar todos estes contadores e estas tarefas.

Toda a lógica do sistema pode ser dividida em três "processadores" organizados em diferentes níveis de hierarquia (Figura 5.21). O PreScaler faz o processamento a nível de bit (Quad Decoder) e modifica o tamanho do contador para um valor apropriado para que o microcontrolador o possa acompanhar. O contador, além da contagem, guarda a posição desta contagem em um Buffer FIFO. O microcontrolador controla toda a comunicação com o microcomputador e esse faz as tarefas de nível mais alto, tais como, a interface usuário-máquina, processamentos mais complexos e armazenamento permanente de dados.

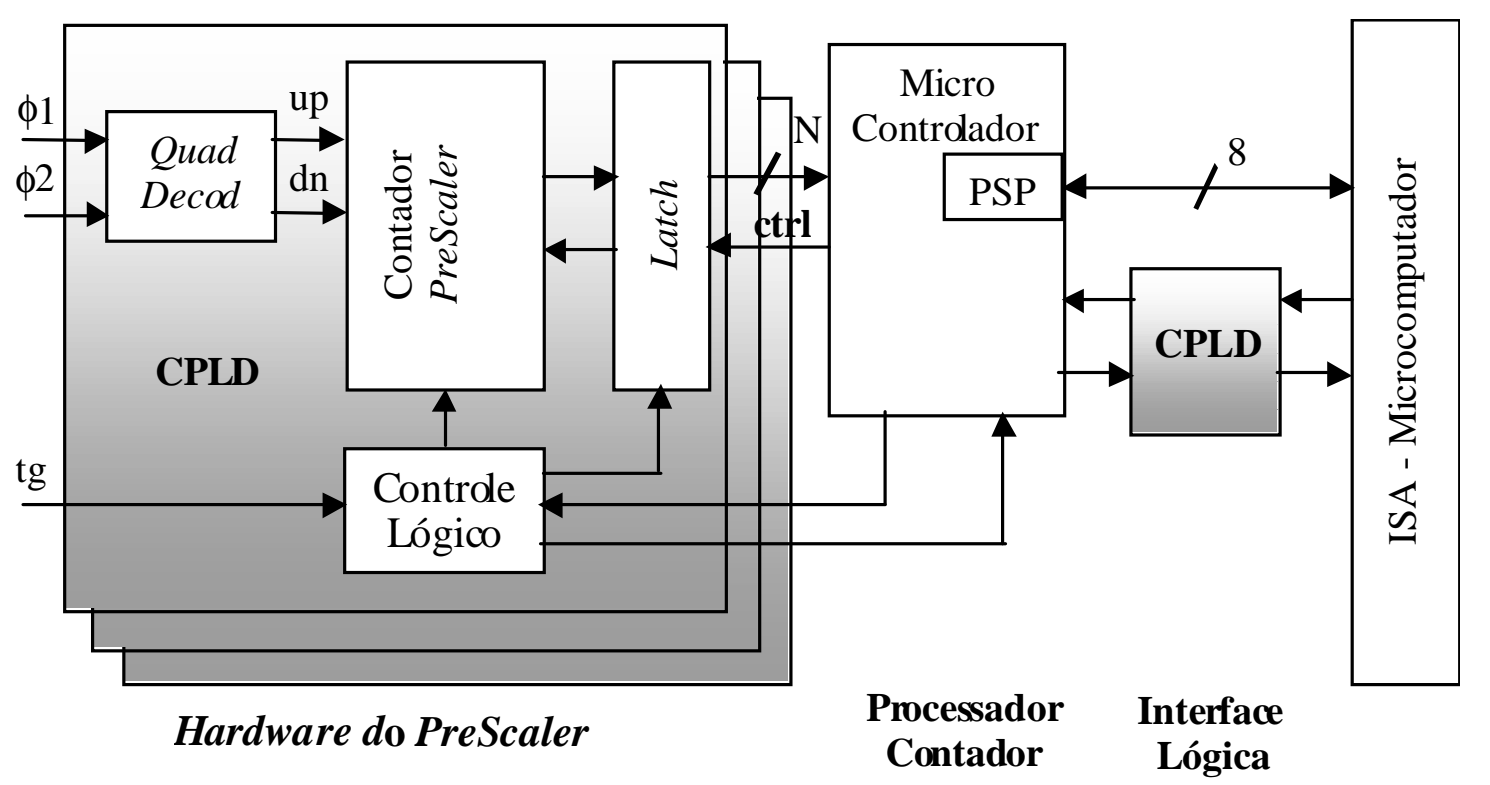

Figura 5.21: Hardware do PreScale com a arquitetura do software de contagem.

O PreScaler foi construído usando o CPLD Altera EPF7128, devido ao fato da implementação do PreScaler ser feita usando poucos bits.

A velocidade de Clock não é tão crucial para o CPLD, assim foi usado $16 \mathrm{MHz}$. 
Para o controle dos contadores foi utilizado um microcontrolador PIC 16C64 com frequência de Clock de 4MHz. Uma estimativa obtida através de simulação mostrou a necessidade de executar 3500 instruções entre duas leituras do PreScaler. Assim um PreScaler de 8 bits é suficiente, pois trabalha com um período de leitura de $=5,12 \mathrm{~ms}$, podendo assim executar 5120 instruções. A contagem é implementada usando uma palavra de 24 bits e enviado byte a byte para o microcomputador, usando Transmissão Paralela (Parallel Slave Port ou PSP).

O microcomputador recebe estas informações através do barramento de dados ISA, onde a placa é conectada. Neste computador está implementado o programa computacional MaqMed 2000. Tal programa tem acesso aos dados da forma mais conveniente, que é através de funções implementadas em uma DLL, tais funções estão descritas no Apêndice B.

O microcomputador controla o software contador e é responsável por alguns comandos, tais como: zerar o microcontrolador, limpar os contadores, tanto o de hardware como o de software, carregar os contadores dos três PreScaler, especificar um dos três contadores, ler o status do sistema, entre outros.

\subsubsection{O Programa computacional MaQMed 2000}

O MaqMed 2000 foi desenvolvido em ambiente DELPHI. A programação visual $D E L P H I$ é apropriada para a manipulação de dados e possui fácil implementação. Isso deve-se ao fato de existir uma biblioteca de componentes visuais (VCL) disponível, ou seja, o programador não precisa implementar rotinas para a construção de botões, janelas, gráficos e outros, para que o programa fique com visual agradável e de fácil utilização.

O programa MaqMed 2000 está gravado em uma mídia de CD anexado na contracapa, além do programa executável, o código fonte e várias imagens das telas do programa podem ser acessadas.

O aplicativo consiste de uma série de janelas e menus que convida o usuário a selecionar e desenvolver as tarefas de medição. As primeiras 
rotinas implementadas no programa podem ser visualizadas no fluxograma da Figura 5.22.

Após o inicio do aplicativo uma janela, Figura 5.23, com instruções conduz o usuário a escolher a origem do sistema de coordenadas que será utilizado como referência para os cálculos da compensação dos erros. Movimentando os carros da máquina o usuário define a posição no volume de trabalho, que deve ser necessariamente a seguinte: o carro $X$ na frente da máquina, o $\mathrm{Y}$ no extremo esquerdo e o braço $\mathrm{Z}$ totalmente recuado. Após colocar a máquina nessa posição informa ao programa, através da tecla ENTER, que a origem foi definida. Um sistema de coordenadas é colocado no extremo inferior do eixo Z, como mostra a Figura 5.24a.

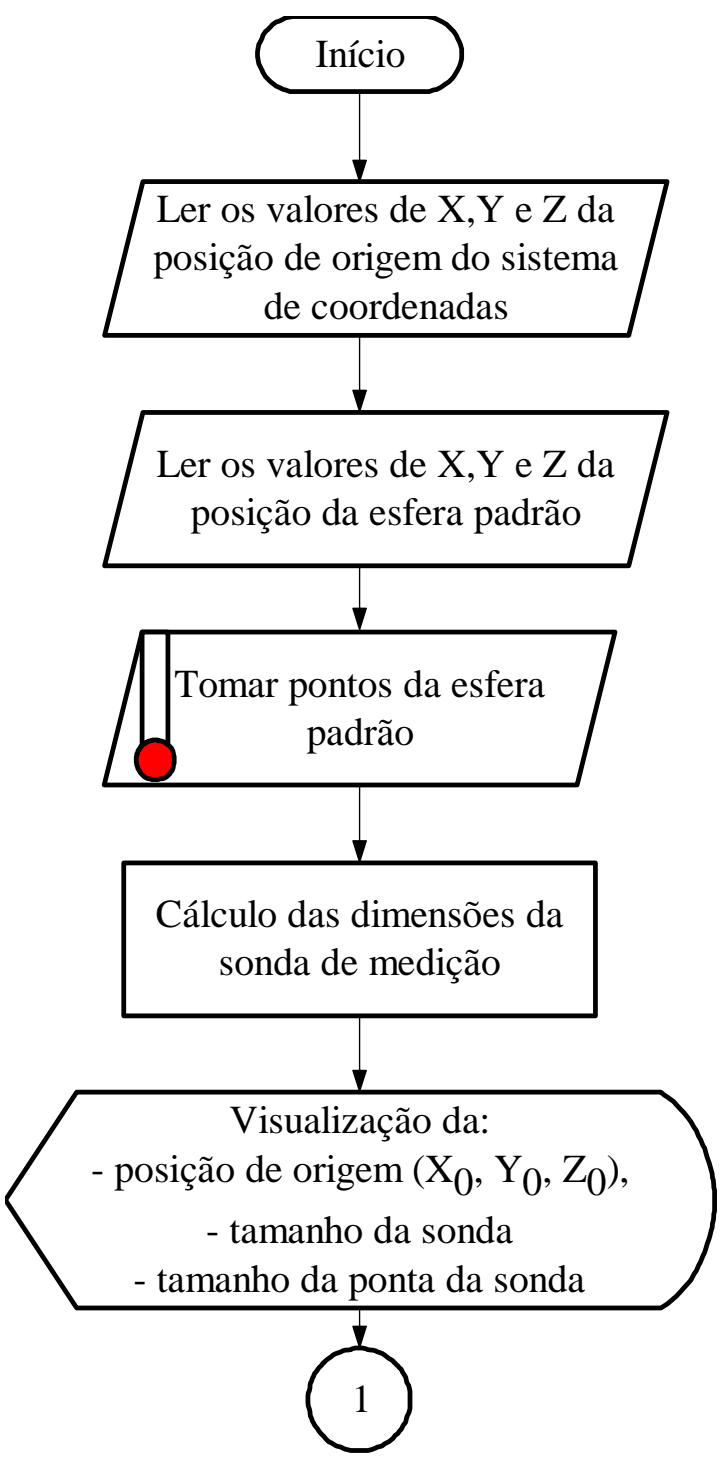

Figura 5.22: Fluxograma das primeiras rotinas 


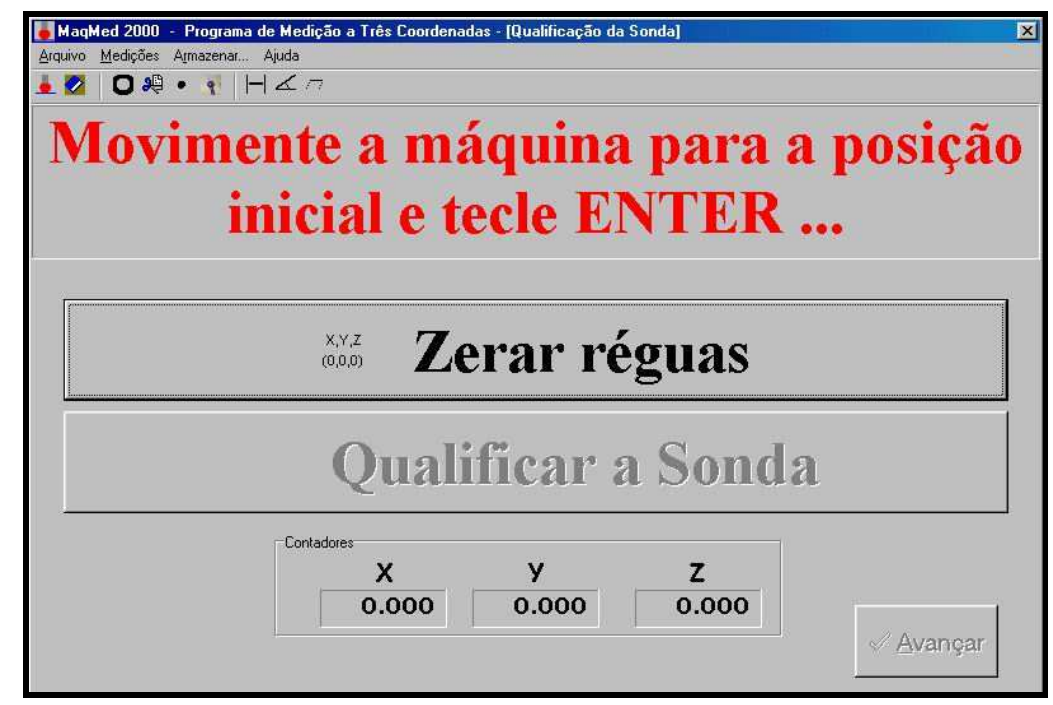

Figura 5.23: Tela inicial do MaqMed 2000

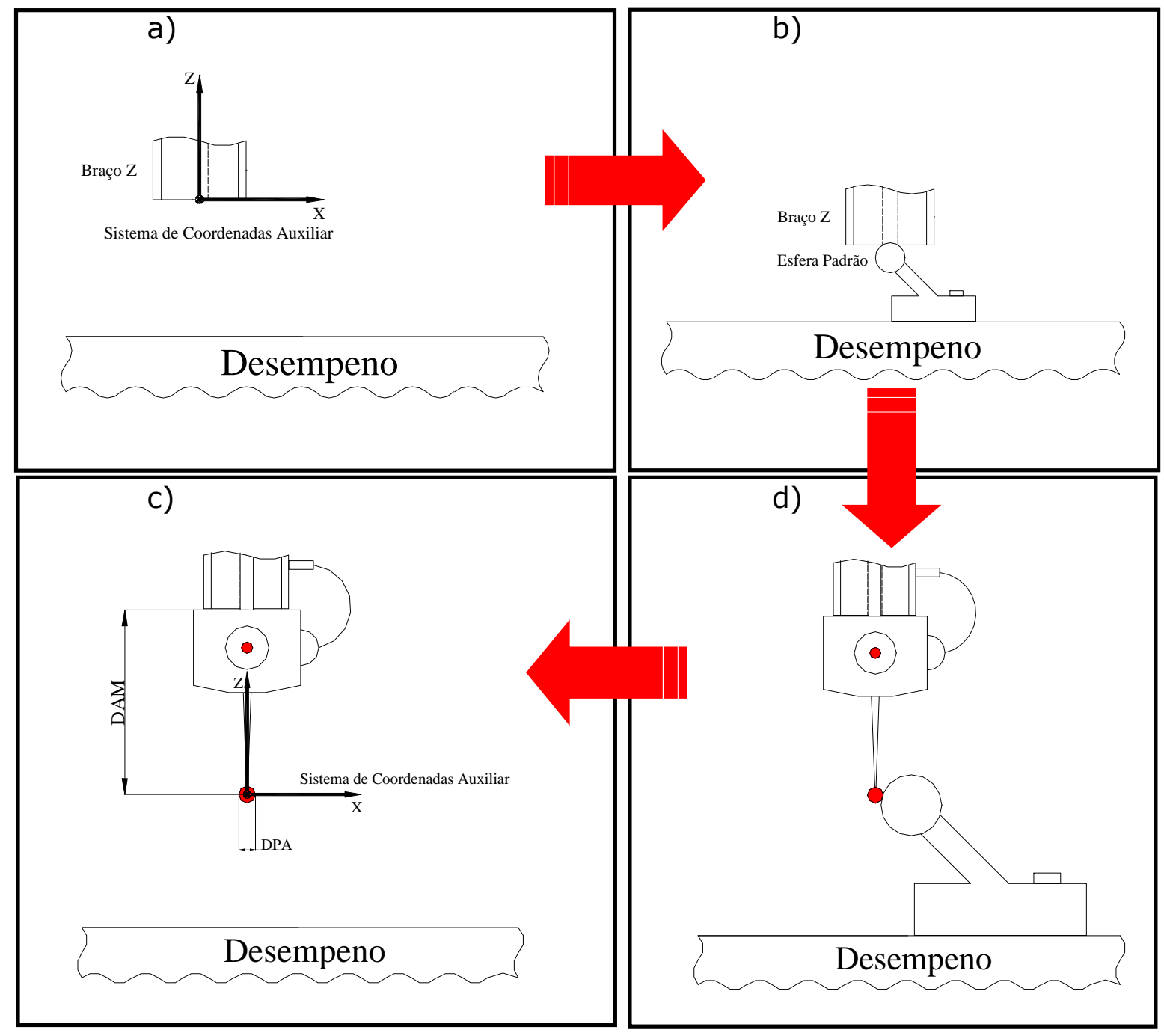

Figura 5.24: Procedimentos para qualificação do apalpador 
O passo seguinte é a qualificação do apalpador, ou seja, determinar a dimensão do apalpador de medição (DAM) e o diâmetro da esfera da ponta do apalpador (DPA). Isso é feito através de um procedimento que utiliza uma esfera padrão com dimensões conhecidas pelo programa computacional. Os procedimentos para qualificação do apalpador podem ser vistos na Figura 5.24: o usuário deve posicionar o extremo inferior do eixo Z sobre a esfera padrão, Figura 5.24b, e informar o programa, através da tecla ENTER, que foi definida a posição da esfera padrão.

O apalpador de medição deve ser inserido no braço $Z$ da máquina e, devem ser tomados no mínimo quatro pontos coordenados sobre a esfera padrão, Figura 5.24d. Através desses pontos foram calculados a DAM e o DPA, e o programa compensará esses valores das coordenadas medidas, ou seja, o sistema de coordenadas auxiliar será transferido para o centro da ponta do apalpador de medição, Figura 5.24c.

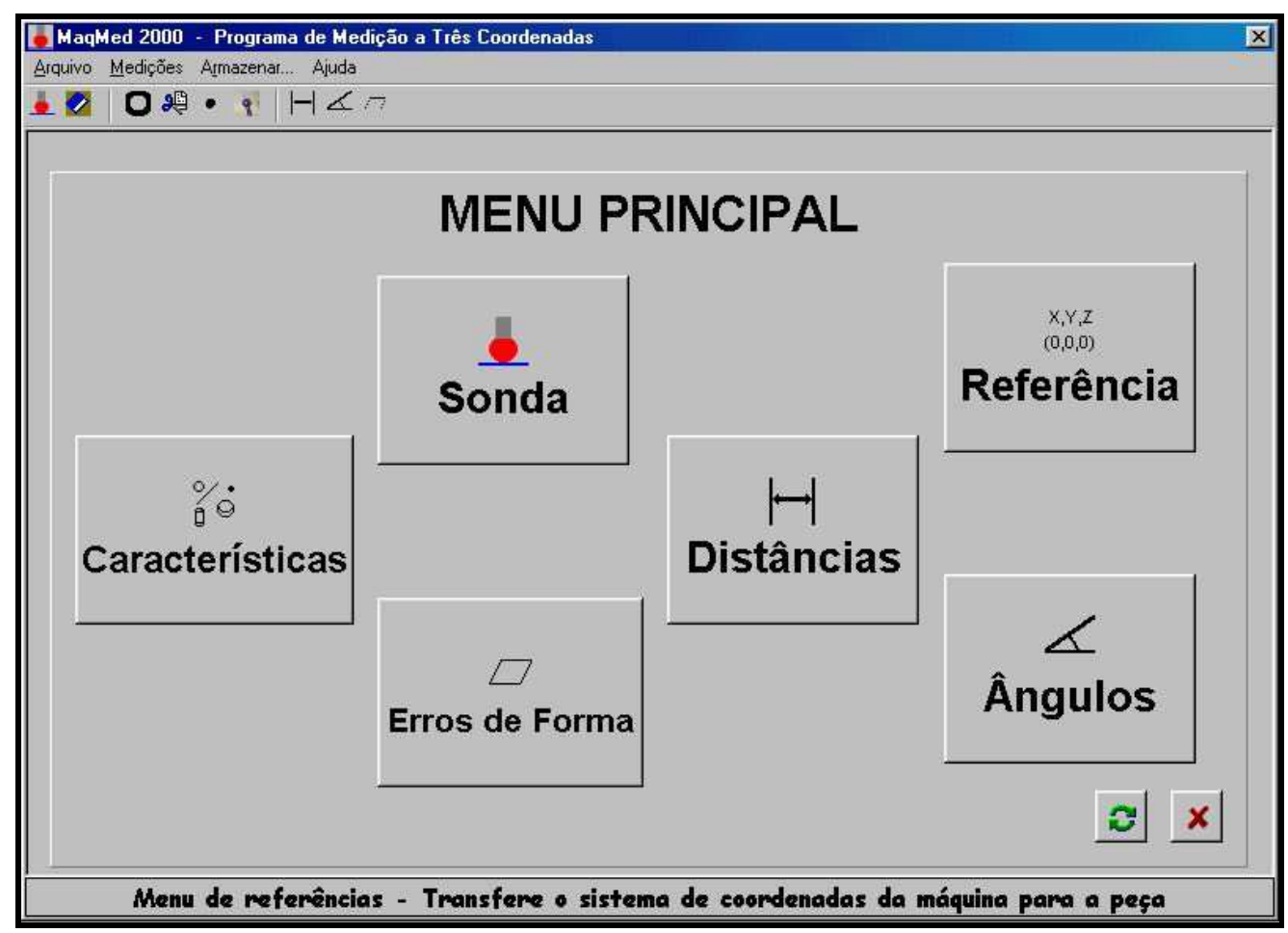

Figura 5.25: Tela do Menu Principal

Após a qualificação do apalpador pode ser iniciado o processo de medição de peças. O mensurando deve ser fixado sobre o desempenho da 
máquina e escolhe-se no menu principal o item "referência", Figura 5.25, este menu possui rotina para transferir o sistema de coordenadas da máquina para a peça, isto é feito para facilitar as medições. O diagrama de blocos da Figura 5.26 mostra a sequência de operações a serem efetuadas.

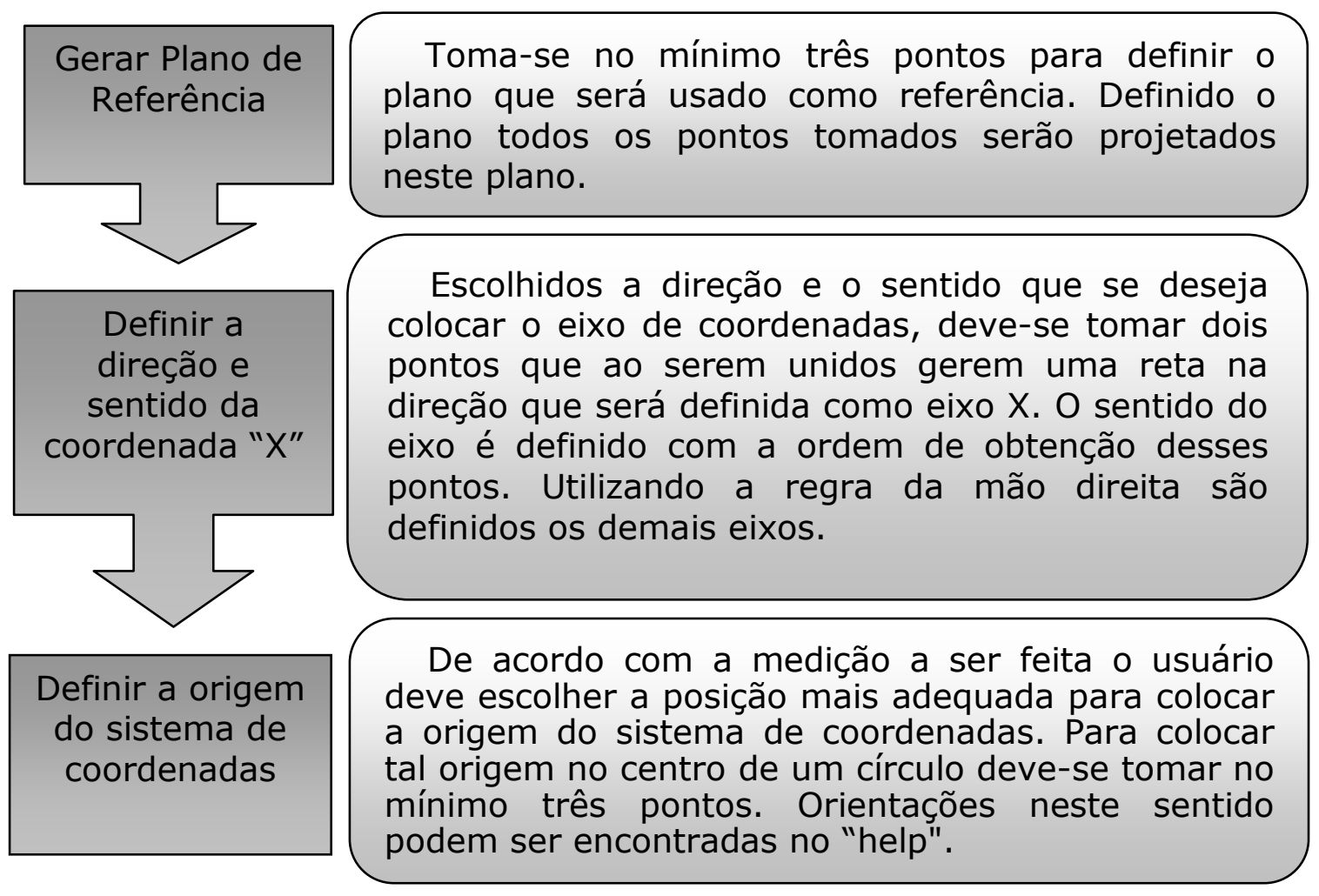

Figura 5.26: Diagrama de blocos da sequência de operações para o alinhamento

Gerada a "referência" deve-se escolher o tipo de medição a ser feita, Figura 5.27, a partir da escolha do usuário o programa executa um PROCEDIMENTO correspondente a essa opção. Tomam-se pontos no perfil da peça, utilizando o apalpador de medição, que deve ser, no mínimo, a quantidade necessária para a definição da geometria e então o programa apresenta uma tela de resultados contendo a característica desejada. $\mathrm{O}$ desvio padrão das medições, se o número de pontos for maior que o mínimo necessário para o cálculo da característica, e a incerteza associada a esta medição também são mostrados na tela de resultados.

Para a medição do diâmetro de um furo, por exemplo, deve-se escolher no menu "características" o modo círculo, Figura 5.28. Tomar pelo 
menos três pontos no perfil da peça, neste caso três pontos definirão o círculo. Caso sejam tomados mais pontos o programa ajusta um círculo, através do Método dos Mínimos Quadrados a esses pontos. Após efetuar os cálculos o aplicativo mostrará uma tela contendo o diâmetro calculado do furo, as coordenadas $X$ e $Y$ do centro em relação à origem do sistema de coordenada, o desvio padrão das medições, e o valor da incerteza associada à medição.

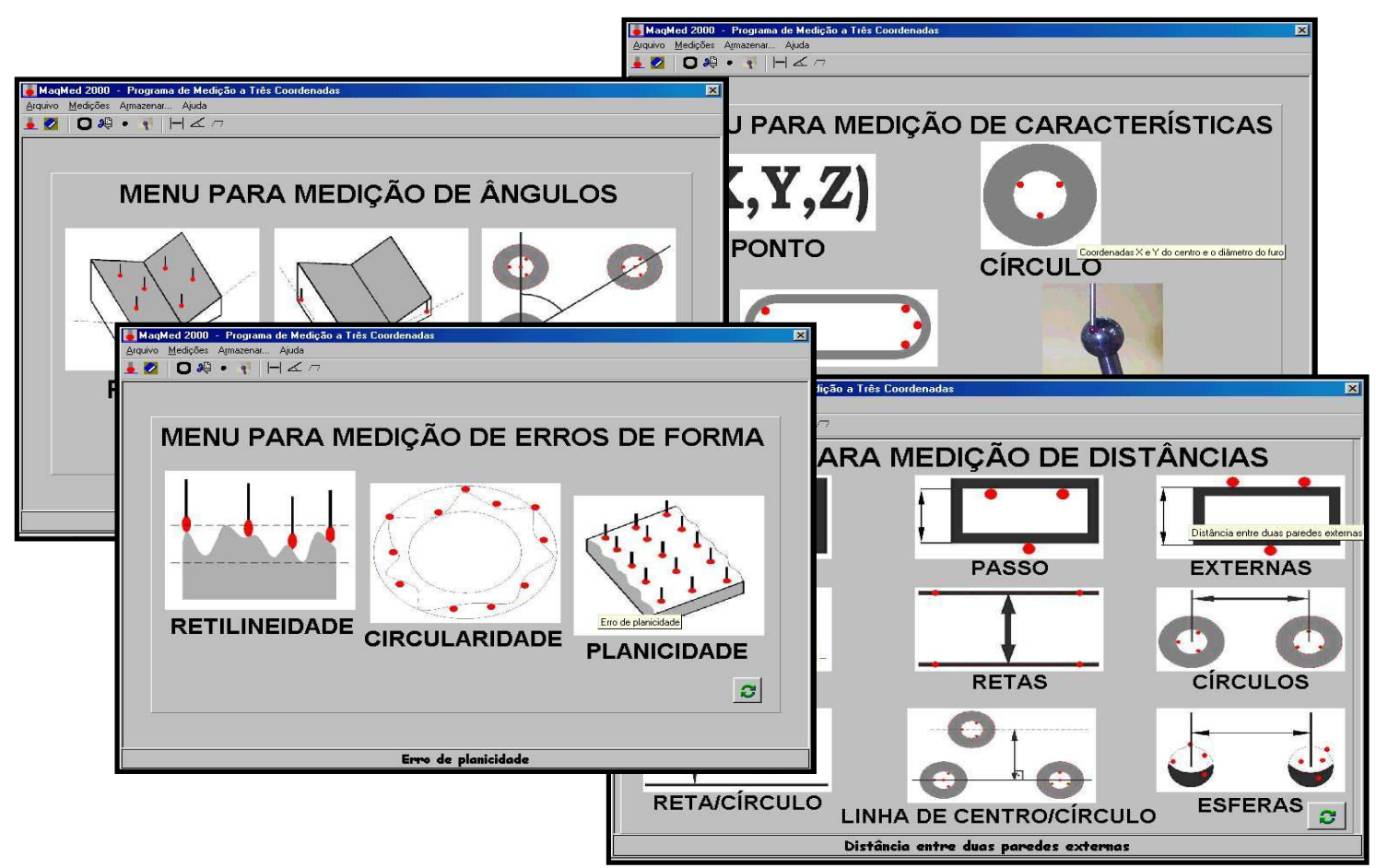

Figura 5.27: Telas para escolha da medição

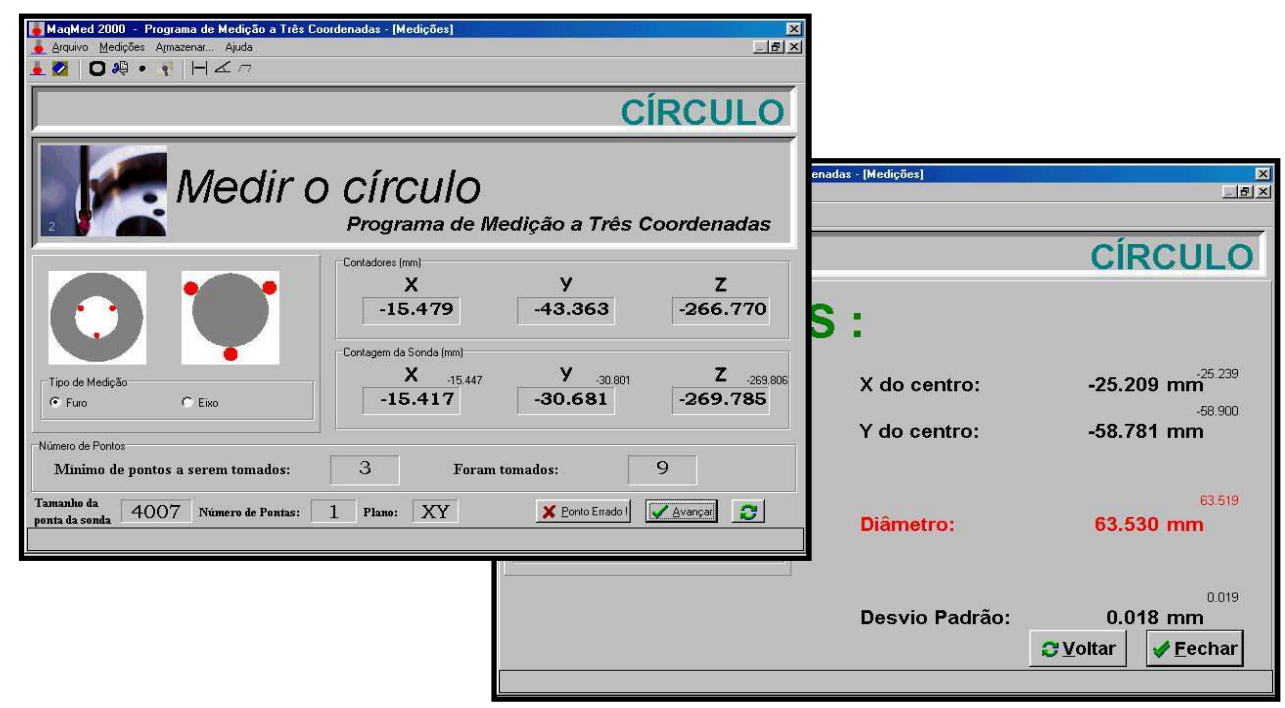

Figura 5.28: Tela para medição de um furo e tela de resultados 
A Figura 5.29 apresenta o fluxograma do MaqMed 2000, onde pode ser visualizado os passos computacionais para medição a três coordenadas, que são: a escolha da medição, a coleta dos pontos através do apalpador, a compensação das coordenadas, o ajuste dos pontos e a apresentação dos resultados.

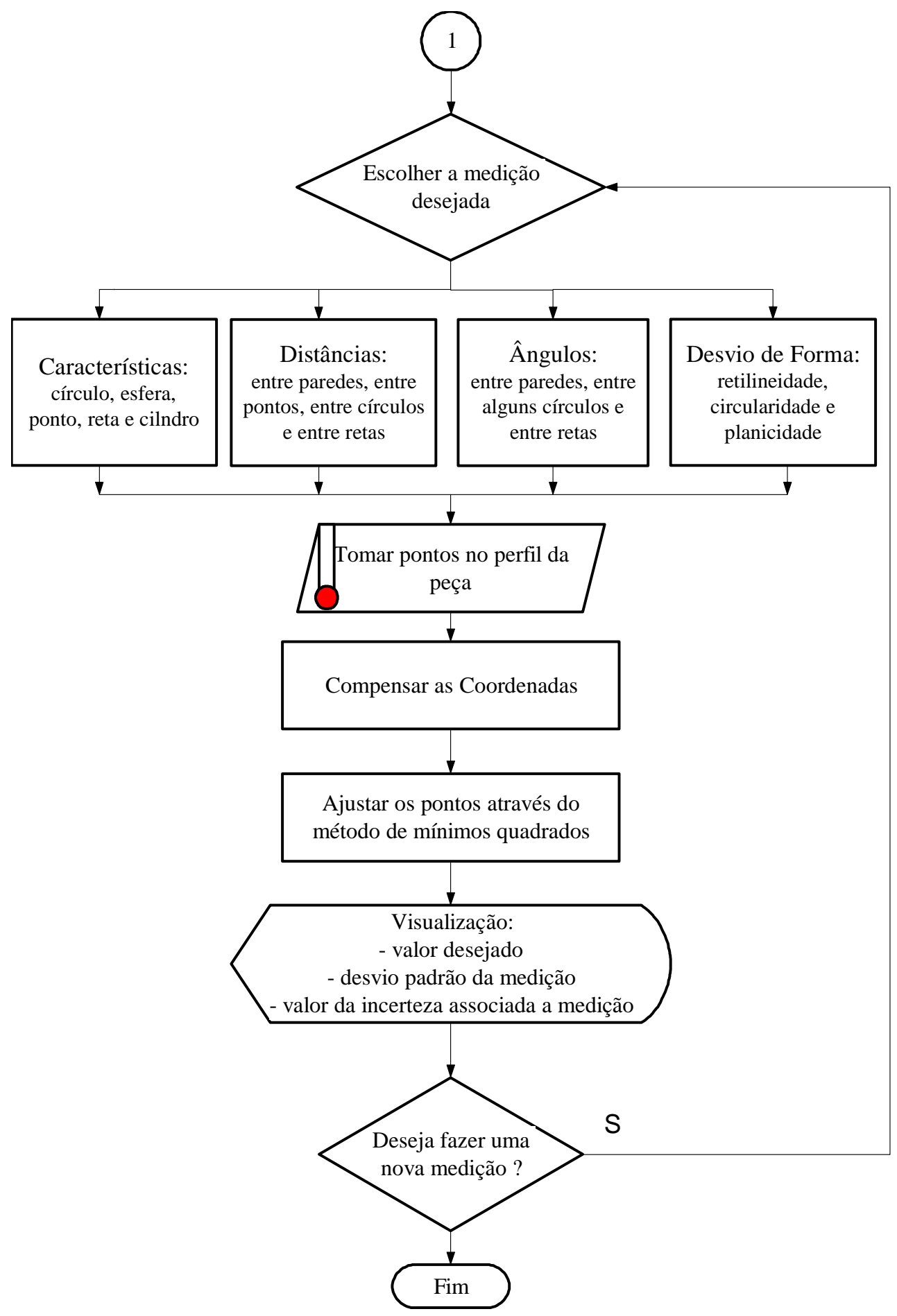

Figura 5.29: Fluxograma de medições 
No que diz respeito à compensação dos erros, quando o apalpador de medição toca um ponto sobre uma peça, este envia um sinal e as coordenadas do ponto são "congeladas" e armazenadas no programa MaqMed 2000. Antes de qualquer cálculo ser efetuado com os pontos, é feita a compensação dos erros deste ponto, utilizando-se as equações do MRSE. Tais equações são compostas de somas de erros, que foram quantificados através da calibração da MM3C.

A calibração da máquina foi feita através de medições da barra de furos e esquadro mecânico nas três direções do volume de trabalho da máquina. Os valores foram inseridos nas sub-rotinas de compensação do MaqMed 2000, permitindo compensar de forma direta todas as coordenadas do volume de trabalho da MM3C.

A eficiência do Sistema proposto, aplicado na MM3C do tipo Ponte Móvel, foi verificada através de um anel padrão medido em várias posições no volume de trabalho da máquina, os pontos coordenados foram tratados pelo MaqMed 2000 através de duas rotinas: uma com procedimentos de compensação dos erros e outra sem tais procedimentos. Os valores foram ajustados e os resultados foram comparados e analisados. Os resultados obtidos foram ainda comparados ao valor calibrado da peça padrão. Foi medida também a distância entre paredes de um bloco padrão.

\subsection{Estimativa das incertezas no cálculo das componentes do erro volumétrico}

A estimativa da incerteza de medição é parte obrigatória como forma de expressar a qualidade dos resultados obtidos nos testes experimentais.

Para facilitar a apresentação da metodologia utilizada para a estimativa das incertezas de medição, foram construídas tabelas contendo os cálculos que foram realizados.

Inicialmente serão apresentadas as equações para o cálculo das componentes $\mathrm{X}, \mathrm{Y}$ e $\mathrm{Z}$ do erro volumétrico além das expressões resultantes 
da aplicação da Lei de Propagação de Incertezas. Entretanto, em todas as expressões observa-se a presença de grandezas que por sua vez são calculadas a partir de medições realizadas com a utilização de artefatos padrões: a barra de furos e o esquadro mecânico. Assim, em seguida são apresentadas as equações para o cálculo dessas grandezas.

$\mathrm{Na}$ grande maioria das medições dimensionais realizadas os valores das grandezas são influenciados por fatores do ambiente, tais como temperatura, umidade, e do próprio instrumento como, por exemplo, a sua resolução. A influência desses fatores, muitas vezes, não necessariamente precisam ser corrigidas, devido à ordem de grandeza requerida. Entretanto, contribuem para a incerteza das medições.

\subsubsection{Estimativa da INCERTEZA NA DETERMinAÇÃo dAS COMPONENTES $X, Y$ E Z DO ERRO VOLUMÉTRICO}

A equação matemática que descreve a componente $Y$ do erro Volumétrico é apresentada na equação (5.16):

$$
\begin{gathered}
E_{Y}\left(X_{i}, Y_{j}, Z_{k}\right)=E_{Y}\left(X_{0}, Y_{j}, Z_{0}\right)+d_{-} \operatorname{yaw} Y\left(X_{i}, Y_{j}\right)+d_{-} \operatorname{pitch} Y\left(Y_{j}, Z_{k}\right)+ \\
d_{-} Y Z\left(Z_{k}\right)+d_{-} X Y\left(X_{i}, Z_{k}\right)
\end{gathered}
$$

onde:

$E_{Y}\left(X_{0}, Y_{j}, Z_{0}\right)$ : erro de escala medido utilizando a barra de furos;

d_yawY $\left(X_{i}, Y_{j}\right)$ : erro calculado através de medições utilizando a barra de furos;

d_pitchY $\left(Y_{j}, Z_{k}\right)$ : erro calculado através de medições utilizando a barra de furos;

d_YZ( $\left.Z_{k}\right)$ : erro calculado através de medições utilizando o esquadro e o apalpador LVDT;

d_XY $\left(X_{i}, Z_{k}\right)$ : erro calculado através de medições utilizando o esquadro e o apalpador LVDT.

Aplicando a lei da propagação das incertezas na equação (5.16) tem-se a equação (5.17), que é a expressão utilizada para a estimativa da incerteza da componente $\mathrm{Y}$ do erro volumétrico. 


$$
\begin{aligned}
& u_{c}^{2}\left(E_{Y}\left(X_{i}, Y_{j}, Z_{K}\right)\right)=\left(\frac{\partial E_{Y}\left(X_{i}, Y_{j}, Z_{K}\right)}{\partial E_{Y}\left(X_{0}, Y_{j}, Z_{0}\right)}\right)^{2} u_{E^{\prime}\left(X_{0}, Y_{j}, Z_{0}\right)}^{2}+\left(\frac{\partial E_{Y}\left(X_{i}, Y_{j}, Z_{K}\right)}{\partial d_{-} y a w Y\left(X_{i} Y_{j}\right)}\right)^{2} u_{d_{-} y a w Y\left(X_{i} Y_{j}\right)}^{2}+ \\
& +\left(\frac{\partial E_{Y}\left(X_{i}, Y_{j}, Z_{K}\right)}{\partial d_{-} \operatorname{pitch} Y\left(Y_{j}, Z_{k}\right)}\right)^{2} u_{d_{-} \operatorname{pitchY} Y\left(Y_{j}, Z_{k}\right)}^{2}+\left(\frac{\partial E_{Y}\left(X_{i}, Y_{j}, Z_{K}\right)}{\partial d_{-} Y Z\left(Z_{k}\right)}\right)^{2} u_{d_{-} Y Z\left(Z_{k}\right)}^{2}+\left(\frac{\partial E_{Y}\left(X_{i}, Y_{j}, Z_{K}\right)}{\partial d_{-} X Y\left(X_{i}, Z_{k}\right)}\right)^{2} u_{d_{-} X Y\left(X_{i}, Z_{k}\right)}^{2}
\end{aligned}
$$

A estimativa da incerteza para a determinação da componente $X$ e $Z$ do erro volumétrico foi calculada de forma análoga.

\subsubsection{ESTIMATIVA DA INCERTEZA NA MEDIÇÃO DAS DISTÂNCIAS ENTRE OS FUROS DA BARRA NA MM3C}

A equação matemática que descreve a grandeza medida, no caso, a distância entre furos utilizando a MM3C é apresentada na equação (5.18).

$$
d=L_{m m 3 C}+L_{o_{B}} \alpha_{B}\left(t_{B}-20\right)-L_{0_{B}} \alpha_{\text {Régua }}\left(t_{\text {Régua }}-20\right)+R,
$$

onde

$d$ : distância entre os centros de furos;

$L_{\text {MM3C: }}$ medida da distância entre os centros de furos em uma MM3C;

$R$ : resolução da $\mathrm{MM} 3 \mathrm{C}$;

$L o_{B}$ : comprimento nominal entre os centros dos furos;

$\alpha_{B}$ : coeficiente de dilatação térmica do aço;

$t_{B}$ : temperatura da barra de furos;

$\alpha_{\text {régua }}:$ coeficiente de dilatação térmica do vidro;

$t_{\text {régua: }}$ temperatura da régua.

Aplicando a lei da propagação das incertezas na equação (5.18) tem-se:

$$
\begin{aligned}
u_{c}^{2}(d)= & \left(\frac{\partial d}{\partial L_{M M 3 C}}\right)^{2}\left(u_{L_{\text {MM } 3 C}}\right)^{2}+\left(\frac{\partial d}{\partial L_{o_{B}}}\right)^{2}\left(u_{L_{o_{B}}}\right)^{2}+\left(\frac{\partial d}{\partial \alpha_{B}}\right)^{2}\left(u_{\alpha_{B}}\right)^{2}+\left(\frac{\partial d}{\partial t_{B}}\right)^{2}\left(u_{t_{B}}\right)^{2}+ \\
& \left(\frac{\partial d}{\partial \alpha_{\text {Régua }}}\right)^{2}\left(u_{\alpha_{\text {Régua }}}\right)^{2}+\left(\frac{\partial d}{\partial t_{\text {régua }}}\right)^{2}\left(u_{\text {régua }}\right)^{2}+\left(\frac{\partial d}{\partial R}\right)^{2}\left(u_{R}\right)^{2}
\end{aligned}
$$


A partir das equações 5.18. e 5.19. tem-se a Tabela 5.2.

Tabela 5.2: Parâmetros para determinação da incerteza de medição das distâncias entre os centros dos furos

\begin{tabular}{|c|c|c|c|c|c|c|}
\hline $\begin{array}{l}\text { Notação da } \\
\text { Incerteza } \\
\text { padronizada }\end{array}$ & $\begin{array}{l}\text { Coeficiente de } \\
\text { sensibilidade }\end{array}$ & $\begin{array}{l}\text { Tipo } \\
\text { de } \\
\text { aval. }\end{array}$ & $\begin{array}{l}\text { Tam. da } \\
\text { Amostra }\end{array}$ & $\begin{array}{c}\text { Distr. de } \\
\text { probabilidade }\end{array}$ & $\begin{array}{l}\text { Grau de } \\
\text { liberdade }\end{array}$ & $\begin{array}{l}\text { Coef. t- } \\
\text { Student } \\
(95 \%)\end{array}$ \\
\hline $\mathrm{u}_{\mathrm{L}_{\mathrm{MM} 3 \mathrm{C}}}$ & $\frac{\partial d}{\partial L_{M M 3 C}}=1$ & A & 5 & normal & 4 & 2,78 \\
\hline $\mathrm{u}_{\mathrm{L}_{\mathrm{o}_{\mathrm{B}}}}$ & $\frac{\partial d}{\partial L_{o_{B}}}=\alpha_{B}\left(t_{B}-20\right)$ & A & 5 & Normal & 4 & 2,78 \\
\hline $\mathrm{u}_{\alpha_{\mathrm{B}}}$ & $\frac{\partial d}{\partial \alpha_{B}}=L_{o_{B}}\left(t_{B}-20\right)$ & B & & retangular & $\infty$ & \\
\hline $\mathrm{u}_{\mathrm{t}_{\mathrm{B}}}$ & $\frac{\partial d}{\partial t_{B}}=L o_{B} \alpha_{B}$ & B & & retangular & $\infty$ & \\
\hline $\mathrm{u}_{\alpha_{\text {Régua }}}$ & $\frac{\partial d}{\partial \alpha_{\text {Régua }}}=L_{o_{\text {Régua }}}\left(t_{\text {Régua }}-20\right)$ & B & & retangular & $\infty$ & \\
\hline $\mathrm{u}_{\mathrm{t}_{\text {Régua }}}$ & $\frac{\partial d}{\partial t_{\text {régua }}}=L o_{\text {régua }} \alpha_{\text {régua }}$ & B & & retangular & $\infty$ & \\
\hline $\mathrm{u}_{\mathrm{R}}$ & $\frac{\partial d}{\partial R}=1$ & B & & triangular & $\infty$ & \\
\hline \multicolumn{7}{|c|}{ Graus de liberdade Efetivo de $d=\frac{\mathrm{u}^{4}(\mathrm{~d})}{\frac{\mathrm{u}_{\mathrm{L}_{\mathrm{MM} 3 \mathrm{C}}}^{4}}{4}}$} \\
\hline
\end{tabular}

\subsubsection{ESTIMATIVA DA INCERTEZA DE MEDIÇÃO DOS ERROS UTILIZANDO O ESQUADRO DE GRANITO E O LVDT}

A equação (5.20) descreve a grandeza medida, no caso, o erro medido utilizando o esquadro mecânico como padrão de referência. Esta equação contém a correção do desvio de ortogonalidade do esquadro e a resolução do apalpador eletrônico LVDT utilizado na medição do erro. Na equação (5.20), D são os deslocamentos medidos utilizando o esquadro e o 


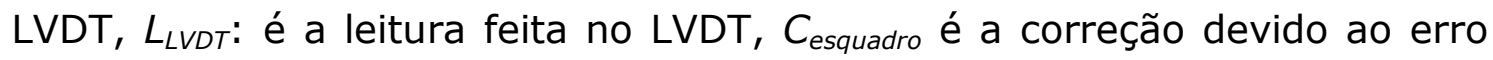
de ortogonalidade do esquadro e $R$ a resolução do LVDT.

$$
D=L_{L V D T}+C_{\text {esquadro }}+R \text {, }
$$

Aplicando a lei da propagação de incertezas na equação (5.20) tem-se:

$$
\mathrm{u}(\mathrm{D})^{2}=\left(\frac{\partial \mathrm{D}}{\partial \mathrm{L}_{\mathrm{LVDT}}}\right)^{2}\left(\mathrm{u}_{\mathrm{L}_{\mathrm{LVDT}}}\right)^{2}+\left(\frac{\partial \mathrm{D}}{\partial \mathrm{C}_{\text {esquadro }}}\right)^{2}\left(\mathrm{u}_{\mathrm{C}_{\text {esquadro }}}\right)^{2}+\left(\frac{\partial \mathrm{D}}{\partial \mathrm{R}}\right)^{2}\left(\mathrm{u}_{\mathrm{R}}\right)^{2}
$$

A partir das equações 5.20. e 5.21. tem-se a Tabela 5.3.

Tabela 5.3: Parâmetros para determinação da incerteza de medição de

\begin{tabular}{|c|c|c|c|c|c|c|}
\hline $\begin{array}{c}\text { Notação da } \\
\text { Incerteza } \\
\text { padronizada }\end{array}$ & $\begin{array}{l}\text { Coeficiente de } \\
\text { sensibilidade }\end{array}$ & $\begin{array}{c}\text { Tipo de } \\
\text { avaliação }\end{array}$ & $\begin{array}{l}\text { Tam. da } \\
\text { Amostra }\end{array}$ & $\begin{array}{c}\text { Distribuição } \\
\text { de } \\
\text { probabilidade }\end{array}$ & $\begin{array}{l}\text { Grau de } \\
\text { liberdade }\end{array}$ & $\begin{array}{c}\text { Coeficiente } \\
\text { t-Student } \\
(95 \%)\end{array}$ \\
\hline $\mathrm{u}_{\mathrm{L}_{\mathrm{LVDT}}}$ & $\frac{\partial D}{\partial L_{L V D T}}=1$ & A & 5 & normal & 4 & 2,78 \\
\hline $\mathrm{u}_{\mathrm{C}_{\text {esquadro }}}$ & $\frac{\partial D}{\partial C_{\text {esquadro }}}=1$ & B & & retangular & $\infty$ & \\
\hline $\mathrm{u}_{\mathrm{R}}$ & $\frac{\partial D}{\partial R}=1$ & B & & triangular & $\infty$ & \\
\hline \multicolumn{7}{|c|}{$\frac{\mathrm{u}^{4}(\mathrm{D})}{4}$} \\
\hline
\end{tabular}
erros utilizando o esquadro e o apalpador LVDT. 


\section{CAPÍTULO 6}

\section{Apresentação e discussão dos}

\section{resultados}

Após a apresentação da parte teórica e dos procedimentos para a compensação do erro da máquina anteriormente descritos, serão agora apresentados os resultados obtidos através da aplicação do método proposto.

Primeiramente foi efetuada a calibração da MM3C. As medições dos erros foram feitas de duas formas distintas. Em uma utilizou-se a barra de furos e na outra o esquadro mecânico e um LVDT.

Através dos dados obtidos durante a calibração da máquina, foi possível a aplicação do MRSE para a geração dos mapas de erros da MM3C.

Posteriormente, as equações que sintetizam os erros volumétricos foram utilizadas no programa computacional MaqMed 2000 no intuito de compensar os erros nas coordenadas dos pontos medidos.

As condições do ambiente durante a calibração da máquina e medição das peças foram as seguintes: a temperatura do ambiente, da MM3C e dos artefatos utilizados foram de $20 \pm 1^{\circ} \mathrm{C}$, a umidade relativa do ar de $40 \% \pm 5 \%$ e a pressão atmosférica de $693 \pm 3 \mathrm{mmHg}$. O tempo de equilibrio térmico utilizado para o conjunto foi de 12 horas. 


\subsection{Resultados da calibração da MM3C}

Para calibração da MM3C foi utilizada a barra de furos e o esquadro mecânico, como mostrado no capítulo anterior. Tais artefatos foram utilizados devido aos baixos custos em relação a outros sistemas de calibração e razoável facilidade de fabricação.

Quando utilizada a barra de furos, a medição foi feita com o apalpador de medição posicionado no braço $Z$, qualificado como ponta única e o diâmetro da ponta do apalpador de $4 \mathrm{~mm}$. O diâmetro da ponta foi escolhido para minimizar a influência da rugosidade superficial da parede interna dos furos nos resultados das medições.

A utilização de um artefato mecânico para calibração de erros é uma proposta interessante visto que permite considerar o sistema de apalpamento do equipamento, no processo de calibração, que é parte obrigatória na sua utilização.

A utilização da barra de furos como artefato para o levantamento de dados para o MRSE mostrou-se ainda favorável por ser um artefato simples, fácil de ser fabricado e manuseado.

Antes da calibração da MM3C, as barras de furos foram précalibradas em uma Máquina de Medir Universal, SIP, que tem resolução 20 vezes menor que a da MM3C, ou seja, de 0,1 $\mu \mathrm{m}$. Foram medidas as distâncias entre o centro do primeiro furo e os centros de todos os outros furos das barras. Foi desenvolvida uma montagem para determinar os centros dos furos, no entanto, foi observado um braço de Abbè que interfere no valor das medições devido à existência de eventuais erros angulares. Afim de corrigir a influência deste erro foi feita a montagem de um sistema interferométrico laser da HP e das ópticas de medição angular. As medições das distâncias entre os centros dos furos e do erro angular foram feitas simultaneamente. Assim, o erro de medição relativa à presença do braço de Abbè pode ser compensado. Os resultados obtidos podem ser observados na Tabela 6.1.

As medições das distâncias foram feitas em uma profundidade específica evitando assim que o erro de cilindricidade tivesse influencia na 
medição. O mesmo cuidado foi tomado quando a medição foi feita na MM3C.

Tabela 6.1: Valores das distâncias dos furos das barras encontrados na SIP

\begin{tabular}{|c|c|c|}
\hline \multicolumn{3}{|c|}{ Barra de 9 furos } \\
\hline Furos & $\begin{array}{c}\text { Distância } \\
\text { entre os furos } \\
(\mathrm{mm})\end{array}$ & $\begin{array}{c}\text { Desvio } \\
\text { Padrão } \\
(\mu \mathrm{m})\end{array}$ \\
\hline $1-2$ & 40,9948 & 0,4 \\
\hline $1-3$ & 81,9963 & 0,8 \\
\hline $1-4$ & 122,9954 & 1,7 \\
\hline $1-5$ & 163,9913 & 1,1 \\
\hline $1-6$ & 204,9924 & 0,9 \\
\hline $1-7$ & 245,9883 & 1,3 \\
\hline $1-8$ & 286,9773 & 1,5 \\
\hline $1-9$ & 327,9642 & 1,9 \\
\hline
\end{tabular}

\begin{tabular}{|c|c|c|}
\hline \multicolumn{3}{|c|}{ Barra de 7 furos } \\
\hline Furos & $\begin{array}{c}\text { Distância } \\
\text { entre os furos } \\
(\mathrm{mm})\end{array}$ & $\begin{array}{c}\text { Desvio } \\
\text { Padrão } \\
(\mu \mathrm{m})\end{array}$ \\
\hline $1-2$ & 40,9948 & 0,9 \\
\hline $1-3$ & 81,9901 & 1,4 \\
\hline $1-4$ & 122,9873 & 1,4 \\
\hline $1-5$ & 163,9874 & 1,2 \\
\hline $1-6$ & 204,9790 & 1,8 \\
\hline $1-7$ & 245,9739 & 1,3 \\
\hline
\end{tabular}

Após a calibração das barras na SIP, essas foram colocadas na MM3C nas posições indicadas na primeira coluna da Tabela 6.2 e utilizando o programa computacional ProgCalibra, parte integrante do MaqMed 2000, que indica a posição a ser colocada a barra na máquina e calcula as coordenadas dos centros dos furos e as distâncias entre o primeiro furo e os demais, distâncias estas necessárias para a análise do comportamento metrológico da MM3C.

Com o apalpador de medição foram tomados 9 pontos coordenados em cada um dos furos, medindo sempre o primeiro furo e cada um dos outros e calculando a distância entre seus centros. Os resultados encontrados podem ser observados na Tabela 6.2.

Os erros de escala foram calculados utilizando os dados obtidos através da calibração da máquina com a barra de furos e a equação (5.15), ou seja, $\mathrm{E}_{\mathrm{i}}=$ Valor encontrado com o ProgCalibra - Leitura da SIP.

A barra foi posicionada paralelamente ao eixo, o mais próximo possível do eixo a ser avaliado, ou seja, nas posições 1, 4 e 6 para $Y, X$ e $Z$ respectivamente. 
Outros erros que ocorrem na mesma direção do movimento foram calculados utilizando os dados obtidos através da calibração da máquina com a barra de furos, tais como Yaw(y), Pitch(y) e o Pitch(x).

Tabela 6.2: Distâncias entre centros das barras de furos e desvio padrão em cada posição (mm).

\begin{tabular}{|c|c|c|c|c|c|c|c|c|}
\hline $\begin{array}{c}\text { Distância entre } \\
\text { os Furos }\end{array}$ & $1-2$ & $1-3$ & $1-4$ & $1-5$ & $1-6$ & $1-7$ & $1-8$ & $1-9$ \\
\hline \multirow[t]{2}{*}{1} & 40,997 & 81,995 & 122,996 & 163,992 & 204,994 & 245,989 & 286,981 & 327,971 \\
\hline & 0,007 & 0,006 & 0,007 & 0,007 & 0,008 & 0,007 & 0,009 & 0,007 \\
\hline \multirow[t]{2}{*}{2} & 40,998 & 81,997 & 122,999 & 163,994 & 204,993 & 245,991 & 286,981 & 327,974 \\
\hline & 0,004 & 0,008 & 0,007 & 0,005 & 0.007 & 0,006 & 0,006 & 0,005 \\
\hline \multirow[t]{2}{*}{3} & 40,997 & 81,994 & 122,996 & 163,992 & 204,994 & 245,989 & 286,981 & 327,970 \\
\hline & 0,006 & 0,004 & 0,005 & 0,005 & 0,004 & 0,005 & 0,007 & 0,005 \\
\hline \multirow[t]{2}{*}{4} & 41,004 & 82,006 & 123,005 & 164,001 & 204,998 & 246,002 & & \\
\hline & 0,004 & 0,005 & 0,005 & 0,007 & 0,005 & 0,006 & & \\
\hline \multirow[t]{2}{*}{5} & 41,005 & 82,005 & 123,004 & 164,001 & 204,997 & 246,002 & & \\
\hline & 0,006 & 0,007 & 0,005 & 0,005 & 0,007 & 0,006 & & \\
\hline \multirow[t]{2}{*}{6} & 40,992 & 81,983 & 122,972 & 163,973 & 204,964 & 245,961 & & \\
\hline & 0,008 & 0,009 & 0,007 & 0,008 & 0,012 & 0,008 & & \\
\hline
\end{tabular}


Foi analisado e verificado que na MM3C avaliada está presente um erro cíclico de baixa frequência, cuja amplitude é de aproximadamente 4 $\mathrm{mm}$. Assim sendo durante a medição da barra de furos na máquina foram tomados vários pontos para determinar o centro do furo. O fato do diâmetro dos furos ser relativamente grande faz com que uma possível influência de erros cíclicos seja minimizada, observe a Figura 6.1.

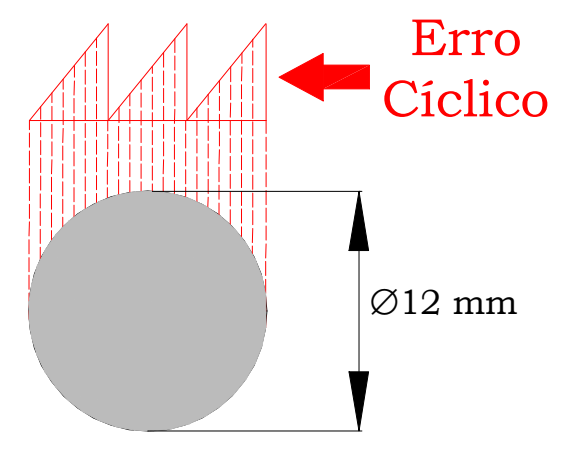

Figura 6.1: Erro Cíclico

Na medição do erro com o esquadro mecânico, foi utilizado um esquadro de granito da marca Mitutoyo com um erro de ortogonalidade de 2,5 arcseg e um apalpador linear digital da marca Tesa, modelo G21, com deslocamento total de $4,3 \mathrm{~mm}$. O esquadro foi posicionado paralelamente a um dos eixos enquanto o apalpador toca a outra face. O apalpador eletrônico foi adaptado no braço Z da MM3C.

Tabela 6.3: Posições de colocação do esquadro na máquina

\begin{tabular}{|c|c|c|}
\hline Posições 1 e 5 & Posições 2 e 6 & Posições 8 e 9 \\
\hline & & \\
\hline
\end{tabular}


Tabela 6.4: Valores do deslocamento experimentado pelo LVDT e desvio padrão $(\mu \mathrm{m})$

\begin{tabular}{|c|c|c|c|c|c|c|c|c|}
\hline \multirow{2}{*}{$\begin{array}{l}\text { Posição do esquadro } \\
\text { na máquina - } \\
\text { direção de medição / } \\
\text { alinhado em }\end{array}$} & \multicolumn{8}{|c|}{ Posição de medição (mm) } \\
\hline & 41 & 82 & 123 & 164 & 205 & 246 & 287 & 328 \\
\hline \multirow{2}{*}{$1-X / Y$} & -1 & -3 & -4 & -8 & -11 & -15 & $-19,5$ & $-25,5$ \\
\hline & 1 & 1 & 0 & 1 & 1 & 1 & 2 & 2 \\
\hline \multirow{2}{*}{$5-X / Y$} & 0 & -2 & -5 & -9 & -13 & -17 & -23 & -31 \\
\hline & 0 & 1 & 0 & 0 & 1 & 1 & 1 & 1 \\
\hline \multirow{2}{*}{$3-Z / Y$} & $-0,5$ & 24 & 62 & 98 & 134 & 170 & 206 & 236 \\
\hline & 1 & 2 & 1 & 2 & 1 & 1 & 1 & 2 \\
\hline \multirow{2}{*}{$2-Y / X$} & 0 & -3 & -5 & -8 & -10 & -12 & -16 & -23 \\
\hline & 0 & 1 & 1 & 1 & 2 & 0 & 2 & 2 \\
\hline \multirow{2}{*}{$6-Y / X$} & 0 & -1 & -2 & -3 & -4 & -6 & -9 & -15 \\
\hline & 0 & 0 & 1 & 0 & 0 & 0 & 1 & 1 \\
\hline \multirow{2}{*}{$4-Z / X$} & 0 & -2 & -5 & -8 & -11 & -14 & -18 & -26 \\
\hline & 0 & 0 & 0 & 1 & 1 & 1 & 0 & 1 \\
\hline \multirow{2}{*}{$7-x / Z$} & 0 & 4 & 10 & 15 & 21 & 29 & 34 & 38 \\
\hline & 0 & 1 & 1 & 1 & 0 & 1 & 0 & 0 \\
\hline \multirow{2}{*}{$8-Y / Z$} & 0 & 2 & 5 & 10 & 12 & 15 & 18 & 19 \\
\hline & 0 & 0 & 1 & 2 & 0 & 1 & 1 & 1 \\
\hline \multirow{2}{*}{$9-Y / Z$} & 0 & 1,5 & 5 & 11 & 12.5 & 15,5 & 19 & 20 \\
\hline & 2 & 1 & 1 & 2 & 2 & 1 & 1 & 0 \\
\hline
\end{tabular}

A medição foi feita da seguinte forma: o apalpador linear é posicionado sobre o esquadro e zerado na primeira posição, então é feita a varredura no esquadro, e nas posições mostradas na Tabela 6.4 foram tomadas as leituras indicadas pelo instrumento. $O$ valor que pode ser visto na Tabela 6.4 é uma média dos 5 valores e o desvio padrão das medições, verifica-se que nas posições $3,7,8$ e 9 uma tendência crescente dos valores e nas posições 1, 2, 4, 5 e 6 uma tendência decrescente. Os altos valores relativos à posição 3 devem-se ao fato do erro de ortogonalidade entre os eixos $Y$ e $Z$ ser grande.

Feita a calibração, como indicada no capítulo 5, pôde-se através das equações do MRSE, as equações (5.7), (5.11) e (5.14), levantar as componentes do erro volumétrico nos três eixos avaliados e em todo 
volume de trabalho. Os gráficos mostrando as superfícies de erros em diferentes planos de medição para os três eixos coordenados, quando aplicado o MRSE podem ser visualizados nos itens $6.1 .1,6.1 .2$ e 6.1.3. São apresentados os erros de posicionamento da ponta do apalpador através de gráficos de erros volumétricos, nas direções $X, Y$ e $Z$.

Para as três componentes as curvas foram sintetizadas em cinco planos, onde os três primeiros são planos $X Y$ em posições diferentes de $Z$. $O$ quarto gráfico é de um plano $X Z$ com a coordenada $Y$ posicionada no centro do eixo e o quinto é de um plano $Y Z$ com a coordenada $X$ posicionada também no centro do eixo.

\subsubsection{COMPONENTE X DO ERRO VOLUMÉtrico}

As superfícies que mostram o comportamento da componente do erro volumétrico na direção $X$ da $M M 3 C$ podem ser visualizadas na Figura 6.2 e Figura 6.3.

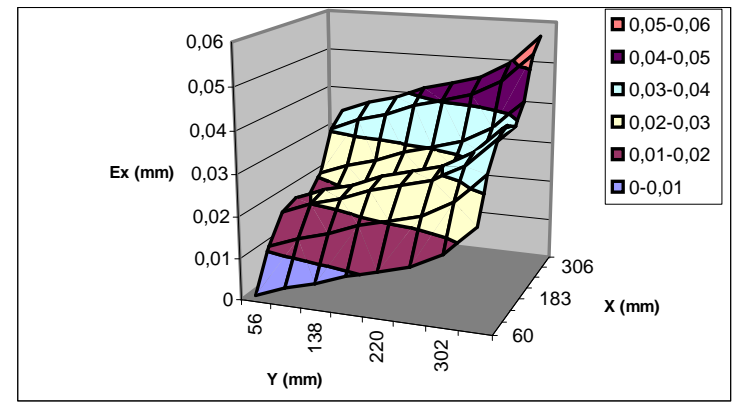

$E_{X}$ no plano $X Y, z=0 \mathrm{~mm}$

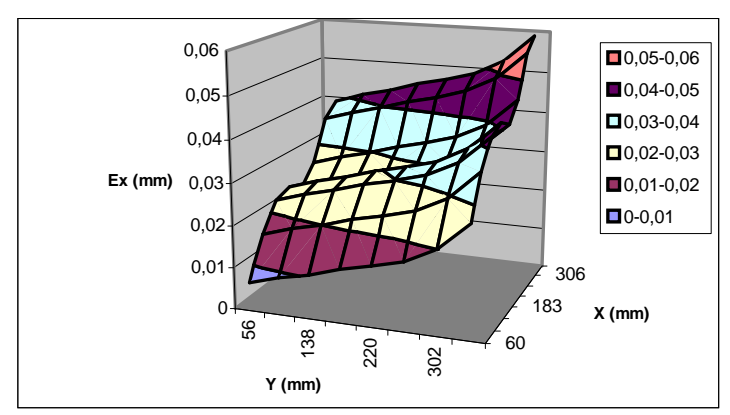

$E_{X}$ no plano $X Y, z=-123 \mathrm{~mm}$

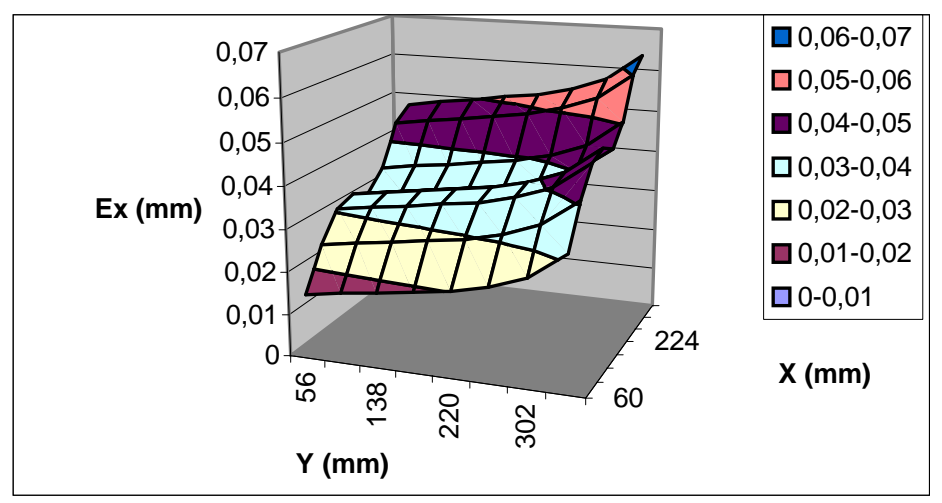

$E_{X}$ no plano $X Y, z=-246 \mathrm{~mm}$

Figura 6.2: Superfícies $E_{X}$ nos diferentes planos de medição 
Observando os gráficos da Figura 6.2 pode-se afirmar que os valores desta componente variam entre $1,5 \mu \mathrm{m}$ e 63,3 $\mu \mathrm{m}$. O erro em cada um dos planos medidos mostrou-se de forma bastante similar, com tendência crescente quando a coordenada $X$ e a coordenada $Y$ aumentam. Há ainda um sensível aumento no erro quando a coordenada $Z$ é mudada, no primeiro ponto do primeiro gráfico em $X=60 \mathrm{~mm} \mathrm{e} Y=56 \mathrm{~mm}$, o valor do erro é de $1,5 \mu \mathrm{m}$, no segundo gráfico $6,7 \mu \mathrm{m}$ e no terceiro gráfico $15,3 \mu \mathrm{m}$, isto se deve ao aumento do braço em $Z$.

O gráfico à esquerda da Figura 6.3 mostra o erro Ex variando de 8 $\mu \mathrm{m}$ até 55,6 $\mu \mathrm{m}$ e no gráfico a direita Ex varia de $17 \mu \mathrm{m}$ a 52,4 $\mu \mathrm{m}$. Ambos os gráficos mostram o aumento do erro quando as coordenadas $X$ e $Y$ aumentam e $Z$ diminui.

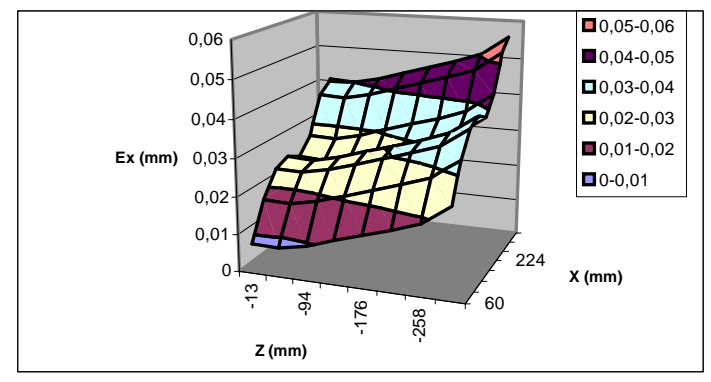

$E_{X}$ no plano $X Z, y=206 \mathrm{~mm}$

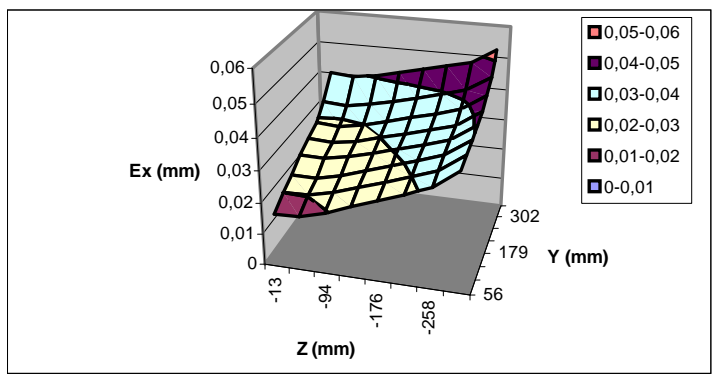

Ex no plano $\mathrm{YZ}, \mathrm{X}=181 \mathrm{~mm}$

Figura 6.3: Superfícies $E_{X}$ nos planos de medição $X Z$ e $Y Z$

\subsubsection{COMPONENTE Y DO ERRO VOLUMÉTRICO}

As superfícies que mostram o comportamento da componente do erro volumétrico na direção $Y$ da MM3C podem ser visualizadas na Figura 6.4 e Figura 6.5 .

A partir dos gráficos da Figura 6.4 pode-se observar que os valores da componente $E_{Y}$ variam entre $16,6 \mu \mathrm{m}$ e $212,8 \mu \mathrm{m}$. O erro em cada um dos planos medidos apresenta-se de forma bastante similar, com tendência crescente quando a coordenada $X$ aumenta. Quando a coordenada $Y$ aumenta não há tendências. Ainda o erro aumenta sensivelmente quando a coordenada $Z$ diminui, no primeiro ponto do gráfico em $X=60 \mathrm{~mm}$ e $Y=56$ 
$\mathrm{mm}$, o valor do erro é de $17,8 \mu \mathrm{m}$, no segundo gráfico $82,6 \mu \mathrm{m}$ e no terceiro gráfico $182,3 \mu \mathrm{m}$, isto se deve ao aumento do braço em $Z$ e o erro de ortogonalidade $Y Z$ que é muito grande e influencia neste erro.

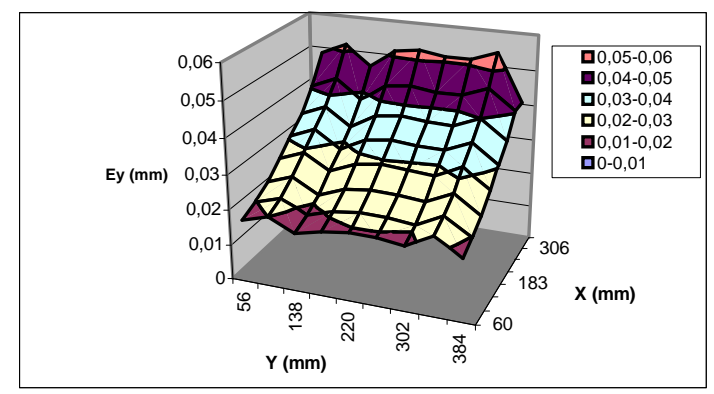

$E_{Y}$ no plano $X Y, z=0 \mathrm{~mm}$

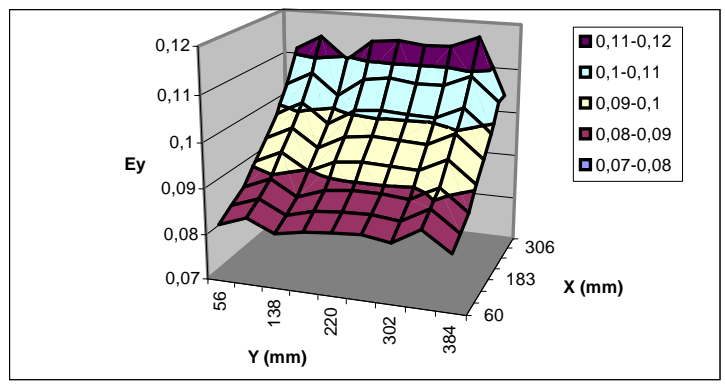

$E_{Y}$ no plano $X Y, z=-123 \mathrm{~mm}$

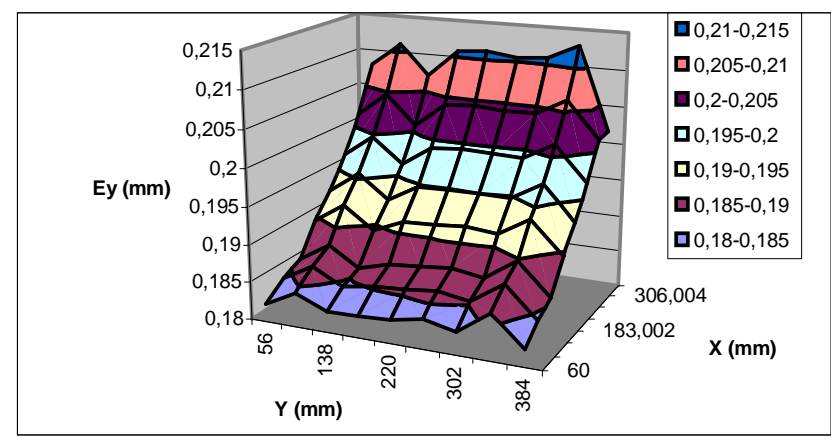

$E_{Y}$ no plano $X Y, z=-246 \mathrm{~mm}$

Figura 6.4: Superfícies $E_{Y}$ nos diferentes planos de medição

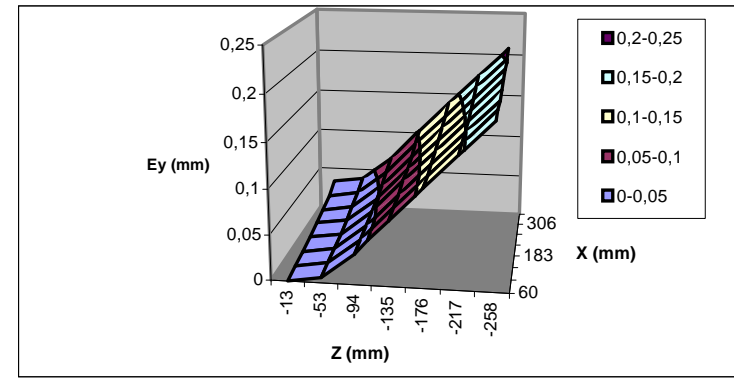

$E_{Y}$ no plano $X Z, y=206 \mathrm{~mm}$

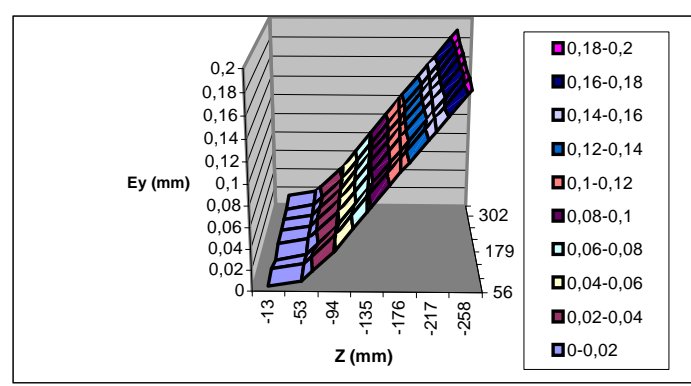

$E_{Y}$ no plano $Y Z, x=181 \mathrm{~mm}$

Figura 6.5: Superfícies $E_{Y}$ nos planos de medição $X Z$ e $Y Z$

O gráfico à esquerda da Figura 6.5 mostra que o erro Ey varia de $0,7 \mu \mathrm{m}$ até 245,1 $\mu \mathrm{m}$ e no gráfico a direita Ey varia de $5 \mu \mathrm{m}$ a $225 \mu \mathrm{m}$. Ambos os gráficos mostram o aumento do erro quando a coordenada $Z$ 
diminui e quando as coordenadas $X$ e $Y$ aumentam nota-se uma suave tendência de crescimento do erro, sendo que a maior tendência pode ser vista no gráfico à esquerda.

\subsubsection{COMPONENTE Z DO ERRO VOLUMÉTRICO}

As superfícies que mostram o comportamento da componente do erro volumétrico na direção $Z$ da $M M 3 C$ podem ser visualizadas na Figura 6.6 e Figura 6.7.

Analisando os gráficos da Figura 6.6 verificou-se que os valores da componente $Z$ variam entre $-17,6 \mu \mathrm{m}$ e 3,7 $\mu \mathrm{m}$. As curvas apresentam a mesma forma e os pontos iniciais de cada uma foram deslocados devido à influência dos braços em $X$ e $Y$.

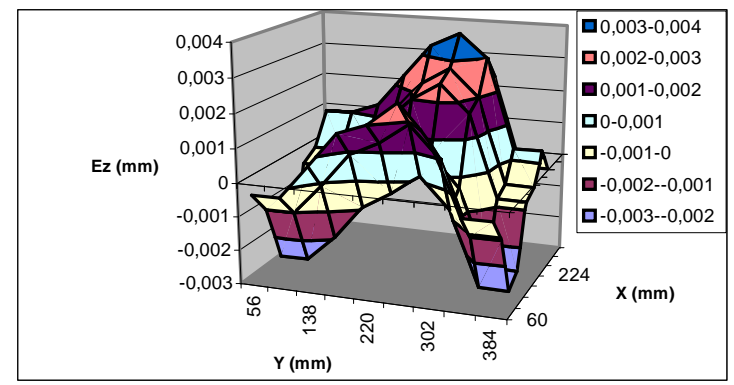

$E_{Z}$ no plano $X Y, z=0 \mathrm{~mm}$

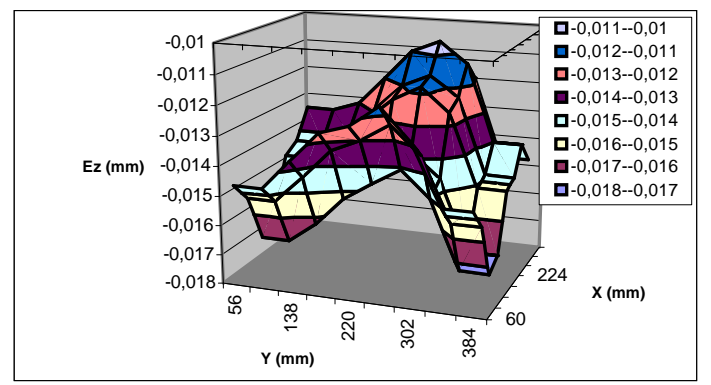

$E_{Z}$ no plano $X Y, z=-123 \mathrm{~mm}$

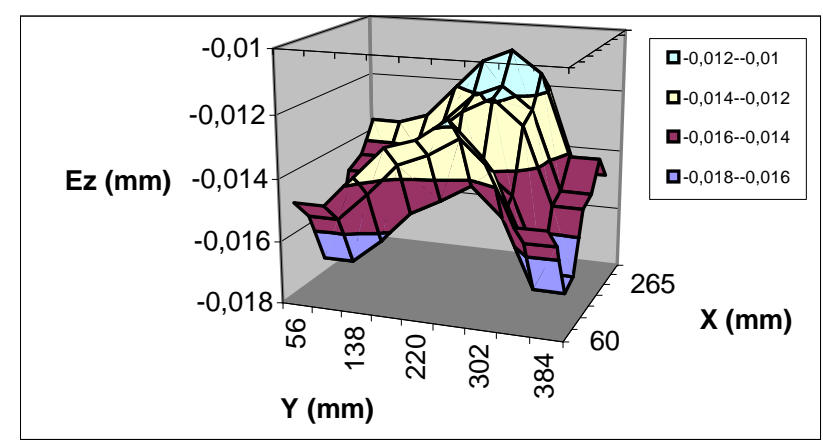

$E_{Z}$ no plano $X Y, z=-246 \mathrm{~mm}$

Figura 6.6: Superfícies $E_{z}$ nos diferentes planos de medição 
O gráfico a esquerda da Figura 6.7 mostra que o erro $E_{z}$ varia de 2,3 $\mu \mathrm{m}$ até $-15,9 \mu \mathrm{m}$ e no gráfico a direita Ez varia de 0 a $-17,7 \mu \mathrm{m}$. Ambos os gráficos mostram a diminuição do erro quando a coordenada $Z$ diminui.

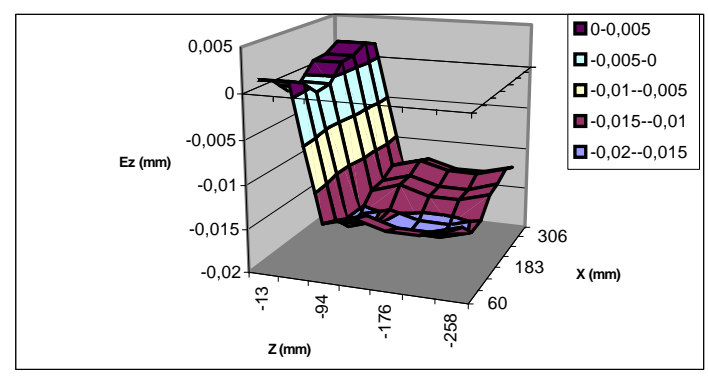

$E_{Z}$ no plano $X Z, y=206 \mathrm{~mm}$

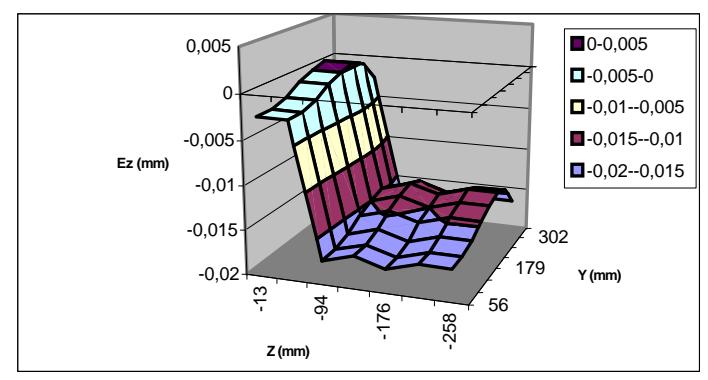

$E_{Z}$ no plano $\mathrm{YZ}, \mathrm{x}=181 \mathrm{~mm}$

Figura 6.7: Superfícies $E_{Z}$ nos planos de medição $X Z$ e $Y Z$

\subsection{Cálculo da incerteza associada às componentes do erro volumétrico}

As equações para o cálculo da incerteza padronizada combinada quando utilizada a barra de furos são apresentadas na Tabela 6.5 e para o esquadro mecânico na Tabela 6.6.

Tabela 6.5: Parâmetros para o cálculo da incerteza padronizada combinada

\begin{tabular}{|c|c|c|c|}
\hline \multicolumn{4}{|c|}{ Barra de furos } \\
\hline Grandeza & Incerteza padronizada & Grandeza & Incerteza padronizada \\
\hline $\mathrm{L}_{\text {MM3C }}$ & $\mathrm{u}_{\mathrm{MM} 3 \mathrm{C}}=\sqrt{\frac{\mathrm{s}^{2}}{\mathrm{~N}}}$ & $t_{\text {Régua }}$ & $u_{t_{\text {Regua }}}=\frac{t_{\text {Régua }}}{\sqrt{3}}$ \\
\hline$t_{B}$ & $u_{t_{B}}=\frac{t_{B}}{\sqrt{3}}$ & $\alpha_{\text {Régua }}$ & $\begin{array}{l}\text { Conservativa de } 10 \% \\
\mathrm{u}_{\alpha_{\text {Régua }}}=\frac{0,01 \cdot \alpha_{\text {Régua }}}{\sqrt{3}}\end{array}$ \\
\hline$\alpha_{B}$ & $\begin{array}{c}\text { Conservativa de } 10 \% \\
\qquad \mathrm{u}_{\alpha_{\mathrm{B}}}=\frac{0,01 \cdot \alpha_{\mathrm{B}}}{\sqrt{3}}\end{array}$ & $R$ & $\mathrm{u}_{\mathrm{R}_{\mathrm{MM} 3 \mathrm{C}}}=\frac{\operatorname{Res} \mathrm{s}_{\mathrm{MM} 3 \mathrm{C}}}{\sqrt{6}}$ \\
\hline
\end{tabular}


Tabela 6.6: Parâmetros para o cálculo da incerteza padronizada combinada

\begin{tabular}{|c|c|c|c|c|}
\hline \multicolumn{5}{|c|}{ Esquadro mecânico } \\
\hline Grandeza & Incerteza padronizada & Grandeza & Incerteza padronizada \\
\hline $\mathrm{L}_{\mathrm{LVDT}}$ & $\mathrm{u}_{\mathrm{LVDT}}=\sqrt{\frac{\mathrm{s}^{2}}{\mathrm{~N}}}$ & $\mathrm{R}$ & $\mathrm{u}_{\mathrm{R}_{\mathrm{LVDT}}}=\frac{\operatorname{Res}_{\mathrm{LVT}}}{\sqrt{6}}$ \\
\hline $\mathrm{C}_{\text {Esquadro }}$ & $\mathrm{u}_{\text {Esquadro }}=\frac{\mathrm{C}_{\text {Esquadro }}}{\sqrt{3}}$ & & \\
\end{tabular}

Tabela 6.7: Incerteza na medição da barra de furos na posição $Y=164 \mathrm{~mm}$

\begin{tabular}{|c|c|c|c|c|c|}
\hline $\begin{array}{c}\text { Grandeza } \\
X_{i}\end{array}$ & Estimativa & $\begin{array}{c}\text { Incerteza } \\
\text { padronizada }\end{array}$ & Unidade & $\begin{array}{l}\text { Coef. de } \\
\text { sensib. }\end{array}$ & {$\left[\frac{\partial \mathrm{f}}{\partial \mathrm{X}_{\mathrm{i}}}\right]^{2} \cdot \mathrm{u}^{2}\left(\mathrm{x}_{\mathrm{i}}\right)$} \\
\hline $\mathrm{L}_{\text {MM3C }}$ & 1,52 & 1,52 & $\mu \mathrm{m}$ & 1 & $2,3.10^{-6}$ \\
\hline$t_{B}$ & 0 & 0,58 & ${ }^{0} \mathrm{C}$ & $1,64.10^{-4}$ & $9.10^{-9}$ \\
\hline$t_{\text {Régua }}$ & 0 & 0,29 & ${ }^{0} \mathrm{C}$ & $1,64.10^{-3}$ & $2,2.10^{-7}$ \\
\hline$R_{\text {MM3C }}$ & 2 & 0,8 & $\mu \mathrm{m}$ & 1 & $6,7.10^{-7}$ \\
\hline & & & & $\sqrt{\text { Soma }}$ & $1,46 \mu \mathrm{m}$ \\
\hline
\end{tabular}

O grau de liberdade efetivo calculado é 8, então para uma probabilidade de $95 \%, k=2,31$. Portanto a incerteza expandida para esta posição é de $3,37 \mu \mathrm{m}$.

Uma vez concluído o cálculo das incertezas associadas a cada uma das componentes das equações dos erros volumétricos, procede-se a combinação adequada e obtém-se as incertezas associadas às componentes $E_{X}, E_{Y}$ e $E_{Z}$.

Tabela 6.8: Incerteza associada às componentes do erro volumétrico.

\begin{tabular}{|c|c|}
\hline Componente & Incerteza $(\mu \mathrm{m})$ \\
\hline $\mathrm{u}_{\mathrm{C}_{\mathrm{EX}}}$ & 3,18 \\
\hline $\mathrm{u}_{\mathrm{C}_{\mathrm{EY}}}$ & 3,86 \\
\hline $\mathrm{u}_{\mathrm{C}_{\mathrm{EZ}}}$ & 2,64 \\
\hline
\end{tabular}


Os valores verificados na Tabela 6.8 podem ser considerados como incerteza padrão combinada de qualquer ponto do volume de trabalho da máquina.

\subsection{Programa computacional MaqMed 2000}

O programa desenvolvido permite a medição de círculos, oblongos, esferas, pontos, distâncias entre entes geométricos, além da medição de ângulos. Nas medições com a MM3C foi utilizado um apalpador eletrônico por contato do tipo touch-trigger, da marca Renishaw, modelo TP1s, e vários tamanhos de pontas e hastes que puderam ser trocadas. Todas as pontas utilizadas eram esféricas e de rubi sintético. Tal apalpador é introduzido no braço $Z$ da máquina e a medição é feita ponto a ponto. Além disso um sinal auditivo é acionado juntamente com o sinal de trigger.

A fixação da peça paralelamente a todos os eixos da MM3C é extremamente difícil, assim é necessário que se faça o alinhamento dos eixos coordenados, ou que sejam colocados os eixos da máquina na mesma direção do plano de medição, este procedimento é feito virtualmente através do MaqMed 2000.

As operações de nivelamento e alinhamento da peça em relação aos eixos coordenados da máquina tornam-se, consideravelmente, simples e rápidas com o uso do microcomputador, pois não é necessário realizá-las fisicamente, no programa computacional MaqMed 2000 há rotinas que ajustam essas posições.

O procedimento de alinhamento da peça consiste em determinar a posição da peça (sistema de coordenadas $X_{P}, Y_{P}, Z_{P}$ ) no sistema de coordenadas da máquina, $X_{M}, Y_{M}, Z_{M}$, Figura 6.8. O MaqMed 2000 faz essa determinação e utiliza as coordenadas modificadas para todos os cálculos que virão posteriormente.

Os procedimentos para o alinhamento são os seguintes: primeiramente é encontrado um plano que será denominado de "plano de referência", ou seja, são tomados pontos coordenados na peça e o programa computacional calcula este plano. Após os cálculos, os pontos que forem tomados em qualquer posição da máquina serão rebatidos neste 
plano. A direção e sentido do eixo $X$ são encontrados tomando-se dois pontos no plano definido. Sendo um sistema ortogonal, através da regra da mão direita é encontrado $Y$ e $Z$.

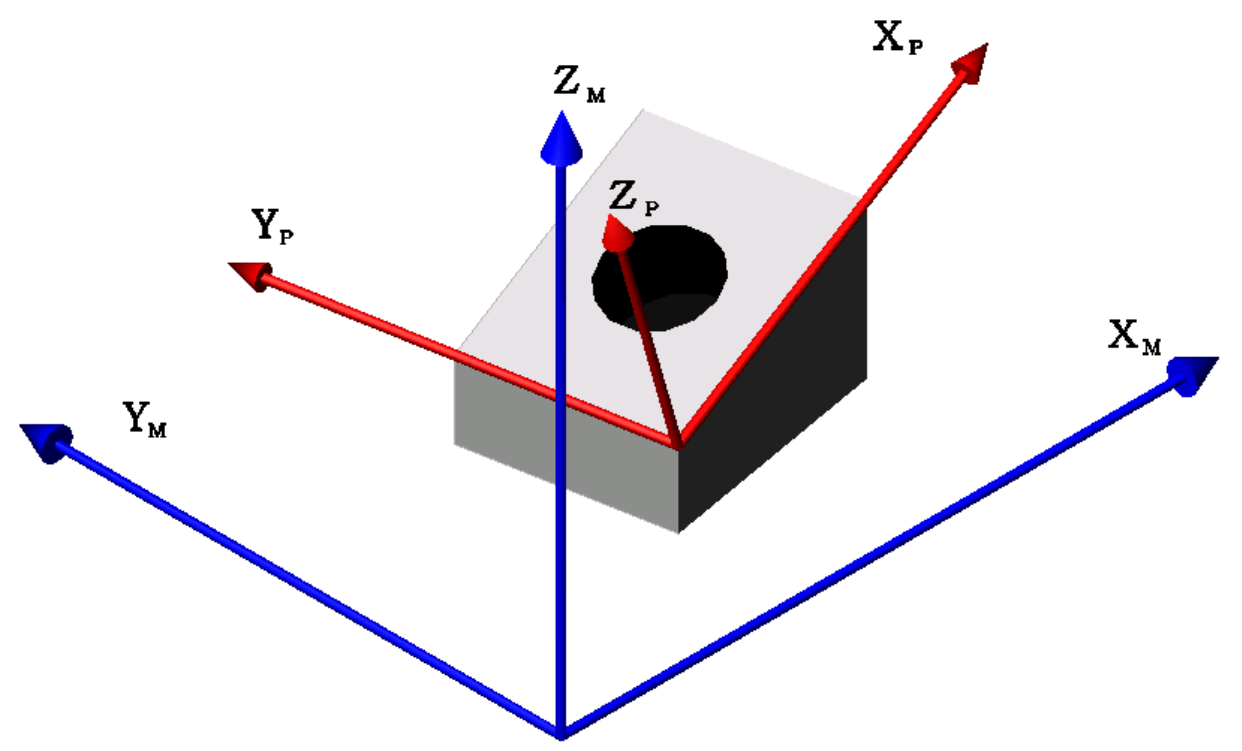

Figura 6.8: Sistema de coordenadas da peça e da MM3C

Na Figura 6.8 pode-se observar que o furo a ser medido está no plano $X_{P} Y_{P}$, isto garante que os valores do diâmetro e do centro do círculo não estarão alterados devido a falta de alinhamento da peça.

Através dos co-senos diretores é feita a mudança de coordenadas e adotado outro sistema mais conveniente, a matriz de transformação utilizada foi:

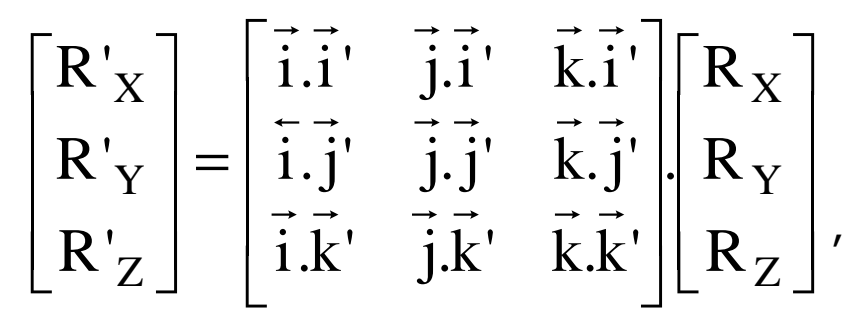

onde:

$>R_{X}, R_{Y}$ e $R_{Z}$ são os pontos no sistema de coordenadas da máquina $\mathrm{e}$;

$>\mathrm{R}_{X}^{\prime}, \mathrm{R}_{Y}^{\prime}$ e $\mathrm{R}_{Z}^{\prime}$ são os pontos no sistema de coordenadas da peça. 
Para transferir um sistema de coordenadas $X Y Z$ para outro sistema $X^{\prime} Y^{\prime} Z^{\prime}$ com origem em $(0,0,0)$ e $\left(X_{0}, Y_{0}, Z_{0}\right)$, com ângulos de orientação $\theta$, $\alpha$ e $\phi$ entre os eixos $X$ e $X^{\prime}, Y$ e $Y^{\prime}$ e $Z$ e $Z^{\prime}$ respectivamente, precisa-se determinar a transformação que superpõe os eixos $X Y Z$ aos eixos $X^{\prime} Y^{\prime} Z^{\prime}$. Isso pode ser feito em 2 passos: primeiro é transladado o sistema $X^{\prime} Y^{\prime} Z$ ' até $\mathrm{XYZ}$ de modo as origens sejam coincidentes com a origem do sistema $\mathrm{XYZ}$ : $T\left(-X_{0},-Y_{0},-Z_{0}\right)$ e depois é rotacionar o eixo $X^{\prime}, Y^{\prime}$ e $Z^{\prime}$ de forma que eles coincidam com o eixo $X, Y$ e $Z$ respectivamente, $R(-\theta,-\alpha,-\phi)$.

Gerado o alinhamento deve-se escolher o tipo de medição a ser feita. A partir da escolha do usuário, o programa executa um PROCEDIMENTO correspondente a essa opção. Tomam-se pontos no perfil da peça, utilizando o apalpador de medição, em pelo menos o número mínimo de pontos necessários para a definição da geometria, só então o programa apresenta uma tela de resultados contendo a medida da característica desejada e o desvio padrão.

Cada ponto tomado pelo apalpador é armazenado e corrigido através de um procedimento de compensação. Então as características são calculadas com os pontos compensados e com os pontos sem a compensação. Os valores obtidos podem ser comparados.

\subsubsection{VALIDAÇÃo do Sistema MAQMed 2000}

Para a validação do programa computacional desenvolvido foram utilizados pontos coordenados de entes geométricos conhecidos. Tais pontos foram introduzidos no MaqMed 2000 e foi verificado se os valores dos resultados são iguais aos da geometria euclidiana escolhida para o teste. Por exemplo, tomando-se pontos coordenados de um círculo perfeito, verifica-se os valores do diâmetro e das coordenadas do centro deste círculo através das rotinas de cálculos do MaqMed 2000. Ou ainda, oferecendo variações radiais no círculo e conhecendo o erro de circularidade, verificamse os resultados obtidos através do programa. Foi verificado que as diferenças nos resultados são devido ao algoritmo utilizado. 
$\mathrm{Na}$ validação do interfaceamento entre a placa e o programa computacional, foi utilizado o Interferômetro Laser para medição do posicionamento da máquina e analisadas as leituras das réguas ópticas.

Finalmente, para validar todo o Sistema (interfaces máquina/computador/operador) foram feitas medições de um bloco padrão e de um anel padrão, em diversas posições e orientações no volume de trabalho da MM3C. Os pontos coordenados foram tratados no programa computacional que possui as rotinas de medição. Os resultados obtidos foram comparados aos valores dos cálculos com os pontos coordenados sem a influência da compensação.

O programa computacional MaqMed 2000 utiliza-se das equações do MRSE para compensar os erros da MM3C analisada, no programa tem subrotinas que calculam, por exemplo, diâmetro de um furo ou distância entre paredes, utilizando valores sem e com compensação de erros. Foram feitas medições utilizando um artefato padrão em várias posições da MM3C.

Na primeira etapa foram feitas medições lineares de distâncias entre paredes. Foi utilizado um bloco padrão de $100 \mathrm{~mm}$ de comprimento nominal, posicionado no volume de trabalho da máquina com as fases de medição no plano $Y Z$ e no plano $X Z$. O bloco padrão foi colocado ainda em duas posições diferentes em $Z$.

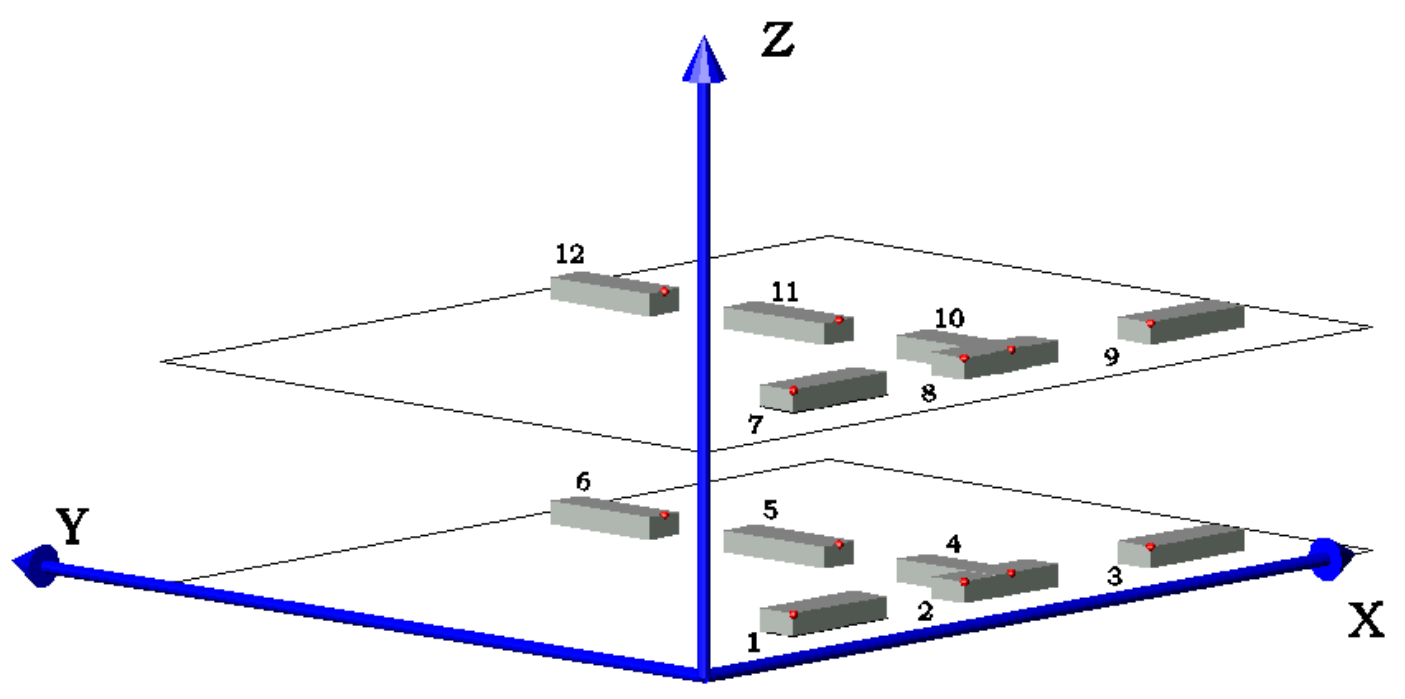

Figura 6.9: Posições ocupadas pelo bloco padrão durante o experimento 
As posições ocupadas pelo bloco padrão durante o experimento podem ser verificadas no esquema da Figura 6.9. Foram tomados vários pontos em uma das faces do bloco e calculada a equação de uma reta através do Método dos Mínimos Quadrados, na outra face tomou-se um ponto coordenado, então foi calculada a distância entre a reta e o ponto.

Os pontos vermelhos que podem ser visualizados na Figura 6.9 são os pontos coordenados onde foram medidos os blocos, estas coordenadas são mostradas na Tabela 6.9 e Tabela 6.10.

Tabela 6.9: Comparação dos valores obtidos com e sem compensação de erros na medição das distâncias na direção $X$.

\begin{tabular}{|c|c|c|c|c|}
\hline \multirow{3}{*}{$\begin{array}{c}\text { Posição do } \\
\text { bloco padrão } \\
\text { na MM3C }\end{array}$} & \multicolumn{4}{|c|}{ Valores de 5 medições em cada posição } \\
\hline & \multicolumn{2}{|c|}{$Z=-200 \mathrm{~mm}$} & \multicolumn{2}{|c|}{$Z=-45 \mathrm{~mm}$} \\
\hline & sem compensação & com compensação & sem compensação & com compensação \\
\hline \multirow{5}{*}{$\begin{array}{c}\text { Posições } 1 \text { e } 7 \\
X=60 \mathrm{~mm} \\
Y=56 \mathrm{~mm}\end{array}$} & 100,029 & 100,005 & 100,027 & 100,003 \\
\hline & 100,030 & 100,006 & 100,025 & 100,001 \\
\hline & 100,060 & 100,003 & 100,032 & 100,008 \\
\hline & 100,027 & 100,003 & 100,031 & 100,007 \\
\hline & 100,025 & 100,001 & 100,029 & 100,005 \\
\hline \multirow{5}{*}{$\begin{array}{c}\text { Posições } 2 \text { e } 8 \\
X=131 \mathrm{~mm} \\
Y=56 \mathrm{~mm}\end{array}$} & 100,023 & 100,012 & 100,018 & 100,006 \\
\hline & 100,027 & 100,010 & 100,018 & 100,007 \\
\hline & 100,020 & 100,009 & 100,015 & 100,004 \\
\hline & 100,026 & 100,013 & 100,017 & 100,007 \\
\hline & 100,026 & 100,012 & 100,017 & 100,007 \\
\hline \multirow{5}{*}{$\begin{array}{c}\text { Posições } 3 \text { e } 9 \\
X=200 \mathrm{~mm} \\
Y=56 \mathrm{~mm}\end{array}$} & 100,027 & 100,007 & 100,021 & 100,001 \\
\hline & 100,027 & 100,007 & 100,022 & 100,002 \\
\hline & 100,030 & 100,010 & 100,022 & 100,002 \\
\hline & 100,025 & 100,005 & 100,020 & 100,000 \\
\hline & 100,028 & 100,008 & 100,022 & 100,002 \\
\hline $\begin{array}{c}\text { Desvio Padrão } \\
(\mu \mathrm{m})\end{array}$ & 9,1 & 3,6 & 5,3 & 2,7 \\
\hline
\end{tabular}

Nos valores obtidos pode-se verificar que as distâncias calculadas sem compensação variam para as medições na posição e de uma posição para outra, enquanto os resultados utilizando os valores compensados 
mostraram alta acuracidade nos resultados. O desvio padrão encontrado para todas as medições em todo volume de trabalho diminuíram de 9,1 $\mu \mathrm{m}$ e 5,3 $\mu \mathrm{m}$ para 3,6 $\mu \mathrm{m}$ e $2,7 \mu \mathrm{m}$ respectivamente.

Foi verificado através do certificado de calibração do bloco padrão, da caixa de grau 0 da TESA, que o valor nominal do bloco é de 100,001 mm e adotado este valor como valor verdadeiro. Calculou-se então os resíduos dos valores encontrados para cada posição analisada, ou seja, fez-se a diferença entre o valor calculado com compensação e sem compensação com o valor verdadeiro.

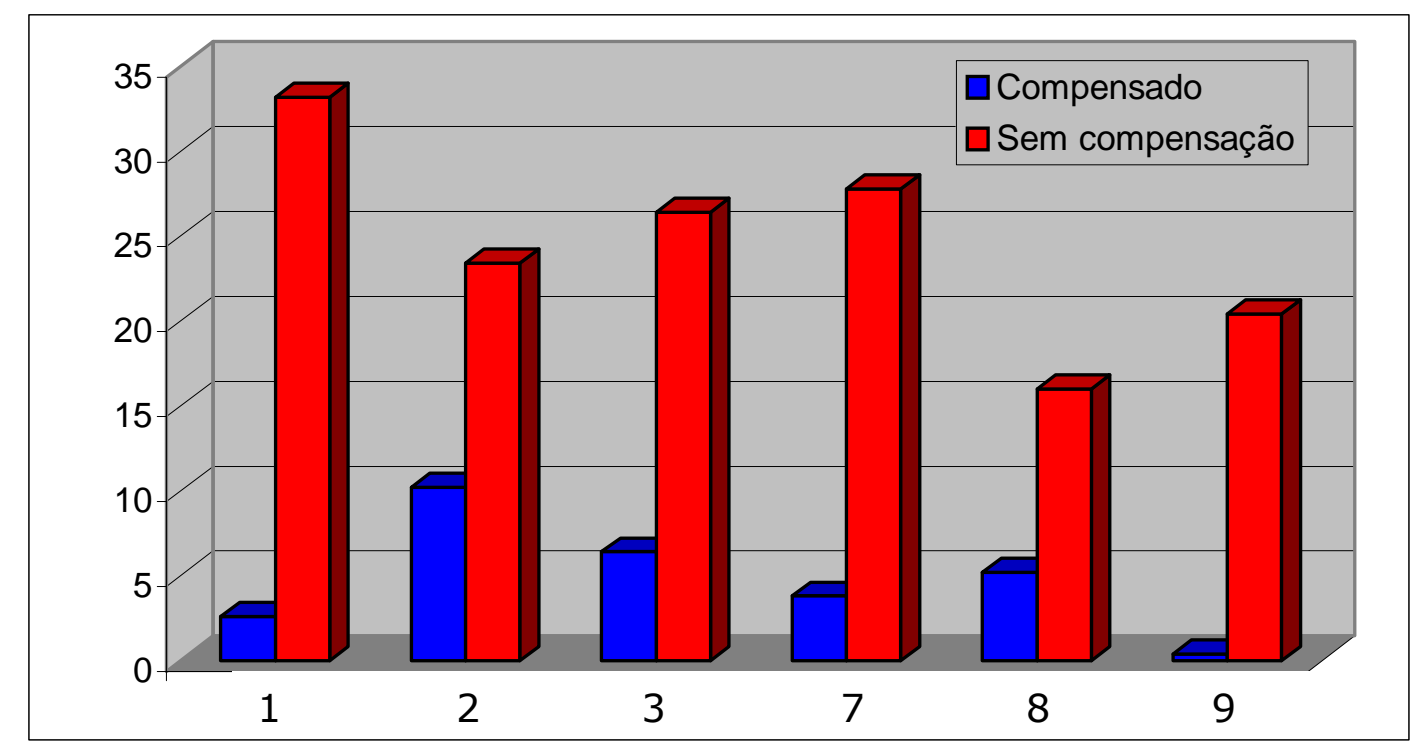

Figura 6.10: Resíduos na medição da distância na direção X ( $\mu \mathrm{m})$

$\mathrm{Na}$ abscissa do gráfico da Figura 6.10 tem-se os números das posições ocupadas pelo bloco padrão durante o experimento e na ordenada os resíduos. Verifica-se que os valores dos resíduos sem compensação são iguais ou menores que $33,2 \mu \mathrm{m}$, enquanto após a compensação, na pior dos casos, não ultrapassam 10,2 $\mu \mathrm{m}$. Nesta direção de medição o MaqMed 2000 permitiu uma ótima redução dos erros, no melhor dos casos de $98 \%$ e no pior de $65 \%$.

Nos valores obtidos pode-se verificar, que as distâncias que foram calculadas sem compensação variam para as medições na posição e de uma posição para outra, enquanto os resultados utilizando os valores 
compensados também variam, mais possuem maior acuracidade. $\mathrm{O}$ desvio padrão encontrado para todas as medições em todo volume de trabalho variam de $4,9 \mu \mathrm{m}$ e $2,8 \mu \mathrm{m}$ para $3,4 \mu \mathrm{m}$ e $2,9 \mu \mathrm{m}$ respectivamente.

Tabela 6.10: Comparação dos valores obtidos com e sem compensação de erros na medição das distâncias na direção Y.

\begin{tabular}{|c|c|c|c|c|}
\hline \multirow{3}{*}{$\begin{array}{c}\text { Posição do } \\
\text { bloco padrão } \\
\text { na MM3C }\end{array}$} & \multicolumn{4}{|c|}{ Valores de 5 medições em cada posição } \\
\hline & \multicolumn{2}{|c|}{$Z=-200 \mathrm{~mm}$} & \multicolumn{2}{|c|}{$Z=-45 \mathrm{~mm}$} \\
\hline & sem compensação & com compensação & sem compensação & com compensação \\
\hline \multirow{5}{*}{$\begin{array}{c}\text { Posições } 4 \text { e } 10 \\
X=181 \mathrm{~mm} \\
Y=56 \mathrm{~mm}\end{array}$} & 99,994 & 99,998 & 100,000 & 99,995 \\
\hline & 100,000 & 99,996 & 99,996 & 99,992 \\
\hline & 99,997 & 99,992 & 99,999 & 99,994 \\
\hline & 100,000 & 99,994 & 99,999 & 99,995 \\
\hline & 99,991 & 99,998 & 100,000 & 99,995 \\
\hline \multirow{5}{*}{$\begin{array}{l}\text { Posições } 5 \text { e } 11 \\
X=181 \mathrm{~mm} \\
Y=156 \mathrm{~mm}\end{array}$} & 99,998 & 99,990 & 99,999 & 99,988 \\
\hline & 99,993 & 99,994 & 99,998 & 99,990 \\
\hline & 99,996 & 99,989 & 100,000 & 99,989 \\
\hline & 99,999 & 99,990 & 99,998 & 99,991 \\
\hline & 100,000 & 99,990 & 99,999 & 99,988 \\
\hline \multirow{5}{*}{$\begin{array}{l}\text { Posições } 6 \text { e } 12 \\
X=181 \mathrm{~mm} \\
Y=250 \mathrm{~mm}\end{array}$} & 100,005 & 99,995 & 100,003 & 99,993 \\
\hline & 100,007 & 99,998 & 100,004 & 99,995 \\
\hline & 100,001 & 99,995 & 100,004 & 99,995 \\
\hline & 100,008 & 99,999 & 100,006 & 99,998 \\
\hline & 100,001 & 99,998 & 100,002 & 99,993 \\
\hline $\begin{array}{c}\text { Desvio Padrão } \\
(\mu \mathrm{m})\end{array}$ & 4,9 & 3,4 & 2,8 & 2,9 \\
\hline
\end{tabular}

No gráfico da Figura 6.11 pode-se verificar que os valores dos resíduos calculados com compensação são iguais ou menores a 3,4 $\mu \mathrm{m}$, e sem a compensação, a tendência dos erros foram aumentar chegando a 11,5 $\mu \mathrm{m}$. Na direção de medição Y o MaqMed 2000 não proporcionou uma redução dos erros tão acentuada chegando a no máximo $80 \%$, e em média $60 \%$.

Após uma análise minuciosa em relação aos resíduos observados nas posições 6 e 12, chegou-se a conclusão que, estes valores não refletem qualquer problema no modelo proposto, isto ocorreu devido às 
extrapolações lineares adotadas. Por serem posições de final de curso da máquina, não foi possível a medição dos erros, por impossibilidade de colocação da barra de furos e do esquadro mecânico, foi feita então a extrapolação dos valores seguindo o modelo proposto. Esse problema pode ser resolvido através de um ajuste fino do modelo.

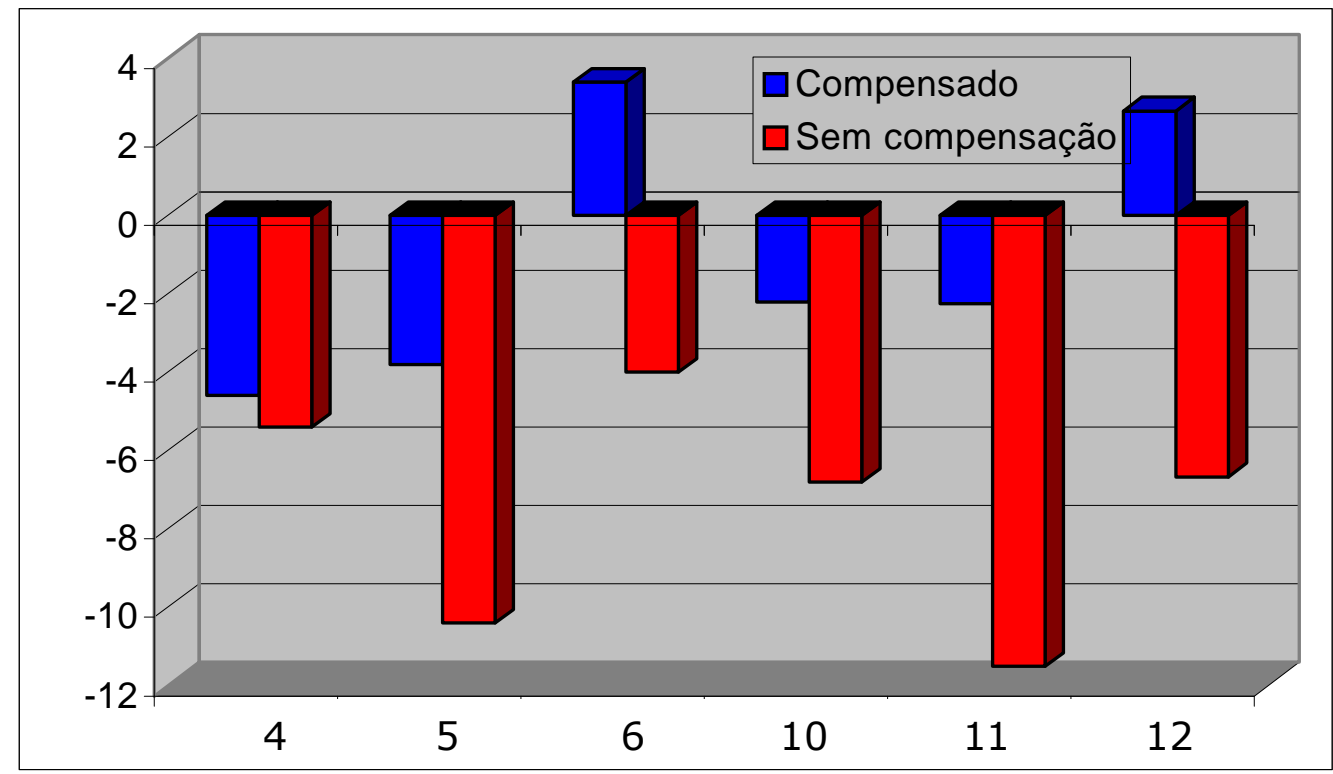

Figura 6.11: Resíduos na medição da distância na direção Y ( $\mu \mathrm{m})$

Na medição do anel padrão, as posições que foram ocupadas pelo artefato durante o experimento, podem ser visualizadas na Figura 6.12 e os pontos coordenados dessas posições são mostrados na Tabela 6.11, onde o ponto indicado é o centro de cada um dos furos. O anel padrão utilizado é de $120 \mathrm{~mm}$ de diâmetro nominal, foi medido a $20^{\circ} \mathrm{C}$ depois de estabilizado.

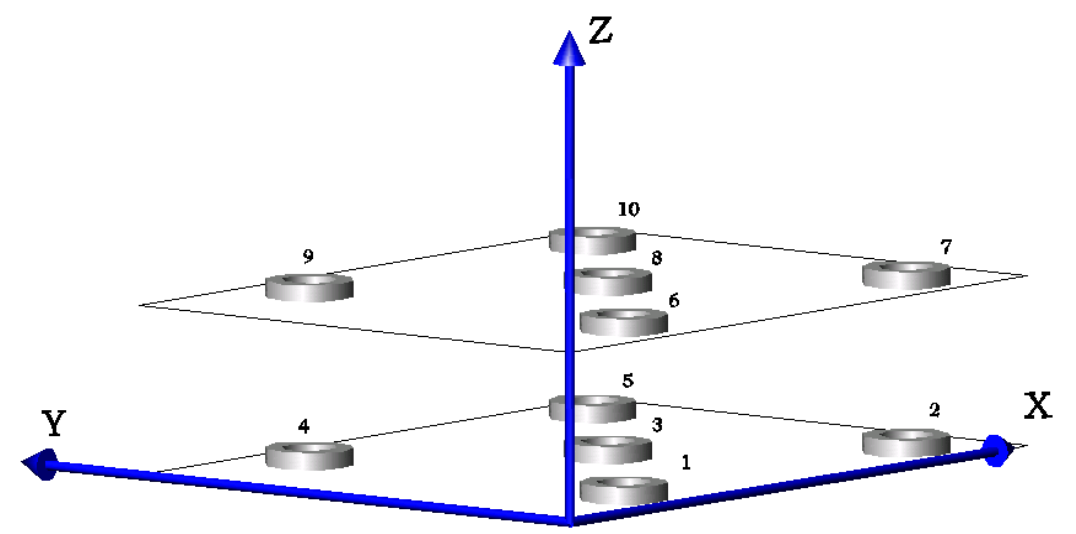

Figura 6.12: Posições ocupadas pelo anel padrão durante o experimento 
Tabela 6.11: Comparação dos valores obtidos com e sem compensação de erros na medição do anel padrão.

\begin{tabular}{|c|c|c|c|c|}
\hline \multirow{3}{*}{$\begin{array}{c}\text { Posição do } \\
\text { anel padrão na } \\
\text { MM3C }\end{array}$} & \multicolumn{4}{|c|}{ Valores de 5 medições em cada posição } \\
\hline & \multicolumn{2}{|c|}{$Z=-190 \mathrm{~mm}$} & \multicolumn{2}{|c|}{$\mathrm{Z}=-35 \mathrm{~mm}$} \\
\hline & sem compensação & com compensação & sem compensação & com compensaçãc \\
\hline \multirow{5}{*}{$\begin{array}{l}\text { Posições } 1 \text { e } 6 \\
X=120 \mathrm{~mm} \\
Y=130 \mathrm{~mm}\end{array}$} & 120,011 & 120,012 & 120,012 & 120,011 \\
\hline & 120,009 & 120,012 & 120,009 & 120,010 \\
\hline & 120,010 & 120,010 & 120,014 & 120,009 \\
\hline & 120,010 & 120,011 & 120,008 & 120,010 \\
\hline & 120,014 & 120,013 & 120,005 & 120,012 \\
\hline \multirow{5}{*}{$\begin{array}{c}\text { Posições } 2 \text { e } 7 \\
X=240 \mathrm{~mm} \\
Y=130 \mathrm{~mm}\end{array}$} & 120,006 & 120,011 & 120,009 & 120,012 \\
\hline & 120,010 & 120,009 & 120,011 & 120,011 \\
\hline & 120,003 & 120,011 & 120,013 & 120,010 \\
\hline & 120,011 & 120,009 & 120,007 & 120,010 \\
\hline & 120,007 & 120,010 & 120,009 & 120,011 \\
\hline \multirow{5}{*}{$\begin{array}{c}\text { Posições } 3 \text { e } 8 \\
X=180 \mathrm{~mm} \\
Y=206 \mathrm{~mm}\end{array}$} & 120,010 & 120,010 & 120,008 & 120,011 \\
\hline & 120,004 & 120,011 & 120,003 & 120,012 \\
\hline & 120,008 & 120,011 & 120,006 & 120,013 \\
\hline & 120,013 & 120,012 & 120,009 & 120,013 \\
\hline & 120,010 & 120,010 & 120,009 & 120,010 \\
\hline \multirow{5}{*}{$\begin{array}{l}\text { Posições } 4 \text { e } 9 \\
X=120 \mathrm{~mm} \\
Y=280 \mathrm{~mm}\end{array}$} & 120,011 & 120,010 & 120,015 & 120,012 \\
\hline & 120,015 & 120,011 & 120,013 & 120,013 \\
\hline & 120,012 & 120,011 & 120,014 & 120,013 \\
\hline & 120,015 & 120,013 & 120,013 & 120,010 \\
\hline & 120,011 & 120,012 & 120,013 & 120,011 \\
\hline \multirow{5}{*}{$\begin{array}{l}\text { Posições } 5 \text { e } 10 \\
X=240 \mathrm{~mm} \\
Y=280 \mathrm{~mm}\end{array}$} & 120,011 & 120,010 & 120,016 & 120,010 \\
\hline & 120,014 & 120,012 & 120,011 & 120,009 \\
\hline & 120,008 & 120,010 & 120,011 & 120,009 \\
\hline & 120,011 & 120,011 & 120,018 & 120,010 \\
\hline & 120,005 & 120,011 & 120,010 & 120,011 \\
\hline \begin{tabular}{|c|} 
Desvio Padrão \\
$(\mu \mathrm{m})$
\end{tabular} & 3,2 & 1,0 & 3,5 & 1,3 \\
\hline
\end{tabular}

Nos valores obtidos pode-se verificar que os diâmetros que foram calculados sem compensação variam para as medições na mesma posição e de uma posição para outra, enquanto os resultados utilizando os valores compensados não há grandes variações em nenhum do dois casos. O desvio 
padrão encontrado quando verificadas todas as medições em todo volume de trabalho diminuíram de 3,2 $\mu \mathrm{m}$ e 3,5 $\mu \mathrm{m}$ para $1 \mu \mathrm{m}$ e 1,3 $\mu \mathrm{m}$ respectivamente. O que mostrou-se muito bom em relação ao modelo de sintetização de erros e os ensaios realizados.

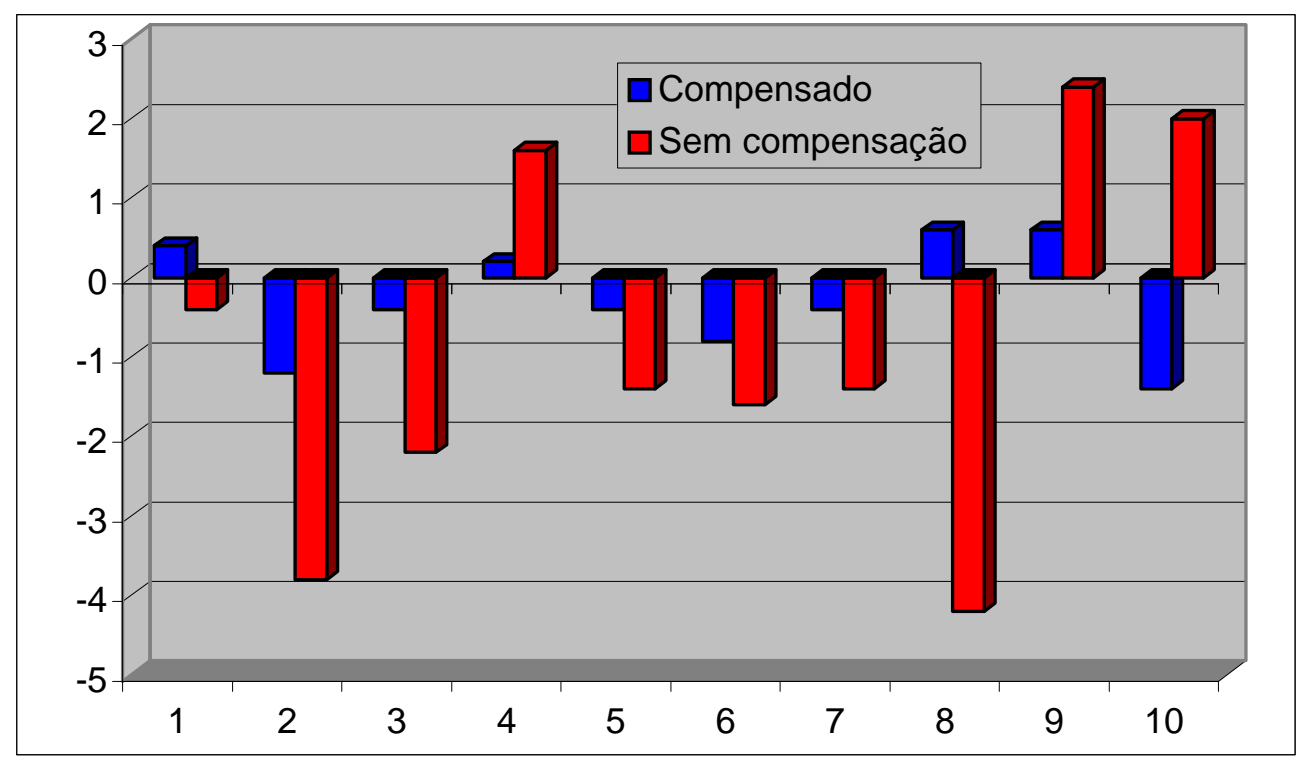

Figura 6.13: Resíduos na medição do diâmetro ( $\mu \mathrm{m})$

$\mathrm{Na}$ medição com anel padrão pode-se aleatorizar os efeitos dos erros pois as medições são feitas na direção $X$ e $Y$ e nos sentidos de ida $e$ volta.

O anel padrão foi pré-calibrado na SIP, e o valor nominal encontrado foi de $120,0112 \mathrm{~mm}$ e esse valor foi adotado como valor verdadeiro. Os cálculos dos valores dos resíduos foram feitos através das médias das cinco posições e do valor verdadeiro.

No gráfico da Figura 6.13 pode-se verificar que os valores calculados sem compensação têm amplitudes de 6,6 $\mu \mathrm{m}$, e após a compensação, as amplitudes caem para aproximadamente 2,0 $\mu \mathrm{m}$. Pode-se verificar que na medição de diâmetros, onde a medição é feita em todas as direções e sentidos o MaqMed 2000 permitiu uma redução dos erros que pode ser considerada ótima, na média de $85 \%$. 


\section{CAPÍTULO 7}

\section{Conclusões e propostas para}

\section{trabalhos futuros}

As realizações científicas na área industrial estão muito ligadas ao aparecimento de novas necessidades. A metrologia acompanha, ou deve acompanhar, o progresso dos meios de fabricação.

A técnica de medição tridimensional permite a execução de tarefas da metrologia que antes implicavam em um grande esforço. Em algumas aplicações, essa técnica representa talvez a única opção de uma medição objetiva e reproduzível.

Os programas herméticos das MM3Cs não permitem ao usuário saber como os cálculos estão sendo feitos com os pontos coordenados e nem o método que está sendo usado para a compensação dos erros. O sistema que foi proposto e construído elimina esta desvantagem, tendo a possibilidade de utilizar qualquer tipo de algoritmo e compará-los, além da inclusão de sistemas de compensação, sabendo-se que, o melhor algoritmo é o que oferece o menor resultado do erro.

O presente trabalho teve por objetivo o desenvolvimento de uma interface eletrônica e computacional para medição a três coordenadas.

Toda a parte eletrônica foi desenvolvida para a aquisição dos sinais das réguas óticas e do apalpador de medição através de um 
interfaceamento que utiliza uma placa de aquisição com um CPLD e um microcontrolador PIC $16 \mathrm{C6} 64$ que foi conectada ao barramento ISA de um microcomputador, detalhado no item 5.3 do capítulo 5 .

O programa computacional da MM3C, MaqMed 2000, foi desenvolvido em ambiente $D E L P H I^{T M}$, devido à facilidade para seu desenvolvimento e manipulação de dados. Os programas foram construídos com um grande número de botões, janelas e gráficos, o que o tornou visualmente agradável e de fácil utilização.

No programa computacional desenvolvido existem rotinas para medição de várias características de medição, tais como dimensões, distâncias e ângulos. O programa permite o alinhamento de peças e contém rotinas de correção dos valores das coordenadas medidas utilizando as equações do Modelo de Reduzido de Sintetização de Erros.

O MaqMed 2000 faz cálculos de características geométricas com os pontos coordenados com e sem compensação, havendo assim a possibilidade de comparação entre os valores obtidos.

Todo o sistema construído mostrou-se confiável e eficiente, além do baixo custo para a implementação.

A técnica de medição tridimensional com auxílio de computador oferece uma série de benefícios que podem ser ressaltados: a grande redução do tempo de medição e de cálculos, especialmente em peças de geometria complexa; o sistema dispensa totalmente as preocupações do operador com o posicionamento físico da peça em relação ao sistema coordenado; a operação pode ser feita por qualquer pessoa que tenha conhecimentos básicos de metrologia, após um treinamento simples quanto à utilização do programa computacional de medição; o aumento da acuracidade de medição, pois o sistema dispensa não somente uma grande quantidade de instrumentos de medição como também a movimentação da peça no desempeno, e realiza a medição com uma pressão de contato constante.

Do desenvolvimento da interface eletrônica e computacional para medição a três coordenadas foi possível chegar às seguintes conclusões:

$\checkmark$ o programa computacional MaqMed 2000 é um programa com o código fonte aberto que pode ser modificado e outras rotinas 
podem ser testadas. Além de amigável ao usuário, simplicidade e facilidade de uso.

$\checkmark$ o Sistema Eletrônico desenvolvido pode ser adaptado a outras MM3Cs sem grandes modificações, desde que a máquina tenha uma saída $A$ quad $B$. Na ausência de tal saída, podem-se desenvolver sistemas eletrônicos que compatibilizem os sinais de outros tipos de escala com os sinais requeridos pela placa construída.

$\checkmark$ a eficiência do Sistema desenvolvido para medir peças e compensar coordenadas, foi testada medindo distâncias entre as faces de medição de um bloco padrão na direção dos eixos $X \mathrm{e}$ $Y$, a porcentagem de melhora entre o valor compensado e sem compensação verificada através da análise dos resíduos. Tal porcentagem aproxima-se dos 92,2\%, quando medido com o maior braço em Z, e 98,1\% com o menor braço. Para o bloco paralelo ao eixo $\mathrm{Y}$, em várias posições na MM3C e próximo ao desempeno, na melhor situação foi de 63,5\%. Quando medido com o menor braço em $Z$, o melhor resultado foi de $80,4 \%$.

$\checkmark$ o Sistema desenvolvido foi testado também na medição de um anel padrão, para compensação tridimensional, quando foi colocado em várias posições na MM3C e próximo ao desempeno a porcentagem de melhora foi de $80,2 \%$. Quando medido com o menor braço em $Z$, foi de $87,4 \%$.

$\checkmark$ a utilização da barra de furos e do esquadro mecânico trouxe várias vantagens, entre elas a possibilidade de utilização do sistema de apalpamento e da estratégia de medição, podendo assim inserir as incertezas relacionadas a esse sistema. Outra vantagem é que os artefatos foram calibrados com instrumentos pertencentes à cadeia de rastreabilidade, assim os erros medidos e calculados são rastreáveis a unidade fundamental.

$\checkmark$ o modelo e os artefatos utilizados reduzem sensivelmente os conjuntos de dados utilizados para a compensação dos erros da máquina. 
$\checkmark$ todo o Sistema proposto pode ser aplicado em outras máquinas e outras configurações de máquinas. O MRSE também pode ser aplicado em outras máquinas, no entanto deve ser feita uma análise minuciosa de sua estrutura, devido a alterações em vetores de erros e na formação dos grupos de erros.

$\checkmark$ A incerteza avaliada para as componentes dos erros volumétricos mostra a boa qualidade do modelo e da calibração da máquina analisada. As incertezas associadas as componentes $E_{X}, E_{Y}$ e $E_{Z}$ foram de 3,18 $\mu \mathrm{m}, 3,86 \mu \mathrm{m}$ e 2,64 $\mu \mathrm{m}$ respectivamente, e mostraram-se coerentes com os valores já apresentados por SATO em 2002 e VALDÉS em 2003.

Durante o desenvolvimento deste trabalho e a partir das observações e conclusões, diferentes propostas para trabalho futuros surgiram. São elas:

$\checkmark$ a aplicação do Sistema proposto em outras máquinas de mesma geometria e com geometrias diferentes.

$\checkmark$ testar outros modelos matemáticos que descrevam o comportamento dos erros, no MaqMed 2000.

$\checkmark$ a verificação da influência da temperatura na aplicação do Sistema.

$\checkmark$ calcular as incertezas associadas a cada uma das características inspecionadas. 


\section{REFERÊNCIAS BIBLIOGRÁFICAS}

ANSI/ASME B 89.6.2 (1973). Temperature and humidity environment for dimensional inspection. Washington.

ANSI/ASME B89.4.1 (1997). Methods for performance evaluation of coordinate measuring machines. Washington.

ANSI/ASME Y14.5.1M (1994). Dimensioning and tolerance - Matematical definitions of principles. American Society of Mechanical Engineers. New York.

AQUINO SILVA, J.B.; BURDEKIN, M. (2002). A modular space frame for assessing the performance of Co-ordinate Measuring Machines (CMMs). Precision Engineering, v.26, p.37-48.

BALSAMO, A. et al. (1997). Results of the CIRP-Euromet Intercomparison of ball plate - based techniques for determining CMM parametric errors. Annals of the CIRP. v.46, p.463-466.

BALSAMO, A.; MARQUES, D. ; SARTORI, S. (1990). A method for thermaldeformation corrections of CMMs. Annals of the CIRP, v.39, n. 1, p.557560.

BARAKAT, N.A.; ELBESTAWI, M.A.; SPENCE, A.D. (2000). Kinematic and geometric error compensation of a coordinate measuring machine. International Journal of Machine Tools \& Manufacture, v.40, p.833-850. 
BARRY N.T.; CHRIS E.K. (1994). Guidelines for evaluating and expressing the uncertaninty of NIST measurements results. NIST technical Note 1297. 20p, Sept.

BELFORTE, G. et al. (1987). Coordinate Measuring Machines and Machine Tools selfcalibration and error correction. - Annals of the CIRP, v.36, p.359364.

BOSCH, J.A. (1995). Evaluation of measurement. in: BOSCH, J.A. Coordinate Measuring Machines and systems. p.1-38. New York, Marcel Dekker, Inc.

BROWN \& SHARP (1988). Coordinate Measuring Systems. User's manual, North Kingstown, U.S.A.

BRYAN, J.B. (1979). The Abbè principle revisited: an updated interpretation. Precision Engineering, v.1, n.1, p.129-132, Jul.

BRYAN, J.B. (1982). A simple method for testing measuring machines and machine tools. Precision Engineering, v.4, n.3, p.124-138.

BRYAN, J.B. (1995). Temperature fundamentals in: $\mathrm{BOSCH}$, J.A. Coordinate Measuring Machines and systems. p. 227-265. New York, Marcel Dekker, Inc.

BSI 6808. (1989). Coordinate Measuring Machines. Part III: Code of pratice. British Standard institution. 
BURDEKIN, M. (1982) Compensation of error in CMMs. NELEX Conference on Metrology, Sept.

BURDEKIN,M.; DI GIACOMO, B.; XIJING, Z. (1984) Calibration software and aplication to co-ordinate measuring machine. Department of Mechanical Engineering - UMIST, Manchester. p.01-07.

BURY, J. (1976). The direct measurement of volumetric error of 3 dimensional co-ordinate machine. - Nelex 76: Metrology Conference, p.1-11

CHEN, J. S.; YUAN, J. X.; NI, J.; WU, S. M. (1993) Real-time compensation for time-variant volumetric errors on a machining. Center Transactions of the ASME, Journal of Engineeering for Industry, v.115, p.472-479, Nov.

CLEMENT, A.; BOURDET, P.; WEILL, R. (1981). Commande adaptive dimensionalle d'une machine a mesurer tridimensionelle, Annals of the CIRP, v.30/1, p.429-432, Jan.

DENAVIT, J.; HARTENBERG, R.S. (1955). A kinematic notation for lower-pair mechanisms based on matrices. Journal of Applied Mechanics, p.215221 , Jun.

DI GIACOMO, B. (1986). Computer aided calibration and hybrid compensation of geometric erros in coordinate measuring machine. Manchester. 418p. Tese (Doutorado) - Institute of Science and Tecnology, University of Manchester. THE VICTORIA UNIVERSITY OF MANCHESTER.

DI GIACOMO, B. (1999). Rastreabilidade das medições a três coordenadas. /Relatório Científico - Processo nº 1997/05517-7/, 89p. 
DI GIACOMO, B.; MARTINEZ ORREGO, R.M.; SATO, D.P.V. (1997). An exploratory study about the second order errors in mathematical models of coordinate measuring machines. Metrocal.

DOEBELIN, E.O. (1990). Measurement systems - application and design. 772p. McGraw-Hill Kogakusha, Ltda.

DRAPER, N.R.; SMITH, H. (1966) Applied regression analysis. John Wiley \& Sons, Inc, New York, 407p.

DUFFIE, N.; YANG, S. (1985). Generation of parametric kinematic errorcorrection functions from volumetric error measurements, Annals of CIRP, v.34, n.1, p.435-438.

EAL-G17 (1995). Coordinate Measurement Machine calibration. 28p. European co-operation for Accreditation of Laboratories Publication Reference - Welac Guidance Document (WGD8), Jan.

ELSHENNAWY, A.K.; HAM, I. (1988). Performance improvement in coordinate measuring machines by error compensation, Journal of Manufacturing Systems, v.9, n.2, p.151-158.

ENCINAS, W. S.; MOREIRA, E. (1999). Hardware and software partition with microcontrollers and CPLDs: a case study. Proc. International Conference on Parallel and Distributed Processing Techniques and Applications - PDPTA'99, p.3002-3008, Las Vegas, NV. 
ESTLER, W.T. (1985) Calibration and use of optical straightedges in the metrology of precision machines. Optical Engineering, v.24, n.3, p.372379, May/Jun.

EVANS, C.J.; HOCKEN, R.J.; ESTLER, W.T. (1996). Self-calibration: reversal, redundancy, error separation, and "absolute testing. CIRP Annals, v.45, n.2.

GUYE, J.J. (1978). Metrological inspection of machining centers, jig boring machines and measuring machines through a statistical approach. Sociéte Genovice d'Instruments de Physique, Geneva, p.141-5.

HARVIE, A. (1986). Factors affecting component measurement on Coordinate Measuring Machines. Precision Engineering, v.8, n.1, p.13-18.

HOCKEN, R. et al. (1977). Three dimensional metrology. CIRP Annals, v.26, p. 403-408.

INMETRO (1995) Vocabulário internacional de termos fundamentais e gerais de metrologia. Duque de Caxias, RJ. 52p.

ISO: GUM (1997). International Organization for Standardization: Guide to the expression of Uncertainty in Measurement. Genova Switzerland.

KIM, S-W. (2001). New design of precision CMM based upon volumetric phasemeasuring interferometry, CIRP Annals, v.50/1, p.357-360. 
KNAPP, W.; TSCHUDI, U.; BUCHER, A. (1991). Comparison of different artefacts for interin coordinate-measuring machine checking: a report form the Swiss Standards Committee. Precision Engineering, v.13, n.4, p.277-291, Oct.

KREJCI, J.V. (1995). Application software in: BOSCH, J.A. Coordinate Measuring Machines and systems. p.103-122. New York, Marcel Dekker, Inc.

KRUTH, J.P.; VANHERCK, P.; VAN DEN BERGH, C. (2001). Compensation of static and transient thermal errors on CMMs. CIRP Annals, v.50/1, p.377380.

KUNZMANN, H.; WÄLDELE, F. (1985). Software correction of coordinate measuring machines. NPL, Sept.

KUNZMANN, H.; WÄLDELE, F.; NI, J. (1995). Accuracy enhancement. in: $\mathrm{BOSCH}$, J.A. Coordinate Measuring Machines and systems. p.279-300. New York, Marcel Dekker, Inc.

LINGARD P.S. et al. (1991). Temperature pertubation effects in a high precision CMM. Precision Engineering, p.41-56.

LINK, W. (1997). Metrologia mecânica - Expressão da incerteza de medição. Programa RH Metrologia, Rio de Janeiro.

LIRA, F.A. (2001). Metrologia na indústria. Editora Érica, São Paulo. 248p. 
LIU, Z.Q.; VENUVINOD, P.K. (1999). Error compensation in CNC turning solely from dimensional measurements of previously machined parts. Annals of the CIRP. v.48, n.1, p.429-432.

MARTINEZ ORREGO, R.M. (1999). Método de calibração direta para máquinas de medir a três coordenadas. 154p. Tese (Doutorado) - Escola de Engenharia de São Carlos - USP, São Carlos.

MOU, J.; LIU, C. (1993). A methodology for machine tools error correction - an adaptive approach. ASME-WAN PED 64, p.69-81.

NI, J. (1995). Accessory elements in: BOSCH, J.A. Coordinate Measuring Machines and systems. p.85-102. New York, Marcel Dekker, Inc.

NI, J.; WÄLDELE, F. (1995). Coordinate Measuring Machine in: BOSCH, J.A. Coordinate Measuring Machines and systems. p.39-74. New York, Marcel Dekker, Inc.

NI, J.; WU, S.M. (1993). An on-line measurement technique for machine volumetric error compensation. Journal of Engineering for Industry, v.115, p.85-92, Feb.

PAHK, H.J.; BURDEKIN, M.S. (1991). Evaluation of the effective parametric errors in coordinate measuring machines using the locus of stylus on the horizontal plane. Proc. Instn. Mech. Engrs., v.205, p.123-138.

PAUL, R.P. (1981). Robot manipulators: mathematics, programming, and control. Massachusetts, The MIT Press, 278p. 
PEGGS, G.N. (1990). Traceability for co-ordinate measurement technology. $27^{\text {th }}$ International MATADOR Conference, Manchester. p. 463-468.

PHILLIPS, S.D. (1995). Performance evaluations, in: BOSCH, J.A. Coordinate Measuring Machines and systems. p.137-226. New York, Marcel Dekker, Inc.

PIRATELLI FILHO, A. (1997). Método para avaliação do desempenho de máquinas de medir a três coordenadas através do planejamento de experimentos. 225p. Tese (Doutorado). Escola de Engenharia de São Carlos - USP, São Carlos.

POOLE, A.B. (1983). The calibration of coordinate measuring machines by statistical method. Quality Assurance, v.9, n.2, p.47-50.

PORTA, C.; WÄLDELE, F. (1986). Testing of three coordinate measuring machine evaluation algorithms. Report EUR 10909 EN, Commission of the European Communities, p.1-35.

SATO, D.P.V. (1998). Uma contribuição ao modelo de sintetização de erros em máquinas ferramentas. 200p. Tese (Doutorado). Escola de Engenharia de São Carlos - USP, São Carlos.

SATO, D.P.V. (2002). Determinação da incerteza de medição a três coordenadas. /Relatório FAPESP, Pós-doutorado, Processo №. 99/08043-1/.

SHEN, Y.; MOON, S. (1996). Error compensation of coordinate measurements in computer-integrated manufacturing using neural networks. Journal of Materials Processing Technology, v.61, p.12-17. 
SHEN, Y.L.; DUFFIE, N.A. (1991). Uncertainties in the acquisition and utilization of coordinate frames in manufacturing systems. Annals of the CIRP, v.40, n.1, p.527-530.

SLOCUM, A.H. (1992). Precision Machine Design. Prentice Hall.

SOSA CARDOZA, J.A. (1995). Máquinas virtuais de medir a três coordenadas. São Carlos. 209p. Tese (Doutorado). Escola de Engenharia de São Carlos USP, São Carlos.

SPUR, G. et al. (1988). Thermal behavior optimization of machine tools. Annals of the CIRP, v.37, n.1, p.401-405.

TAKATSUJI, T.; OSAWA, S.; KUROSAWA, T. (2002). Uncertainty analysis of calibration of geometrical gauges, v.26, p.24-29.

THOMAS, G. (1974). Engineering metrology. Butterworth \& Co. Ltd, London, 420p.

TRAPET, E.; WÄLDELE, F. (1989). Determination of the parametric errors of Co-ordinate Measuring Machine and machine tools using reference object. VDI Berichte, n.761, p.163-175.

VALDÉS, R. A. (2003). Modelo de sintetização de erros termicamente induzidos em Máquinas de Medir a Três Coordenadas. 191p. Tese (Doutorado). Escola de Engenharia de São Carlos - USP, São Carlos.

VELDHUIS, S.; ELBESTAWI, M.A. (1994). Modelling and compensation for five axes machine tool errors, ASME-WAN PED 68, p. 827-839. 
WECK, M. (1984). Handbook of machine tools - Metrological analysis and performance tests. London, John Wiley \& Sons, v.4, 145p.

WECKENMANN, A.; HEINRICHOWSKI, M. (1985). The use of virtual volumetric standards. Precision Engineering, v.7, n.2, p.87-91.

WECKENMANN, A.; KNAUER, M; KILLMAIER,T. (2001). Uncertainty of coordinate measurements on sheet-metal parts in the automotive industry, Journal of Materials Processing Technology, v.115, p. 9-13.

WEEKERS, W.G.; SCHELLEKENS, P.H.J. (1997). Compensation for dynamic errors of coordinate measuring machine. Measurement, v.20, n.3, p.197-209.

WILHELM, R.G.; HOCKEN, R.; SCHWENKE, H. (2001). Task specific uncertainty in coordinate measurement. Annals of the CIRP.

ZHANG, G.; VEALE, R.; CHARLTON, B.; BORCHARDT, B.; HOCKEN, R. (1985) Error compensation of coordinate measuring machines. Tianjim University NBS Gaithersburg Annals of CIRP, v.34, n.1, p.445-448.

ZHANG, G.X.; FU, J.Y.A. (2000). A method for optical CMM calibration using a grid plate. Annals of the CIRP, v.49 p.399-402.

ZIRONDI, R.B. (2002). Modelo reduzido de sintetização de erros para Máquinas de Medir a Três Coordenadas. 162p. Tese (Doutorado) - Escola de Engenharia de São Carlos - USP, São Carlos. 


\section{GLOSSÁRIO}

Acuracidade

Calibração

Compensação de erros

Erro

Erro Volumétrico

Incerteza de medição

Repetibilidade
Grau de concordância entre o valor medido e o valor verdadeiro do mensurando. Exatidão de medição (INMETRO, 1995);

Conjunto de operações que estabelece, sob condições especificadas, a relação entre os valores indicados por um instrumento de medição ou sistema de medição, e os valores correspondentes das grandezas estabelecidas por padrões (INMETRO, 1995);

Procedimento de correção dos erros sistemáticos;

Diferença entre o valor medido de uma grandeza e o valor "verdadeiro" da mesma;

Soma de todos os erro total de uma máquina que em todas as direções de movimentação;

Parâmetro, associado ao resultado de uma medição, que caracteriza a dispersão dos valores que podem ser fundamentalmente atribuídos ao mensurando (INMETRO, 1995);

Grau de concordância entre os resultados de medições sucessivas de um mesmo mensurando efetuadas sob as mesmas condições de medição. 


\section{APÊNDICE A}

\section{Descrição da MM3C utilizada nos testes experimentais}

A MM3C utilizada nos testes experimentais está locada no Laboratório de Metrologia da Escola de Engenharia de São Carlos (EESC) da Universidade de São Paulo (USP).

Fabricada pela Brown \& Sharpe Mfg. Co. em 1988 esta máquina, do tipo Ponte Móvel modelo Microval, possui dimensões e peso apropriados para o seu uso em bancada. Sua estrutura foi construída em alumínio fundido e possui um desempeno de granito apoiado sobre três esferas e suportes em "V".

Na máquina, o eixo de movimentação $Y$, é formado por uma ponte que movimenta-se sobre duas guias montadas diretamente sobre a estrutura.

As duas colunas da ponte sustentam a guia que compõe o eixo $X$ sobre a qual desloca-se, teoricamente, perpendicular ao eixo $\mathrm{Y}$, o carro X. Este sustenta 0 eixo $Z$, também teoricamente, perpendicular, simultaneamente, aos eixos $X$ e $Y$. O eixo $Z$ sustenta a sonda de medição, parte fundamental para a utilização da MM3C.

Em cada uma das guias que determinam os eixos da máquina, estão fixadas escalas ópticas. O sistema de leitura, baseado no Princípio das Franjas de Moiré, é composto por um emissor, uma escala indexável (móvel), uma escala fixa e um receptor em cada eixo. O movimento relativo entre as escalas fixas e móveis provoca uma variação da intensidade da luz que chega ao receptor. Esta variação pode ser interpretada como deslocamento através de uma proporção matemática adequada. (MARTINEZ ORREGO, 1999).

A MM3C realiza o processo de medição utilizando um computador 
dedicado que contém os programas específicos, encarregados da determinação das características geométricas das peças a partir dos pontos coordenados medidos (BROWN \& SHARP, 1988).

A Tabela A.1 resume das características técnicas e condições de operação da MM3C.

Tabela A.1: Características técnicas da MM3C

\begin{tabular}{|c|c|c|c|}
\cline { 2 - 4 } \multicolumn{1}{c|}{} & $\mathrm{X}$ & $\mathrm{Y}$ & $\mathrm{Z}$ \\
\hline Dimensões $(\mathrm{mm})$ & 743 & 730 & 1340 \\
\hline Faixa de operação $(\mathrm{mm})$ & 362 & 412 & 316 \\
\hline
\end{tabular}

\begin{tabular}{|c|c|}
\hline \multicolumn{2}{|c|}{ Condições de operação } \\
\hline Temperatura & 10 a $40^{\circ} \mathrm{C}$ \\
\hline Pressão mínima de ar: & $55 \mathrm{psi}$ \\
\hline Conjunto regulador de pressão: & $50 \mathrm{psi}$ \\
\hline
\end{tabular}




\section{APÊNDICE B}

\section{Rotinas básicas da placa de aquisição para régua ótica}

A placa é acompanhada com um arquivo tipo DLL (Biblioteca de Vínculo Dinâmico) que possui as rotinas básicas para operação. Esta biblioteca permite o uso da placa com qualquer linguagem de programação para Windows ${ }^{T M}$, desde que seja de 32 bits.

Serão mostradas agora algumas funções pré-definidas:

SelPlaca(end): Especifica o endereço base onde a placa será utilizada, através do endereço selecionado pelos jumpers. Deve ser utilizada antes de qualquer outro comando.

end: endereço de entrada e saída da placa.

SetaRes(res): Especifica qual a resolução de contagem, alta ou baixa, da placa que será utilizada. Normalmente trabalhará em alta resolução.

$$
\begin{gathered}
\text { res: } 0 \text { - baixa resolução (4 vezes menor) } \\
1 \text { - Alta resolução }
\end{gathered}
$$

TgCtg(): Gera um trigger por software, congelando simultaneamente a contagem atual dos três eixos. A contagem real segue sendo feita normalmente. Tal função é geralmente utilizada antes da função de leitura de contagem LeCtg.

LeCtg(): Retorna o valor da contagem, que será congelada por trigger externo (normalmente, pela sonda de medição) ou pela função TgCtg, do eixo que for especificado, X, Y ou Z. É um valor inteiro de 32 bits. 
ZeraCtg(): Zera os contadores de todos os 3 eixos.

SetaCtg(ctd): Especifica qual contador será lido pela função LeCtg(). O contador inicial é o $X$.

$$
\text { ctd: } \begin{aligned}
& 0 \text { - lê o eixo } X \\
& 1 \text { - lê o eixo } Y \\
& 2 \text { - lê o eixo } Z
\end{aligned}
$$

NumTg(): Indica se houve trigger de hardware, neste caso retorna o valor 1 , senão retorna o valor 0. A função LeCtg zera este valor. 